Florida International University

FIU Digital Commons

\title{
Identification of Characteristic Volatile Organic Compounds Released during the Decomposition Process of Human Remains and Analogues
}

Norma Iris Caraballo

ncara001@fiu.edu

DOI: $10.25148 /$ etd.FI14040888

Follow this and additional works at: https://digitalcommons.fiu.edu/etd

Part of the Analytical Chemistry Commons, and the Forensic Science and Technology Commons

\section{Recommended Citation}

Caraballo, Norma Iris, "Identification of Characteristic Volatile Organic Compounds Released during the Decomposition Process of Human Remains and Analogues" (2014). FIU Electronic Theses and Dissertations. 1391.

https://digitalcommons.fiu.edu/etd/1391 


\title{
FLORIDA INTERNATIONAL UNIVERSITY
}

Miami, Florida

IDENTIFICATION OF CHARACTERISTIC VOLATILE ORGANIC COMPOUNDS

\section{RELEASED DURING THE DECOMPOSITION PROCESS OF}

HUMAN REMAINS AND ANALOGUES

\author{
A dissertation submitted in partial fulfillment of \\ the requirements for the degree of \\ DOCTOR OF PHILOSOPHY \\ in \\ CHEMISTRY \\ by
}

Norma Iris Caraballo 
To: Dean Kenneth G. Furton

College of Arts and Sciences

This dissertation, written by Norma Iris Caraballo, and entitled Identification of Characteristic Volatile Organic Compounds Released during the Decomposition Process of Human Remains and Analogues, having been approved in respect to style and intellectual content, is referred to you for judgment.

We have read this dissertation and recommend that it be approved.

José Almirall

David Becker

Yong Cai

DeEtta Mills

Kenneth G. Furton, Major Professor

Date of Defense: February 28, 2014

The dissertation of Norma Iris Caraballo is approved.

Dean Kenneth G. Furton

College of Arts and Sciences

Dean Lakshmi N. Reddi

University Graduate School

Florida International University, 2014 
(C) Copyright 2014 by Norma Iris Caraballo

All rights reserved. 


\section{DEDICATION}

This research which consisted of a lot of blood, well not really, sweat, and tears, is dedicated to my mother and best friend, Norma I. Alicea, and my love, Steven J. Bido. Mom, without your love, support, and guidance, I would not have had the strength to fulfill this dream - I am the person I am today because of you. Steve, your candor, which at times was quite brutal, along with your ability to show me that I have nothing to fear, provided me with the courage and determination to embrace any challenge that I was faced with; I am stronger and happier because of you. 


\section{ACKNOWLEDGMENTS}

To my mentor, Dr. Kenneth Furton, thank you for supporting, guiding, and believing in me, the many insightful therapy sessions, allowing me to conduct research on something that I was passionate about, making me laugh and for all of the amazing opportunities. Dr. DeEtta Mills, you have been like another mother to me, I had never envisioned myself in graduate school until you came along, and because of your consistent pushing and not taking no for an answer here I am today, happy and thankful. Dr. José Almirall, I remember coming into your office requesting a letter of recommendation to enter into the Ph.D. Program, giving you several reasons as to why I should be accepted, and after several minutes of me rambling, you looked dead into my eyes and said "I will support you, I know you will be a great researcher" - thank you for believing in me and supporting me from the beginning. Dr. Yong Cai, thank you for always having your door open, ready to listen and help me with the many questions that I had, for keeping me on a realistic path, and for showing me that with research there could still be laughter. Dr. David Becker, thank you for always keeping me on my toes and for providing with a different perspective on my research, it was greatly appreciated.

To Rene Fernandez, Amable Tellez, and Dr. Horatio Veinrean, without your patience and assistance, a majority of this research would not have been possible - thank you. Dr. Daniel Wescott and the FACTS team, thank you for your willingness to collaborate on a portion of this research, your assistance was greatly appreciated.

To my best friend and colleague, Dr. Jessica Brown, thank you for teaching me by drawing, listening to me without judging, guiding me when I was lost, and showing me the fabulousness of wine. Dr. Howard Holness, thank you for listening, guiding, and 
teaching me the ways of being a great scientist. Dr. Lauryn DeGreeff-Silk, thank you for your guidance and for always being my cheerleader. Lorraine Sweeney, thank you for being a super woman and always trying to help in every way possible. To Drs. Jeffrey Wells and John Berry thank you for helping me with the many questions that I had regarding my research.

To Michelle Cerreta and Vanquilla (Van) Shellman, thank you for helping me with my research, as well as for the many laughs, without either of you, I am sure that I would have lost my mind. To Philip Davis, Claudia Sanchez, Adhly Marie Huertas, Vanessa Thompson, Danay Herrera, Stephanie Calle, Thomas Germain Jr., and Nicole Bernhardt, thank you for all the help that you provided me with, as small as you may think it may have been, it helped me tremendously. To Drs. Paola Prada, Maiko Kusano, and Samantha Tolliver, thank you for your guidance and great times.

To my family, my mother, Norma I. Alicea, my brother, Exer Ethan Caraballo, my father, Exer Caraballo, and my step-father, Victor Espinal, thank you for your love, support, and laughter - I love you all. To Steven J. Bido, thank you for lifting the heavy rock I once lived under, for being my personal graphic designer, DJ, and friend, I love you. To my amazing friends Ana Erb, Paul Hirko, Jr., Mitchelle Rodriguez, and Yuliana Rodriguez, thank you for the great times and for always being there for me, even when I went M.I.A., I love you guys.

\section{IN MEMORY}

This research is in memory of my grandmother, Genoveva Alicea, my stepgrandfather, Frankie Quiles, my colleague, Rene Fernandez, and to those individuals whose remains have yet to be found - may they rest in peace. 


\section{ABSTRACT OF THE DISSERTATION \\ IDENTIFICATION OF CHARACTERISTIC VOLATILE ORGANIC COMPOUNDS \\ RELEASED DURING THE DECOMPOSITION PROCESS OF \\ HUMAN REMAINS AND ANALOGUES \\ by}

Norma Iris Caraballo

Florida International University, 2014

Miami, Florida

Professor Kenneth G. Furton, Major Professor

The manner in which remains decompose has been and is currently being researched around the world, yet little is still known about the generated scent of death. In fact, it was not until the Casey Anthony trial that research on the odor released from decomposing remains, and the compounds that it is comprised of, was brought to light. The Anthony trial marked the first admission of human decomposition odor as forensic evidence into the court of law; however, it was not ready for prime time as the scientific research on the scent of death is still in its infancy.

This research employed the use of solid-phase microextraction (SPME) with gas chromatography-mass spectrometry (GC-MS) to identify the volatile organic compounds (VOCs) released from decomposing remains and to assess the impact that different environmental conditions had on the scent of death. Using human cadaver analogues, it was discovered that the environment in which the remains were exposed to dramatically affected the odors released by either modifying the compounds that it was comprised of or by enhancing/hindering the amount that was liberated. In addition, the VOCs released 
during the different stages of the decomposition process for both human remains and analogues were evaluated. Statistical analysis showed correlations between the stage of decay and the VOCs generated, such that each phase of decomposition was distinguishable based upon the type and abundance of compounds that comprised the odor.

This study has provided new insight into the scent of death and the factors that can dramatically affect it, specifically, frozen, aquatic, and soil environments. Moreover, the results revealed that different stages of decomposition were distinguishable based upon the type and total mass of each compound present. Thus, based upon these findings, it is suggested that the training aids that are employed for human remains detection (HRD) canines should 1) be characteristic of remains that have undergone decomposition in different environmental settings, and 2) represent each stage of decay, to ensure that the HRD canines have been trained to the various odors that they are likely to encounter in an operational situation. 


\section{TABLE OF CONTENTS}

CHAPTER

PAGE

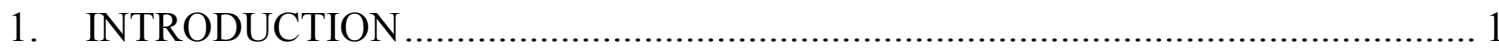

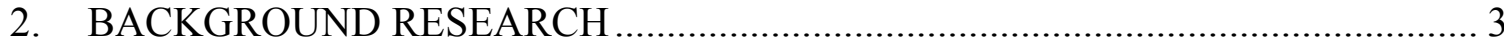

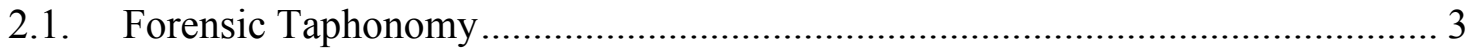

2.1.1. Decomposition Process ................................................................... 4

2.1.2. Human Cadaver Analogues ............................................................ 7

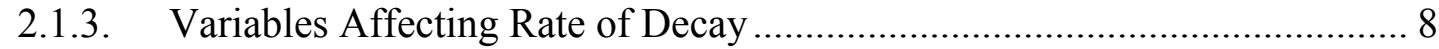

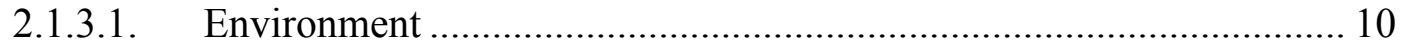

2.1.3.1.1. Frozen Environments .................................................................. 11

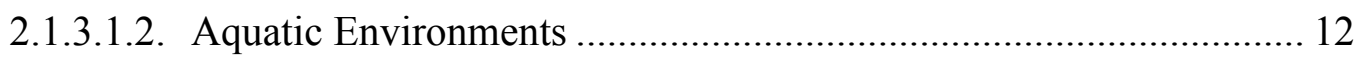

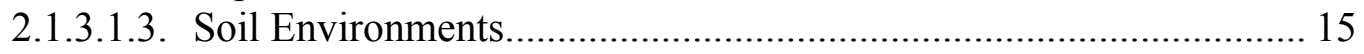

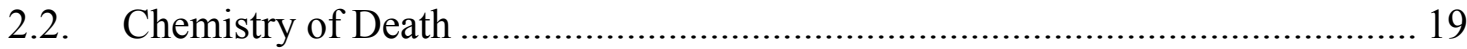

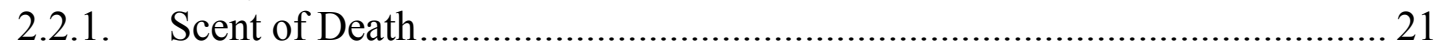

2.2.2. Current Research on the Scent of Death ................................................ 23

2.3. Human Remains Detection Canines.............................................................. 26

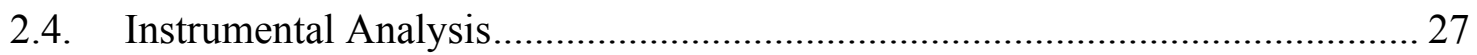

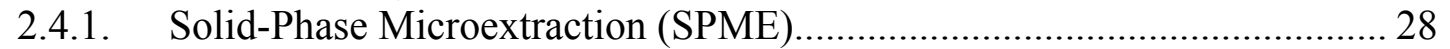

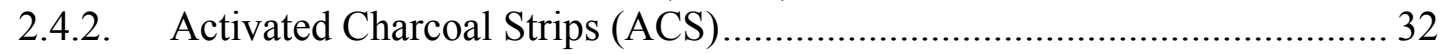

2.4.3. Gas Chromatography-Mass Spectrometry (GC-MS).............................. 34

3. SIGNIFICANCE OF STUDY AND RESEARCH OBJECTIVES ......................... 38

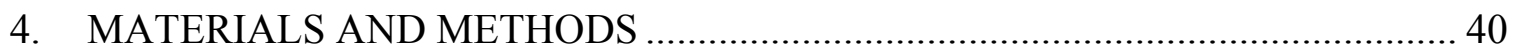

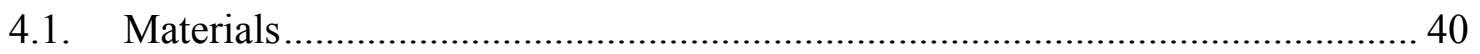

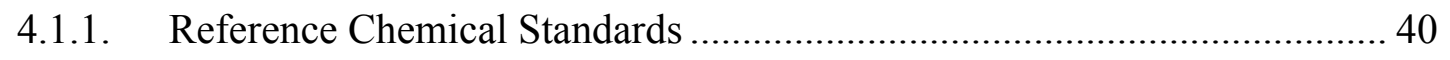

4.1.2. Gas Chromatography-Mass Spectrometry Analysis.................................. 40

4.1.3. Comparison of SPME and ACS for the Extraction of the Liberated VOCs from Decomposing Remains ................................................. 44

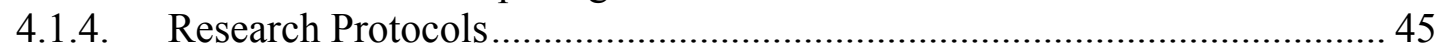

4.1.5. Human Cadaver Analogues .................................................................... 45

4.1.6. Customized Housing and Sampling (H \& S) Chamber .............................. 46

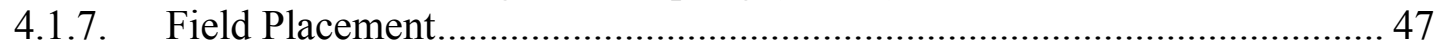

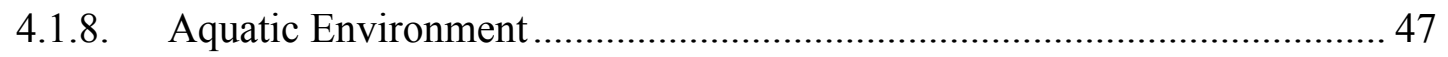

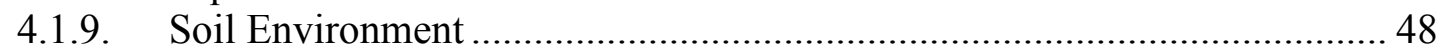

4.1.10. Scent Collection from Human Remains ................................................. 49

4.1.10.1. Subjects and Location of Sampling .................................................. 49

4.1.10.2. Scent Collection............................................................................ 49

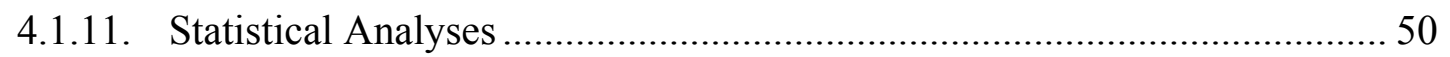

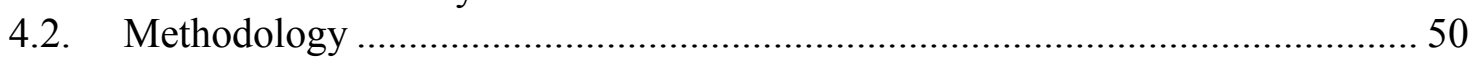

4.2.1. Optimization of a GC-MS Method for the Detection of VOCs

Released from Decomposing Remains ................................................. 51 
4.2.2. Comparison of SPME and ACS for the Extraction of the Liberated VOCs from Decomposing Remains .......................................................... 51

4.2.3. Site Analysis for Field Placement............................................................. 53

4.2.4. Housing and Sampling Chambers............................................................. 56

4.2.5. Comparison of the VOCs Released from Frozen then Thawed and Freshly Killed Decomposing Remains .................................................... 57

4.2.6. Assessment of the VOCs Released from Freshly Killed Remains in their Natural State ...................................................................................... 58

4.2.7. Evaluation of the VOCs Released from Decomposing Remains Submerged in Different Aquatic Environments .................................... 59

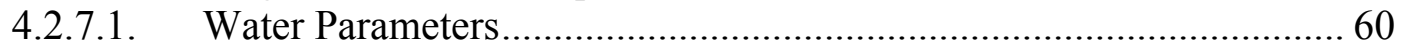

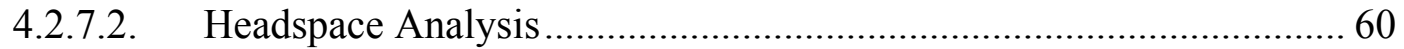

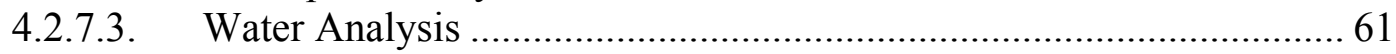

4.2.8. Assessment of the VOCs Released from Decomposing Remains

Buried in Different Soil Environments ...................................................... 61

4.2.9. Evaluation of the VOCs Released from Human Remains ......................... 63

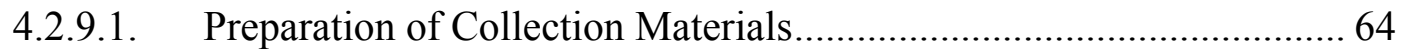

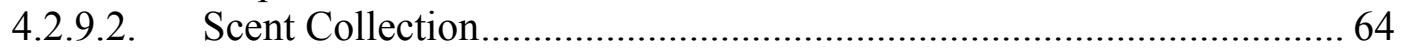

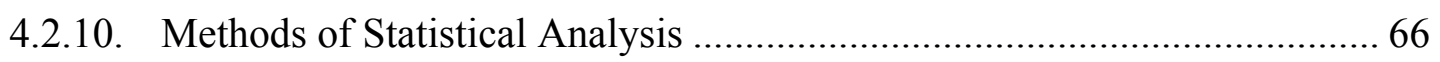

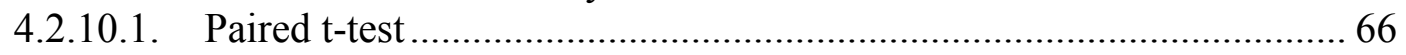

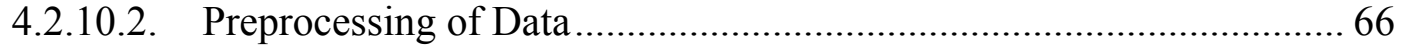

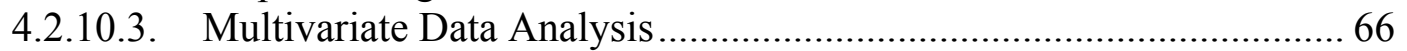

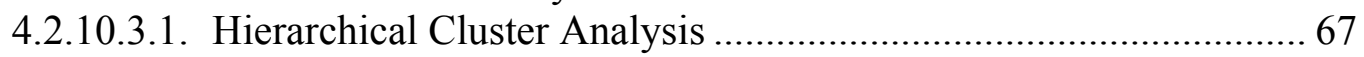

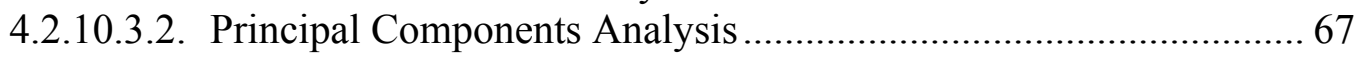

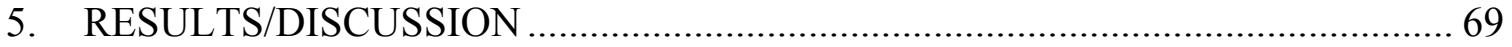

5.1. Method Optimization for the Detection of VOCs Released from

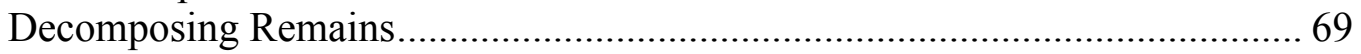

5.1.1. Development of Decomposition-Associated Compounds Database .......... 69

5.1.2. Assessment of Various GC Column Chemistries for GC-MS Analysis.... 72

5.1.3. Gas Chromatograph-Mass Spectrometer Method.................................... 81

5.1.4. Comparison of SPME and ACS for the Extraction of the Liberated VOCs from Decomposing Remains .................................................. 86

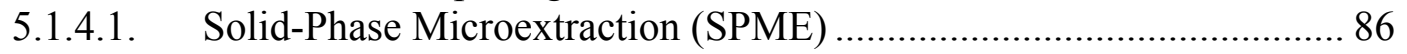

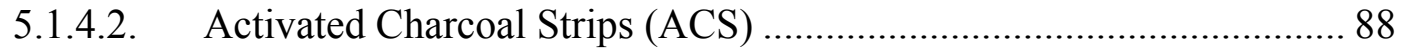

5.2. Research Site for Human Cadaver Analogues ................................................ 89

5.3. Comparison of the VOCs Released from Frozen then Thawed and

Freshly Killed Decomposing Remains ..................................................... 91

5.3.1. Human Cadaver Analogues ................................................................. 91

5.3.2. Temperature and Relative Humidity of Environment ............................ 93

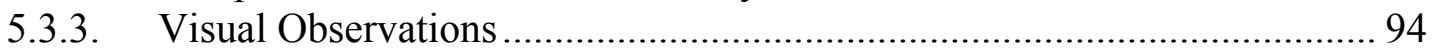

5.3.4. Volatile Organic Compounds Detected from Freshly Killed and Frozen then Thawed Decomposing Remains .......................................... 95

5.3.5. Identification and Assessment of Common Volatile Organic Compounds 
5.4. Assessment of the VOCs Released from Decomposing Remains in their

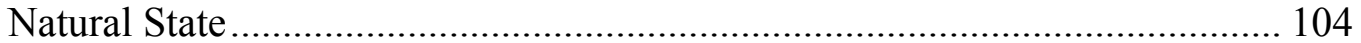

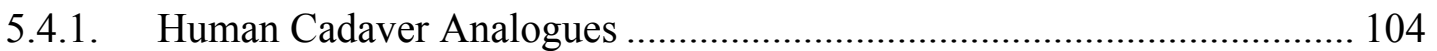

5.4.2. Temperature and Relative Humidity of Environment ............................. 105

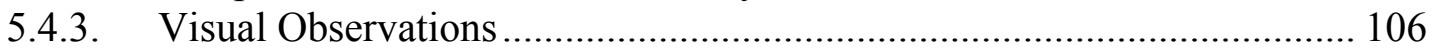

5.4.4. Volatile Organic Compounds Detected from Decomposing Remains ..... 107

5.5. Evaluation of the VOCs Released from Decomposing Remains

Submerged in Different Aquatic Environments.............................................. 115

5.5.1. Human Cadaver Analogues ................................................................. 116

5.5.2. Temperature and Relative Humidity of Environment ............................ 117

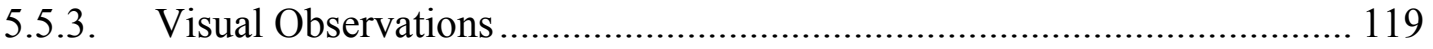

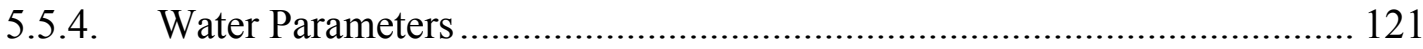

5.5.5. Volatile Organic Compounds Detected from Submerged Remains ......... 125

5.6. Assessment of the VOCs Released from Decomposing Remains

Buried in Different Soil Environments .......................................................... 134

5.6.1. Human Cadaver Analogues .................................................................. 134

5.6.2. Temperature and Relative Humidity of Environment ............................. 135

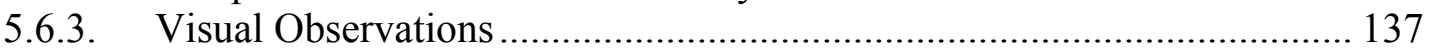

5.6.4. Temperature of Soil at Each Sampling Period........................................ 140

5.6.5. Volatile Organic Compounds Detected from Buried Remains................. 140

5.7. Evaluation of the VOCs Released from Human Remains ............................ 154

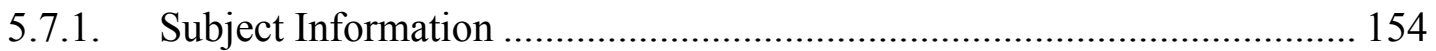

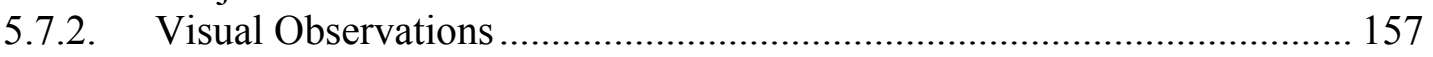

5.7.3. Volatile Organic Compounds Released from Decomposing Human Remains...................................................................................... 161

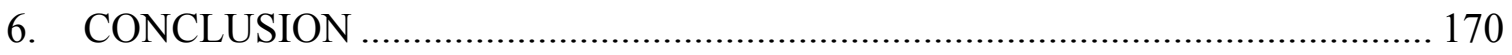

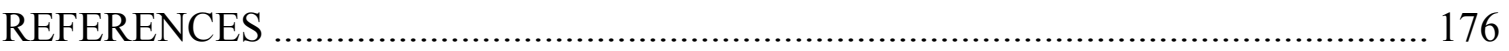

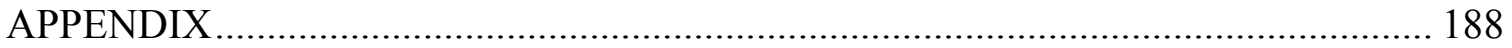

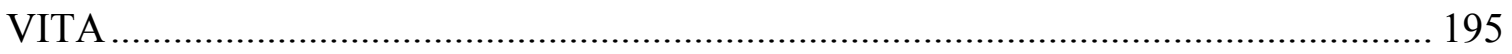




\section{LIST OF TABLES}

TABLE

PAGE

Table 1: Decomposition stages and some physical features that may be observed under gross observation.

Table 2: Some variables found to affect the rate of decay, their assigned point values and a brief description of the physical characteristics that were observed during the decomposition process.....

Table 3: Aqueous environmental and body factors that may affect the rate of decay..... 13

Table 4: Stages of decomposition in an aquatic environment and physical characteristics that may be observed.

Table 5: Commercially available SPME fibers and their polarities. 30

Table 6: Commercially available GC columns, their composition and polarity..... 35

Table 7: List of chemical standards used throughout the course of this research. 41

Table 8: Properties of the soils used to assess the VOCs from buried remains. 62

Table 9: Thirty-one compounds selected to be used for method optimization. 70

Table 10: Temperature measured at each location on roof of AHC1 located at FIU...... 90

Table 11: Mice specifications. 92

Table 12: The average temperature and relative humidity calculated throughout the course of each trial.

Table 13: Presence/Absence of the compounds detected over time for each trial 97

Table 14: Common compounds found in freshly killed and frozen then thawed remains.

Table 15: Mice specifications

Table 16: The average temperature and relative humidity calculated throughout the course of the trial.

Table 17: The volatile organic compounds detected in a minimum of one mouse over the course of the study. 108 
Table 18: List of compounds associated with each stage of decomposition. 114

Table 19: Mice specifications for HPLC-grade water environment. 116

Table 20: Mice specifications for synthetic sea water environment. 116

Table 21: The average temperature and relative humidity calculated throughout the course of each trial for the HPLC-grade water environment.

Table 22: The average temperature and relative humidity calculated throughout the course of each trial for the synthetic sea water environment. 118

Table 23: Compounds detected in both trials of HPLC-grade water environments....... 126

Table 24: Compounds detected in both trials of synthetic sea water environments....... 129

Table 25: Mice specifications for both soil environments. 135

Table 26: The average temperature and relative humidity for both soil types. 136

Table 27: Temperature measurements performed prior to sampling for both Sand and Canadian Sphagnum peat moss. 140

Table 28: Presence/Absence of the compounds detected over time from remains buried in sand.

Table 29: Presence/Absence of compounds detected over time from buried remains in Canadian Sphagnum peat moss.

Table 30: Comparison of the VOCs extracted from both soil environments. 151

Table 31: List of subject information for batches A-E.

Table 32: List of subject information for batches F-J. 156

Table 33: List of compounds identified in a minimum of one subject for each stage of decomposition.

Table 34: Common compounds for each stage of decomposition. 165

Table 35: Decomposition-associated compound database. Listed are compounds pertaining to the functional groups aldehydes, alicyclics, and alcohols. 189 
Table 36: Decomposition-associated compound database. Listed are compounds pertaining to the functional group alcohols, amines, aromatics, and carboxylic acids.

Table 37: Decomposition-associated compound database. Listed are compounds pertaining to the functional groups carboxylic acids, ethers, and esters. .... 191

Table 38: Decomposition-associated compound database. Listed are compounds pertaining to the functional group esters, halogen-containing compounds, heterocyclics, and hydrocarbons.

Table 39: Decomposition-associated compound database. Listed are compounds pertaining to the functional groups hydrocarbons, ketones, and nitrogen-containing compounds

Table 40: Decomposition-associated compound database. Listed are Compounds pertaining to the functional group nitrogen-, oxygen-, and sulfurcontaining compounds. 


\section{LIST OF FIGURES}

FIGURE

PAGE

Figure 1: Sigmoidal curves typically observed with remains decomposing above

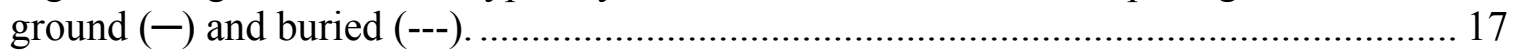

Figure 2: Solid-phase microextraction fiber with assembly..................................... 29

Figure 3: Schematic of Passive Headspace Concentration Extraction technique............. 33

Figure 4: Schematic of a gas chromatograph-mass spectrometer................................ 34

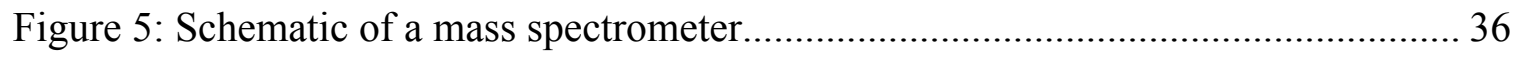

Figure 6: Housing and sampling chamber constructed out of stainless steel with both types of lids, perforated and solid.

Figure 7: Headspace-SPME being performed on a mixture containing decompositionassociated compounds 53

Figure 8: ACS Extraction being performed on a mixture containing decompositionassociated compounds.

Figure 9: Roof of AHC1 located at FIU. Temperature measurements were performed at each location labelled A-I. 55

Figure 10: A shelter created on the roof of AHCI. ................................................... 56

Figure 11: Method comparisons for splitless vs. split injections.................................. 73

Figure 12: Method comparisons of three different flow rates. ................................... 75

Figure 13: Chromatogram obtained using Method E on the GC-MS fitted with an HP-5MS column.

Figure 14: Comparison of a non-polar (HP-5MS) and mid-polar (DB-225MS)

GC column.

Figure 15: Chromatogram obtained using a DB-225MS column.

Figure 16: Comparison of a non-polar (HP-5MS), mid-polar (DB-225MS), and polar (SolGel-Wax) GC columns.

Figure 17: Chromatogram obtained using a SolGel-Wax column. 80 


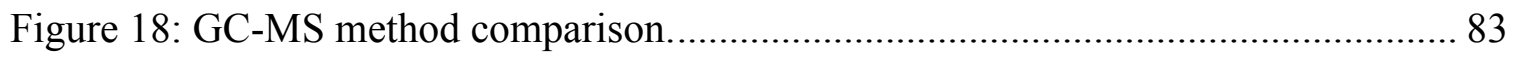

Figure 19: Chromatogram obtained for Method I....................................................... 84

Figure 20: Comparison of the average total abundance, as well as range of compounds extracted by each SPME fiber tested............................................................. 87

Figure 21: Comparison of the number two different SPME fiber coatings...................... 87

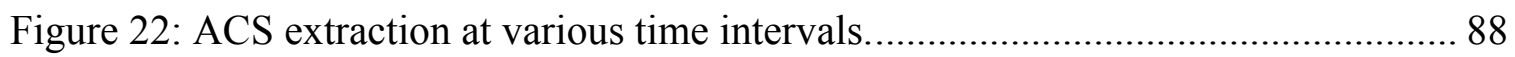

Figure 23: Nine locations were evaluated on the roof of $\mathrm{AHC} 1$ to determine the optimum location to conduct field analyses.................................................................. 89

Figure 24: Temperature measurements at each location over time. .................................. 91

Figure 25: Line graph representing the hourly temperature recordings for each trial...... 94

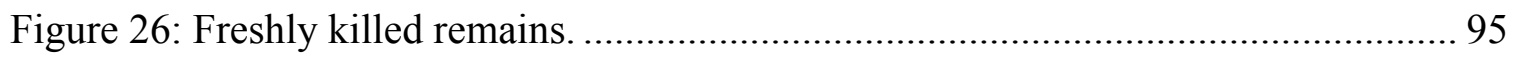

Figure 27: Frozen then thawed remains..................................................................... 95

Figure 28: A box-whisker plot of the freshly killed and frozen then thawed

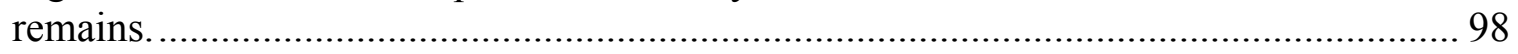

Figure 29: Bar graph showing the average number of common compounds detected from both types of remains. ................................................................................... 100

Figure 30: Odor profiles from each trial for both freshly killed and frozen then

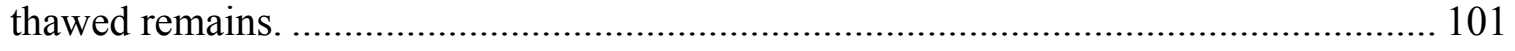

Figure 31: Distribution of chemical functional groups for Days 0, 3, and 5................ 103

Figure 32: Line graph representing the hourly temperature recordings for each micro-t logger, labelled A-D...................................................................................... 106

Figure 33: Human cadaver analogue progressing through different stages

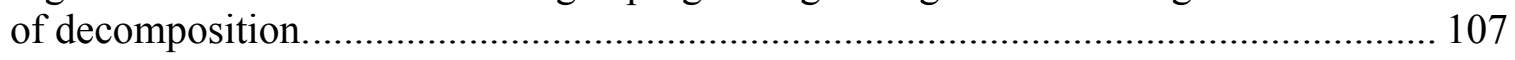

Figure 34: Odor profiles of each mouse over time.................................................... 109

Figure 35: Amount of dimethyl sulfide, disulfide, and trisulfide present in each mouse over time. 
Figure 36: PCA of all mice sampled over time revealing two clusters labelled Phase

I and II.

Figure 37: PCA analysis showing four clusters which is representative of four stages of decomposition.

Figure 38: HCA analysis of mice sampled over time revealing cluster formations for each stage of decomposition.

Figure 39: Odor profiles of each mouse by stage of decomposition.

Figure 40: Line graph representing the hourly temperature recordings for each trial performed for HPLC-grade water environment.

Figure 41: Line graph representing the hourly temperature recordings for each trial performed for synthetic sea water environment.

Figure 42: Day 10 of remains submerged in HPLC-grade (left) and synthetic sea (right) water.

Figure 43: Day 2 of remains submerged in HPLC-grade (left) and synthetic sea (right) water.

Figure 44: Day 6 of remains submerged in HPLC-grade (left) and synthetic sea (right) water.

Figure 45: Parameters measured for Trial 1 of the HPLC-grade water environment..... 122

Figure 46: Parameters measured for Trial 2 of the HPLC-grade water environment..... 123

Figure 47: Parameters measured for Trial 1 of the synthetic sea water environment..... 124

Figure 48: Parameters measured for Trial 2 of the synthetic sea water environment..... 124

Figure 49: Odor profiles from all mice (M) that were submerged in HPLC-grade water.

Figure 50: Relative ratio of the compound(s) extracted from the HPLC-grade water samples that were collected from each mouse (M).

Figure 51: Comparison of the total mass of compounds extracted using headspace and direct immersion SPME from all mice (M). 128

Figure 52: Odor profiles of all mice (M) that were submerged in synthetic sea water. . 130 
Figure 53: Relative ratio of each compound present in the water samples collected from all mice $(\mathrm{M})$.

Figure 54: Comparison of the total mass of compounds extracted from all of the mice (M) submerged in synthetic sea water using headspace and direct immersion SPME.

Figure 55: Line graph representing the hourly temperature recordings for both soil types.

Figure 56: Remains prior to burial in Sand (left) and Canadian Sphagnum peat moss (right).

Figure 57: Remains upon disinterment from Sand (top) and Canadian Sphagnum peat moss (bottom)

Figure 58: Odor profiles of undisturbed (left) and disturbed (right) soil environments for sand.

Figure 59: Comparison of the total mass extracted from undisturbed (left) and disturbed (right) soil environments for buried in sand

Figure 60: Odor profiles of undisturbed (left) and disturbed (right) soil environments for Canadian Sphagnum peat moss.

Figure 61: Comparison of the total mass extracted from undisturbed (left) and disturbed (right) soil environments for Canadian Sphagnum peat moss.

Figure 62: Comparison of the total mass of compounds extracted from remains buried in sand and Canadian Sphagnum peat moss for both undisturbed and disturbed soil environments.

Figure 63: Subject D59-2013 - Stage of Decay - Fresh ............................................ 157

Figure 64: Subject D56-2013 - Stage of Decay - Early/Bloat .................................... 157

Figure 65: Subject D57-2013 - Stage of Decay - Active .......................................... 158

Figure 66: Subject D56-2013 - Stage of Decay - Advanced ..................................... 159

Figure 67: Subject D33-2013 - Stage of Decay - Mummification................................ 160

Figure 68: Subject D24-2013 - Stage of Decay - Skeletonization ............................. 161

Figure 69: Odor profiles for all subjects sampled in each stage of decomposition. ....... 166 
Figure 70: PCA analysis revealing three clusters which is representative of three different stages of decomposition. ............................................................................... 168

Figure 71: HCA of subjects sampled at three different stages of decay......................... 169

Figure 72: HCA of subjects sampled at two different stages of decay........................... 169 


\section{LIST OF ABBREVIATIONS}

ACS Activated Charcoal Strip

ATP Adenosine Triphosphate

$\begin{array}{cl}\text { CAR/PDMS } & \text { Carboxen/Polydimethylsiloxane } \\ \text { CAS } & \text { Chemical Abstracts Service }\end{array}$

$\begin{array}{cl}\text { DI-SPME } & \text { Direct Immersion Solid-Phase Microextraction } \\ \text { DVB/CAR/PDMS } & \text { Divinylbenzene/Carboxen/Polydimethylsiloxane } \\ \text { DVB/PDMS } & \text { Divinylbenzene/Polydimethylsiloxane } \\ \text { FACTS } & \text { Forensic Anthropology Center at Texas State } \\ \text { FKD } & \text { Freshly Killed } \\ \text { FTW } & \text { Frozen then Thawed } \\ \text { GC } & \text { Gas Chromatography } \\ \text { GC-MS } & \text { Gas Chromatography-Mass Spectrometry } \\ \text { H \& S } & \text { Housing and Sampling } \\ \text { HCA } & \text { Hierarchical Cluster Analysis } \\ \text { HPLC } & \text { High Performance Liquid Chromatography } \\ \text { HRD } & \text { Human Remains Detection } \\ \text { HS-SPME } & \text { Headspace Solid-Phase Microextraction } \\ \text { IACUC } & \text { Institutional Animal Care and Use Committee } \\ \text { MS } & \text { Mass Spectrometry } \\ \text { PA } & \text { Polyacrylate } \\ \text { PC } & \text { Principal Component } \\ \text { PCA } & \text { Principal Components Analysis } \\ \text { PDMS } & \text { Polydimethylsiloxane }\end{array}$




$\begin{array}{cl}\text { PEG } & \text { Polyethylene Glycol } \\ \text { PMI } & \text { Post-Mortem Interval } \\ \text { RH } & \text { Relative Humidity } \\ \text { RSD } & \text { Relative Standard Deviation } \\ \text { SPME } & \text { Solid-Phase Microextraction } \\ \text { TDS } & \text { Total Dissolved Solids } \\ \text { TIC } & \text { Total Ion Chromatogram } \\ \text { TOD } & \text { Time of Death } \\ \text { VOCs } & \text { Volatile Organic Compounds }\end{array}$




\section{INTRODUCTION}

The manner in which remains decompose has been and is currently being researched around the world, yet little is still known about the generated scent of death. In fact, it was not until The State of Florida vs. Casey Marie Anthony [1] - a trial that garnered extensive media coverage comparable to that of both O.J. Simpson and the Menendez brothers - that research on the odor released from decomposing remains, and the compounds that they are comprised of, was brought to light.

On July 15, 2008 in Orange County, Florida, Casey Marie Anthony’s mother placed her first call to emergency dispatchers to report her granddaughter, Caylee Anthony, missing; as she had not been seen for over 30 days [2-4]. Anthony's vehicle, a 1998 white Pontiac Sunfire, was also reported missing [2]. After the vehicle had been found at a local wrecker yard, Anthony's mother called emergency dispatch for the second time stating that her daughter's vehicle smelled as though a dead body had been present; she later retracted her statement [2-4]. The facility manager of the wrecker yard, Simon Birch, informed police officials that as Anthony's father went to retrieve the vehicle from the facility he opened the driver side door releasing an extremely unpleasant, yet familiar, odor [2]. Birch stated that the pungent smell, although not as strong, was the same odor that he had previously experienced from a vehicle that contained the remains of a man who committed suicide approximately five days prior [2].

During the course of the investigation, Officer Jason Forgey and his K-9 partner, Gerus, who was trained to detect and alert to the odor released from decomposing human remains, were contacted to perform a cadaver search of Anthony's vehicle; Gerus 
provided a positive alert to the rear passenger fender/trunk area [2]. In October 2008, Casey Marie Anthony made national and international headlines after she was arrested and charged with first degree murder for the death of her 2-year old daughter, Caylee [15]. In December of that year, the remains of a small child, later identified to be that of Anthony's daughter, were found in a wooded area near the home of Anthony's parents [3-5]. Unbeknownst at the time, the unpleasant odor that was mentioned throughout the course of the investigation would play a critical role during Anthony's capital murder trial.

On May 24, 2011, The State of Florida vs. Casey Marie Anthony commenced with the prosecution asserting that Anthony suffocated her daughter with duct tape while the defense claimed that she drowned in her grandparents' above ground swimming pool, and rather than reporting the incident, Anthony's father assisted in disposing of her body $[1,4,5]$. During the trial the unpleasant odor that was previously mentioned - on more than one occasion - while investigating Caylee's disappearance was brought into question. Evidence obtained from Anthony's vehicle had been collected and tested to determine if the foul odor generated was from decomposing human remains [6-10]. The expert witness for the prosecution testified that analytical results revealed five compounds that were considered significant products of decomposition and that the only justifiable explanation for their presence was that decomposing human remains were, at some point, present [6-9]. Conversely, the expert witness for the defense stated to the court that there was currently no instrumental method that had been scientifically validated to determine the presence or absence of compounds associated with human decomposition; furthermore, the compounds previously identified as products of 
decomposition by the prosecution's expert witness could have been generated from trash found within Anthony's vehicle [11,12]. On July 5, 2011, the jury found Anthony notguilty of first degree murder [4,5].

The Anthony trial marked the first admission of human decomposition odor as forensic evidence into the court of law; however, as Dr. Lawrence Kobilinsky, Chairman of the Department of Sciences at John Jay College of Criminal Justice in New York City, stated, it was not "ready for prime time" $[11,13]$. The scientific research on the scent of death is still in its infancy, as was exhibited in the Anthony trial, and there is still much to explore. Thus, the goal of my dissertation research was to identify the compounds that were released from decomposing animal and human remains during different stages of decomposition. Additionally, different environmental factors (i.e., frozen, aquatic, soil) were assessed, using human cadaver analogues, to determine their impact on the liberation of the scent of death.

\section{BACKGROUND RESEARCH}

\subsection{Forensic Taphonomy}

Taphonomy, derived from the Greek words taphos and nomos, meaning "burial" and "a system of laws," respectively, can be defined as "the study of postmortem processes which affect (1) the preservation, observation, or recovery of dead organisms, (2) the reconstruction of their biology or ecology, or (3) the reconstruction of the circumstances of their death" $[14,15]$. Forensic taphonomy is a branch of forensic 
anthropology that aids in criminal investigations by reconstructing the events that occurred ante-, peri-, and post-mortem. This is done through the collection and analysis of data with regards to the environmental conditions in which the remains are located, determining if any perceived modifications to the remains occurred ante-, peri-, or postmortem, and estimating the time since death $[15,16]$.

When the expertise of an anthropologist, who specializes in forensic taphonomy, is requested at a crime scene, it must be ascertained whether the site where the remains were found is where the death occurred or if the remains were moved post-mortem. Additionally, it must be determined if the remains are complete or incomplete as a result of selective transport or scavenging $[15,17]$. As part of reconstructing the scene, the post-mortem interval (PMI), commonly referred to as "time since death", must be estimated [15,17]. Although PMI may be difficult to discern, the biological patterns of other organisms, such as insects and plants, are often used in the assessment, as well as the gross examination of the decomposing soft tissue that encompasses the body $[15,17]$. Thus, it is necessary for forensic scientists to be highly knowledgeable in the different stages of decomposition as this aspect of their assessment is extremely critical in death investigations.

\subsubsection{Decomposition Process}

In a case that involves decomposed human remains, the site of where the death occurred, along with the locality of the body, tends to be the focal point of the investigation [17]. Traditionally, forensic anthropologists will use their knowledge of the 
environment, as well as gross observations of the remains to reveal information that can aid investigators by not only providing an estimated PMI, but also in identifying how the individual lived, as well as how they died [15,17-19]. The manner in which a body decomposes is highly complex as it is not a sole event, but rather a process starting from time of death and ending when the remains have been reduced to bones $[19,20]$. The decomposition process has been broken down into a number of different stages (varying from one to nine), depending upon the research group and their location, but typically averaging five to six stages [20]. Nonetheless, each phase of decomposition is characterized by certain physical features in which the remains will undergo as it advances through the decay process. Six stages of decomposition are presented in Table 1 along with some physical characteristics that may be observed during each phase. It should be noted that active and advanced decay have often been combined into one stage - decay, however, they are separated in Table 1 to provide additional information on the physical characteristics observed at each stage. In addition, not all remains will undergo mummification as this stage is highly dependent upon environmental conditions [19,21].

To appropriately assist in death investigations, it is imperative that forensic scientists have the necessary knowledge, skill, and understanding of the various stages of decomposition. To date, only a few studies have been performed using human cadavers as they are difficult to obtain, there is a negative public opinion surrounding the study of decomposing human remains, and there is a lack of suitable areas for placement and study [22]. Thus, researchers have turned to the use of human cadaver analogues to explore the rate of decay. 
Table 1: Decomposition stages and some physical features that may be observed under gross observation.

\begin{tabular}{|c|c|c|}
\hline $\begin{array}{c}\text { Stage of } \\
\text { Decomposition }\end{array}$ & Physical Characteristics & $\begin{array}{l}\text { Literature } \\
\text { Reference }\end{array}$ \\
\hline Fresh & $\begin{array}{l}\text { - Commences soon after death until } \\
\text { first signs of bloat } \\
\text { - No discoloration }\end{array}$ & {$[19-21,23-27]$} \\
\hline Early/Bloat & $\begin{array}{l}\text { - Greenish discoloration of skin } \\
\text { - Marbling of skin } \\
\text { - Bloating of the remains } \\
\text { - } \text { Gas and fluid accumulation followed } \\
\text { by purging }\end{array}$ & {$[18-21,23-30]$} \\
\hline Active Decay & $\begin{array}{l}\text { - Skin is breaking a part and the } \\
\text { remains begin to deflate } \\
\text { - Darkening of the skin }\end{array}$ & {$[20,21,25-27,30]$} \\
\hline Advanced Decay & $\begin{array}{l}\text { - Corpse dries and cartilage, hair, } \\
\text { bones and some fragments of flesh } \\
\text { remain } \\
\text { - Formation of adipocere, a wax-like } \\
\text { substance }\end{array}$ & $\begin{array}{c}{[19-} \\
21,25,27,29,30]\end{array}$ \\
\hline Mummification* & $\begin{array}{l}\text { - Remains appear drier, flatter, and } \\
\text { leather-like, with some bone exposed }\end{array}$ & {$[20,26,26,30,31]$} \\
\hline $\begin{array}{l}\text { Dry Remains or } \\
\text { Skeletonization }\end{array}$ & $\begin{array}{l}\text { - Bones appear greasy to dry } \\
\text { - No soft tissue present, only bones and } \\
\text { hair }\end{array}$ & {$[19,20,25-27,30]$} \\
\hline
\end{tabular}

*Not all remains will undergo this stage of decomposition, as it is dependent upon the environment. 


\subsubsection{Human Cadaver Analogues}

For decades the rate of decay has been explored, under various conditions, using human cadaver analogues, such as cats [29], dogs [25], mice [32-36], opossums [29], pigs [16,27,30,37-50], rabbits [29,36,51-54], rats [33,55], sheep [32], and squirrels [29]. Currently, the most commonly used surrogates for human decomposition studies are pigs (Sus scrofa domesticus), as they are described as having a similar internal anatomy, adult body weight, heart size-body weight ratio, diet (omnivores), gut fauna, and skin $[27,56]$. Furthermore, Schoenly et al. [57] supported the use of a pig model as a human cadaver analogue after determining that forensically important arthropods did not have a significant preference between human and pig remains. Nonetheless, they are relatively expensive to purchase and maintain, require a minimum of five months to be classified as adults, and they would require a larger site for field placement to conduct decompositionrelated studies [56]. To overcome these challenges different animal models could be used as a human surrogate as long as they (a) decompose similarly to humans, (b) are easy to obtain, (c) are inexpensive, and (d) do not arouse negative public opinion [58]. Aside from decomposition studies, animal models are commonly used for medical research, specifically in human diseases and disorders, because their genetics, anatomy, and physiology are similar to that of humans [59]. According to Simmons [59], the most commonly used mammal employed in experimental studies are rodents, specifically mice, as they are not difficult to obtain, easy to handle, have a high rate of reproduction, are relatively inexpensive, and most importantly, they are easy to manipulate. When conducting scientifically valid research, it is imperative that experimental conditions are 
controlled, in such a way that one variable is manipulated while the others remain constant, allowing for observations to be made as a consequence of the singularly changed variable [59]. When studying the decomposition process, the ability to manipulate variables is highly advantageous, as there are a multitude of parameters that can affect the rate of decay.

\subsubsection{Variables Affecting Rate of Decay}

In death investigations the expertise of a forensic anthropologist is often sought to interpret the scene, as well as the remains, to reveal information that could lead to the identification of the victim and the circumstances surrounding their demise [19]. Thus, it is of importance that forensic scientists are not only equipped with the knowledge surrounding the different stages of decomposition, but also the various parameters that can enhance or hinder its progression. Mann et al. compiled a preliminary report listing some of the variables that have been observed to affect the rate of decay in the peerreviewed article, "Time Since Death and Decomposition of the Human Body: Variables and Observations in Case and Experimental Field Studies" [22]. In addition, each parameter was subjectively rated on a scale of $1-5(1=$ least impactful; $5=$ most impactful) with regard to its likelihood to effect the manner in which remains decompose. A summarized version of this list of variables, their assigned point value, and a brief description on the affect that each variable has on decomposing remains, can be found in Table 2. Overall, the authors' concluded that temperature, accessibility of insects, and the depth in which the remains are buried are the most critical variables affecting the rate 
Table 2: Some variables found to affect the rate of decay, their assigned point values and a brief description of the physical characteristics that were observed during the decomposition process. The 1-5 point value represents how likely it will affect the rate of decay with 1 signifying the least impactful and 5 representing the most impactful.

\begin{tabular}{|c|c|c|}
\hline Variable & $\begin{array}{l}\text { Point } \\
\text { Value }\end{array}$ & Physical Characteristics \\
\hline Temperature & 5 & $\begin{array}{l}\text { In cold or freezing weather, the rate of decay is greatly } \\
\text { reduced or ceases entirely; whereas, in warm to hot } \\
\text { environments, remains can become completely } \\
\text { skeletonized in approximately } 2-4 \text { weeks. }\end{array}$ \\
\hline Access by Insects & 5 & $\begin{array}{l}\text { The majority of soft tissue destruction is because of } \\
\text { feeding by insects. If insect infestation is prevented, the } \\
\text { rate of decay will be greatly reduced. }\end{array}$ \\
\hline Burial and Depth & 5 & $\begin{array}{l}\text { Burial slows the rate of decay; remains buried } \\
\text { approximately } 3-4 \mathrm{ft} \text {. may take years to decompose, } \\
\text { whereas those buried in shallower graves }(1-2 \mathrm{ft} \text {.) may } \\
\text { skeletonize in a few months to a little over a year. }\end{array}$ \\
\hline $\begin{array}{c}\text { Trauma } \\
\text { (Penetrating/Crushing) }\end{array}$ & 4 & $\begin{array}{l}\text { Remains with any penetrating wounds or gross trauma will } \\
\text { decompose more readily than remains without trauma. }\end{array}$ \\
\hline Humidity/Aridity & 4 & $\begin{array}{l}\text { High humidity was correlated with increased insect activity } \\
\text { which in turn enhances the rate of decay. Arid } \\
\text { environments cause desiccated and mummified remains } \\
\text { with little destruction from insects hindering the } \\
\text { decomposition process. }\end{array}$ \\
\hline Body Size and Weight & 3 & $\begin{array}{l}\text { Individuals that were larger at death decomposed quicker } \\
\text { than those that were thinner. }\end{array}$ \\
\hline Clothing & 2 & $\begin{array}{l}\text { Clothing protects the remains from sunlight, which the } \\
\text { maggots avoid, encouraging the swiftness of the } \\
\text { decomposition process. }\end{array}$ \\
\hline $\begin{array}{l}\text { Type of Surface Placed } \\
\text { Upon }\end{array}$ & 1 & $\begin{array}{l}\text { Remains placed upon a concrete surface decomposed } \\
\text { slower than those placed upon the surface of a natural } \\
\text { environment (e.g., soil). }\end{array}$ \\
\hline Soil $\mathrm{pH}$ & - & Impact on the rate of decay is unknown. \\
\hline
\end{tabular}


of decay. Moreover, trauma to the body played an integral role in the decomposition process since the insects are attracted to the wounds, facilitating the expeditious soft tissue destruction.

Since the article by Mann et al. [22] was published, a multitude of studies, using both human and animal remains, were performed, by various research groups, to assess the impact that different variables (e.g., submerged, stored in a vehicle, etc.) had on the rate of decay [20,21,31,37-42,50,51,60-64]. Each study found that the variable being evaluated enhanced, hindered, or did not affect the progression of decomposition. Nonetheless, the assessment of these variables has brought to light the role the environment plays on the decomposition process.

\subsubsection{Environment}

The ecological region and climatic conditions, as well as the placement of the remains in soil or aquatic environments, can cause specific variations on the typical progression of decomposition. Thus, several studies have been performed in areas where temperatures and environmental factors differ for the purpose of assessing the potential effect that it has on the rate of decay. For the purpose of simplicity and this dissertation research, three different environmental conditions will be reviewed: frozen, soil, and aquatic. 


\subsection{Frozen Environments}

During the decomposition process, the soft tissue undergoes putrefaction (anaerobic degradation) and decay (aerobic degradation) depending upon the temperature [65]. Putrefaction is said to occur at moderate temperatures and cease in environments that are less than $4^{\circ} \mathrm{C}$ - the temperature of the average refrigerator [65]. To date, many decompositional studies have been performed under warm or hot climatic conditions altering the rate at which the remains decompose, but not the sequence $[55,66]$. Conversely, in frozen environments, the rate slows to virtually zero while the pattern of decomposition is substantially altered by hastening certain decompositional changes while reducing others $[55,65,66]$.

Through insect and microbiological succession, in addition to assessing the rate of decay and disarticulation (separation at the joint), Micozzi [55] compared the effects of freshly killed (FKD) remains to those that were frozen then thawed (FTW). The data revealed that the rate of disarticulation was slower in those remains that were FKD than those that were FTW. Additionally, the freeze-thaw cycle hindered the growth and participation of enteric microorganisms, which significantly aids in the decomposition process, whereas in the FKD remains, anaerobic degradation proceeded more rapidly. Moreover, freezing was found to weaken the skin, connective tissues, and joints enabling aerobic degradation and disarticulation by increasing the vulnerability of the internal organs to foreign organisms and insects. Thus, Micozzi [55] concluded that frozen then thawed remains decompose predominantly through aerobic degradation from the "outside-in", whereas those remains that were freshly killed decompose through 
anaerobic degradation from the "inside-out". Thus, to obtain a more accurate picture of the decompositional sequence, the author suggested that future studies be performed using remains that were freshly killed.

\subsection{Aquatic Environments}

Each crime scene is distinctive; thus, in special environments, such as aquatic, care must be taken when processing submerged remains. Different bodies of water, such as oceans, rivers, lakes, and ponds will differ with regard to temperature, depth, salinity, oxygenation, current movement (i.e., stagnant, free flowing), life forms (i.e., scavengers), bacterial activity, shores, and floor geology. Thus, depending upon these factors, the manner in which remains respond (e.g., sink, float, remain submerged, cast upon shores, disarticulated, consumed by scavengers, remain stationary, etc.) upon entering the water may differ. Moreover, human remains in water may experience various conditions (Table 3) which is dependent upon the remains themselves, as well as the water environment, that can enhance or hinder the rate of decay [61,72].

In comparison to remains that are above ground exposed to air, those that were submerged in water were found to decompose at a much slower rate, approximately half the time needed for decomposition in air, depending upon the environment. The reduced rate of decay could be attributed to the cooler temperatures of the water, as well as the hindrance of insect activity and scavengers [61]. Payne and King [73] assessed insect activity on submerged pig remains and found that water effectively limited the number and kind of arthropods that scavenged the carcass. Furthermore, the authors' discovered 
Table 3: Aqueous environmental and body factors that may affect the rate of decay.

\begin{tabular}{|c|c|}
\hline Aqueous Environmental Factors & Body Factors \\
\hline Temperature & Covered (e.g., clothed) \\
\hline Depth of the Body of Water & Physique (e.g., thin, overweight) \\
\hline Current Movement & Submerged \\
\hline Microbes & Floating \\
\hline Obstruction/Debris & Trauma \\
\hline Time of Year & Presence of Adipocere \\
\hline Chemistry of the Water & -- \\
\hline Sedimentation/Geology & -- \\
\hline Insect Activity & -- \\
\hline
\end{tabular}

that submerged remains decomposed differently than those above ground and that at each stage of decay a particular group of insects were present. A study conducted by Tomberlin and Adler [60] found that the habitat (land or water), as well as the time of year, influenced the manner in which remains decomposed and insects colonized. It should be noted that the authors' designed the experiment to exclude the influence of water (non-natural habitat), as well as minimized decomposition by aquatic arthropods through the use of artificial containers. Haefner et al. [74] evaluated the decomposition 
of human cadaver analogues submerged in a lotic aquatic system (i.e., stream) and identified five stages of decomposition based upon physical characteristics (Table 4).

Table 4: Stages of decomposition in an aquatic environment and physical characteristics that may be observed.

\begin{tabular}{|c|c|}
\hline Stage of Decomposition & Physical characteristics \\
\hline Submerged Fresh & $\begin{array}{l}\text { - No signs of decomposition } \\
\text { - Sunken } \\
\text { - Ends when body floats to surface }\end{array}$ \\
\hline Early Floating & $\begin{array}{l}\text { - } \text { Bloat } \\
\text { - Algal growth }\end{array}$ \\
\hline Early Floating Decay & $\begin{array}{l}\text { - Minor decay } \\
\text { - Sloughing of flesh } \\
\text { - Thinning or loss of muscle mass } \\
\text { - Eyes and soft tissue disarticulate } \\
\text { - Head and legs intact } \\
\text { - Identity of carcass evident }\end{array}$ \\
\hline Advanced Floating Decay & $\begin{array}{l}\text { - } \text { Major deterioration visible } \\
\text { - } \text { Ribs and skull exposed } \\
\text { - } \text { Damaged bones } \\
\text { - } \text { Loss of bones } \\
\text { - } \text { Identity of carcass } \\
\text { indistinguishable } \\
\text { - Stage ends as remains sink }\end{array}$ \\
\hline Sunken Remains & $\begin{array}{l}\text { - Any skin present has "soup-like" } \\
\text { consistency } \\
\text { - Small pieces of bone present }\end{array}$ \\
\hline
\end{tabular}


In comparison to the decomposition stages of remains in non-aquatic environments, similarities were observed, such as bloating, flesh decay, disarticulation of bones, etc., but many differences were evident as well. In addition, another study found that depending upon whether the remains were submerged in freshwater or saltwater, stagnant or free flowing, as well as the depth in which they were placed slightly modified the manner in which they decomposed. For instance, in the fresh stage for saltwater environments, the remains floated rather than sunk, and the active and advanced stages of decomposition could not be distinguished [75]. Dodson [76] explained that factors, such as $\mathrm{pH}$, oxygen content, salinity and temperature of the aquatic environment are influential in the rate and mode of decomposition.

Aquatic environments are probably one of the most pervasive settings in taphonomy as it can transport and modify remains. Moreover, the hydrodynamic and chemistry of decomposition is still not fully understood; strides are being made, but research in the area is still minimal.

\subsection{Soil Environments}

Soil has four major components that can be broken down into two sections: pore space and soil solids. Pore space consists of air (c. 20-30\%) and water (c. 20-30\%), whereas soil solids is comprised of mineral particles (c. 45\%), such as gravel, sand, silt, and clay and organic matter (c. 1-5\%) [67].

Organic matter is defined as any material, generated by a living plant, animal, or micro-organism that is returned to the soil where it undergoes decomposition [68]. 
Although the amount of organic matter in soil is relatively small, it still plays an important role in biological (i.e., food source for microorganisms and small animals), chemical (i.e., cation exchange capacity) and physical (i.e., binding mineral particles forming stable aggregates) processes $[67,68]$. The rate at which organic matter decomposes and accumulates can be affected by the type, climate, carbon-to-nitrogen ratio, micro-organism activity, water drainage, and soil texture [69].

Of the different physical properties associated with soil, texture is considered to be one of the most important characteristics because of its profound effect on other properties (i.e., chemical). Soil, defined by its texture, is proportionate to three mineral particles: sand, silt, and clay, which have diameters of 0.05-2.0 $\mathrm{mm}, 0.002-0.05 \mathrm{~mm}$, and $<0.002 \mathrm{~mm}$, respectively. Those particles that are greater than $2.0 \mathrm{~mm}$ are not considered in texture, but may impact water retention, as well as other properties (i.e., air movement) [67]. The mineral particles are arranged and bound to form the varying structure of the soil which are large clusters called aggregates or 'peds'. For example, granular soils, like sand, consist of loosely packed spheroidal peds that are bound by various organic substances, such as iron oxides, clays, or carbonates. The manner in which these structures are formed is of importance as it governs the movement of air and water throughout the soil. For instance, coarse sand has a low moisture content because of gravitational drainage resulting in soil drought [67].

Soil, as well as the body, are extremely complex matrices; thus, death investigations that involve buried remains must be carefully evaluated as the rate of decomposition is approximately eight times slower than what is typically observed above ground [61]. Carter and Tibbett [70] evaluated several studies that were performed on 
the rate of decay, and using the stages of decomposition described by Payne [30], found that the manner in which the remains decomposed above and below soil followed a sigmoidal pattern (Figure 1).

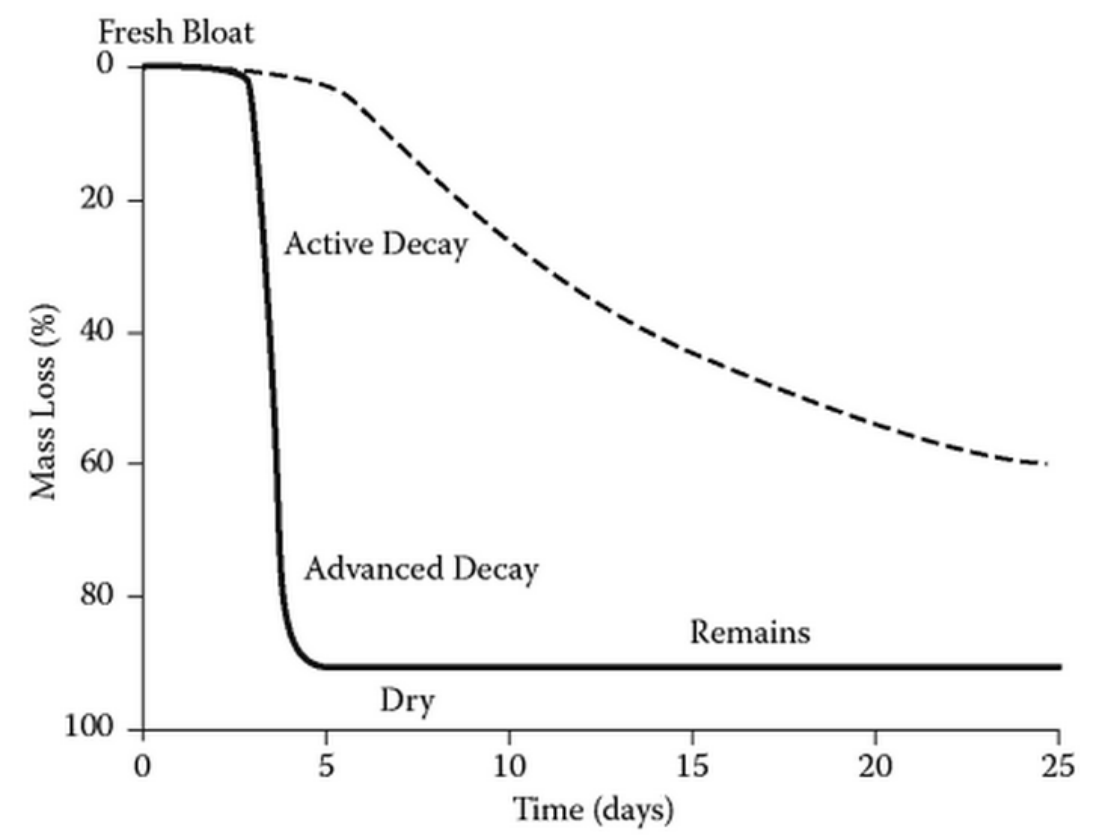

Figure 1: Sigmoidal curves typically observed with remains decomposing above ground (-) and buried (---) [70].

According to Rodriguez [61], there are two major factors that affect the rate of decay of buried remains: 1) limitation of insect and animal activity, and 2) soil environment. Depending upon the depth of burial, carrion insects have little to no access to the remains resulting in minimal soft-tissue degradation and thus, hindering the rate of decay. At shallow depths, soil-dwelling insects and micro-organisms are most prolific because of the enriched upper soil enhancing the rate of decomposition. Moreover, during warm climatic conditions, the remains will experience significant bloating causing the soil to rise, creating cracks and crevices in which carrion insects can migrate through and oviposit upon the tissues, contributing to a more rapid rate of decay [61]. 
Soil acts as a barrier to solar radiation; thus, fluctuating temperatures will stabilize at depths greater than two feet. At burials greater than 4 feet, the rate of decomposition will decrease significantly resulting in virtually intact remains, with minimal soft-tissue degradation for at least one year [61]. In winter months, cadavers buried in shallow graves undergo mummification as the cold temperatures delay or cease the decomposition process; similar to freeze-drying, the remains will desiccate as the temperatures begin to rise in the spring [61].

Carter et al. [63] buried human cadaver analogues in three contrasting soils: loamy sand, sand, and clay, to evaluate the effects that soil moisture had on the rate of decay. Keeping in mind that the soil structure governs the movement of water, the authors' found that the moisture content in soil had to be optimum in order for remains to proceed through the different stages of decay, indicating that if the soil moisture was too high or too low, the processes associated with cadaver decomposition will be hindered. It was suggested that the soil with high moisture content hindered the movement of air affecting aerobic microbial metabolism. Additionally, the soil with low moisture content also affected the mobility of soil microbes resulting in a lack of nutrient supply which is needed to remain active

Soil, a highly multifarious entity with characteristics, such as $\mathrm{pH}$, moisture content, temperature, nutrient availability, microbial activity, and texture can affect the processes associated with in-soil decomposition [67-69,71]. To date, numerous studies have explored the affects that soil has on the rate of decay and while some progress has been achieved, little is still known about its contribution to the process. 


\subsection{Chemistry of Death}

The manner, in which remains decompose, physically, has been studied under various conditions using both human and animal remains; however, little attention has been given to the chemical changes that occur upon death.

Alive, the chemistry of living cells is characterized as having a low temperature (c. $37^{\circ} \mathrm{C}$ ), the right amount and balance of water, highly catalytic by enzymes, and segregated into pathways associated with numerous lipid-bound membranes and organelles. When a disruption occurs at the cellular level, restoration is performed through a collection of chemical processes involving oxygen-required energy transformations. If order is not restored, an anoxic environment is created causing an increase in carbon dioxide in the blood, a decrease in $\mathrm{pH}$, and an accumulation of waste, triggering the gradual disorganization of cells which ultimately leads to their death; this state is referred to as autolysis $[24,77]$. Attributable to the lack of oxygen, the production of adenosine triphosphate (ATP), an important intercellular energy transporter, is disrupted effecting ATP-driven biosynthesis, specifically the production of complex chemical compounds from simpler molecules. Consequently, without ATP, cells are unable to move essential molecules and ions. Moreover, facilitated transport fails because carrier proteins are denatured and are not replaced. Activated by a decreasing $\mathrm{pH}$, potentially destructive hydrolytic enzymes which were once stored within membrane-lined organelles, are released into the cytoplasm rapidly denaturing molecules and remaining outer membranes. Thereafter, cells will detach from one another causing 
them to breakdown releasing nutrient-rich fluid which facilitates indigenous, bacteria driving putrefactive change $[23,24,77,78]$.

In the putrefaction stage, the environment within the body is almost completely anaerobic facilitating the rapid growth of the bacterial inhabitants found within the bowel. These microbes migrate into local tissues, gaining accessibility to the lymphatic system, blood capillaries, and veins, eventually reaching all the tissues within the body. Simultaneously, within the respiratory system, a similar bacterial invasion begins. In the body, there are aerobic and anaerobic microbes that act upon the remains $[23,77]$. The aerobic microbes deplete the surrounding tissue of oxygen which consequently, reduces their abundance, but establishes more favorable conditions for the anaerobic microbes, which are considered more destructive. The process continues with the microbes degrading carbohydrates, proteins, and lipids to simpler molecules causing the remains to change color (i.e., marbling), bloat, and release a putrid odor that has come to be known as the scent of death. The accumulation of gases and fluids within the intestines will purge from the remains, sometimes severe enough to tear the skin causing post-mortem injuries $[23,24,77]$. Thereafter, decay is said to begin. In this stage, muscle, which is composed of proteins, and thus, amino acids, are degraded through microbial action and also contribute to the unpleasant odor that is released. During this stage of the decomposition process, and depending upon the environment, body fluids are rapidly leaking out of the remains, there is a high abundance of aerobic and anaerobic microbes, and insect and scavenger activity are present - greatly contributing to the deterioration of the remains $[23,24,77]$. In warm, moist environments and under high $\mathrm{pH}$ conditions, adipocere will result in saponification ("making soap") or grave wax which forms from 
the hydrolysis of lipids producing fatty acids that are further hydrogenated or oxidized. The consistency of adipocere varies, but often appears as a yellowish-white, greasy, waxlike substance $[24,71,77]$. If skin survives the decay process, mummification, produced from dehydrated or desiccated tissue with an appearance that is leathery or parchmentlike, is typically the end result. Skeletal remains undergo diagenesis which is a process that modifies the organic (collagen) and inorganic (e.g., calcium) components of bone that is exposed to the environment, especially areas with high moisture. This is said to occur through the exchange of natural constituents between bone and environment, deposition or adsorption onto the bone, and/or leaching from the bone [24,77].

Living and dying are both highly complex processes. For a forensic scientist to accurately interpret decomposing remains, as well as the scene, gross observations should not be solely relied upon, the chemical aspects that contribute to decomposition, including the unpleasant odors that are released, should also be considered.

\subsubsection{Scent of Death}

During the putrefactive stage of decomposition, microbes will act quickly upon the cells within their immediate environment, degrading macromolecules, such as carbohydrates, proteins, and lipids, into smaller, simpler molecules that range in volatility $[23,24,77]$.

In the initial stages of decomposition, carbohydrates, such as glycogen, are broken down by micro-organisms into glucose monomers and then further degraded into pyruvate $[23,79-81]$. Thereafter, through bacteria and yeast fermentation, the volatile 
organic compounds (VOCs) ethanol and acetic acid are generated. Additionally, through the same fermentation process, other by-products are also produced, they include: pyruvic acid, lactic acid, butanoic acid, propanoic acid, acetaldehyde, acetone, 1propanol, 2-propanol, 1-butanol, and 1,3-butanediol [71,79,80,82].

Protein decomposition, or proteolysis, occurs via enzymatic action at a rate that is determined by the temperature of the remains, moisture content, and microbial activity. Proteolysis is reduced when the remains are cooled, but hastened when warmed. Additionally, decomposition proceeds under moist conditions, whereas it is slowed when it is dry. Microbial activity present prior to death will accelerate protein decay. During proteolysis, proteins are broken down into proteoses, peptones, polypeptides, and amino acids, producing nitrogen-containing compounds, such as skatole and indole [23]. Moreover, proteins that contain sulfur-containing amino acids, such as cysteine, cystine, and methionine, produce hydrogen sulfide gas, sulfides, ammonia, thiols, and pyruvic acid, via desulfhydralation and microbial degradation [78].

The adipose (fat) tissue in a human body is comprised of, by weight, $5-30 \%$ water, $2-3 \%$ proteins, and $60-85 \%$ lipids (fats), $90-99 \%$ of which are triglycerides [71,83]. Microbial lipolytic enzymes produce glycerol and fatty acids through the hydrolysis of triglycerides. Moreover, fatty acids, such as linoleic acid, were found, typically, to be in high abundance within the lipid membranes [79,84]. Upon aerobic oxidation of linoleic acid several aldehydes were produced, such as 2,-decadienal, 3nonenal, hexanal, 2,4,7-decatrienal, 2,6-nonadienal, 3-hexanal, and propanal. In addition, compounds of other chemical functional groups were produced which included ketones, hydrocarbons, acids, and epoxides [79]. 
To determine the biological and chemical processes that result in the scent of death; it is imperative to understand and identify the compounds that comprise the characteristic odor. Employing different analytical techniques, several research groups have investigated decomposition odor, under various conditions, using either human remains or surrogates, in hopes of trying to identify the compounds that constitute the unpleasantly distinctive scent.

\subsubsection{Current Research on the Scent of Death}

To date, limited research has been performed on the scent of death, possibly as a result of issues with methodology or sampling population (i.e., human remains). Thus, several research groups have turned to the use of human cadaver analogues, in instances where human remains cannot be employed, to evaluate the VOCs released during the decomposition process. Together, with studies conducted on both human remains and analogues a multitude of VOCs, consisting of various functional groups, have been identified.

In a two-part study, the scent of death was evaluated from samples that were collected below, above, and at the surface of four individuals that were buried. In phase one [85], over four hundred VOCs consisting of cyclic and non-cyclic hydrocarbons, nitrogen-containing, sulfur-containing, fatty acid methyl esters, oxygenated, halogenated compounds, and a group of miscellaneous compounds assumed to be related to the burial process, but likely the products of degraded vegetation. In the second phase [86], the 
authors' identified thirty compounds, from the over four hundred VOCs originally identified, as important markers in human decomposition.

Statheropoulos et al. [87] evaluated the VOCs released from two human cadavers, with an estimated time of death of 3-4 weeks, identifying over eighty compounds from various chemical functional groups. Another study by Statheropoulos et al. [88] identified over thirty VOCs from one cadaver with an estimated time of death of 4 days. DeGreeff and Furton [89] evaluated twenty-seven deceased individuals from two locations, a crematorium and a morgue, discovering thirteen common VOCs and considering them to be of significance to the odor profile of human remains. In addition, the scent from living and deceased humans was compared; common compounds were present, but a greater abundance of VOCs were identified from human remains. Furthermore, the living human scent samples revealed differences inter-subject, whereas less variation was observed from the human remains samples demonstrating that there is a more generalized, rather than distinct, odor upon death.

Hoffman et al. [90] evaluated the VOCs released from fourteen separate decomposing tissue samples that were used for victim-recovery canine training aids; they consisted of tissue from a blood clot, blood clot from a placenta, blood, muscle, a testicle, skin, body fat attached to skin, adipocere, fat tissue, bone and teeth. The length of time in which the remains were decomposing was not specified. Over thirty decompositionassociated compounds were identified from different chemical functional groups: acids/acid esters, aldehydes, halogens, aromatic hydrocarbons, ketones, sulfides and alcohols. Cablk et al. [91] paralleled the previously mentioned study, under more controlled conditions, using decomposed animal tissue consisting of bone, fat, muscle, 
and skin from cow, chicken, and pig. The length of time in which the remains decomposed varied as the remains collected from cow and pig were considered fresh, whereas the chicken remains were purchased frozen. The authors' discovered over forty compounds consisting of fatty acid methyl esters, alcohols, aldehydes, aromatic hydrocarbons, ketones, alkanes, a sulfide, and an amine.

Dekeirsschieter et al. [92] placed human cadaver analogues, in metal mesh cages to avoid scavenging by carnivores, at three different locations: a forest, an urban site, and a crop field. The VOCs that were released during the decomposition process were assessed and over a hundred compounds were identified, consisting of fourteen acids, eleven esters, eight ketones, eight aldehydes, nine alcohols, sixteen cyclic and eleven non-cyclic hydrocarbons, seven sulfur-containing, nineteen nitrogen-containing, and one halogenated compound. To mimic a clandestine grave, Brasseur et al. [93] buried two human cadaver analogues, in shallow graves at a forest biotope, to evaluate the VOCs released from the remains as they decomposed and to assess any potential variations due to the soil matrix. After six months of burial, the remains were excavated and soil samples were collected from various depths and subsequently analyzed. Over thirty compounds (e.g., methyl-branched alkanes) were found at all depths, whereas twenty VOCs (e.g., ketones, nitriles, etc.) were specifically found in soil collected below the decomposing remains.

The previously mentioned studies represent a majority of the scientific literature regarding the scent of death, revealing that this area of research is still in its infancy. Understanding the VOCs released during decomposition is extremely important as it not only aids scientist in understanding the biological and chemical processes that occur at 
death, but it can also aid with training human remains detection canines and subsequently, criminal investigations.

\subsection{Human Remains Detection Canines}

Canis familiaris, the domestic dog, is a readily available, inexpensive tool that is commonly employed by law enforcement officials, as well as rescue teams, to detect illicit drugs, explosives, and accelerants, as well as living and deceased individuals $[94,95]$.

Canines rely heavily upon their sense of smell to assess their environment [16]. A canine's olfactory acuity is roughly 10,000-100,000 times greater than that of humans, and depending upon their training, can detect odorants at concentrations as low as 1-2 parts per trillion $[96,97]$. Their unique nasal airflow pattern provides them with the ability to separate and process odors, allowing them to locate the source of the odorant; thus, making them ideal for specialized detection work, such as the location of human remains $[16,94,95,98]$.

Human remains detection (HRD) canines, often referred to as cadaver or victimrecovery canines, are air-scent dogs trained to alert to the odor of human remains, at varying stages of decomposition, by communicating to their handler that it has located the source of the odor $[94,99]$. According to the Scientific Working Group on Dog and Orthogonal detector Guidelines (SWGDOG) [99], HRD canines can be trained on a variety of human remains, for instance human blood (fresh and old), burned human tissue, and human decomposition material, such as tissue, adipocere, body fluids, and 
wet and dry bone. Care should be taken when handling such materials, as they pose a hazard to both canine and handler. Furthermore, the manner in which the materials are obtained, used, handled, stored, and disposed of needs to be in compliance with local, state, and federal regulations.

Lasseter et al. [100] conducted five field trials to assess the abilities of HRD canines to locate buried decomposing human and animal remains at different depths. The results revealed that the canines' ability to locate the human remains varied on the basis of the stage of decomposition and depth in which they were buried. The authors' brought to light, not only the need for standardized canine training, but also the limitations that exist in obtaining appropriate materials for HRD training. DeGreeff et al. [101] developed canine training aids using a non-contact, dynamic air-flow device to sample deceased individuals. The training materials were then tested with HRD canines and a majority of the canines, close to $90 \%$, alerted correctly, but the question still remains: what are the compound(s) that these specially trained canines smelling?

Through further exploration, using various analytical methods, the knowledge surrounding the scent of death, and possibly surrounding the core compounds that it is comprised of, can be enhanced.

\subsection{Instrumental Analysis}

For the extraction of volatile organic compounds, solid-phase microextraction or activated charcoal strips can be employed. Thereafter, separation and detection of the 
compounds can be performed with gas chromatography-mass spectrometry. These techniques and the manner in which they are utilized will be further discussed.

\subsubsection{Solid-Phase Microextraction (SPME)}

The analysis of volatile and semi-volatile organic compounds, in various areas of chemistry (e.g., environmental, fragrance, flavor, and forensic), can be performed using solid-phase microextraction (SPME), a rapid, portable, solvent-less, and non-exhaustive technique [102-104]. Solid-phase microextraction was developed by Janusz Pawliszyn at the University of Waterloo to address the need for a rapid sample preparation technique that can be used in the laboratory, as well as out in the field $[102,103,105]$. It can best be described as a short, thin, fused silica solid rod that is coated with a selective polymer, ranging in thickness from $7-100 \mu \mathrm{m}$, and protected by a metal sheath when not in use $[102,105]$. For simplicity, the coated silica rod is placed into a fiber holder and, together, appears as a modified syringe (Figure 2) [102,104].

The SPME technique consists of two processes: (1) the partitioning of analytes between the sample (gaseous or aqueous) and the coated fiber, and (2) the desorption of the concentrated analytes from the fiber coating into an analytical instrument, such as a gas chromatograph-mass spectrometer [102,104]. In the first phase, the coated fiber, which can vary in thickness and chemistry, is exposed to the sample allowing for the target analyte(s) to be extracted. The thickness of the fiber coating is directly proportional to the amount of analyte extracted, as well as the length of time needed to 
perform the extraction. Thus, a thicker coating will extract more of a particular analyte which is advantageous; however, the extraction time will also increase which may be

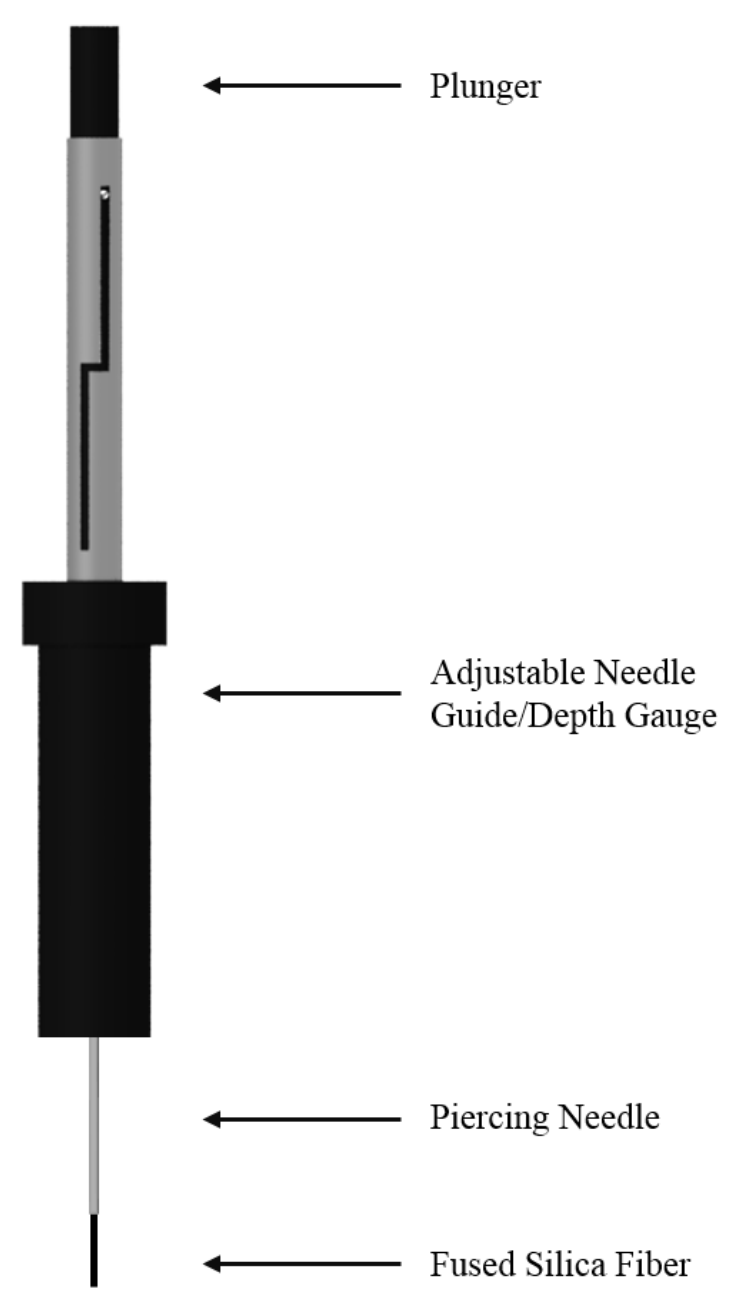

Figure 2: Solid-phase microextraction fiber with assembly.

considered unfavorable for certain applications $[102,104,106]$. The chemistry of the fiber coating is critical when using SPME as both the sample and fiber coating are competing for the target analyte(s). Therefore, it is imperative that the affinity of the fiber coating 
for the target analyte(s) is stronger than that of the sample. It is here that the principle "like dissolves like" applies, where the chemistry of the fiber coating is selected based upon the polarity (polar, bi-polar, non-polar) of the target analytes, as well as the range of their vapor pressure(s) [102]. Table 5 lists the six types of SPME fibers, as well as their polarities, that are commercially available through Supelco (Bellefonte, PA) [106-108].

Table 5: Commercially available SPME fibers and their polarities.

\begin{tabular}{|c|c|c|}
\hline Fiber Chemistry & Acronym & Polarity \\
\hline Carboxen/Polydimethylsiloxane & CAR/PDMS & Bi-Polar \\
\hline Divinylbenzene/Polydimethylsiloxane & DVB/PDMS & Bi-Polar \\
\hline Divinylbenzene/Carboxen/Polydimethylsiloxane & DVB/CAR/PDMS & Bi-Polar \\
\hline Polydimethylsiloxane & PDMS & Non-Polar \\
\hline Polyacrylate & PA & Polar \\
\hline Polyethylene Glycol & PEG & Polar \\
\hline
\end{tabular}

There are two modes in which SPME sampling can be performed: direct immersion and headspace. In direct, liquid sampling, the fiber is immersed directly into the aqueous sample (i.e., water without interfering contaminants) where a concentration equilibration occurs between the fiber coating, often referred to as the stationary phase, and the aqueous phase. As a result, the amount of analyte extracted for a finite sample volume can be determined using Equation 1 where $n_{f}$ is the amount of analyte extracted, $K_{f s}$ is the partition coefficient between the fiber coating and the aqueous phase, $V_{f}$ is the 
volume coating, $C_{0}$ is the initial concentration of the analyte in the sample, and $V_{s}$ is the volume of the sample [102].

\section{Equation 1}

However, if the sample volume is relatively large in comparison to the sample volume, Equation 1 can be simplified to Equation 2 where the amount of analyte extracted is independent of the sample volume [109].

$$
n_{f}=K_{f s} V_{f} C_{0}
$$

\section{Equation 2}

Conversely, for headspace $n_{f}=\frac{K_{f s} V_{f} V_{s} C_{0}}{K_{f s} V_{f}+V_{s}}$ sampling the fiber is not directly immersed into the matrix, but rather exposed to the area above the sample, which is advantageous for solid or highly contaminated samples (e.g., soil, sludge, wastewater, etc.). For this mode of sampling, the denominator of Equation 1, which represents the analyte capacity for each phase, is modified to Equation 3 with the addition of $\left(K_{h s}\right)$, the partition coefficient between the headspace and the sample, and $\left(V_{h}\right)$, the volume of the headspace [102].

$$
n_{f}=\frac{K_{f s} V_{f} V_{s} C_{0}}{K_{f s} V_{f}+K_{h s} V_{h}+V_{s}}
$$

Equation 3

The versatility of SPME has been explored across a variety of applications including the detection of drugs from different biological specimens [110], phthalate esters from environmental waters [111], accelerants from fire debris [112], and explosives from aqueous and post-explosion debris [113], as well as for the 
characterization of food products [114], human scent [101,115-119], and the scent of death [89-91,120-123]. To date, SPME has been routinely used with gas chromatography-mass spectrometry (GC-MS), but for compounds that are not that volatile or thermally labile, SPME can also be used with high performance liquid chromatography (HPLC) and liquid chromatography-mass spectrometry (LC-MS) $[106,124]$.

\subsubsection{Activated Charcoal Strips (ACS)}

In addition to solid-phase microextraction, activated charcoal strips (ACS) have also been employed for headspace analysis, specifically for the recovery of accelerant vapors from fire debris [125]. Commercially available, ACS is a relatively simple, clean, and sensitive method that minimizes preparation and handling time [125-127]. Best described as an adsorbent carbon that is impregnated upon a flexible polymer substrate, it is often employed with a technique known as passive headspace concentration extraction [128]. This non-destructive and versatile method requires an air tight container (e.g., paint can) where the ACS is suspended, for a specific period of time, in the headspace of a sample, allowing for the adsorption of the target analyte(s) onto the surface (Figure 3). Thereafter, the strip is removed, the target analyte(s) are extracted using a solvent, such as carbon disulfide or diethyl ether, and subsequently analyzed [128,129].

The use of ACS has its advantages, such as: (1) adsorption of the target analyte(s) can be performed with or without heating the sample, (2) headspace analysis can be performed during transport, and (3) multiple strips could be used and those that are not 
immediately analyzed could be preserved for future examinations. Conversely, it does have its share of drawbacks. For instance, heating the sample will result in the adsorption of high molecular weight compounds while displacing those compounds that are more volatile. In addition, the extraction of the target analyte(s) from the ACS requires the use

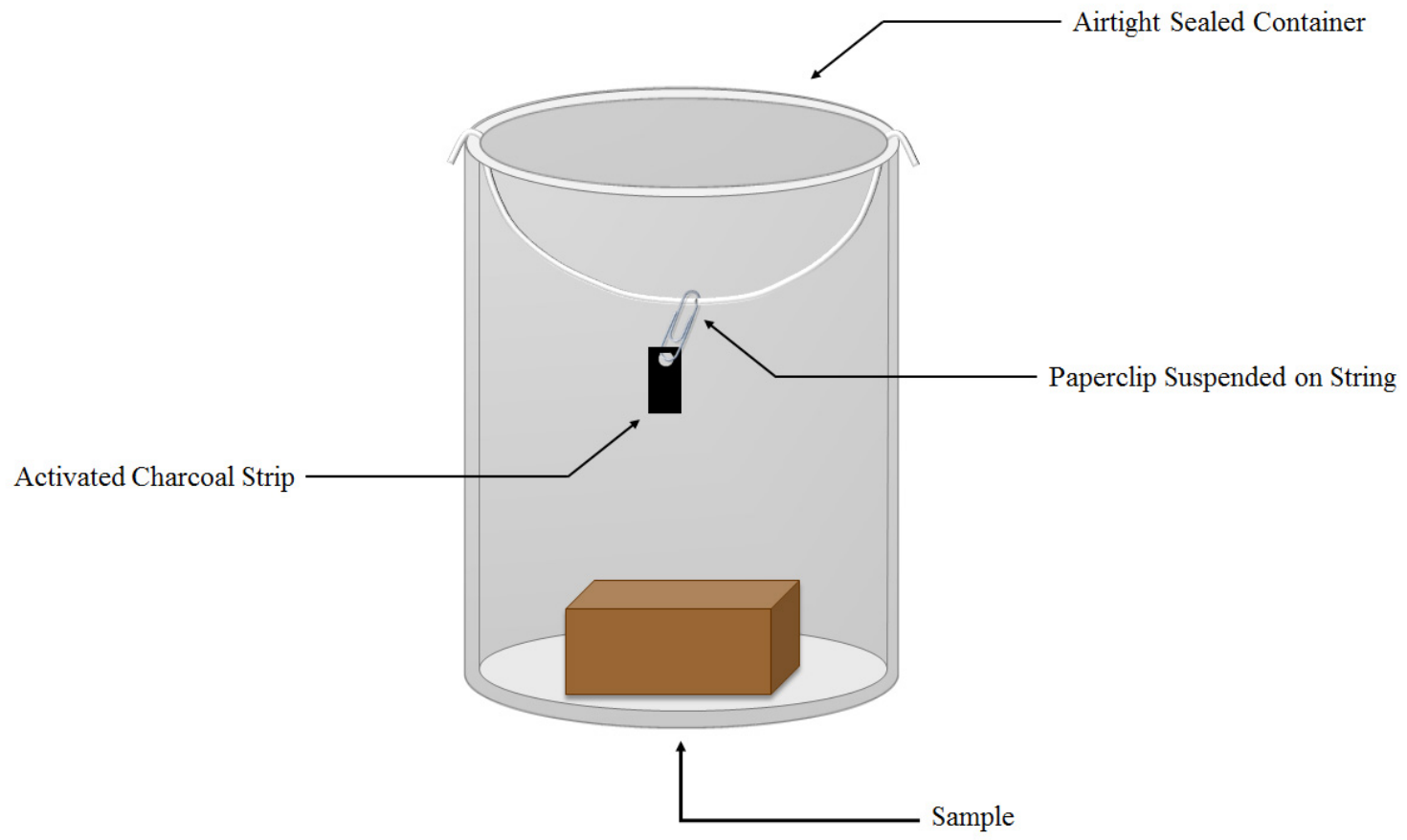

Figure 3: Schematic of Passive Headspace Concentration Extraction technique.

of solvents that are potentially toxic and hazardous to the analyst and environment. Moreover, ACS has a high affinity for hydrocarbons which is a major shortcoming for those analyses requiring the extraction of highly polar compounds $[125,126,128]$. To date, little to no research, other than for the detection of ignitable liquids from various matrices $[125,126,128]$ and volatile organic compounds from ecstasy tablets [122], has 
been explored with activated charcoal strips; thus, its versatility in other applications, including the detection of decomposition odor, is not known.

\subsubsection{Gas Chromatography-Mass Spectrometry (GC-MS)}

Compounds that have sufficient volatility and do not degrade at high temperatures can be analyzed using gas chromatography-mass spectrometry (GC-MS, Figure 4), a hyphenated technique that allows for the separation and identification of unknown mixtures [130]. Typically, a mixture of compounds is injected into a heated inlet where it is vaporized and transported into a column containing a liquid or solid stationary phase. The chemically inert carrier gas, often referred to as the mobile phase, transports the compounds through the column $[130,131]$. Often times, helium is used as the carrier gas

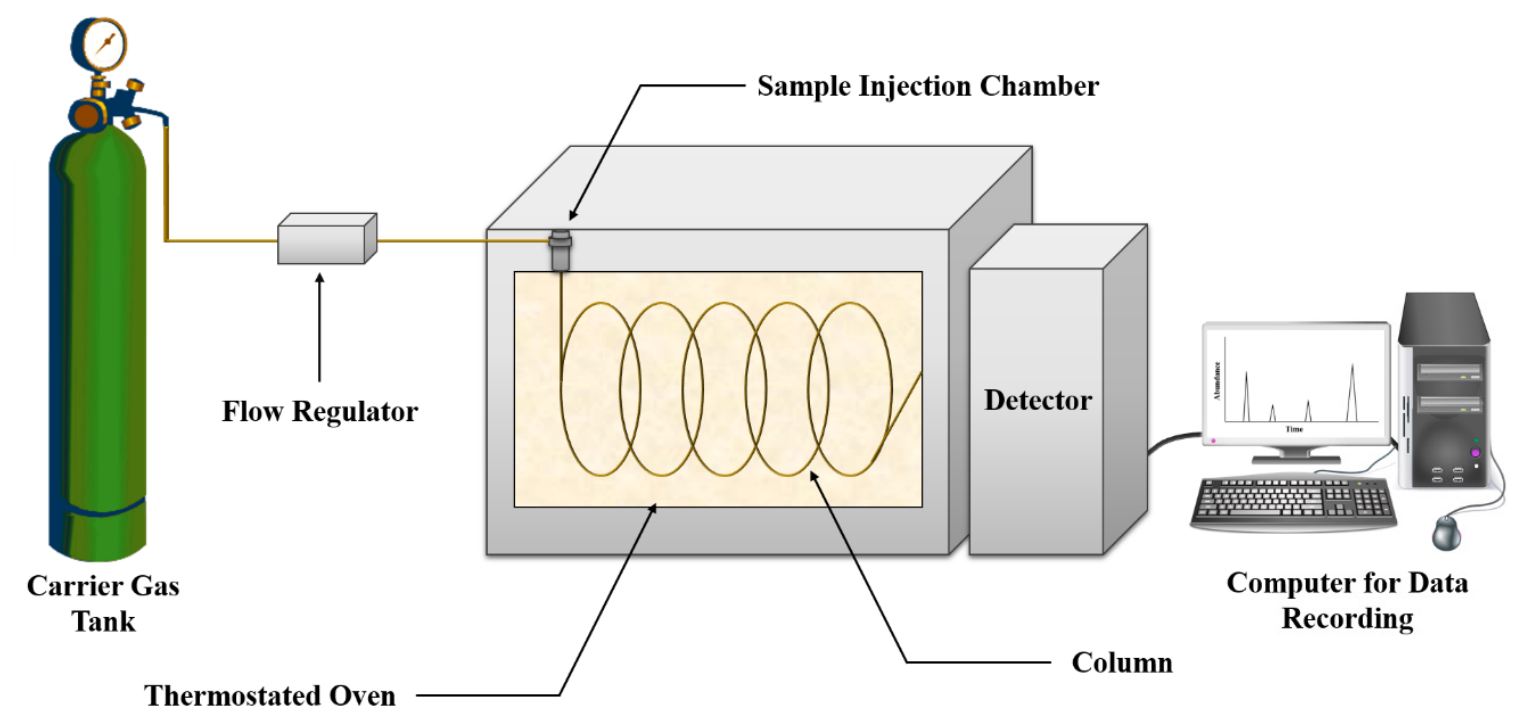

Figure 4: Schematic of a gas chromatograph-mass spectrometer. 
as it is highly inert, safer (non-explosive) to use, and provides reasonable chromatographic efficiency; however, argon, nitrogen, and hydrogen can also be used [130-132]. As the compounds transport, via the carrier gas, through the column, partitioning between the mobile and stationary phase is said to occur; this causes each component to move through the column at a different velocity promoting separation. The stationary phase, which can vary in chemistry, plays a critical role during the separation process as those compounds that have a greater affinity for it, will reside longer, elongating the amount of time needed to elute from the column. Aside from seeking clear separation, caution must be made when selecting a column, as depending upon the target analyte(s) and the type of stationary phase chosen, distorted peaks (e.g., tailing, broadening, etc.) can be generated. Thus, it is imperative that some level of compatibility between the target analyte(s) and the stationary phase exists. Similar to selecting an appropriate SPME fiber for analysis, the principle "like dissolves like" also applies when selecting a GC column, in such that the polarities of both the target analyte(s) and the stationary phase needs to be considered $[130,131]$. Currently, there are a variety of commercially available columns that range in composition and polarity; some are listed in Table $6[133,134]$. Upon separation, the compound(s) elute from the gas

Table 6: Commercially available GC columns, their composition and polarity $[133,134]$.

\begin{tabular}{|c|c|c|}
\hline Common Name & Composition & Polarity \\
\hline DB-1MS & $100 \%$ Dimethylpolysiloxane & Non-Polar \\
\hline DB-5MS & $5 \%$ Phenyl $95 \%$ dimethyl arylene siloxane & Non-Polar \\
\hline
\end{tabular}




\begin{tabular}{|c|c|c|}
\hline DB-35, HP-35 & $35 \%$ Phenyl 65\% dimethylpolysiloxane & Mid-Polar \\
\hline DB-225MS, DB-225 & $\begin{array}{c}\text { 50\% Cyanopropyl-phenyl 50\% } \\
\text { dimethylpolysiloxane }\end{array}$ & Mid-Polar \\
\hline DB-Wax & Polyethylene glycol & Polar \\
\hline SolGel-Wax & Polyethylene glycol in a Sol-Gel matrix & Polar \\
\hline
\end{tabular}

chromatograph and are transferred to a detector, most commonly a mass spectrometer, where the compound(s) are qualitatively and quantitatively analyzed [131].

Mass spectrometers (MS) have revolutionized analytical chemistry because of their extreme sensitivity, limits of detection, speed, and range of applications (e.g., forensic toxicology, environmental and food chemistry, etc.) $[135,136]$. For this type of analysis, the sample is first introduced into the ionization source (Figure 5), which can vary by type (e.g., electron impact, chemical ionization, etc.) depending upon the analytical application, generating charged molecules and/or fragments [136]. Thereafter, the

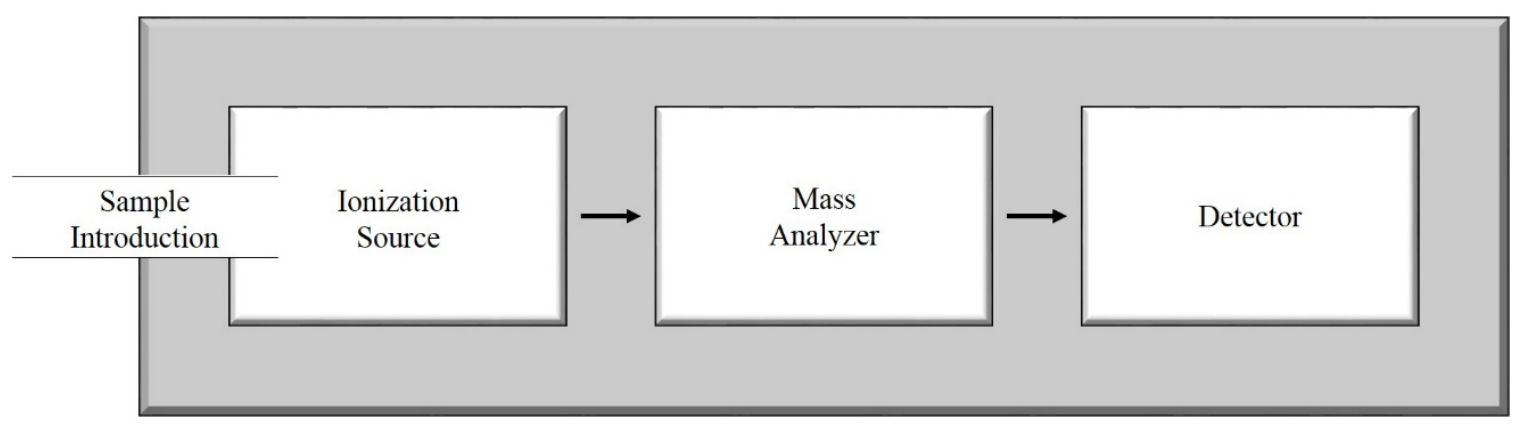

Figure 5: Schematic of a mass spectrometer.

ionized molecules and/or fragments enter the mass analyzer (i.e., quadrupole, ion trap, etc.) where they are manipulated through electric and/or magnetic fields and subsequently 
separated based upon their mass-to-charge ratio $(\mathrm{m} / \mathrm{z})[135,136]$. As the ions pass through the mass analyzer they are detected by an electron multiplier or photomultiplier tube, which varies depending upon the design of the instrument and the analytical application, generating an electrical current that is proportional to their abundance [135]. A computer dedicated to the mass spectrometer records the data generated and converts it into a compatible format; for example, for GC-MS analysis, a total ion chromatogram (TIC), a plot of the total ion current versus time, is generated. The TIC consists of a mass spectrum, a plot of the ion abundance versus the mass-to-charge ratio, for each peak which can be used to identify the compound that is eluting at that particular time $[131,135,136]$. The identity of an unknown compound is often times determined through the use of a mass spectral reference library; however, a comparison of the mass spectrum of a certified reference standard that was analyzed using the same GC-MS method should also be used [131,135].

Gas chromatography-mass spectrometry is a widely used analytical technique that has been proven to be highly advantageous for the analysis of various compounds of forensic interest, such as drugs, accelerants, explosives, paints, human scent, and decomposition odor. Often referred to as the "gold standard", GC-MS has become recognized as an invaluable instrument in forensic laboratories [131]. 


\section{SIGNIFICANCE OF STUDY AND RESEARCH OBJECTIVES}

Research on the scent of death is relatively minimal, with a majority being conducted under conditions that were not well controlled (i.e., remains were refrigerated or frozen upon death, experienced trauma, used pieces rather than whole bodies) which in turn affected the rate of decay and subsequently, the VOCs released. Thus, the objective of this dissertation research was to evaluate the scent of death during the different stages of decomposition, under a more controlled setting, using human and animal remains. Furthermore, frozen, aquatic, and soil environments were assessed to determine the impact that these conditions had on the liberated volatile organic compounds.

This dissertation presents the results of the laboratory and field experiments that were performed to satisfy said objectives. The tasks that were performed are listed below:

1. Method optimization for the detection of volatile organic compounds released from decomposing remains.

A. Conduct a literature review to develop a Microsoft Excel Spreadsheet containing the volatile organic compounds that were previously reported from various types of decomposing remains.

a. From compilation, select compounds to be used for method optimization.

B. Assess various column chemistries for gas chromatography-mass spectrometry analysis.

a. DB-5 (non-polar) 
b. DB-225 (mid-polar)

c. SolGel-Wax (polar)

C. Develop a gas chromatography-mass spectrometry method

D. Compare solid-phase microextraction and activated charcoal strips to determine the optimum extraction technique for decomposition odor.

2. Compare the volatile organic compounds released from frozen then thawed and freshly killed decomposing remains.

3. Assess the volatile organic compounds released from decomposing remains in their natural state (not influenced by environmental adjustments).

4. Evaluate the volatile organic compounds released from decomposing remains submerged in different aquatic environments.

A. HPLC-grade water

B. Synthetic sea water

5. Assess the volatile organic compounds released from decomposing remains that are buried in different soil environments.

\section{A. Sand}

B. Canadian Sphagnum peat moss

C. Evaluate the impact that disturbing the soil environment, for both sand and Canadian Sphagnum peat moss, has on the liberated VOCs.

6. Evaluate the volatile organic compounds released from decomposing human remains during different stages of decomposition. 


\section{MATERIALS AND METHODS}

\subsection{Materials}

\subsubsection{Reference Chemical Standards}

The reference chemical standards that were used during the course of this research, along with their chemical abstracts service (CAS) number and associated lot/batch number are listed, by chemical functional group, in Table 7; they were purchased from Sigma-Aldrich (St. Louis, MO), Alfa Aesar (Ward Hill, MA), or Fisher Scientific (Pittsburgh, PA). In addition, the solvents that were used were HPLC grade dichloromethane and high performance liquid chromatography (HPLC) grade methanol purchased from Fisher Scientific (Pittsburgh, PA).

\subsubsection{Gas Chromatography-Mass Spectrometry Analysis}

Instrumental analysis was performed using a Varian CP-3800 gas chromatograph coupled to a Saturn 2000 Mass Spectrometer (Agilent Technologies, Inc., Santa Clara, CA) with helium as the carrier gas. For liquid injections, a Combipal auto sampler was employed. 
Table 7: List of chemical standards used throughout the course of this research.

\begin{tabular}{|c|c|c|c|}
\hline NAME & COMMON NAME & CAS \# & LOT/BATCH\# \\
\hline \multicolumn{4}{|c|}{ ALCOHOLS } \\
\hline benzyl alcohol & & $100-51-6$ & 03453EC \\
\hline 4-methyl-phenol & p-cresol & $106-44-5$ & $11 K 3739$ \\
\hline phenol & & $108-95-2$ & $128 \mathrm{~K} 1106$ \\
\hline benzene-1,4-diol & hydroquinone & $123-31-9$ & BCBD0571V \\
\hline 1-octen-3-ol & & $3391-86-4$ & 90002415 \\
\hline 1-hexadecanol & & $36653-82-4$ & $\mathrm{BCBC} 1361 \mathrm{~V}$ \\
\hline phenylethyl alcohol & & $60-12-8$ & 09131EI \\
\hline ethanol & ethyl alcohol & $64-17-5$ & 18896APV \\
\hline ethanol & ethyl alcohol & $64-17-5$ & LG8657 \\
\hline isopropyl alcohol & 2-propanol & $67-63-0$ & 104015 \\
\hline 2-furanmethanol & furfuryl alcohol & $98-00-0$ & A0290966 \\
\hline \multicolumn{4}{|c|}{ ALDEHYDES } \\
\hline benzaldehyde & & $100-52-7$ & 982126 \\
\hline heptanal & heptaldehyde & $111-71-7$ & $11825 \mathrm{JD}$ \\
\hline decanal & capraldehyde & $112-31-2$ & 086K1467 \\
\hline dodecanal & lauric aldehyde & $112-54-9$ & 09521LD \\
\hline octanal & octyl aldehyde & $124-13-0$ & 74497LJ \\
\hline nonanal & nonyl aldehyde & $124-19-6$ & MKBH9672V \\
\hline (E)-2-nonenal & trans-2-nonenal & $18829-56-6$ & MKAA1393 \\
\hline (E)-2-octenal & trans-2-octenal & $2548-87-0$ & 05529EO \\
\hline 3-methyl-butanal & isovaleraldehyde & $590-86-3$ & MKBJ9598V \\
\hline hexanal & caproaldehyde & $66-25-1$ & MKBD1396 \\
\hline acetaldehyde & ethanal & $75-07-0$ & $12912 \mathrm{AQ}$ \\
\hline \multicolumn{4}{|c|}{ ALICYCLICS } \\
\hline d-limonene & $(\mathrm{R})-(+)$-limonene & $5989-27-5$ & $08603 \mathrm{HJ}$ \\
\hline cyclohexylcyclohexane & 1,1-bicyclohexyl & $92-51-3$ & 12196EMV \\
\hline methylcyclopentane & & $96-37-7$ & MKBC8861V \\
\hline \multicolumn{4}{|c|}{ AMINES } \\
\hline pyrrole & & $109-97-7$ & $3661 \mathrm{~J}$ \\
\hline indole & & $120-72-9$ & LB88794V \\
\hline 3-methyl-1H-indole & skatole & $83-34-1$ & 01423HDV \\
\hline
\end{tabular}




\begin{tabular}{|c|c|c|c|}
\hline NAME & COMMON NAME & CAS \# & LOT/BATCH\# \\
\hline \multicolumn{4}{|c|}{ AROMATICS } \\
\hline toluene & & $108-88-3$ & 94296 \\
\hline toluene & & $108-88-3$ & 895624 \\
\hline benzene & & $71-43-2$ & BCBF0115V \\
\hline 1-methylnaphthalene & $\begin{array}{c}\alpha \text {-methyl } \\
\text { naphthalene }\end{array}$ & $90-12-0$ & MKBD0415 \\
\hline \multicolumn{4}{|c|}{ CARBOXLYIC ACIDS } \\
\hline n-butyric acid & butanoic acid & $107-92-6$ & A0264062 \\
\hline valeric acid & pentanoic acid & $109-52-4$ & BCBF1032V \\
\hline hexanoic acid & & $142-62-1$ & SHBB4435V \\
\hline 2-methyl-hexanoic acid & & $4536-23-6$ & MKBJ9849V \\
\hline isovaleric acid & $\begin{array}{l}\text { 3-methyl-butanoic } \\
\text { acid } \\
\end{array}$ & $503-74-2$ & MKBJ8734V \\
\hline palmitic acid & hexadecanoic acid & $57-10-3$ & $100 \mathrm{M} 1202 \mathrm{~V}$ \\
\hline glacial acetic acid & & $64-19-7$ & 031642 \\
\hline 4-methylvaleric acid & $\begin{array}{l}\text { 4-methyl-pentanoic } \\
\text { acid }\end{array}$ & $646-07-1$ & MKBK0046V \\
\hline $\begin{array}{c}\text { 2-methyl-propanoic } \\
\text { acid }\end{array}$ & isobutyric acid & $79-31-2$ & 048K0022 \\
\hline \multicolumn{4}{|c|}{ ESTERS } \\
\hline ethyl butyrate & $\begin{array}{c}\text { butanoic acid, ethyl } \\
\text { ester }\end{array}$ & $105-54-4$ & 10822DAV \\
\hline propyl butyrate & $\begin{array}{c}\text { butanoic acid, propyl } \\
\text { ester }\end{array}$ & $105-66-8$ & 0912LD \\
\hline methyl palmitate & & $112-39-0$ & $125 \mathrm{~K} 614$ \\
\hline methyl palmitate & & $112-39-0$ & $100 \mathrm{M} 1423 \mathrm{~V}$ \\
\hline ethyl acetate & $\begin{array}{l}\text { acetic acid, ethyl } \\
\text { ester }\end{array}$ & $141-78-6$ & 00449AE \\
\hline $\begin{array}{c}\text { nonanoic acid, methyl } \\
\text { ester }\end{array}$ & methyl nonanoate & $1731-84-6$ & WA12895 \\
\hline $\begin{array}{c}\text { benzenepropanoic acid, } \\
\text { ethyl ester }\end{array}$ & $\begin{array}{c}\text { ethyl 3- } \\
\text { phenylpropionate }\end{array}$ & $2021-28-5$ & S44655V \\
\hline
\end{tabular}




\begin{tabular}{|c|c|c|c|}
\hline NAME & COMMON NAME & CAS \# & LOT/BATCH\# \\
\hline \multicolumn{4}{|c|}{ HALOGEN-CONTAINING } \\
\hline tetrachloroethylene & & $127-18-4$ & PS00344BR \\
\hline chloroform & & $67-66-3$ & $01340 \mathrm{CC}$ \\
\hline \multicolumn{4}{|c|}{ HETEROCYCLICS } \\
\hline 2-pentyl furan & & $3777-69-3$ & MKBF9842V \\
\hline 2-ethyl furan & & $3208-16-0$ & 10719DC \\
\hline \multicolumn{4}{|c|}{ HYDROCARBONS } \\
\hline eicosane & & $112-95-8$ & 02204EH \\
\hline 2,4-dimethylhexane & & $589-43-5$ & MKBH4570V \\
\hline tetradecane & & $629-59-4$ & $13401 \mathrm{LZ}$ \\
\hline nonadecane & & $629-92-5$ & BCBC4741V \\
\hline 2,2-dimethylbutane & & $75-83-2$ & MKBD0934V \\
\hline \multicolumn{4}{|c|}{ KETONES } \\
\hline 2-heptanone & & $110-43-0$ & 05520EJ \\
\hline 2-undecanone & & $112-12-9$ & MKBC8917 \\
\hline acetone & & $67-64-1$ & MKBL4368V \\
\hline acetone & & $67-64-1$ & 23596PMV \\
\hline 2-decanone & & $693-54-9$ & WA15705 \\
\hline 2-butanone & & $78-93-3$ & 01952TD \\
\hline acetophenone & & $96-86-2$ & $07404 \mathrm{KC}$ \\
\hline \multicolumn{4}{|c|}{ NITROGEN-CONTAINING } \\
\hline benzonitrile & & $100-47-0$ & 10703EX \\
\hline pyridine & & $110-86-1$ & SHBB2478V \\
\hline acetonitrile & & $75-05-8$ & 00639CE \\
\hline \multicolumn{4}{|c|}{ SULFUR-CONTAINING } \\
\hline dimethyl trisulfide & & $3658-80-8$ & $12115 \mathrm{JA}$ \\
\hline dimethyl trisulfide & & $3658-80-8$ & $13137 \mathrm{DE}$ \\
\hline dimethyl trisulfide & & $3658-80-9$ & MKBJ8038V \\
\hline dimethyl disulfide & & $624-92-0$ & $42 \mathrm{~K} 3401$ \\
\hline dimethyl sulfide & & $75-18-3$ & 06844LE \\
\hline dimethyl sulfide & & $75-18-4$ & $42 \mathrm{~K} 3401$ \\
\hline benzothiazole & & $95-16-9$ & STBC2703V \\
\hline
\end{tabular}


Three different GC columns were evaluated: an Agilent J\& W HP-5MS, $30 \mathrm{~m}$ x $0.25 \mathrm{~mm}$ (i.d.) with a film thickness of $0.25 \mu \mathrm{m}$, an Agilent J\&W Scientific DB-225MS, $30 \mathrm{~m} \times 0.25 \mathrm{~mm}$ (i.d.) with a $0.25 \mu \mathrm{m}$ film thickness, and a SGE SolGel-Wax, $30 \mathrm{~m} \mathrm{x}$ $0.25 \mathrm{~mm}$ (i.d.) with a film thickness of $0.25 \mu \mathrm{m}$. The Agilent HP-5MS and J\&W Scientific DB-225MS columns were purchased from Agilent Technologies, Inc. (Santa Clara, CA) and the SGE SolGel-Wax column was purchased from Fisher Scientific (Pittsburgh, PA).

4.1.3. Comparison of SPME and ACS for the Extraction of the Liberated VOCs from Decomposing Remains

Two extraction methods were evaluated solid-phase microextraction (SPME) and activated charcoal strip (ACS). The SPME fibers were purchased from Supelco (Bellefonte, PA) and consisted of the: $85 \mu \mathrm{m}$ Polyacrylate (PA), $7 \mu \mathrm{m}$ Polydimethylsiloxane (PDMS), $30 \mu \mathrm{m}$ Polydimethylsiloxane (PDMS), $100 \mu \mathrm{m}$ Polydimethylsiloxane (PDMS), $75 \mu \mathrm{m}$ Carboxen/Polydimethylsiloxane (CAR/PDMS), 50/30 $\mu \mathrm{m}$ Divinylbenzene/Carboxen/Polydimethylsiloxane (DVB/CAR/PDMS), $65 \mu \mathrm{m}$ Divinylbenzene/Polydimethylsiloxane (DVB/PDMS), and $60 \mu \mathrm{m}$ Polyethylene Glycol (PEG) fiber. For ACS analysis, ten 8 x $20 \mathrm{~mm}$ strips, donated by Albrayco Technologies (Cromwell, CT) along with unwaxed dental floss (Publix Super Markets, Miami, FL) and recycled \#1 paper clips (Acco Brands Corporation, Lake Zurich, IL) were used. Compound mixtures were created in a 4-mL, clear glass, screw top vial with a PTFE/Silicone septum (Supelco, Bellefonte, PA). Extractions were performed using 40- 
mL clear glass, screw top vials with PTFE/Silicone septa (Supelco, Bellefonte, PA). The activated charcoal strips were eluted with carbon disulfide (Lot\# 07782HH, Sigma Aldrich, St. Louis, MO) and mixed using a Fisher Scientific Digital Vortex Mixer (Pittsburgh, PA).

\subsubsection{Research Protocols}

Prior to conducting any experiments on human cadaver analogues, approval from Florida International University's Institutional Animal Care and Use Committee (IACUC) was obtained. The protocol approval numbers were: 11-011, 12-014, and IACUC-13-037.

\subsubsection{Human Cadaver Analogues}

Transgenic mice that were housed in the same environment and fed the same diet were used as human cadaver analogues for this research. All mice were scheduled to be euthanized as part of another experiment and were donated by The Animal Care Facility located at Florida International University (Miami, FL). Since Micozzi [55] found that cervical dislocation caused decomposition to proceed more readily around the area of trauma, all mice were euthanized via carbon dioxide to avoid introducing variables that could affect the rate of decay. 


\subsubsection{Customized Housing and Sampling (H \& S) Chamber}

Housing and sampling chambers were designed and constructed from stainless steel by Exer Caraballo (Stainless Concepts, Miami, FL). Each H \& S chamber was $10.16 \mathrm{~cm}$ wide $\mathrm{x} 17.78 \mathrm{~cm}$ long $\mathrm{x} 10.16 \mathrm{~cm}$ deep and contained a latching mechanism on each side to lock the lids in place (Figure 6). Two types of stainless steel lids were

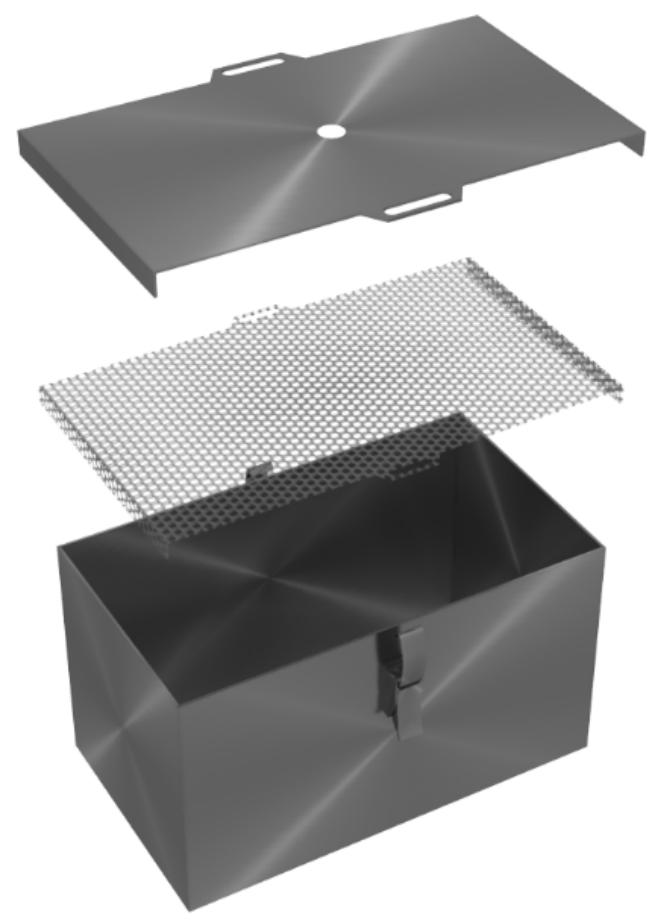

Figure 6: Housing and sampling chamber constructed out of stainless steel with both types of lids, perforated and solid.

created: perforated and solid. The solid lids were created with a centralized hole, measuring $1.27 \mathrm{~cm}$ in diameter, for the placement of a $1.4 \mathrm{~cm}$ Suba-Seal ${ }^{\circledR}$ silicone rubber septum (Sigma Aldrich, St. Louis, MO). The solid lids were further sealed with colored label tape (Fisher Scientific, Pittsburg, PA). Prior to use, all sampling chambers and lids were cleaned using Decon* Contrex* AL Alkaline Liquid Detergent (Fisher Scientific, 
Pittsburg, PA), rinsed with acetone (Sigma Aldrich, St. Louis, MO) and baked in an Isotemp Oven (Fisher Scientific, Pittsburgh, PA).

\subsubsection{Field Placement}

The human cadaver analogues were exposed to outdoor environmental conditions on the secure roof of the Academic Health Center 1 (AHC1) building located at Florida International University (Miami, FL). The height of the building was measured using a Leica Geosystems Disto $^{\mathrm{TM}}$ A8 (Leica Geosystems Inc., Norcross, GA). The optimum location for field placement was determined through temperature measurements using a DLAF8000 4-in-1 Environmental Airflow Meter (General Tools, New York, NY).

The remains were placed under a shelter that was created using two $1.5 \mathrm{~m}$ folding tables (Walmart, Pembroke Pines, FL), polypropylene twine (Home Depot, Davie, FL), and two $1.8 \mathrm{~m}$ x $2.4 \mathrm{~m}$ HDX general purpose tarps (Home Depot, Pembroke Pines, FL). Micro-t loggers (Nexsens Technology, Fairborn, OH) were used to record the temperature and relative humidity throughout the course of each trial.

\subsubsection{Aquatic Environment}

High Performance Liquid Chromatography (HPLC) Grade Water (Lot \#123950, CAS\# 7732-18-5) and Synthetic Sea Water ASTM D 1141 - Substitute Ocean Water (Lot\# 2305599) were used and purchased from Fisher Scientific (Pittsburg, PA). 
The $\mathrm{pH}$, temperature, conductivity, total dissolved solids, and salinity of the water were measured using an Oakton PCSTestr 35 Waterproof Multiparameter Tester (Oakton, Vernon Hills, IL). The dissolved oxygen content was measured using a Milwaukee MW600 Portable Meter (Milwaukee Instruments, Inc., Rocky Mount, NC) or Extech DO600 Waterproof ExStik II Dissolved Oxygen Meter (Test Equipment Depot, Melrose, MA).

For direct immersion SPME (DI-SPME) analysis, water was collected from each H \& S chamber using a calibrated Fisherbrand ${ }^{\mathrm{TM}}$ Finnpipette Adjustable-Volume Pipetter (Fisher Scientific, Pittsburgh, PA) and was delivered into a 4-mL, clear glass, screw top vial with a PTFE/Silicone septum (Supelco, Bellefonte, PA) that contained a PTFE 7 x 2 mm micro magnetic stir bar (Chemglass Life Sciences, Vineland, NJ). Agitation was performed using a Corning laboratory stirrer/hot plate (Fisher Scientific, Pittsburgh, PA). All stir bars were cleaned with Decon* Contrex* AL Alkaline Liquid Detergent (Fisher Scientific, Pittsburg, PA), rinsed with acetone (Sigma Aldrich, St. Louis, MO) and baked in an Isotemp Oven (Fisher Scientific, Pittsburgh, PA).

\subsubsection{Soil Environment}

Previously characterized sand and Canadian Sphagnum peat moss were used and donated by Dr. Yong Cai's Research Laboratory at Florida International University.

The temperature of the soil was measured using a Fisher Scientific ${ }^{\mathrm{TM}} \mathrm{Traceable}^{\mathrm{TM}}$ International Standards Extreme-Accuracy Digital Thermometer (Fisher Scientific, Pittsburg, PA). 


\subsubsection{Scent Collection from Human Remains}

\subsubsection{Subjects and Location of Sampling}

Human remains samples were collected from subjects located at the Forensic Anthropology Center at Texas State (FACTS) University in San Marcos, TX. Through the Body Donation program, the subjects used in this study were donated either by the subject prior to death or by their family members. Legal documents permitting the release of the remains to the facility were completed for each subject.

\subsubsection{Scent Collection}

Scent samples were collected using Dukal brand, 2" x 2", 8-ply, sterile gauze pads (Dukal Corporation, Syosset, NY) that were pre-treated with HPLC-grade methanol (Fisher Scientific, Pittsburgh, PA), and baked in an Isotemp Oven (Fisher Scientific, Pittsburgh, PA). They were each stored in a 40-mL clear glass, screw top vial with PTFE/Silicone septum (Supelco, Bellefonte, PA), sealed with Curwood Parafilm M ${ }^{\mathrm{TM}}$ (Fisher Scientific, Pittsburgh, PA) and wrapped in Publix Aluminum Foil (Publix, Miami, FL). Thereafter, each vial was packaged in a Ziploc Snack Bag (Publix, Miami, FL), a Publix Freezer Resealable Bag or a Ziploc Freezer Quart Bag (Publix, Miami, FL), and a Barrier Foil Ziplock Bag (Ted Pella, Inc., Redding, CA). Packaged materials were stored in quart size paint cans (Home Depot, Miami, FL) that were cleaned using Decon* 
Contrex* AL Alkaline Liquid Detergent (Fisher Scientific, Pittsburg, PA), rinsed with acetone (Sigma Aldrich, St. Louis, MO) and baked in an Isotemp Oven (Fisher Scientific, Pittsburgh, PA). The temperature and relative humidity within the paint can were measured using Micro-t loggers (Nexsens Technology, Fairborn, OH).

The collection materials were removed and retrieved from the $40-\mathrm{mL}$ clear glass, screw top vial with PTFE/Silicone septum (Supelco, Bellefonte, PA) using Trim Slant Tip Tweezers (Publix, Miami, FL) that were cleaned with Sterile Alcohol Prep Pads (Fisher Healthcare, Houston, TX). The stainless steel bars were also cleaned using the Sterile Alcohol Prep Pads (Fisher Healthcare, Houston, TX) and placed into Publix Quart Size Freezer Bag or a Ziploc Quart Size Freezer Bag (Publix, Miami, FL). Upon completion, the vials were re-packaged using the same materials described in Section 4.1.10.2. Temperature was recorded using a Thermo-Anemometer 405-V1 (Testo, Sparta, $\mathrm{NJ})$.

\subsubsection{Statistical Analyses}

Paired t-test was performed using Microsoft ${ }^{\circledR}$ Excel ${ }^{\circledR} 2010$ and 2013 (Microsoft, Redmond, WA). Principal Components Analysis (PCA) was conducted using JMP® 7.0.1 (SAS Institute Inc., Cary, NC) statistical software. Hierarchical Cluster Analysis was performed using Minitab ${ }^{\circledR}$ 15.1.0.0 (Minitab Inc., State College, PA). 


\subsection{Methodology}

4.2.1. Optimization of a GC-MS Method for the Detection of VOCs Released from Decomposing Remains

To determine an optimum GC-MS method for the analysis of decomposition odor, a literature review on the compounds that were previously found to be released from decomposing remains was performed and compiled into a Microsoft ${ }^{\circledR}$ Excel ${ }^{\circledR}$ spreadsheet referred, from this point forward, as the Decomposition-Associated Compound Database (Appendix). Thirty-one compounds, consisting of relatively low and high boiling point compounds (to cover a broad range), from a majority of the chemical functional groups were selected. Thereafter, $60 \mathrm{ppm}$ mixtures were created and analyzed sequentially via GC-MS fitted with the following three GC columns: HP-5MS (non-polar), DB-225MS (mid-polar), and SolGel-Wax (polar). Different GC-MS parameters were evaluated, such as split vs. splitless, flow rate, and the GC oven temperature ramp. The sensitivity, selectivity, and variability for each column and tested parameter were compared and upon final assessment the optimum GC column and GCMS method were derived. 
4.2.2. Comparison of SPME and ACS for the Extraction of the Liberated VOCs from Decomposing Remains

A mixture containing $c .0 .01 \mathrm{~g}$ of each of the thirty-one decomposition-associated compounds was created in a 4-mL glass vial. Thereafter, $5 \mu \mathrm{L}$ of the mixture was spiked into seven $40-\mathrm{mL}$ glass vials and allowed to equilibrate for thirty seconds. Headspace SPME (Figure 7) was performed for thirty seconds with an $85 \mu \mathrm{m}$ PA, $75 \mu \mathrm{m}$ CAR/PDMS, $7 \mu \mathrm{m}$ PDMS, 50/30 $\mu \mathrm{m}$ DVB/CAR/PDMS, $30 \mu \mathrm{m}$ PDMS, $100 \mu \mathrm{m}$ PDMS, $65 \mu \mathrm{m}$ DVB/PDMS, and a $60 \mu \mathrm{m}$ PEG fiber. The process was repeated two additional times, with the same SPME fiber to reduce variability, resulting in three trials. Thereafter, the two SPME fiber coatings that resulted in the greatest number of extracted compounds were re-evaluated using a diluted mixture. For this study, $5 \mu \mathrm{L}$ of a $155 \mathrm{ppm}$ standard mixture was pipetted into six $40-\mathrm{mL}$ vials where they were allowed to equilibrate for one hour. A thirty minute headspace SPME extraction was performed, in triplicate, for each fiber coating. All HS-SPME extractions were analyzed using the optimized GC-MS method determined in Section 4.2.1.

Each ACS strip, with an original size of 8 × $20 \mathrm{~mm}$, was cut into a smaller piece with dimensions of $8 \times 5 \mathrm{~mm}$ and an approximate weight of $0.02 \mathrm{~g}$. Using the mixture containing the thirty-one decomposition-associated compounds, $5 \mu \mathrm{L}$ was spiked into a 40-mL vial. Thereafter, the smaller piece of ACS was suspended above the sample using a small paper clip and unwaxed dental floss (Figure 8). The passive headspace concentration extraction was performed in triplicate for thirty seconds, thirty minutes, one hour, and twenty-four hours. Each ACS was then eluted with $100 \mu \mathrm{L}$ of carbon 


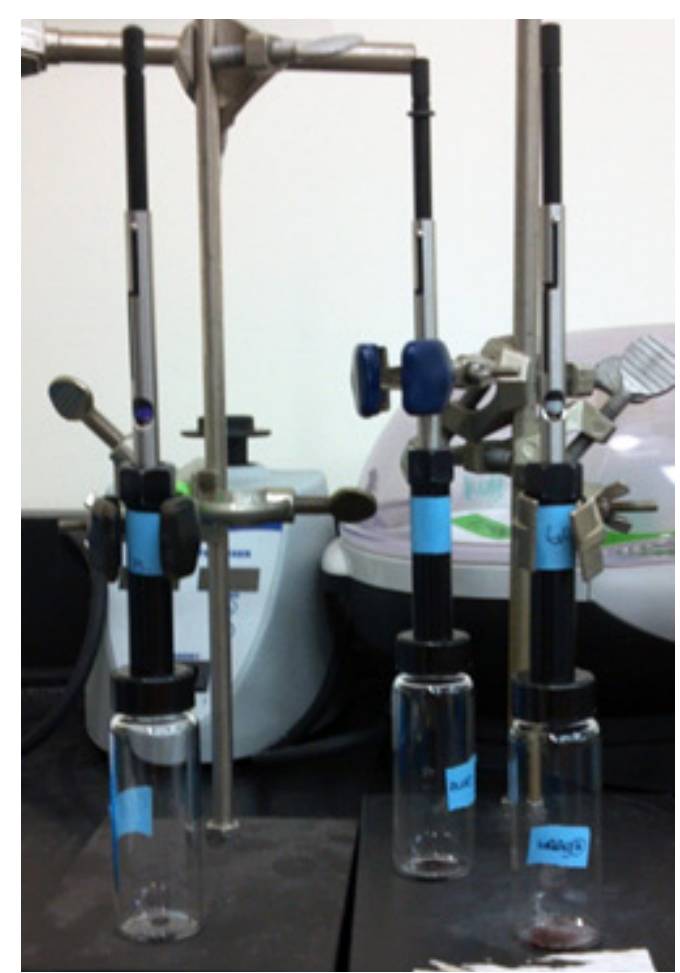

Figure 7: Headspace-SPME being performed on a mixture containing decomposition-associated compounds.

disulfide and mixed using a digital vortex mixer set at $1400 \mathrm{rpm}$ for two minutes. Using a manual syringe, $1 \mu \mathrm{L}$ of the diluted solution was extracted and subsequently analyzed using the optimized GC-MS method determined in Section 4.2.1.

The sensitivity, selectivity, and variability for both SPME and ACS were compared and the optimum extraction method was derived.

\subsubsection{Site Analysis for Field Placement}

To mimic real-life scenarios, all studies evaluating the scent of death were performed in the field where the remains were exposed to outdoor environmental conditions. Permission and access was granted to the secure roof of the Academic 


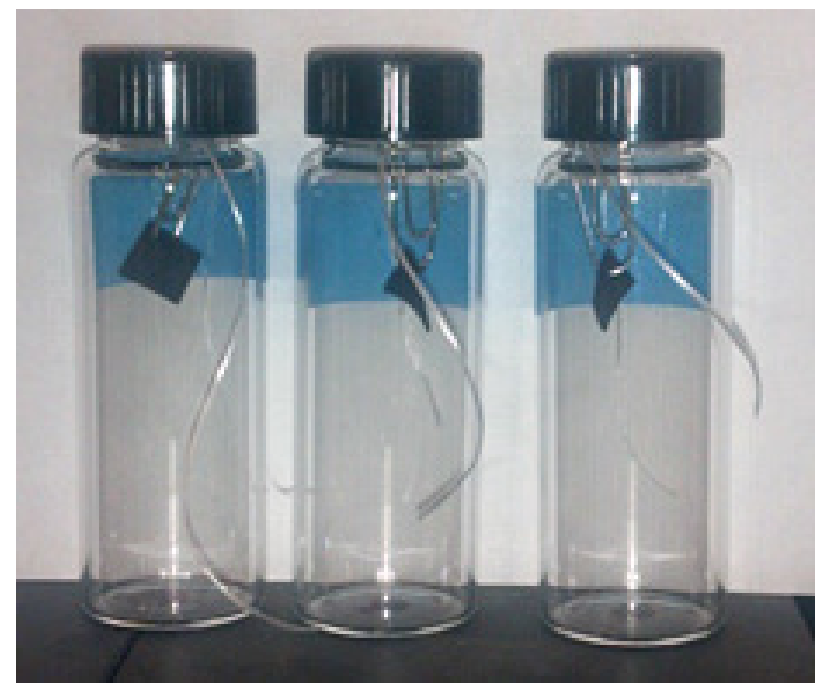

Figure 8: ACS Extraction being performed on a mixture containing decomposition-associated compounds.

Health Center 1 (AHC1) building located at Florida International University (Miami, FL) (Figure 9). The height of the building was measured using a hand held meter. To determine the optimum placement of the decomposing remains, different areas on the roof were evaluated. As temperature plays a pivotal role during the decomposition process, by either enhancing or hindering the progression, the optimum location was deemed as the area that experiences an increase and decrease in temperature, similar to the appearance of a Gaussian curve, during an eight hour period. 
Figure 9: Roof of AHC1 located at FIU. Temperature measurements were performed at each location labelled A-I.

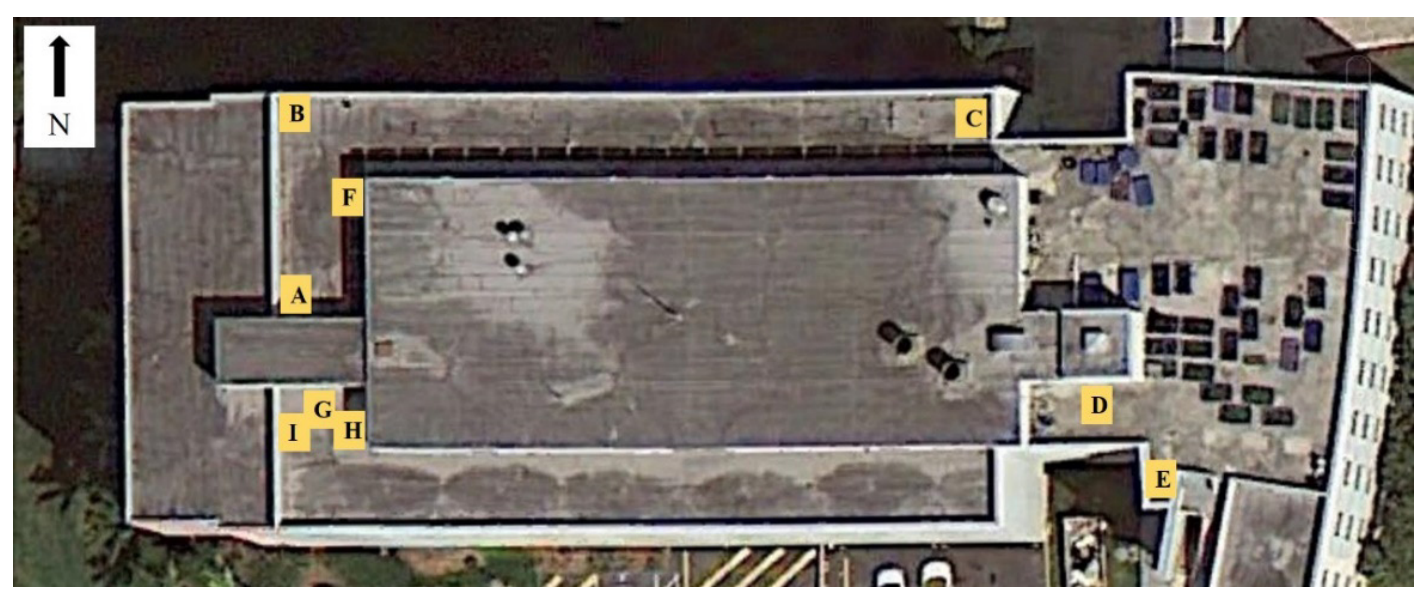

Using a 4-in-1 meter, temperature was measured over a period of nine hours on Wednesday, January 18, 2012 at nine different locations labelled A-I in Figure 9. Upon identifying the optimal site for field placement, shelter(s) were created using foldable table(s), tarp(s), and polyethylene twine. The housing and sampling chambers containing the human cadaver analogues were placed below the shelter to prevent desiccation, as well as to minimize potential rainfall from entering the $\mathrm{H} \& \mathrm{~S}$ chambers (Figure 10). 


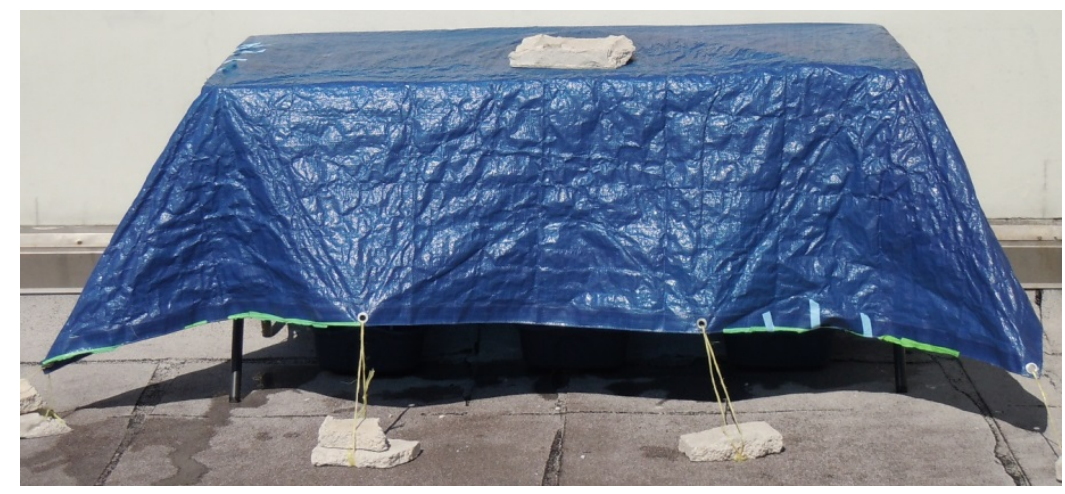

Figure 10: A shelter created on the roof of AHCI.

\subsubsection{Housing and Sampling Chambers}

Prior to use the $\mathrm{H} \& \mathrm{~S}$ chambers, along with the perforated and solid lids were cleaned using alkaline liquid detergent, rinsed with acetone and placed into an Isotemp oven set at $105^{\circ} \mathrm{C}$ for a minimum of 24 hours. Each chamber was placed c. $0.46 \mathrm{~m}$ a part. When the remains were not being sampled, the perforated lids were latched to the chambers so that they were continuously exposed to outdoor environmental conditions while minimizing insect activity. At time of sampling, the perforated lids were replaced with those that were solid that contained a new silicone rubber septa. The lids were latched to the chambers and then further sealed with label tape to minimize the escape of the liberated VOCs. To provide a sufficient amount of time for compounds to accumulate in the headspace, while minimizing the effects on the rate of decay, the solid lids remained on for 3 hours. Thereafter, headspace extractions were performed for 1 hour and subsequently analyzed using the optimized GC-MS method determined in Section 4.2.1. Micro-t loggers were placed on the left side of each H \& S chamber to 
record the temperature and relative humidity every hour throughout the course of each trial.

4.2.5. Comparison of the VOCs Released from Frozen then Thawed and Freshly Killed Decomposing Remains

The VOCs liberated during the decomposition process of frozen then thawed (FTW) and freshly killed (FKD) remains were evaluated to assess the impact that frozen environments have on the scent of death.

Four trials were performed, consisting of a blank (environmental control), one freshly killed (FKD) and one frozen then thawed (FTW) transgenic mouse. Those mice that were used for the frozen-thaw cycle were euthanized, photographed, weighed, measured and then placed into a freezer at $c .-20^{\circ} \mathrm{C}$ for 22 hours. Thereafter, the remains were removed from the freezer to thaw at room temperature $\left(c .22^{\circ} \mathrm{C}\right)$ for 3 hours and then placed into their corresponding $\mathrm{H} \& \mathrm{~S}$ chamber. Those mice that were designated as freshly killed were euthanized, photographed, weighed, measured and subsequently placed into their corresponding $\mathrm{H} \& \mathrm{~S}$ chamber. Both types of mice, along with a control, were transported to the roof of $\mathrm{AHC1}$ where they were placed under the shelter, but still exposed to outdoor environmental conditions, for a period of six days. All mice were positioned on their dorsal surface to ensure that they were exposed, identically, to the same environmental conditions over time.

The H \& S chambers were covered with the perforated lids for 21 hours, at time of sampling they were replaced with those that were solid at the following intervals: 24 
hours (Day 1), 48 hours (Day 2), 72 hours (Day 3), 96 hours (Day 4), and 120 hours (Day 5) after time of death. For the first sampling period (Day 0), an exception was made in which the solid lids were placed immediately upon field placement. Sampling and analysis was performed as described in Section 4.2.4. A blank (control) H \& S chamber was also sampled and the VOCs that were detected were not considered compounds of interest and disqualified during final analysis.

Photographs were taken throughout the course of the study to monitor any physical changes.

4.2.6. Assessment of the VOCs Released from Freshly Killed Remains in their Natural State

A major portion of my dissertation research was spent assessing the influence of different environments (i.e., frozen, aquatic, and soil) on the VOCs released during the decomposition process. However, a thorough assessment could not be made until the scent of death was studied with remains in their natural state (no environmental influences). Thus, the VOCs liberated from freshly killed remains, in their natural state and with a known time of death, were assessed. Additionally, through this investigation, compounds specific to each stage of decomposition were evaluated.

Five transgenic mice were euthanized, photographed, weighed, measured, and placed into their corresponding $\mathrm{H} \& \mathrm{~S}$ chamber. The mice, along with a blank (environmental control), were transported to the roof of $\mathrm{AHC} 1$ where they were exposed to outdoor environmental conditions for a period of almost two weeks. The mice were 
positioned on their dorsal surface to ensure that the cadavers were all exposed to the same environmental conditions in an identical fashion.

The $\mathrm{H} \& \mathrm{~S}$ chambers were covered with the perforated lids until the day of sampling when they were replaced with those that were solid. The mice were sampled within 1 hour of being euthanized (Day 0), thereafter, they were sampled 2, 4, 6, 8, and 10 days from time of death. Sampling and analysis was performed as described in Section 4.2.4. A blank H \& S chamber (environmental control) was also sampled and the VOCs that were detected were not considered compounds of interest and disqualified during final analysis.

Photographs were taken throughout the course of the study to monitor any observed changes.

4.2.7. Evaluation of the VOCs Released from Decomposing Remains Submerged in Different Aquatic Environments

To date, little to no research has been performed on the scent of death generated from submerged remains. As proof of concept, two different types of aquatic environments, HPLC-grade water and synthetic sea water, were evaluated to assess its impact on the evolution of VOCs from submerged remains. HPLC-grade water is ultrapure water with minimal contaminants, such as bacteria and organics (which can affect the decomposition process), after being filtered [137]. The synthetic sea water, produced following ASTM D1141 guidelines, is a substitute for ocean water that can be used in a laboratory setting where reproducible results are desired [138]. 
Two trials, each consisting of three freshly killed transgenic mice, were performed for both aquatic environments. The mice were euthanized, photographed, weighed, measured, and placed into their corresponding $\mathrm{H} \& \mathrm{~S}$ chamber. The mice, along with a blank (environmental control), were transported to the roof of AHC1 and each chamber was filled with $900 \mathrm{~mL}$ of water, leaving $c .2 .5 \mathrm{~cm}$ of headspace. The remains had the ability to move three-dimensionally in water; thus, some mice were positioned on their backs, while others were on their side. Nonetheless, they were all exposed to the same outdoor environmental conditions for a period of almost two weeks. Photographs were taken throughout the course of the study to monitor any observed changes.

\subsubsection{Water Parameters}

To monitor the affects that the decomposing remains had on the aquatic environments, the $\mathrm{pH}$, conductivity $(\mu \mathrm{S})$, total dissolved solids (TDS; ppm), temperature $\left({ }^{\circ} \mathrm{C}\right)$, and dissolved oxygen content $(\mathrm{mg} / \mathrm{L})$ were measured, using portable meters, prior to sampling.

\subsubsection{Headspace Analysis}

The $\mathrm{H} \& \mathrm{~S}$ chambers were covered with the perforated lids until the day of sampling when they were replaced with those that were solid. The mice were sampled within 1 hour of being euthanized (Day 0), thereafter, they were sampled 2, 4, 6, 8, and 
10 days from time of death. Sampling and analysis was performed as described in Section 4.2.4. A blank $\mathrm{H} \& \mathrm{~S}$ chamber (environmental control) was also sampled and the VOCs that were detected were not considered compounds of interest and disqualified during final analysis.

\subsubsection{Water Analysis}

As submerged remains decompose, compounds that are released from the body may have a stronger affinity for the water and thus, not readily released into the headspace. Upon completion of headspace extraction, $4 \mathrm{~mL}$ of water was pipetted from each $\mathrm{H} \& \mathrm{~S}$ chamber, including the blank, and delivered into its corresponding 4-mL glass vial that contained a micro magnetic stir bar. One hour extractions were conducted, using the optimized technique determined in Section 4.2.2., as the water was agitated with a laboratory stirrer/hot plate on speed three. Thereafter, GC-MS analysis was performed using the optimized method determined in Section 4.2.1.

4.2.8. Assessment of the VOCs Released from Decomposing Remains Buried in Different Soil Environments

Several studies have been performed assessing the VOCs released from remains buried in different soil types, but many of the studies were not well controlled. In addition, the characteristics of the soil that can affect the rate of decay, such as $\mathrm{pH}$, total organic carbon, and cation exchange capacity, were not known. Thus, to assess the 
impact that certain soil characteristics has on the scent of death a proof of concept investigation was performed using two previously characterized soils: sand and Canadian Sphagnum peat moss (Table 8) [139]. Additionally, when investigators and/or rescue teams are in search of buried human remains, soil probes are often used to vent the area causing an increase exchange of air and releasing decomposition odor that can subsequently be detected by HRD canines [94]. Therefore, the present study had two goals, one, was to assess the effects that different soil types had on the VOCs released, and the second, was to disturb the soil, mimicking real-life scenarios, to evaluate the Table 8: Properties of the soils used to assess the VOCs from buried remains.

\begin{tabular}{|c|c|c|}
\hline & Sand & $\begin{array}{c}\text { Canadian Sphagnum Peat } \\
\text { Moss }\end{array}$ \\
\hline $\mathbf{p H}$ & 4.5 & 3.4 \\
\hline Total Organic Carbon (\%) & 0.01 & 53.20 \\
\hline Cation Exchange Capacity (mg/L) & 0.20 & 120 \\
\hline
\end{tabular}

compounds that were released.

A total of four freshly killed transgenic mice were euthanized, photographed, weighed, and measured for each soil environment. The H \& S Chamber was filled with $2.5 \mathrm{~cm}$ of soil prior to placing the mice on their dorsal surface. Thereafter, the containers were filled, leaving $c .1$ inch of headspace, resulting in a total of $c .1500 \mathrm{~g}$ of sand or $c .100$ $\mathrm{g}$ of Canadian Sphagnum peat moss. The mice, along with two blanks (disturbed and undisturbed soil environments), were transported to the roof of AHC1 where they were exposed to outdoor environmental conditions for a period of almost three weeks. 
The H\& S chambers were covered with the perforated lids until the day of sampling when they were replaced with those that were solid. The mice were sampled within 1 hour of being euthanized (Day 0), thereafter, they were sampled 2, 4, 6, 8, 10, $12,14,16$, and 18 days from time of death. Those chambers that were designated to be disturbed were probed with a glass rod, with a diameter of $0.5 \mathrm{~cm}$, at a depth of $c .4 .5 \mathrm{~cm}$ above the remains. The glass rod was cleaned in between samples. Sampling and analysis was performed as described in Section 4.2.4. Both blank H \& S chambers were also sampled and the VOCs that were detected were not considered compounds of interest and disqualified during final analysis.

Temperature was randomly taken three times from each $\mathrm{H} \& \mathrm{~S}$ chamber and recorded. Photographs were taken throughout the course of the study to monitor any observed changes.

\subsubsection{Evaluation of the VOCs Released from Human Remains}

Several research groups have explored the scent of death from decomposing human remains; however, a majority of the studies that were conducted did not mention the stage of decay at the time the VOCs were collected. Moreover, the physical changes observed during the decomposition process have been extensively studied, yet little is known about the chemical changes. Thus, the purpose of this task was to evaluate the scent of death at various stages of decomposition to determine if each phase was comprised of specific compounds, as well as if common compounds were present throughout the course of decomposition. 


\subsubsection{Preparation of Collection Materials}

Curran et al. [115] and Prada et al. [140] found that although scent collection materials (i.e., cotton gauze) were "biologically clean" they were not "analytically clean". Thus, prior to sampling, the collection materials were spiked with $2 \mathrm{~mL}$ of HPLC-grade methanol and set to bake for 2 hours at $105^{\circ} \mathrm{C}$ in an Isotemp Oven. Thereafter, to ensure cleanliness, they were analyzed using the optimized extraction technique determined in Section 4.2.2., following a 24 hour equilibration period [115]. During extraction, the samples were heated at $c .55^{\circ} \mathrm{C}$ and subsequently analyzed using the GC-MS method that was determined in Section 4.2.1. [141]. Each vial was sealed with parafilm, wrapped in aluminum foil, placed into a resealable snack bag, then a resealable freezer quart bag, and lastly into barrier foil bag. A total of seven pre-treated, packaged, and labelled materials were stored in a quart size paint can to reduce background contamination during shipment, as scent collection was being performed at the FACTS Facility in Texas. Overall, ten paint cans were shipped, 2-Day or Overnight, via FedEx. The temperature and relative humidity were monitored during transport.

\subsubsection{Scent Collection}

Twenty-eight human subjects, at various stages of decomposition, were sampled at the FACTS facility. Sampling protocols for both human remains and the environment (blank) were created, as well as videos, to ensure that the scent collection was being 
performed correctly. A Sampling Documentation Sheet was also created and filled out for each subject, as well as the environmental blank.

Using clean forceps, the collection material was removed from the subject's designated vial, placed upon their stomach region, along with a piece of aluminum foil to avoid collecting VOCs from the environment, and held in place by a cleaned stainless steel bar that was stored in a resealable bag for 15 minutes. Thereafter, with clean forceps, the collection material was removed from the remains, placed back into its original vial, sealed with parafilm, wrapped with aluminum foil, placed into a resealable snack bag, then a resealable freezer quart bag, and lastly into its original barrier foil bag. For the environmental blank, a location that was c. 20 feet away from any decomposing remains was used to sample the environment. Using clean forceps, the collection material was removed from its designated vial, placed upon the surface of a piece of aluminum foil that was placed on the ground, and held in place by a cleaned stainless steel bar that was stored in a resealable bag for 15 minutes. The material was retrieved using cleaned forceps, reinserted into its corresponding vial, and re-packaged in the same fashion as the human remains samples.

Upon completion, all samples were shipped 2-Day or Overnight via FedEx. The temperature and relative humidity were monitored during transport. Once received, headspace extraction was performed, using the optimized method determined in Section 4.2.2., which included a 21 hour extraction while heated at $c .55^{\circ} \mathrm{C}$, and subsequently analyzed using the GC-MS method that was determined in Section 4.2.1. [101,141]. 


\subsubsection{Methods of Statistical Analysis}

\subsubsection{Paired t-test}

During method optimization, paired t-test was performed to determine if there was a significant difference between the methods being evaluated.

\subsubsection{Preprocessing of Data}

Prior to conducting multivariate data analysis, preprocessing of the data was performed to eliminate or minimize extraneous sources of random or systematic variation. Normalizing was the preprocessing tool that was selected as it places all the samples on the same scale. This method can be performed by dividing each variable by a constant, such as 1-norm, which, with regard to this research, is defined as the sum of the absolute value of all the variables in a sample [142].

\subsubsection{Multivariate Data Analysis}

The scent of death from decomposing remains was comprised of a multitude of VOCs at varying abundances; hence, the data collected was considered to be multivariate and were analyzed using Hierarchical Cluster Analysis (HCA) and Principal Components Analysis (PCA). 


\subsection{Hierarchical Cluster Analysis}

Hierarchical cluster analysis is a technique that evaluates the distances between all samples revealing their similarity or dissimilarity in the form of a dendogram. Every sample, initially, is treated as a cluster, thereafter, those clusters that are closest together are joined, and this process is replicated until there is only one cluster that remains. The formation of clusters is dependent upon the distance, measured, most often, by the Euclidean distance (Equation 4), of two points in $n$-dimensional space.

$$
d=\sqrt{\left(x_{1}-y_{1}\right)^{2}+\left(x_{2}-y_{2}\right)^{2}+\cdots+\left(x_{n}-y_{n}\right)^{2}} \quad \text { Equation } 4
$$

After the clusters are formed, they can be linked via two methods: single and centroid linkage. The single-linkage approach unites clusters on the basis of the distance between the "nearest neighbors", whereas with centroid linkage, clusters are joined at their

centroid which is the calculated average of the points within a cluster. A major advantage of $\mathrm{HCA}$ is that the dendogram reveals all of the variation within the data set that is being analyzed; however, it does not indicate which variable, or in this case, compound, is contributing to that variation. Through the use of PCA, this downfall can be overcome $[142,143]$.

\subsection{Principal Components Analysis}

Principal Components Analysis (PCA) is a statistical method that can effectively reveal relatedness, deviations, or groupings within a data set. The idea behind PCA is 
that variations or correlations can be discerned using a small number of axes, commonly referred to as principal components, a linear combination of the original variables describing each sample. The first principal component (PC) accounts for the direction that has the maximum variation. The successive PCs depict the remaining variations in decreasing amounts. Mathematically, a PC can be determined through eigenvectors and eigenvalues, which are always in pairs. Using a technique known as eigenanalysis (a method that simplifies coordinates), eigenvectors, which provide directionality, are obtained from the covariance matrix. Note that the term covariance refers to the measurement of the joint variations of two variables. Along with every eigenvector there is a corresponding eigenvalue which is a number that describes the amount of variance within the data set; together, each principal component is elucidated. Upon performing PCA analysis, a condensed summary of the data set is generated and can be analyzed, graphically, through a score and loading plot. These plots are complementary and superimposable to one another meaning that the direction in one plot is paralleled on the other. By interpreting both plots, valuable information regarding the data set can be obtained, as the score plot reveals correlations among the samples and the loading plot shows the variables that are responsible [142-144]. 


\section{RESULTS/DISCUSSION}

5.1. Method Optimization for the Detection of VOCs Released from Decomposing Remains

The purpose of this task was to determine the optimum GC column, GC-MS method, and extraction technique for the analysis of decomposition-associated compounds.

\subsubsection{Development of Decomposition-Associated Compounds Database}

Over four hundred compounds were identified from literature review [24,85$93,120-123,145-150]$ and compiled into a spreadsheet referred to as the DecompositionAssociated Compound Database (Appendix). All the compounds were classified by their chemical functional group and listed from lowest to highest boiling points. In addition, the type of remains (e.g., human remains, pig remains, intact or not intact, etc.) from which the compound was recovered and the corresponding literature reference were also documented. Shown in Table 9 are the thirty-one VOCs that were selected for method optimization, which includes compounds with low and high boiling points (to cover a broad range) and a majority of the chemical functional groups. 
Table 9: Thirty-one compounds selected to be used for method optimization.

\begin{tabular}{|c|c|c|c|}
\hline COMPOUND & COMMON NAME & CAS\# & BOILING POINT $\left({ }^{\circ} \mathrm{C}\right)$ \\
\hline \multicolumn{4}{|c|}{ ALCOHOLS } \\
\hline ethanol & ethyl alcohol & $64-17-5$ & 78.29 \\
\hline benzene-1,4-diol & hydroquinone & $123-31-9$ & 202.00 \\
\hline \multicolumn{4}{|c|}{ ALDEHYDES } \\
\hline acetaldehyde & ethanal & $75-07-0$ & 20.10 \\
\hline hexanal & caproaldehyde & $66-25-1$ & 131.00 \\
\hline decanal & capraldehyde & $112-31-2$ & 208.50 \\
\hline \multicolumn{4}{|c|}{ ALIPHATICS } \\
\hline methylcyclopentane & & $96-37-7$ & 70.50 \\
\hline d-limonene & $(\mathrm{R})-(+)$-limonene & $5989-27-5$ & 178.00 \\
\hline cyclohexylcyclohexane & & $92-51-3$ & 238.00 \\
\hline \multicolumn{4}{|c|}{ AMINES } \\
\hline pyrrole & & $109-97-7$ & 129.79 \\
\hline 3-methyl-1H-indole & skatole & $83-34-1$ & 266.00 \\
\hline \multicolumn{4}{|c|}{ AROMATICS } \\
\hline benzene & & $71-43-2$ & 80.09 \\
\hline toluene & & $108-88-3$ & 110.63 \\
\hline 1-methylnaphthalene & $\begin{array}{c}\alpha \text {-methyl } \\
\text { naphthalene }\end{array}$ & $90-12-0$ & 244.70 \\
\hline \multicolumn{4}{|c|}{ CARBOXYLIC ACIDS } \\
\hline acetic acid & & 64-19-7 & 117.90 \\
\hline palmitic acid & hexadecanoic acid & $57-10-3$ & 351.50 \\
\hline
\end{tabular}




\begin{tabular}{|c|c|c|c|}
\hline COMPOUND & COMMON NAME & CAS\# & BOILING POINT $\left({ }^{\circ} \mathrm{C}\right)$ \\
\hline \multicolumn{4}{|c|}{ ESTERS } \\
\hline ethyl acetate & & $141-78-6$ & 77.11 \\
\hline methyl palmitate & & $112-39-0$ & 417.00 \\
\hline \multicolumn{4}{|c|}{ HALOGEN-CONTAINING } \\
\hline chloroform & & $67-66-3$ & 61.17 \\
\hline tetrachloroethylene & & $127-18-4$ & 121.30 \\
\hline \multicolumn{4}{|c|}{ HETEROCYCLICS } \\
\hline 2-ethyl furan & & $3208-16-0$ & 92.50 \\
\hline 2-pentyl furan & & $3777-69-3$ & 178.00 \\
\hline \multicolumn{4}{|c|}{ HYDROCARBONS } \\
\hline 2,2-dimethylbutane & & $75-83-2$ & 50.00 \\
\hline eicosane & & $112-95-8$ & 343.00 \\
\hline \multicolumn{4}{|c|}{ KETONES } \\
\hline acetone & & $67-64-1$ & 56.05 \\
\hline 2-butanone & & $78-93-3$ & 79.59 \\
\hline acetophenone & & $96-86-2$ & 202.00 \\
\hline 2-undecanone & & $112-12-9$ & 231.50 \\
\hline \multicolumn{4}{|c|}{ NITROGEN-CONTAINING } \\
\hline acetonitrile & & $75-05-8$ & 81.65 \\
\hline benzonitrile & & $100-47-0$ & 191.10 \\
\hline \multicolumn{4}{|c|}{ SULFUR-CONTAINING } \\
\hline dimethyl sulfide & & $75-18-3$ & 37.33 \\
\hline dimethyl trisulfide & & $3658-80-8$ & 183.10 \\
\hline
\end{tabular}




\subsubsection{Assessment of Various GC Column Chemistries for GC-MS Analysis}

To determine the optimum GC-MS method for the analysis of decompositionassociated compounds, GC columns of varying chemistries (non-polar, mid-polar, and polar) were assessed using $1 \mu \mathrm{L}$ of a $60 \mathrm{ppm}$ thirty-one compound standard mixture solution. Initial investigations were conducted using the HP-5MS (non-polar column) to assess the sensitivity, selectivity, and variability of two different GC-MS parameters: split vs. splitless injection and the flow rate of the carrier gas. Listed below are the summarized GC-MS methods that were evaluated for split and splitless injection.

Method A: Splitless injection; flow rate was $0.5 \mathrm{~mL} / \mathrm{min}$.; initial oven temperature was $40^{\circ} \mathrm{C}$ which was held for five minutes and then ramped to $300^{\circ} \mathrm{C}$ at $10^{\circ} \mathrm{C} /$ minute where it was held for two minutes resulting in a total run time of thirty-three minutes.

Method B: Split 20 to 1 injection; flow rate was $0.5 \mathrm{~mL} / \mathrm{min}$; initial oven temperature was $40^{\circ} \mathrm{C}$ which was held for five minutes and then ramped to $300^{\circ} \mathrm{C}$ at $10^{\circ} \mathrm{C} /$ minute where it was held for two minutes resulting in a total run time of thirty-three minutes.

Method C: Split 50 to 1 injection; flow rate was $0.5 \mathrm{~mL} / \mathrm{min}$; initial oven temperature was $40^{\circ} \mathrm{C}$ which was held for five minutes and then ramped to $300^{\circ} \mathrm{C}$ at $10^{\circ} \mathrm{C} /$ minute where it was held for two minutes resulting in a total run time of thirty-three minutes.

Method D: Splitless injection for 5 minutes then split 50 to 1; flow rate was $0.5 \mathrm{~mL} / \mathrm{min}$.; 
initial oven temperature was $40^{\circ} \mathrm{C}$ which was held for five minutes and then ramped to $300^{\circ} \mathrm{C}$ at $10^{\circ} \mathrm{C} /$ minute where it was held for two minutes resulting in a total run time of thirty-three minutes.

The results of Methods A-D were compared (Figure 11). The splitless injection resulted in a greater abundance of compounds, but generated a relative standard deviation (RSD) of $1.03 \%$ and only twelve out of the thirty-one compounds were detected. Splitless for 5 minutes, then split 50 to 1 produced similar results to that seen with the splitless injection method, but a greater RSD was obtained; however, three additional compounds were detected. Overall, the split injection methods detected a greater number of compounds with less variation, but the abundances were relatively low in comparison to Methods A and D.

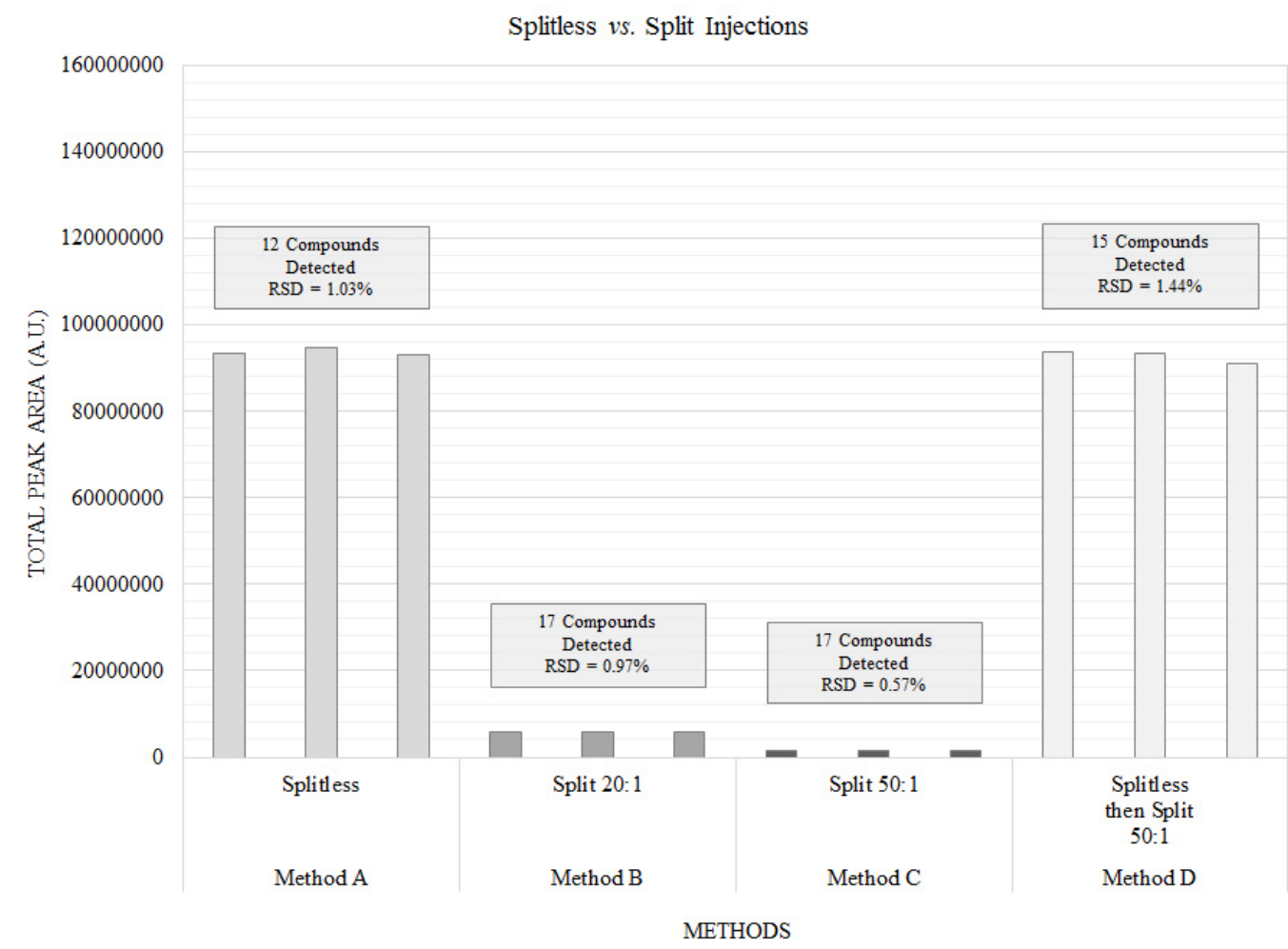

Figure 11: Method comparisons for splitless vs. split injections. 
Upon final data analysis, Method D (Splitless then Split 50:1 after 5 minutes) was selected to assess three different flow rates: $0.5,1.0$, and $1.3 \mathrm{~mL} / \mathrm{min}$., as it generated more compounds than Method A with greater abundance than the split injection methods. Listed below are the summarized GC-MS methods that were evaluated for each flow rate.

Method D: Splitless injection for 5 minutes then split 50 to 1; flow rate was $0.5 \mathrm{~mL} / \mathrm{min}$.; initial oven temperature was $40^{\circ} \mathrm{C}$ which was held for five minutes and then ramped to $300^{\circ} \mathrm{C}$ at $10^{\circ} \mathrm{C} /$ minute where it was held for two minutes resulting in a total run time of thirty-three minutes.

Method E: Splitless injection for 5 minutes then split 50 to 1; flow rate was $1.0 \mathrm{~mL} / \mathrm{min}$; initial oven temperature was $40^{\circ} \mathrm{C}$ which was held for five minutes and then ramped to $300^{\circ} \mathrm{C}$ at $10^{\circ} \mathrm{C} /$ minute where it was held for two minutes resulting in a total run time of thirty-three minutes.

Method F: Splitless injection for 5 minutes then split 50 to 1 ; flow rate was $1.3 \mathrm{~mL} / \mathrm{min}$; initial oven temperature was $40^{\circ} \mathrm{C}$ which was held for five minutes and then ramped to $300^{\circ} \mathrm{C}$ at $10^{\circ} \mathrm{C} /$ minute where it was held for two minutes resulting in a total run time of thirty-three minutes.

The results of Method D-F were compared and are presented in Figure 12. The flow rate that resulted in a greater abundance and number of compounds was Method D, but with a $1.44 \%$ variation. Method E and F detected the same number of compounds, 


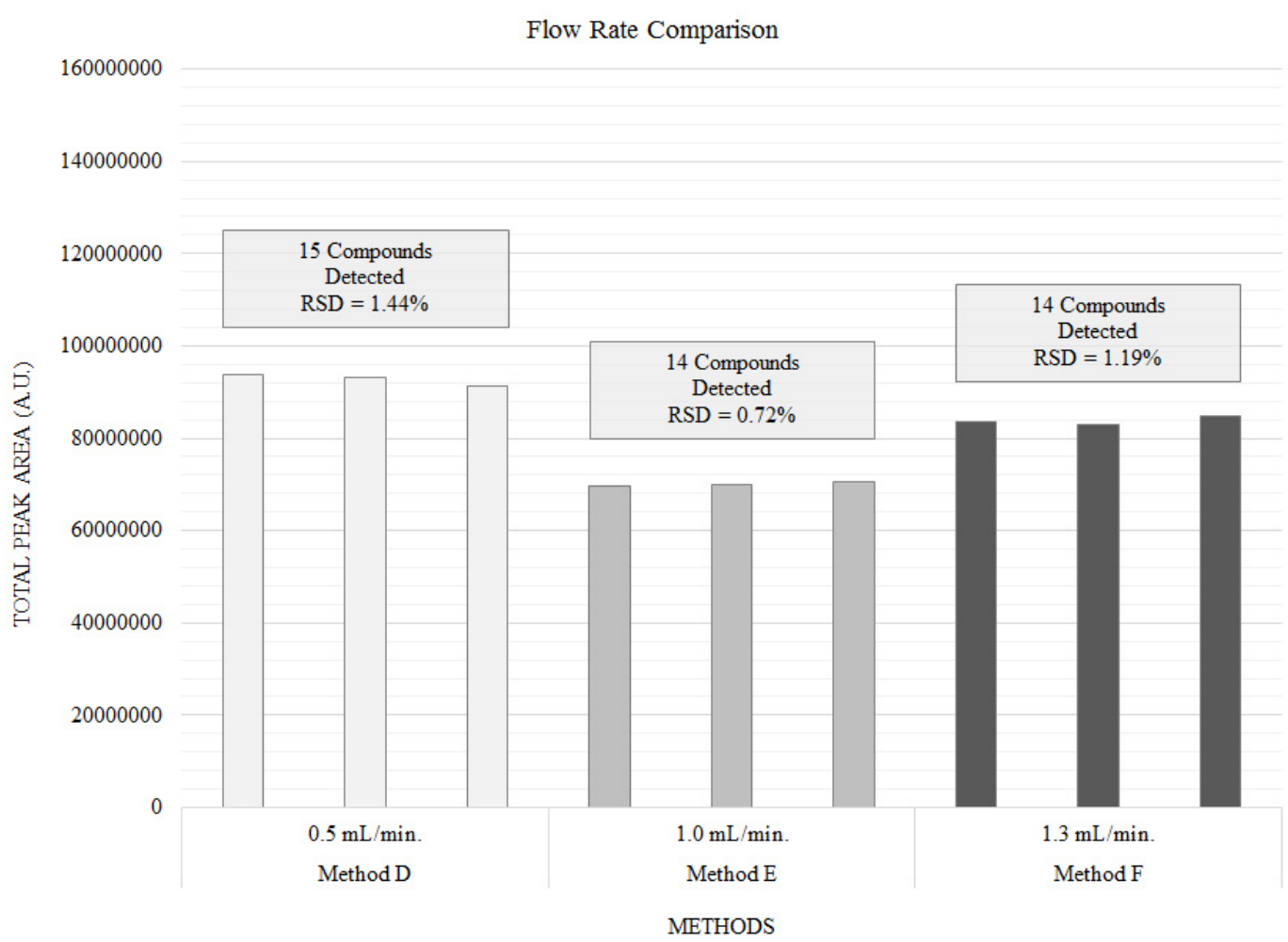

Figure 12: Method comparisons of three different flow rates.

one less than Method D, but Method E had less variation $(0.72 \%)$ in comparison to Method F (1.19\%). Thus, it was determined that the optimum method for GC-MS analysis, fitted with an HP-5MS column, was Method E. However, upon review of the chromatograms, a majority of the compounds that were detected were not well resolved, as peak tailing and co-elution were observed (Figure 13); therefore, the HP-5MS column was replaced with one that was mid-polar (DB-225MS) to determine if sensitivity, variability, and selectivity could be improved. Using $1 \mu \mathrm{L}$ of a $60 \mathrm{ppm}$ thirty-one compound standard mixture solution, the sensitivity, selectivity, and variability of the DB-225MS GC column was assessed and compared to the results obtained for the HP5MS using the optimum method. To perform an accurate comparison, the optimized parameters selected during the assessment of the HP-5MS column were applied during 


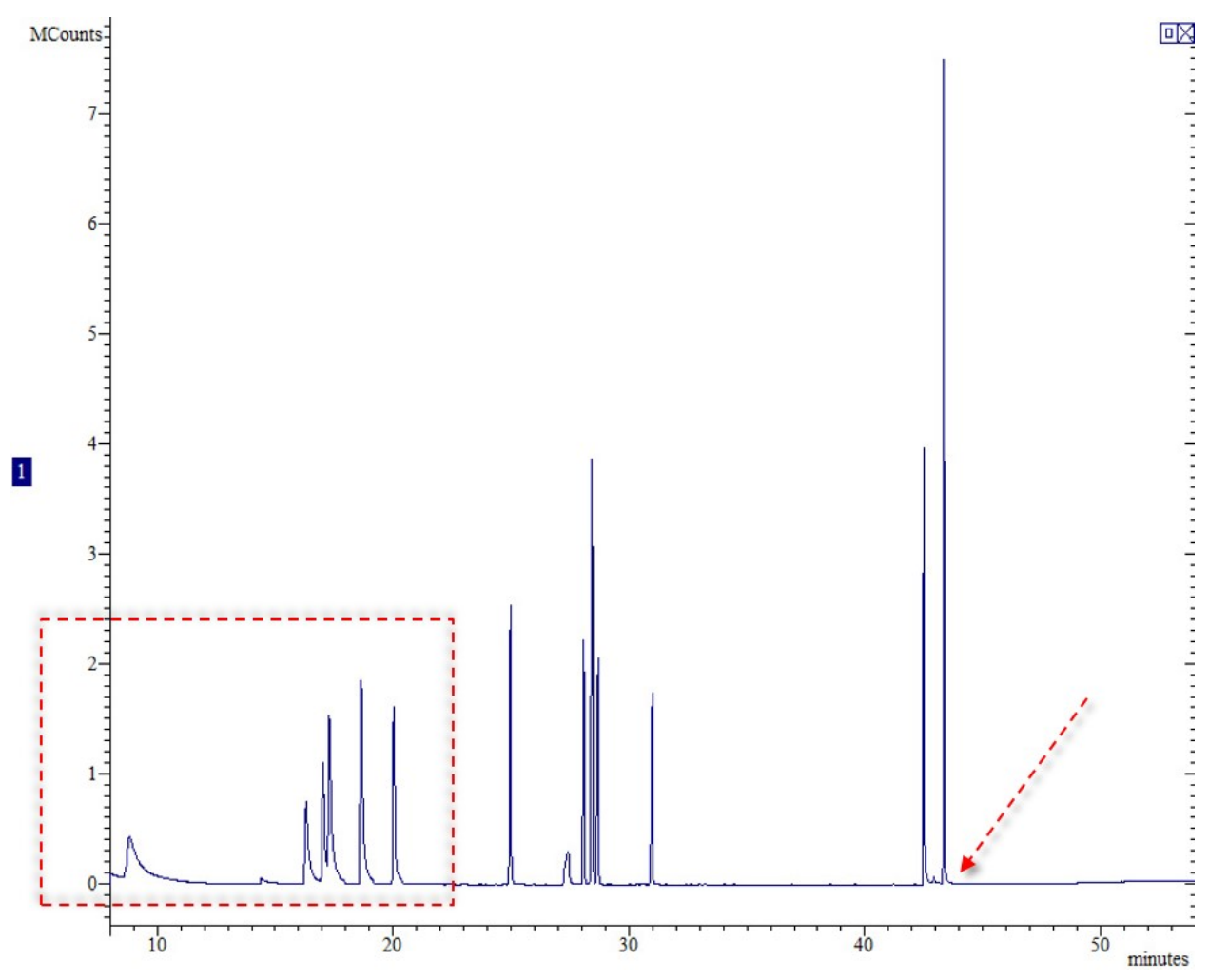

Figure 13: Chromatogram obtained using Method $\mathbf{E}$ on the GC-MS fitted with an HP-5MS column. The dashed box and arrow highlights the poorly resolved peaks.

the evaluation of the DB-225MS column. However, the maximum temperature of the GC oven had to be reduced because of the thermal constraints of the stationary phase. Therefore, the method used was: splitless injection for 5 minutes then split 50 to 1; flow rate was $1.0 \mathrm{~mL} / \mathrm{min}$; initial oven temperature was $40^{\circ} \mathrm{C}$ which was held for five minutes and then ramped to $230^{\circ} \mathrm{C}$ at $10^{\circ} \mathrm{C} /$ minute where it was held for two minutes resulting in a total run time of twenty-six minutes. A comparison between the HP-5MS (non-polar) and DB- 225MS (mid-polar) GC columns was performed (Figure 14) and it was discovered that a greater abundance of compounds, with minimal variability, was obtained using the HP-5MS GC column. 


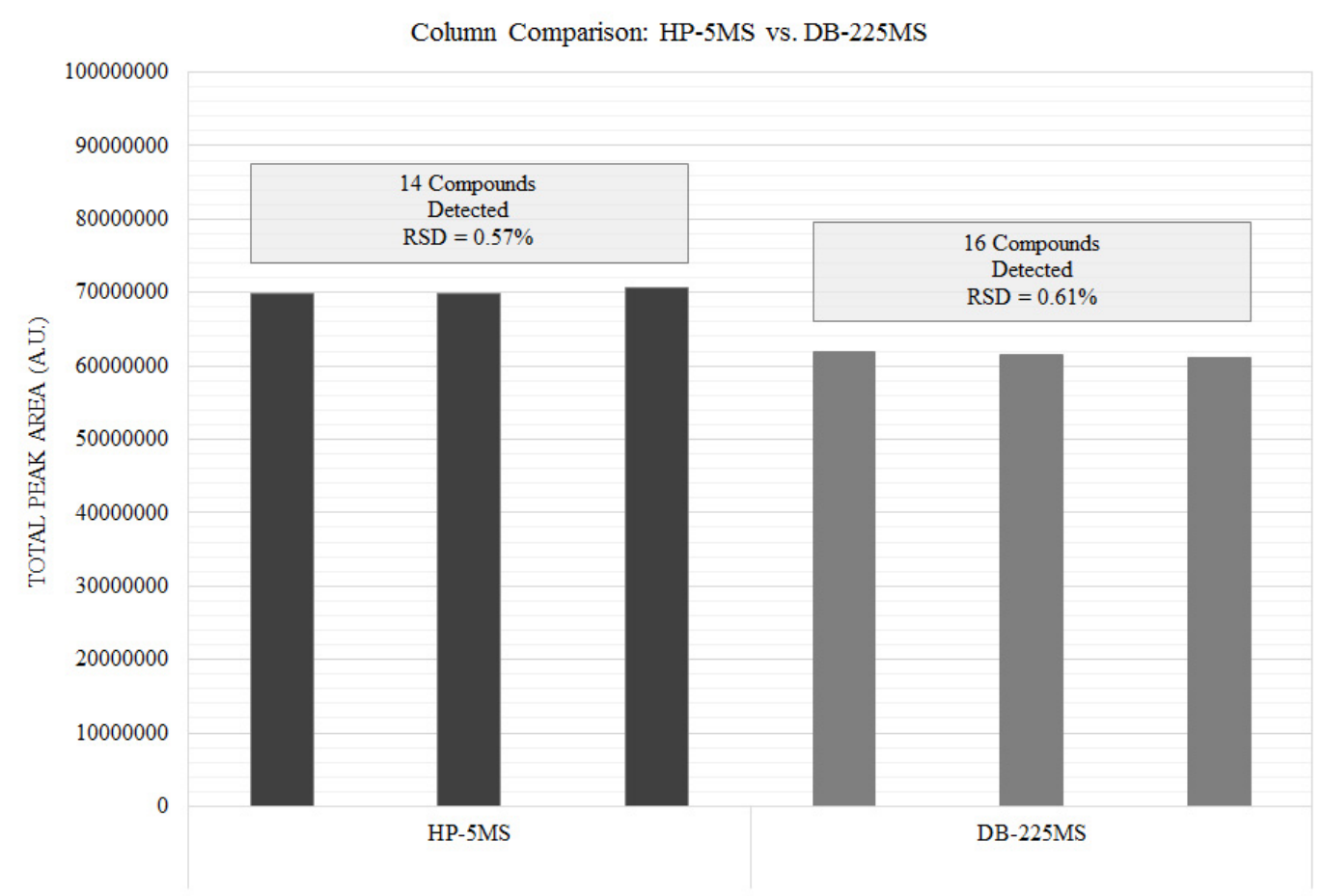

GC COLUMN TYPE

Figure 14: Comparison of a non-polar (HP-5MS) and mid-polar (DB-225MS) GC column.

Nevertheless, when the GC was fitted with the DB-225MS two additional compounds were detected showing that the mid-polar column was, to some extent, more selective. A paired t-test was performed using the average of the total peak area that was obtained for each trial and column. The results revealed that there was a significant difference, with regard to the total peak area, between both columns as $t_{\text {calc }}=17.12$ was greater than the $\mathrm{t}_{\text {critcal }}=4.30$ at $\mathrm{P}=0.05$. However, when considering selectivity, the DB-225MS showed improved resolution for some compounds, but some peak tailing and co-elution was still seen (Figure 15). 
The slight improvement in the selectivity that was observed with the DB-225MS may be attributed to its polarity, as it is more polar than that of the HP-5MS column making it more suitable for the polar compounds that are present in the decomposition-

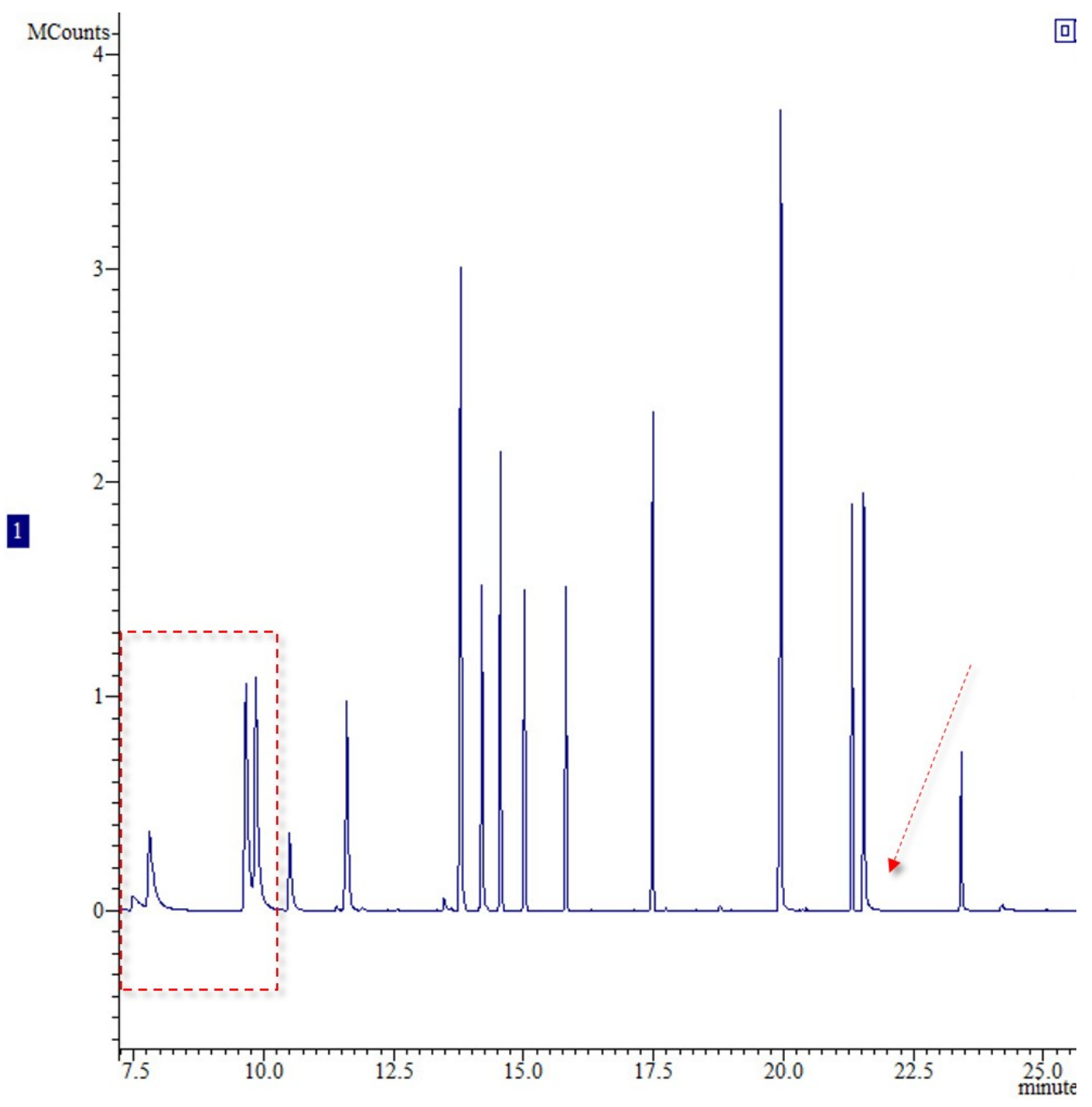

Figure 15: Chromatogram obtained using a DB-225MS column. The dashed box and arrow highlight the poorly resolved peaks. 
associated compound mixture. To assess this hypothesis, an even more polar column was evaluated to determine if, in fact, an enhancement was achieved.

To properly compare the SolGel-Wax (polar) column with the previously tested columns, a GC-MS method was created with the previously optimized parameters (e.g., flow rates, etc.). Again, the maximum temperature of the $\mathrm{GC}$ oven had to be modified because of the thermal constraints of the stationary phase. Therefore, the method used was: splitless injection for 5 minutes, then split 50 to 1 ; flow rate was $1.0 \mathrm{~mL} /$ minute; initial oven temperature was $40^{\circ} \mathrm{C}$ which was held for five minutes and then ramped to $260^{\circ} \mathrm{C}$ at $10^{\circ} \mathrm{C} /$ minute where it was held for two minutes resulting in a total run time of twenty-nine minutes.

Using $1 \mu \mathrm{L}$ of a $60 \mathrm{ppm}$ thirty-one compound standard mixture solution, the sensitivity,

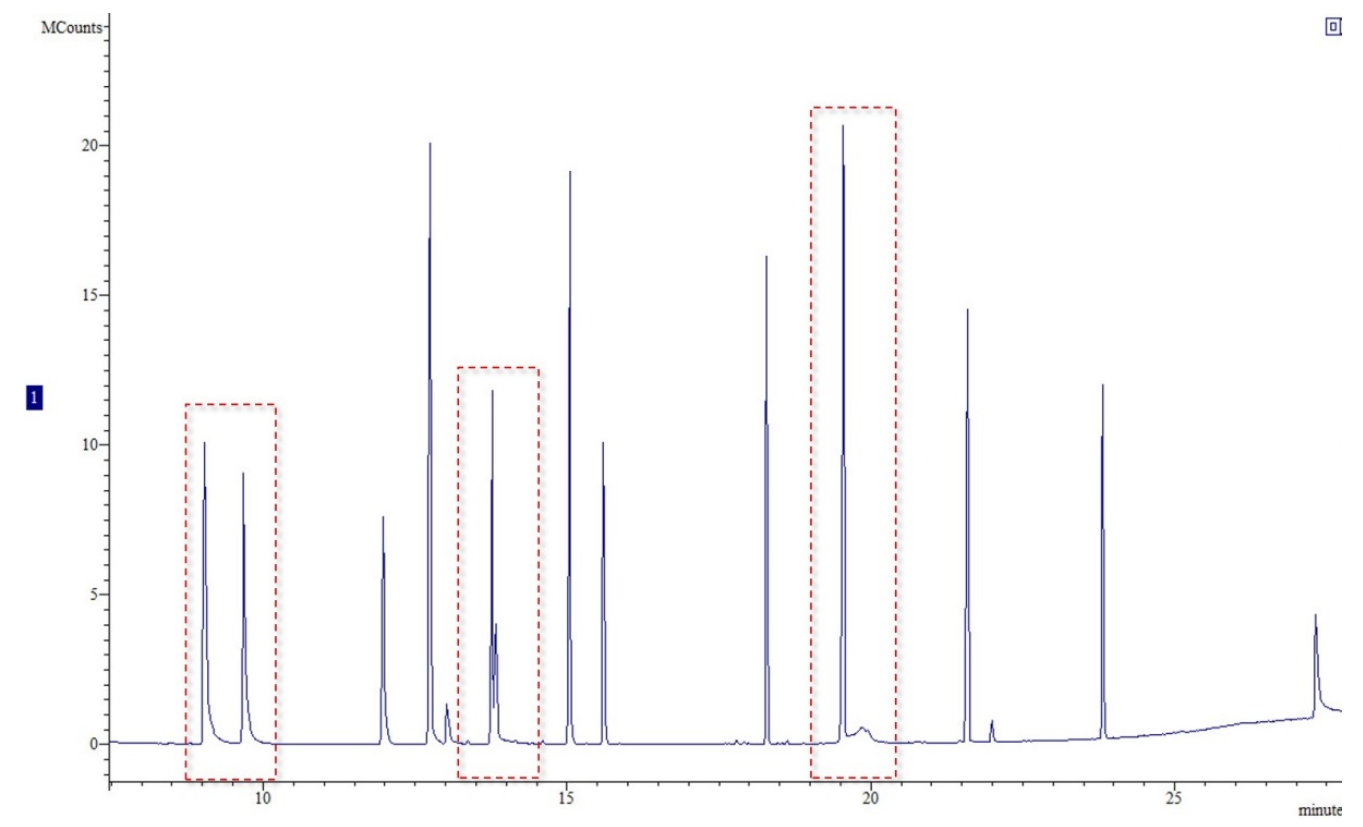

Figure 16: Comparison of a non-polar (HP-5MS), mid-polar (DB-225MS), and polar (SolGel-Wax) GC columns. 
selectivity, and variability of the SolGel-Wax GC column was assessed and compared to the results obtained for both the HP-5MS (non-polar) and DB-225MS (polar). From Figure 16, it can be observed that the SolGel-Wax column provided the greatest abundance of compounds in comparison to the HP-5MS and DB-225MS. The previous study found that there was a significant difference between the non- and mid-polar columns. A paired t-test was performed to determine if there was a significant difference between the polar and non-polar columns as the HP-5MS resulted in a greater abundance of compounds with minimal variation. The results revealed that there was a significant

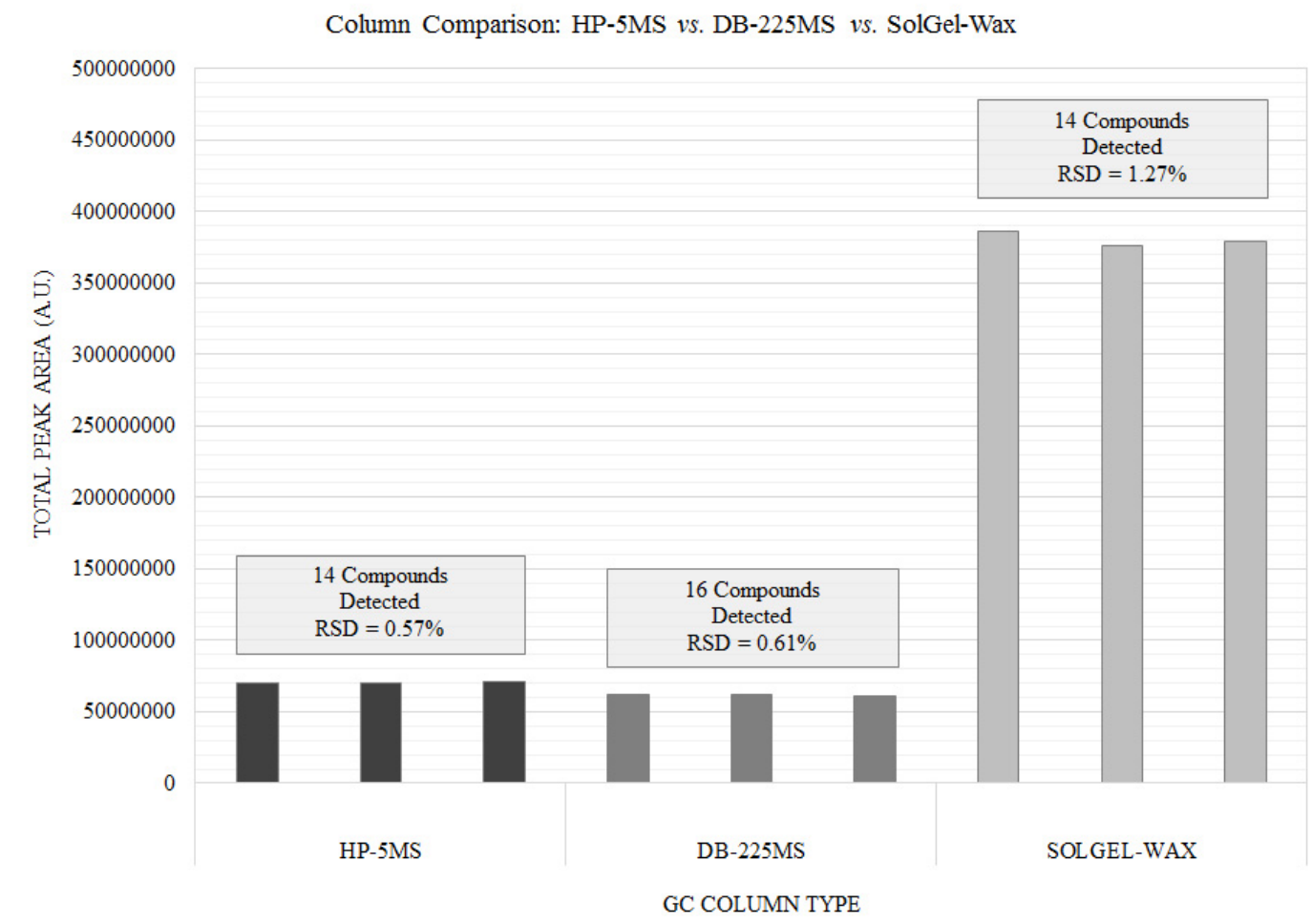

Figure 17: Chromatogram obtained using a SolGel-Wax column. The dashed boxes highlight the poorly resolved peaks. 
difference between both columns as $\mathrm{t}_{\text {calc }}=106.91$ was greater than the $\mathrm{t}_{\text {critcal }}=4.30$ at $\mathrm{P}=$ 0.05. Moreover, upon review of the chromatogram for the $60 \mathrm{ppm}$ thirty-one compound mixture that was separated using the SolGel-Wax column, the peaks were more resolved as there was minimal peak tailing and co-elution (Figure 17). Although

the polar column generated a higher variability when compared to that of the non-polar column, the superb sensitivity could not be ignored and was therefore chosen for all future studies

Having selected the optimum column, the GC oven temperature ramp was the final parameter that was evaluated to establish a GC-MS method that would result in the best sensitivity and selectivity.

\subsubsection{Gas Chromatograph-Mass Spectrometer Method}

To determine the optimum GC-MS method, different GC temperature ramps were assessed using $1 \mu \mathrm{L}$ of a $60 \mathrm{ppm}$ thirty-one compound standard mixture solution. In addition, split vs. splitless injections were re-evaluated as it was discovered that the SolGel-Wax column was easily amenable to overloading which could have caused the poorly resolved peaks seen in Figure 17. Listed below are the summarized GC-MS methods that were evaluated; including the originally tested method in Section 5.1.2.

Method H (Original Method): Splitless injection for 5 minutes then split 50 to 1; flow rate was $1.0 \mathrm{~mL} / \mathrm{minute}$; initial oven temperature was $40^{\circ} \mathrm{C}$ which was held for five minutes 
and then ramped to $260^{\circ} \mathrm{C}$ at $10^{\circ} \mathrm{C} /$ minute where it was held for two minutes resulting in a total run time of twenty-nine minutes.

Method I: Splitless injection for 2 minute then split 50 to 1; flow rate was $1.0 \mathrm{~mL} / \mathrm{minute}$; initial oven temperature was $35^{\circ} \mathrm{C}$ which was held for five minutes and then ramped to $260^{\circ} \mathrm{C}$ at $10^{\circ} \mathrm{C} /$ minute where it was held for two minutes resulting in a total run time of thirty minutes.

Method J: Splitless injection for 2 minutes then split 50 to 1; flow rate was 1.0 $\mathrm{mL} / \mathrm{minute}$; initial oven temperature was $40^{\circ} \mathrm{C}$ which was held for five minutes and then ramped to $260^{\circ} \mathrm{C}$ at $10^{\circ} \mathrm{C} /$ minute where it was held for two minutes resulting in a total run time of twenty-nine minutes.

Method K: Splitless injection for 1 minute, then split 50 to 1; flow rate was 1.0 $\mathrm{mL} /$ minute; initial oven temperature was $40^{\circ} \mathrm{C}$ which was held for five minutes and then ramped to $260^{\circ} \mathrm{C}$ at $10^{\circ} \mathrm{C} /$ minute where it was held for two minutes resulting in a total run time of twenty-nine minutes.

The results of Method H-K were compared (Figure 18). Method I resulted in the greatest number of compounds with the least variation (1.04\%). However, not all compounds were detected nor were they well resolved (Figure 19); in addition overloading was still occurring. Therefore, further investigations were performed by modifying the manner of injection (split vs. splitless) while using the GC oven 
temperature ramp of Method I to determine if selectivity could be enhanced and if additional compounds could be detected.

Through multiple trials and errors, two methods that solely varied in split ratio were attained: Method L and M; both methods allowed for the detection of all thirty-one compounds that were present in the standard mixture. It should be noted that when performing liquid injections, acetaldehyde, ethanol, benzene, ethyl acetate, chloroform, 2-ethyl furan, and 2-butanone were found to co-elute with one another or with the solvent, methylene chloride, resulting in their inability to be confirmed using certified

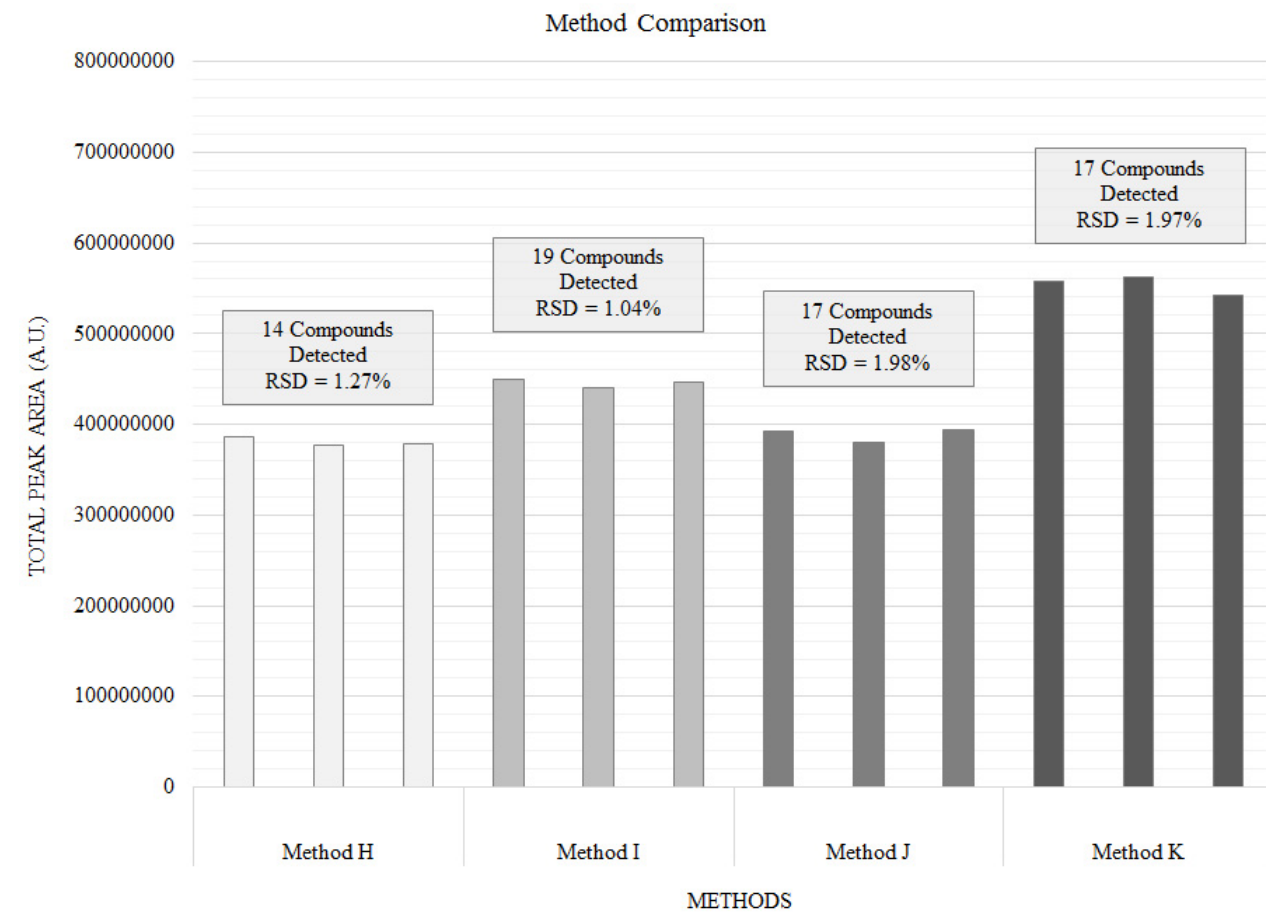

Figure 18: GC-MS method comparison. 


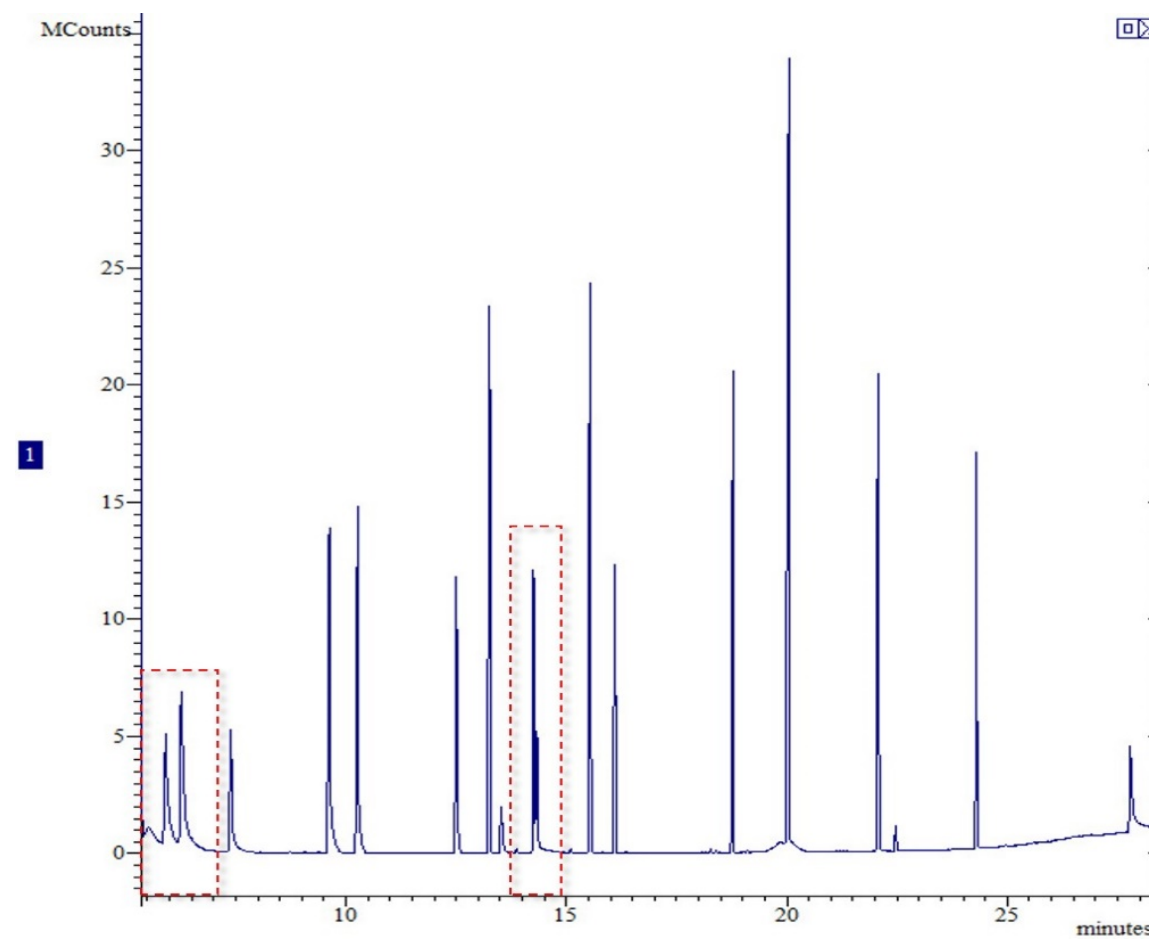

Figure 19: Chromatogram obtained for Method I. The dashed boxes highlight the poorly resolved peaks.

reference standards.

The specifications for Method L and M are listed below.

Method L: Split 50 to 1; flow rate was $1.0 \mathrm{~mL} / \mathrm{minute}$; initial oven temperature was $35^{\circ} \mathrm{C}$ which was held for five minutes, followed by a ramp of $10^{\circ} \mathrm{C} /$ minute till $37^{\circ} \mathrm{C}$ where it was held for 1.50 minutes, then ramped at $20^{\circ} \mathrm{C} /$ minute to $80^{\circ} \mathrm{C}$ where it was held for 9.50 minutes, and then ramped to a final temperature of $260^{\circ} \mathrm{C}$ at $20^{\circ} \mathrm{C} /$ minute where it was held for 2.65 minutes resulting in a total run time of thirty minutes. For liquid injections, the method consisted of three segments in which the ionization mode was either on or off. In segment one and three, the ionization mode (electron impact, EI) was 
turned on, for segment two, which is where the solvent elutes; the ionization mode was turned off. This allowed for early eluting compounds, such as 2,2-dimethylbutane, methylcyclopentane, acetone, and dimethyl sulfide to be detected.

Method M: Split 20 to 1; flow rate was $1.0 \mathrm{~mL} /$ minute; initial oven temperature was $35^{\circ} \mathrm{C}$ which was held for five minutes, followed by a ramp of $10^{\circ} \mathrm{C} /$ minute till $37^{\circ} \mathrm{C}$ where it was held for 1.50 minutes, then ramped at $20^{\circ} \mathrm{C} /$ minute to $80^{\circ} \mathrm{C}$ where it was held for 9.50 minutes, and then ramped to a final temperature of $260^{\circ} \mathrm{C}$ at $20^{\circ} \mathrm{C} /$ minute where it was held for 2.65 minutes resulting in a total run time of thirty minutes. For liquid injections, the method consisted of three segments in which the ionization mode was either on or off. In segment one and three, the ionization mode (electron impact, EI) was turned on, for segment two, which is where the solvent elutes; the ionization mode was turned off. This allowed for early eluting compounds, such as 2,2-dimethylbutane, methylcyclopentane, acetone, and dimethyl sulfide to be detected.

The two methods, which differed solely in split ratio, were utilized throughout the remainder of this research, as the SolGel-Wax column proved to be extremely sensitive to highly concentrated compounds. In Section 5.1.2. Assessment of Various GC Column Chemistries for GC-MS Analysis, split and splitless injections were evaluated and included in the examination of Split 20:1 and 50:1. A paired t-test was performed and revealed that both manners of injections were significantly different $(\mathrm{P}=0.05)$; however, both detected the same number of compounds with minimal variation. Since, additional method optimization studies were needed and required the use of the decompositionassociated thirty-one compound standard mixture solution, Method L was employed to 
minimize column overload. For the analysis of the VOCs released from decomposing remains, Method M was used.

5.1.4. Comparison of SPME and ACS for the Extraction of the Liberated VOCs from Decomposing Remains

To determine the optimum extraction method for the analysis of decompositionassociated compounds, two different techniques were investigated: solid-phase microextraction and activated charcoal strips. When comparing SPME and ACS at a thirty second extraction time, SPME proved to be more superior as it extracted a greater number and abundance of compounds with less variability then ACS. Moreover, it was discovered that CAR/PDMS was the optimum SPME fiber for the extraction of decomposition-associated compounds. These findings are described in more detail in the subsequent sections.

\subsubsection{Solid-Phase Microextraction (SPME)}

Eight SPME fibers of various coating chemistries were evaluated, using a nondiluted standard mixture of the compounds listed in Section 5.1.1., to determine which fiber was most sensitive and selective. Five microliters of the standard mixture was pipetted into a 40-mL vial and allowed to equilibrate for thirty seconds; thereafter, a thirty second headspace extraction was performed. The process was repeated two additional times, generating a total of three trials for each SPME fiber, and subsequently 
analyzed using the optimized GC-MS method. Presented in Figure 20 is the average total peak area for each SPME fiber, as well as the range of extracted compounds.

As the CAR/PDMS and DVB/CAR/PDMS SPME fibers extracted the greatest number of compounds, they were further assessed using a more diluted mixture. Five microliters of a $155 \mathrm{ppm}$ diluted mixture was pipetted into six $40-\mathrm{mL}$ vials and set aside to equilibrate for one hour. Thereafter, using three different CAR/PDMS and DVB/CAR/PDMS SPME fibers, a thirty minute headspace extraction was performed. The results of the study presented in Figure 21 show that the DVB/CAR/PDMS SPME
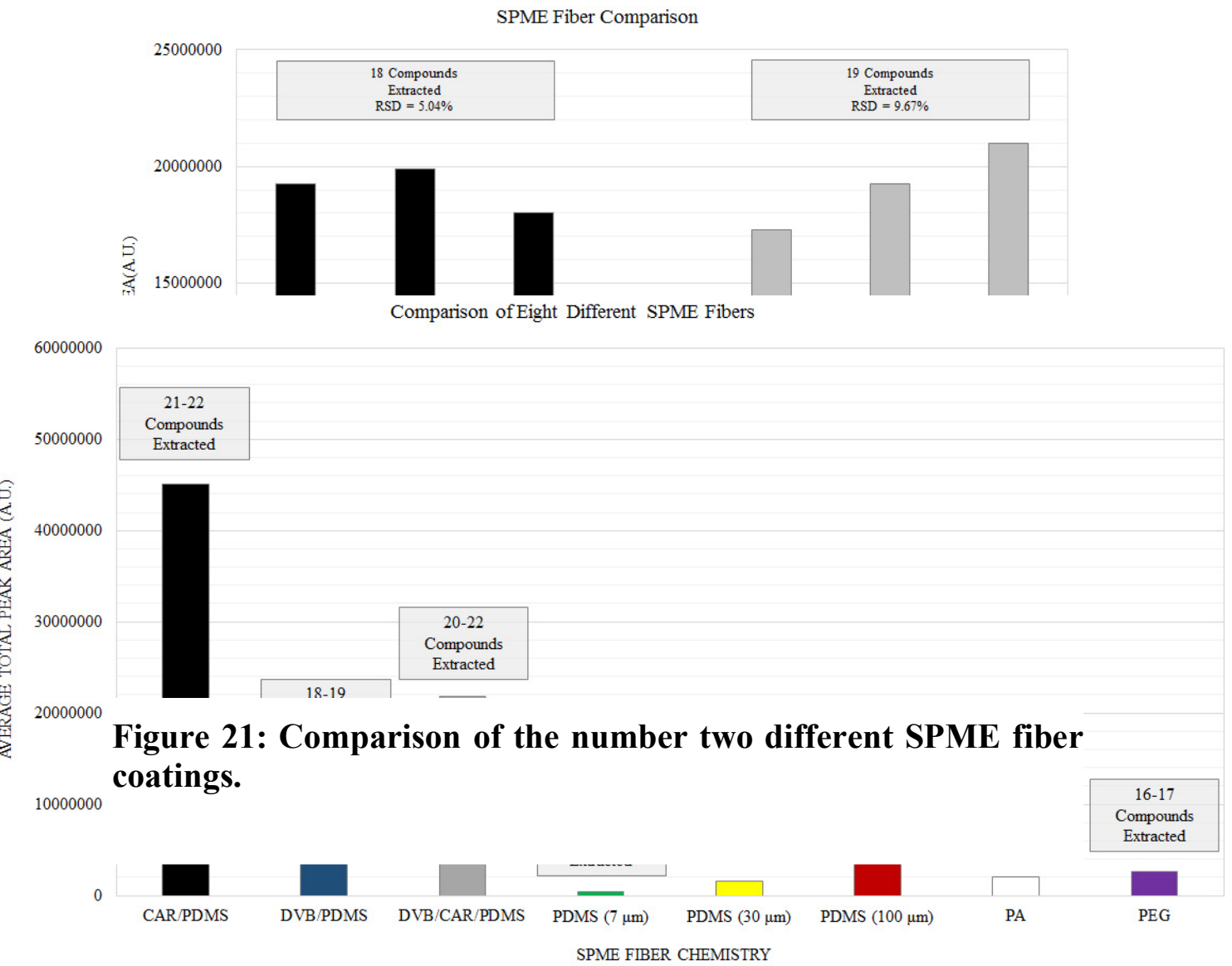

Figure 20: Comparison of the average total abundance, as well as range of compounds extracted by each SPME fiber tested. 
fiber extracted one additional compound; however, the RSD was larger than what was observed with the CAR/PDMS SPME fiber. Paired t-test was performed to determine if there was a significant difference between both fiber types. With a $t_{\text {calc }}$ of 0.09 which is less than the $\mathrm{t}_{\text {critical }}$ of 4.30 at $\mathrm{P}=0.05$, no significant difference between fiber types was revealed. Therefore, Carboxen/Polydimethylsiloxane (CAR/PDMS) was selected as the optimum fiber as it proved to be sensitive and selective with minimal variation.

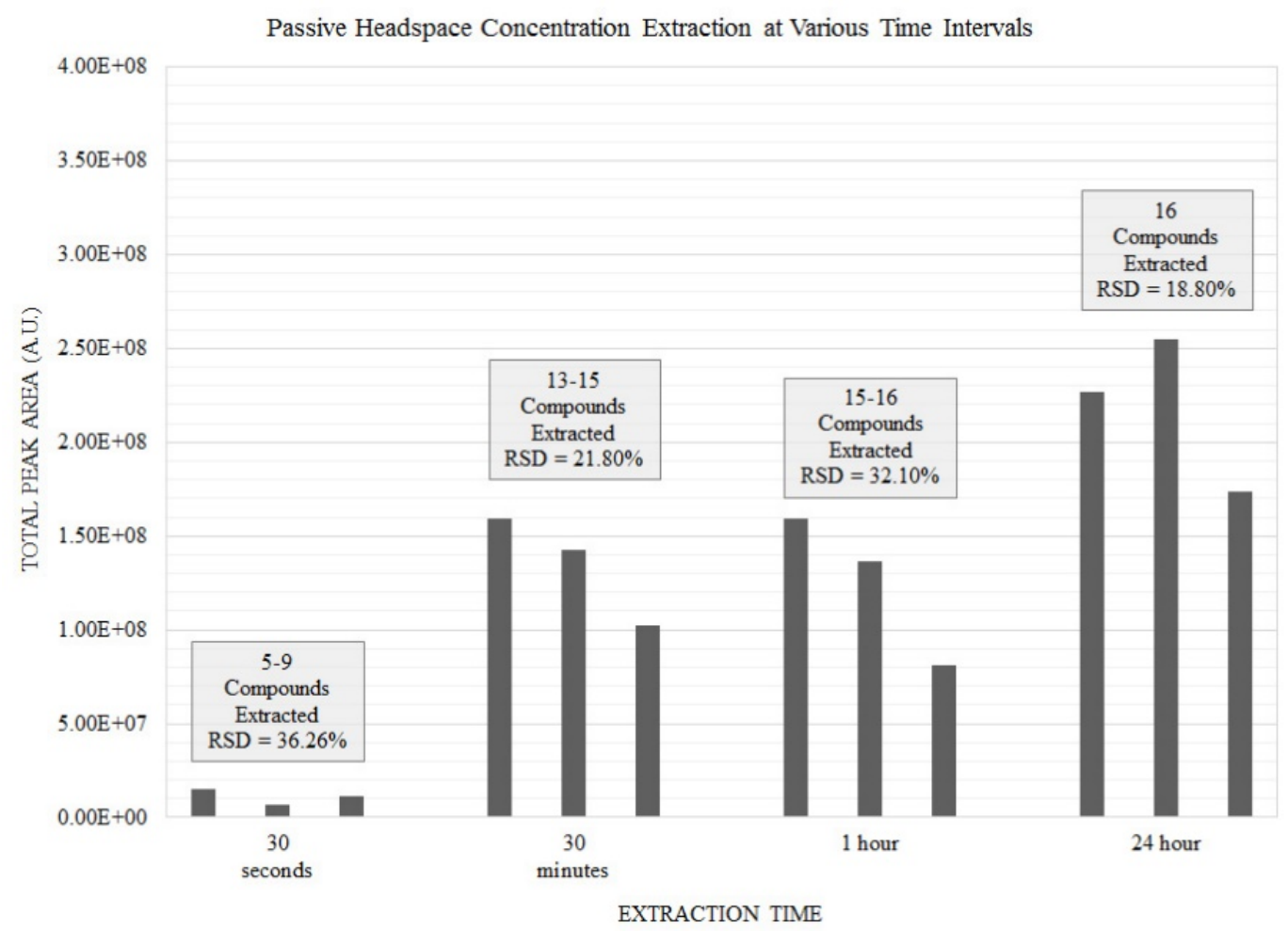

Figure 22: ACS extraction at various time intervals.

5.1.4.2. Activated Charcoal Strips (ACS)

Passive headspace concentration extraction was performed using segmented activated charcoal strips. Five microliters of a non-diluted standard mixture consisting of the compounds listed in Section 5.1.1. was pipetted into a 40-mL vial. A segmented ACS 
was suspended in the headspace using a small paperclip and unwaxed dental floss. Extractions were performed, in triplicate, for thirty seconds, thirty minutes, one hour, and twenty-four hours and then the compounds were eluted with carbon disulfide and subsequently analyzed using the optimized GC-MS method. From the results presented in Figure 22, ACS proved to be insufficient at extracting a large number of the decomposition-associated compounds such that even an extraction time of twenty-four hours, only sixteen compounds were extracted. Moreover, there were large variations $(\mathrm{RSD}>18.80 \%)$ at each time interval evaluated.

\subsection{Research Site for Human Cadaver Analogues}

All studies were performed at FIU upon the secured roof of AHC 1 that had an approximate height of $22 \mathrm{~m}$ (Figure 23). The purpose of this task was to determine the

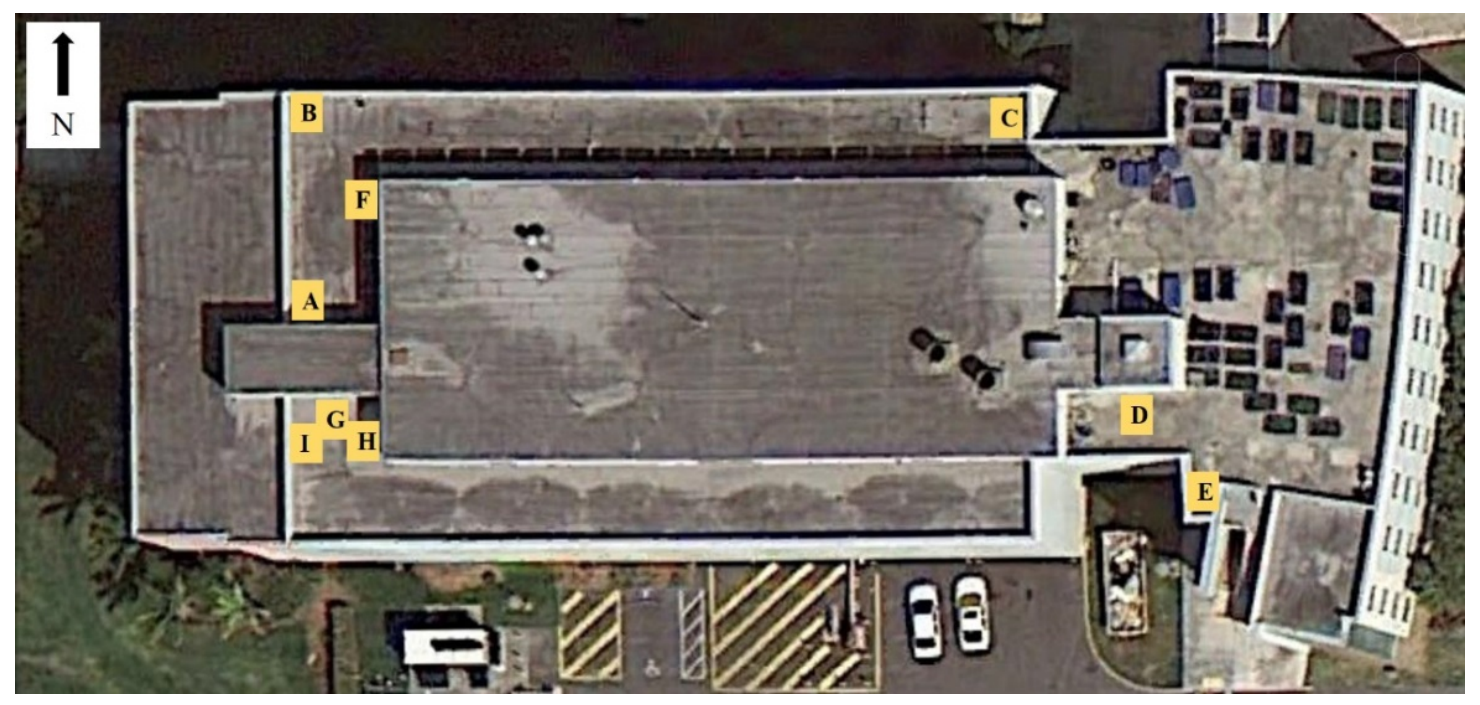

Figure 23: Nine locations were evaluated on the roof of $\mathrm{AHC1}$ to determine the optimum location to conduct field analyses. 
optimum location for the field placement of the decomposing remains. The optimal location would be an area that would, over a period of eight hours, experience an increase in temperature until it reaches maximum and then slowly decreases giving the appearance of a Gaussian curve if the temperature versus time were plotted.

The temperatures at locations A-I were measured using a temperature meter, documented (Table 10) and graphed (Figure 24) to determine the optimum location to conduct decomposition-related analyses.

Table 10: Temperature measured at each location on roof of AHC1 located at FIU.

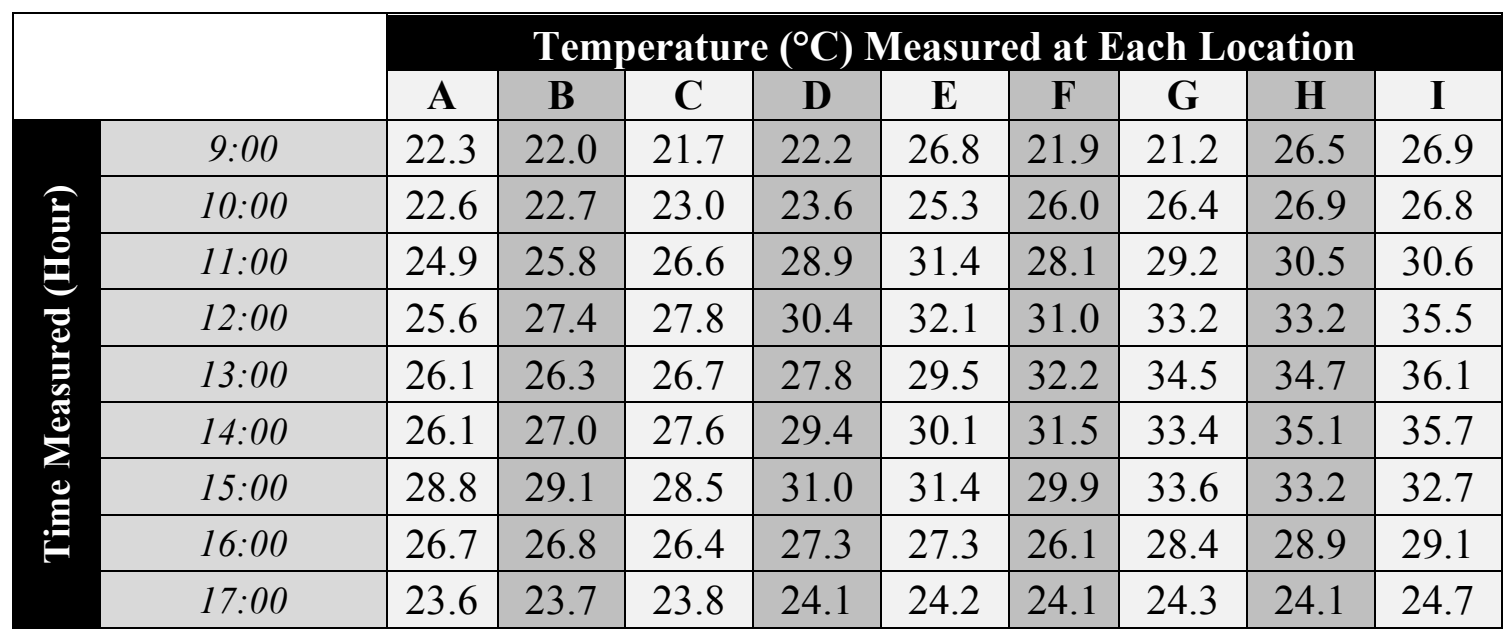

Upon review of the temperature data that was collected, both Site $\mathrm{H}$ and I showed

steady increases and decreases in temperature almost to the resemblance of Gaussian curves; however, between 11:00 - 14:00 hours, the temperature was slightly higher for Site I. Thus, the location that was selected for field analyses of decomposing remains was Site I, and it was there that shelters were created (see Section 4.2.3.). 


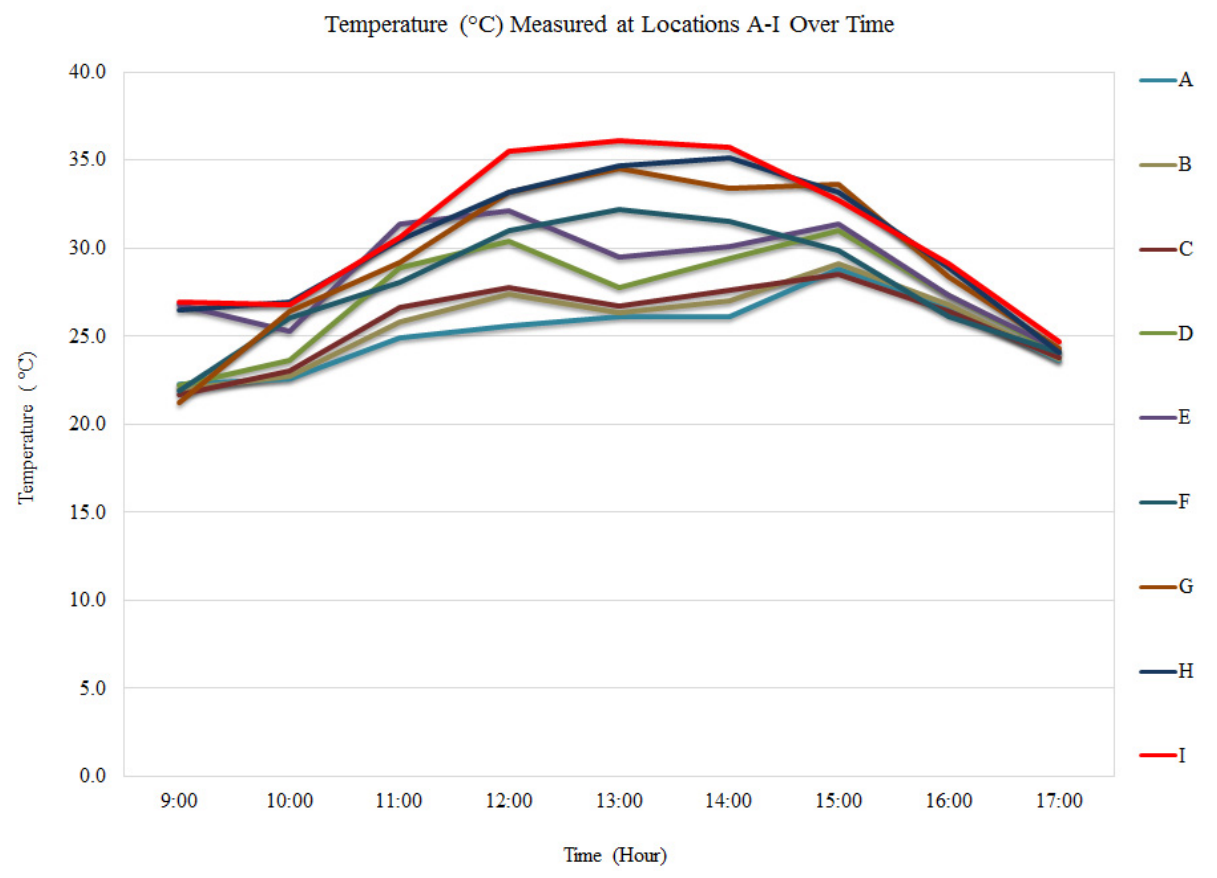

Figure 24: Temperature measurements at each location over time.

5.3. Comparison of the VOCs Released from Frozen then Thawed and Freshly Killed Decomposing Remains

The purpose of this study was to assess the impact that frozen environments have on the liberated VOCs through the comparison of frozen then thawed and freshly killed decomposing remains. Moreover, the results of this study were used to determine how the mice would be euthanized and stored for the remaining studies.

\subsubsection{Human Cadaver Analogues}


A total of 8 adult, transgenic mice that were housed and fed identically were used; their specifications are listed in Table 11. Their average mass was $36 \pm 4 \mathrm{~g}$ for the female mice and $35 \pm 4 \mathrm{~g}$ for the male mice. The average total lengths of the female and male mice were $17.6 \pm 0.4 \mathrm{~cm}$ and $16.7 \pm 1.6 \mathrm{~cm}$, respectively. Four trials were performed each consisting of one freshly killed and one frozen then thawed mouse, as well as a control (an empty sampling chamber). Once euthanized, mice designated as frozen then thawed (FTW) were immediately placed into a freezer at $-20^{\circ} \mathrm{C}$ for 22 hours and then allowed to thaw at room temperature $\left(22^{\circ} \mathrm{C}\right)$ for 3 hours. Those mice designated as freshly killed (FKD) were euthanized 1 hour prior to field placement.

Table 11: Mice specifications.

\begin{tabular}{|c|c|c|c|c|c|c|}
\hline \multirow{2}{*}{ Trial } & Type & Gender & $\begin{array}{c}\text { Weight } \\
(\mathbf{g})\end{array}$ & $\begin{array}{c}\text { Body } \\
\text { Length } \\
(\mathbf{c m})\end{array}$ & $\begin{array}{c}\text { Tail } \\
\text { Length } \\
(\mathbf{c m})\end{array}$ & $\begin{array}{c}\text { Total } \\
\text { Length } \\
(\mathbf{c m})\end{array}$ \\
\hline \multirow{2}{*}{$\boldsymbol{1}$} & Freshly Killed & Female & 41 & 9.7 & 8.4 & 18.1 \\
\cline { 2 - 7 } & Frozen then Thawed & Female & 37 & 8.9 & 8.2 & 17.1 \\
\hline \multirow{2}{*}{$\boldsymbol{2}$} & Freshly Killed & Female & 35 & 9.2 & 8.3 & 17.5 \\
\cline { 2 - 7 } & Frozen then Thawed & Female & 31 & 9.3 & 8.4 & 17.7 \\
\hline \multirow{3}{*}{3} & Freshly Killed & Male & 39 & 9.6 & 8.5 & 18.1 \\
\cline { 2 - 7 } & Frozen then Thawed & Male & 34 & 7.0 & 8.1 & 15.1 \\
\hline \multirow{2}{*}{$\boldsymbol{4}$} & Freshly Killed & Male & 36 & 9.0 & 9.0 & 18.0 \\
\cline { 2 - 7 } & Frozen then Thawed & Male & 30 & 8.0 & 7.4 & 15.4 \\
\hline
\end{tabular}




\subsubsection{Temperature and Relative Humidity of Environment}

The average temperature and relative humidity were deduced from the hourly measurements that were collected throughout the course of the trial (Table 12). The hourly temperature measurements, for all trials, resulted in a similar pattern with a steady increase slightly before noon where then the maximum temperature was reached and then a steady decrease as evening approached (Figure 25).

Table 12: The average temperature and relative humidity calculated throughout the course of each trial.

\begin{tabular}{|c|c|c|c|c|c|c|}
\hline \multirow[b]{2}{*}{ Trial } & \multicolumn{6}{|c|}{ Average Temperature $\left({ }^{\circ} \mathrm{C}\right)$} \\
\hline & $\begin{array}{c}\text { Day 0 } \\
(1100-2300 \text { Hours })\end{array}$ & $\begin{array}{c}\text { Day } 1 \\
(0000-2300 \text { Hours })\end{array}$ & $\begin{array}{c}\text { Day } 2 \\
(0000-2300 \text { Hours })\end{array}$ & $\begin{array}{c}\text { Day } 3 \\
(0000-2300 \text { Hours })\end{array}$ & $\begin{array}{c}\text { Day } 4 \\
(0000-2300 \text { Hours })\end{array}$ & $\begin{array}{c}\text { Day } 5 \\
(0000-1300 \text { Hours })\end{array}$ \\
\hline 1 & 24.1 & 22.8 & 21.9 & 21.8 & 23.0 & 20.8 \\
\hline 2 & 21.9 & 22.2 & 23.3 & 23.7 & 23.7 & 24.0 \\
\hline 3 & 27.1 & 23.8 & 24.1 & 23.7 & 23.5 & 23.5 \\
\hline 4 & 25.6 & 23.6 & 25.2 & 25.0 & 23.7 & 21.4 \\
\hline \multirow[b]{2}{*}{ Trial } & \multicolumn{6}{|c|}{ Average Relative Humidity (\%) } \\
\hline & $\begin{array}{c}\text { Day 0 } \\
(1100-2300 \text { Hours }) \\
\end{array}$ & $\begin{array}{c}\text { Day } 1 \\
(0000-2300 \text { Hours }) \\
\end{array}$ & $\begin{array}{c}\text { Day } 2 \\
(0000-2300 \text { Hours }) \\
\end{array}$ & $\begin{array}{c}\text { Day } 3 \\
(0000-2300 \text { Hours }) \\
\end{array}$ & $\begin{array}{c}\text { Day } 4 \\
(0000-2300 \text { Hours }) \\
\end{array}$ & $\begin{array}{c}\text { Day } 5 \\
(0000-1300 \text { Hours })\end{array}$ \\
\hline 1 & 80.1 & 91.8 & 90.0 & 86.6 & 92.0 & 90.1 \\
\hline 2 & 67.6 & 73.8 & 76.0 & 75.4 & 75.1 & 82.0 \\
\hline 3 & 43.6 & 66.4 & 60.0 & 60.5 & 62.6 & 74.9 \\
\hline 4 & 52.5 & 62.4 & 60.6 & 62.9 & 75.8 & 94.2 \\
\hline
\end{tabular}




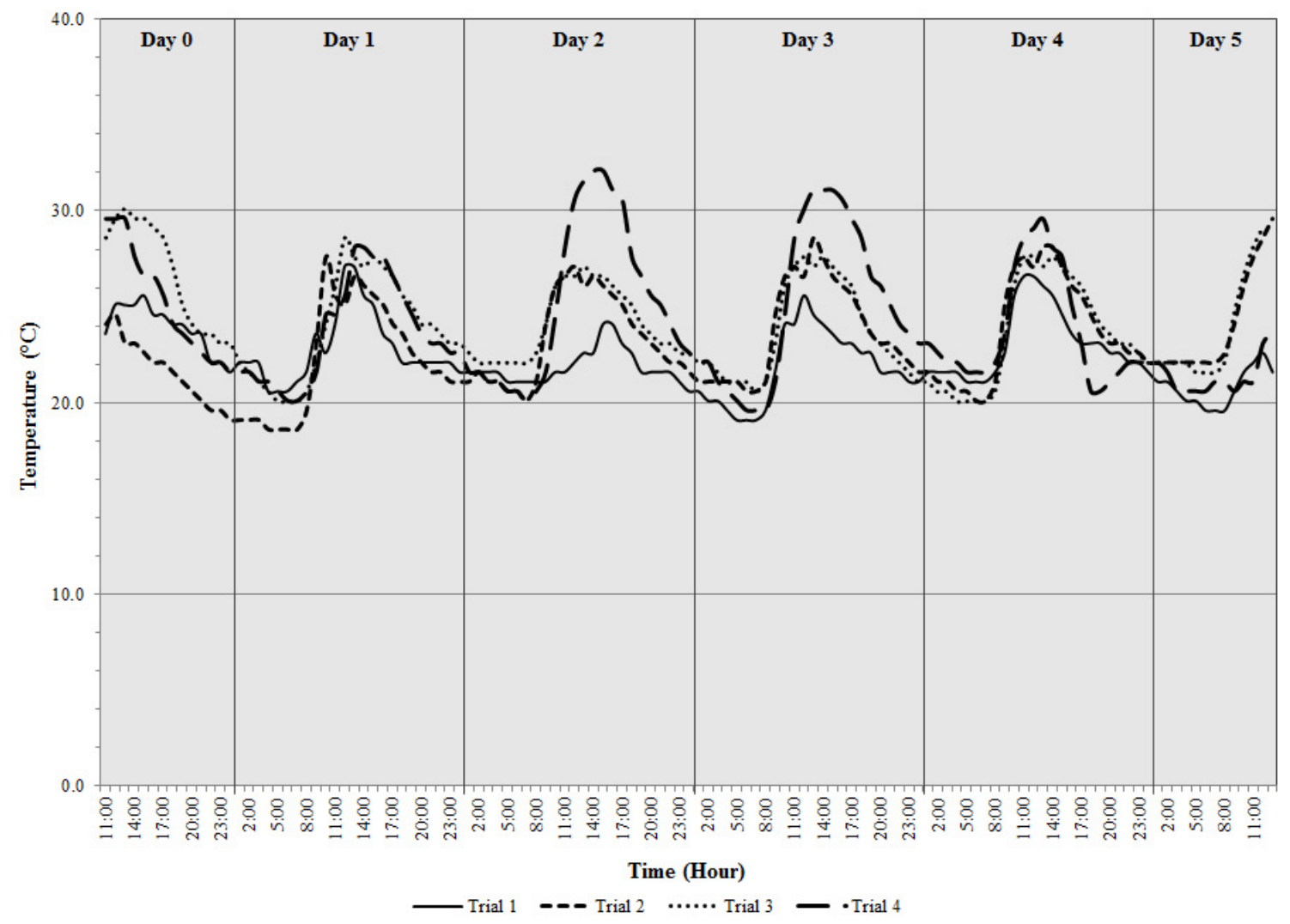

Figure 25: Line graph representing the hourly temperature recordings for each trial.

\subsubsection{Visual Observations}

Photographs were taken throughout the course of the trial. For the purpose of simplicity, photos taken on Days 1, 3, and 5 are presented (Figures 26 and 27) for both freshly killed and frozen then thawed remains. As decomposition progressed, bloating in both sets of remains was observed; however, marbling and green discoloration, physical characteristics of bloating, is more apparent in the FTW than in the FKD remains. 


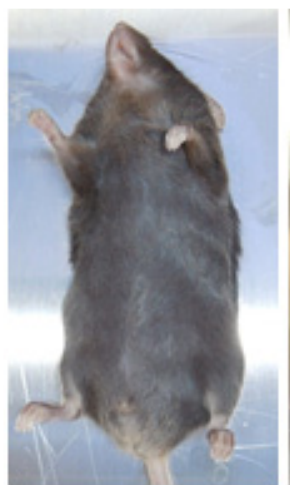

Day 1

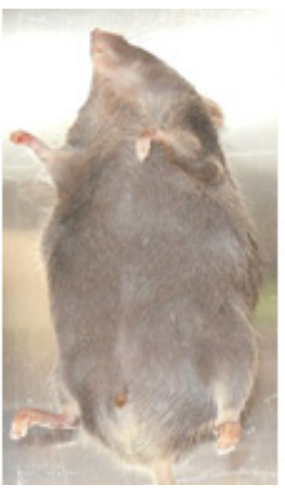

Day 3

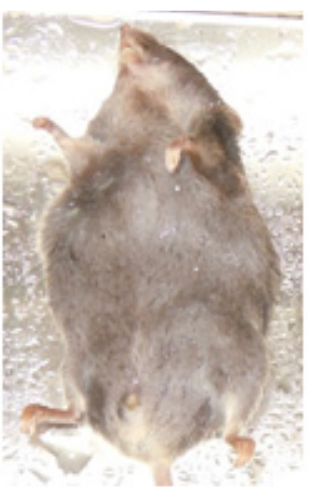

Day 5

Figure 26: Freshly killed remains.

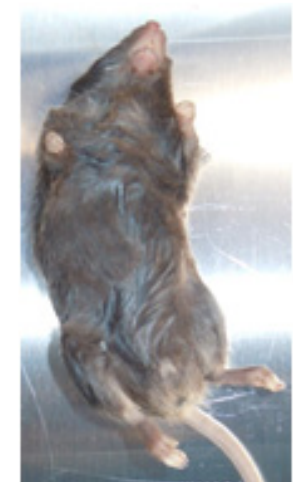

Day 1

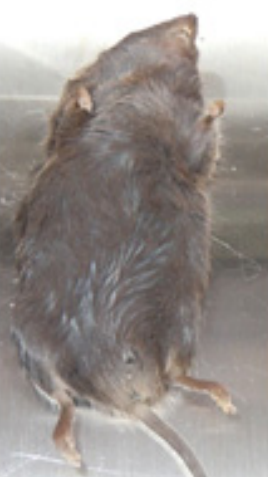

Day 3

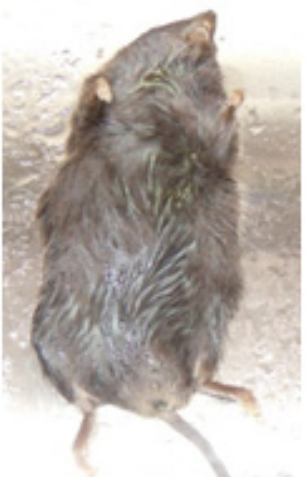

Day 5

Figure 27: Frozen then thawed remains.

5.3.4. Volatile Organic Compounds Detected from Freshly Killed and Frozen then Thawed Decomposing Remains

A total of nineteen VOCs, which ranged in chemical functionality, were extracted from both sets of decomposing remains. Upon GC-MS analysis, all compounds detected were verified using certified reference standards via the Varian MS Workstation Software, Version 6.6 (Service Pack 1). 
Of the nineteen compounds that were identified, only sixteen were previously reported in literature as being decomposition-associated compounds [24,85-93,120123,145-147,149,150]. The present study was the first to detect 2,4-dimethylhexane, butanoic acid propyl ester, and benzenepropanoic acid ethyl ester as compounds released from decomposing remains. Table 13 displays the presence/absence of the VOCs that were identified for each trial from both sets of remains over time. Pentanoic acid 4methyl, butanoic acid propyl ester, and benzenepropanoic acid ethyl ester, were only found in FTW remains, whereas 3-methyl-1H-indole was detected solely in FKD remains. Butanoic acid and 3-methyl-butanoic acid were present in both FKD and FTW remains throughout the entire sampling period for all trials. When comparing the overall number of compounds detected, those remains that were FTW produced a greater number of VOCs at Day 5 than those that were freshly killed.

The distribution of the total peak areas for the VOCs extracted were assessed for all trials using a box-whisker plot (Figure 28). After Day 3, the total peak areas were greater for the FTW remains than for those that were freshly killed. In addition, when comparing Day 5 for both sets of remains, the total peak area was greater, with a larger range, for 


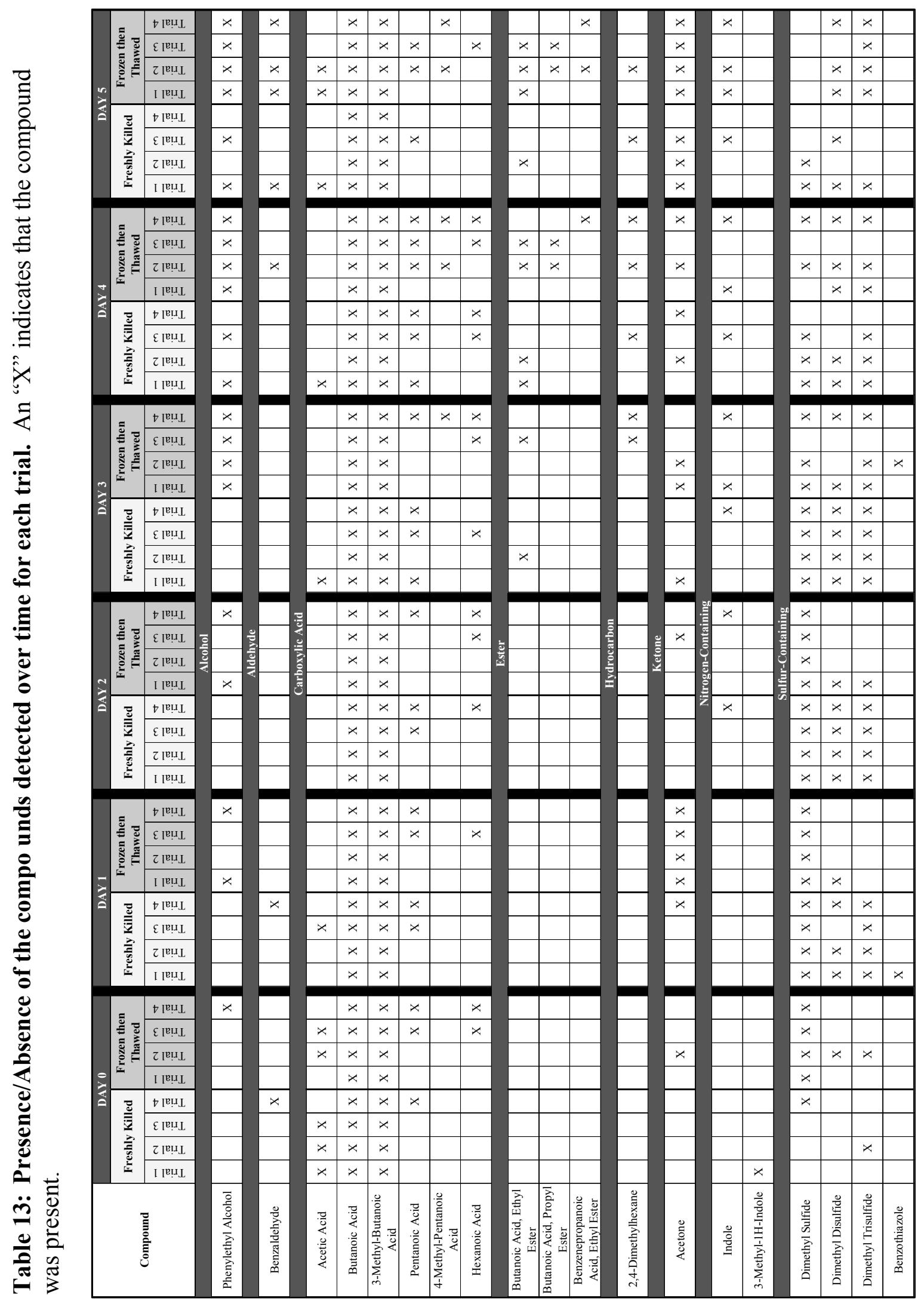




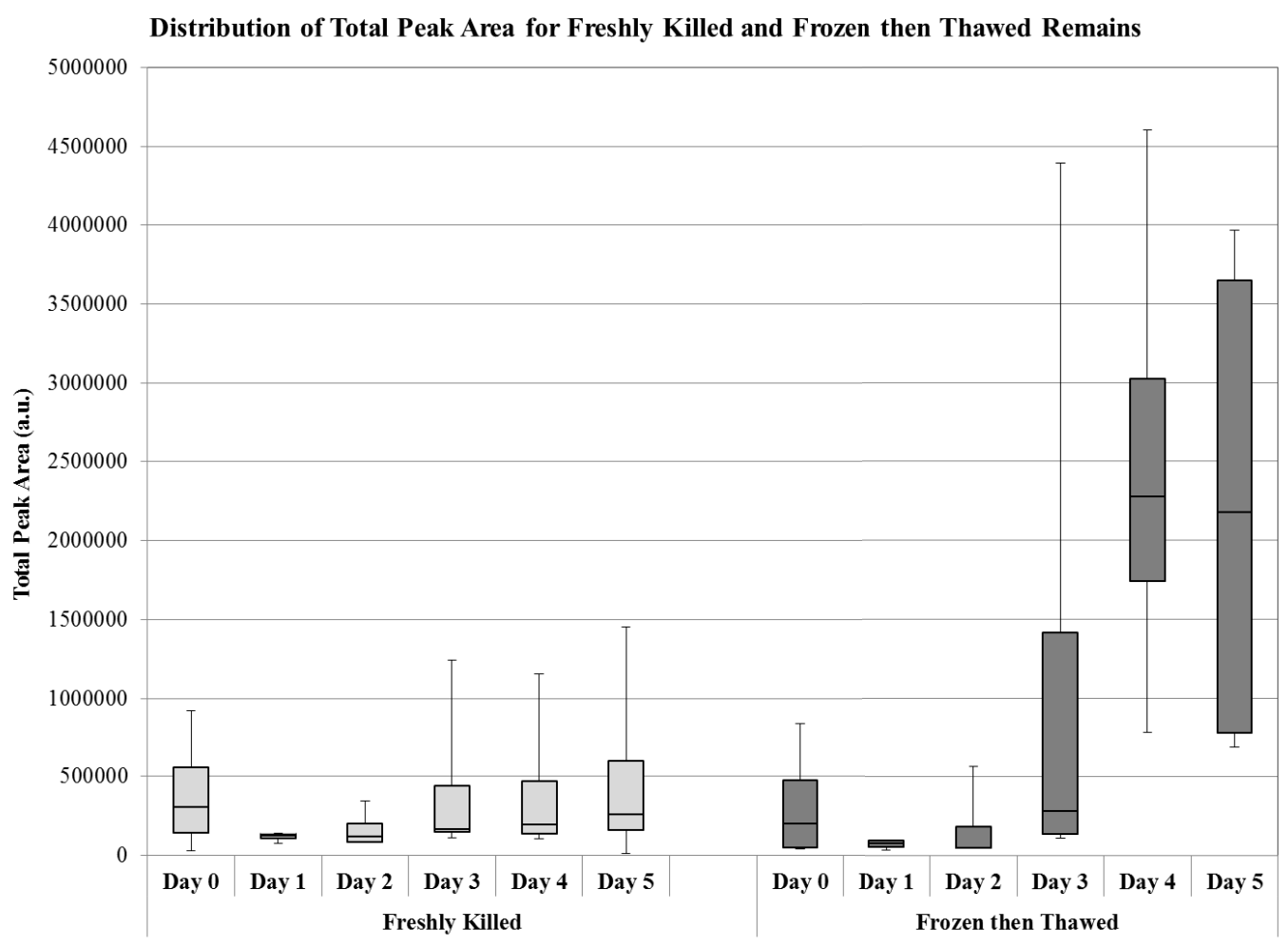

Figure 28: A box-whisker plot of the freshly killed and frozen then thawed remains. Boxes show the upper (75\%) and the lower (25\%) quartile, the line in the center of each box represents the median and the whiskers show the maximum and minimum range of the total peak areas over time.

those that were FTW than for those that were freshly killed. This may be attributable to the manner in which they decomposed as Micozzi [55] assessed FKD and FTW decomposing rat remains over a period of six days and found that FTW remains decomposed from the "outside-in", whereas those that were FKD decomposed from the "inside-out".

\subsubsection{Identification and Assessment of Common Volatile Organic Compounds}

Of the nineteen compounds that were previously mentioned in Table 13, those 
VOCs that were present in a minimum of three out of the four trials were recognized as being common compounds. Butanoic acid, 3-methyl-butanoic acid, pentanoic acid, acetone, dimethyl sulfide, dimethyl disulfide, and dimethyl trisulfide were found to be common in both sets of remains (Table 14). However, acetic acid was found to be only common in FKD remains, whereas phenylethyl alcohol, benzaldehyde, butanoic acid ethyl ester, and indole were common to those that were frozen then thawed. When assessing each set of remains for common VOCs, the mice that were FKD had eight compounds in common, whereas those that were FTW had eleven common VOCs. In addition, the average number of common compounds for each sampling period was evaluated (Figure 29). From Days $0-4$ the average number of compounds that were present were similar for both types of remains; thereafter, at Day 5, those that were FTW had more than two times the amount of VOCs than those that were freshly killed.

Using those compounds that were determined to be common, the odor profiles for the FKD and FTW remains were generated (Figure 30). Each color bar corresponds to a particular VOC and its length is representative of the relative abundance, or percent of that compound, to the total composition of the decomposition odors that were generated. From the odor profiles, it was observed that the detected compounds and abundances changed as the remains decomposed. These findings were in agreement with Dekeirsshieter et al. [92] and Vass et al. [85,86] who found that not only do the remains change visually as they progress through the decomposition process, but so does the pattern of VOCs. In addition, Micozzi [55] found that the manner in which the remains were treated upon death (FKD or FTW) played a pivotal role during the decomposition process and the observed change in the type and relative ratio of VOCs were in accord 
Table 14: Common compounds found in freshly killed and frozen then thawed remains. An " $\mathrm{X}$ " indicates that the compound was present.

\begin{tabular}{|c|c|c|}
\hline Freshly Killed & Compound Name & Frozen then Thawed \\
\hline & Phenylethyl Alcohol & $\mathrm{X}$ \\
\hline $\mathrm{X}$ & Benzaldehyde & $\mathrm{X}$ \\
\hline $\mathrm{X}$ & Acetic Acid & $\mathrm{X}$ \\
\hline $\mathrm{X}$ & Butanoic Acid & $\mathrm{X}$ \\
\hline $\mathrm{X}$ & 3-Methyl-Butanoic Acid & $\mathrm{X}$ \\
\hline & Pentanoic Acid & $\mathrm{X}$ \\
\hline $\mathrm{X}$ & Butanoic Acid, Ethyl Ester & $\mathrm{X}$ \\
\hline $\mathrm{X}$ & Acetone & $\mathrm{X}$ \\
\hline $\mathrm{X}$ & Indole & $\mathrm{X}$ \\
\hline $\mathrm{X}$ & Dimethyl Sulfide & $\mathrm{X}$ \\
\hline & Dimethyl Disulfide & $\mathrm{X}$ \\
\hline
\end{tabular}

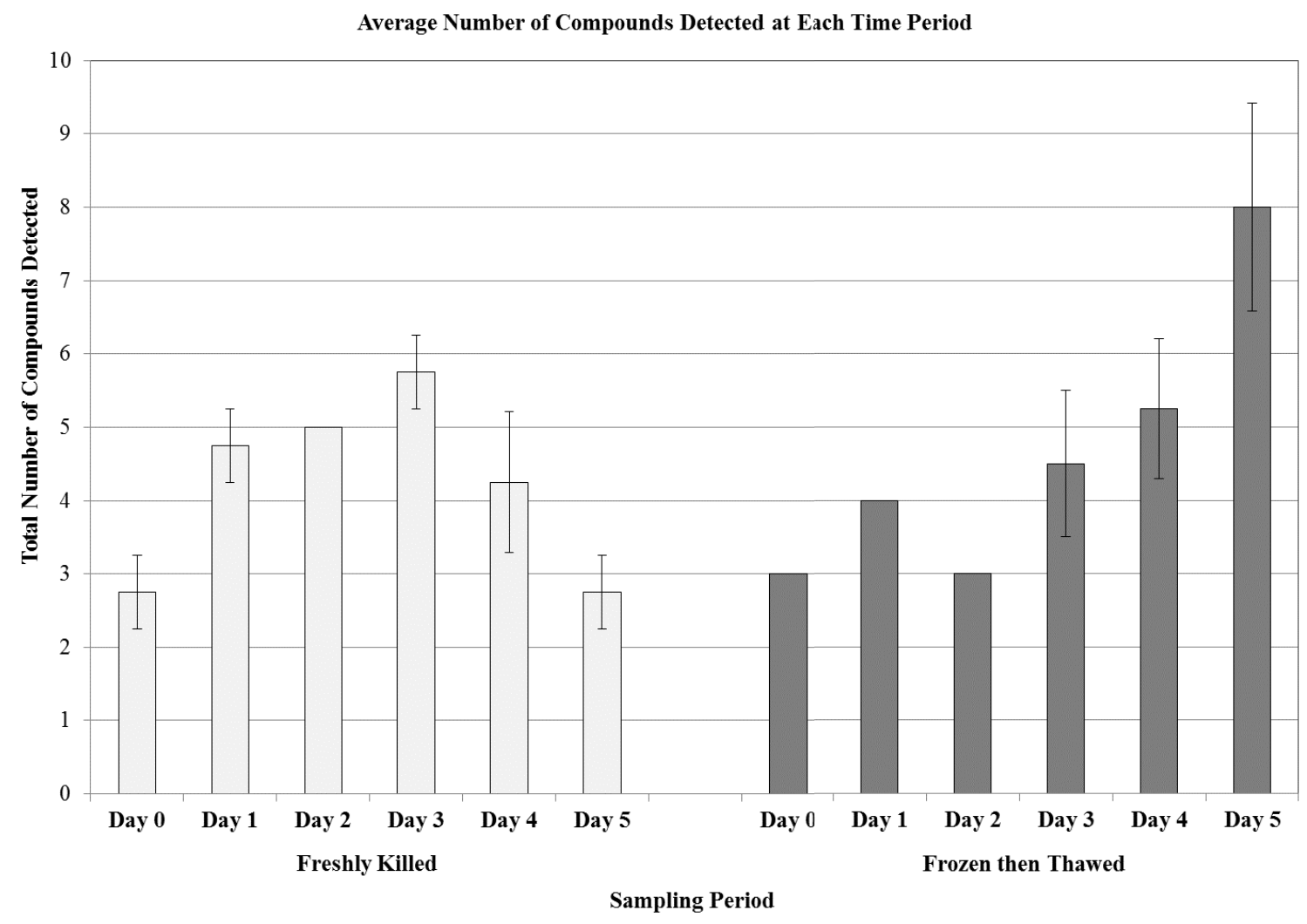

Figure 29: Bar graph showing the average number of common compounds detected from both types of remains. Error bars represent the standard deviation between trials; those without signifies that there was no deviations within that trial. 


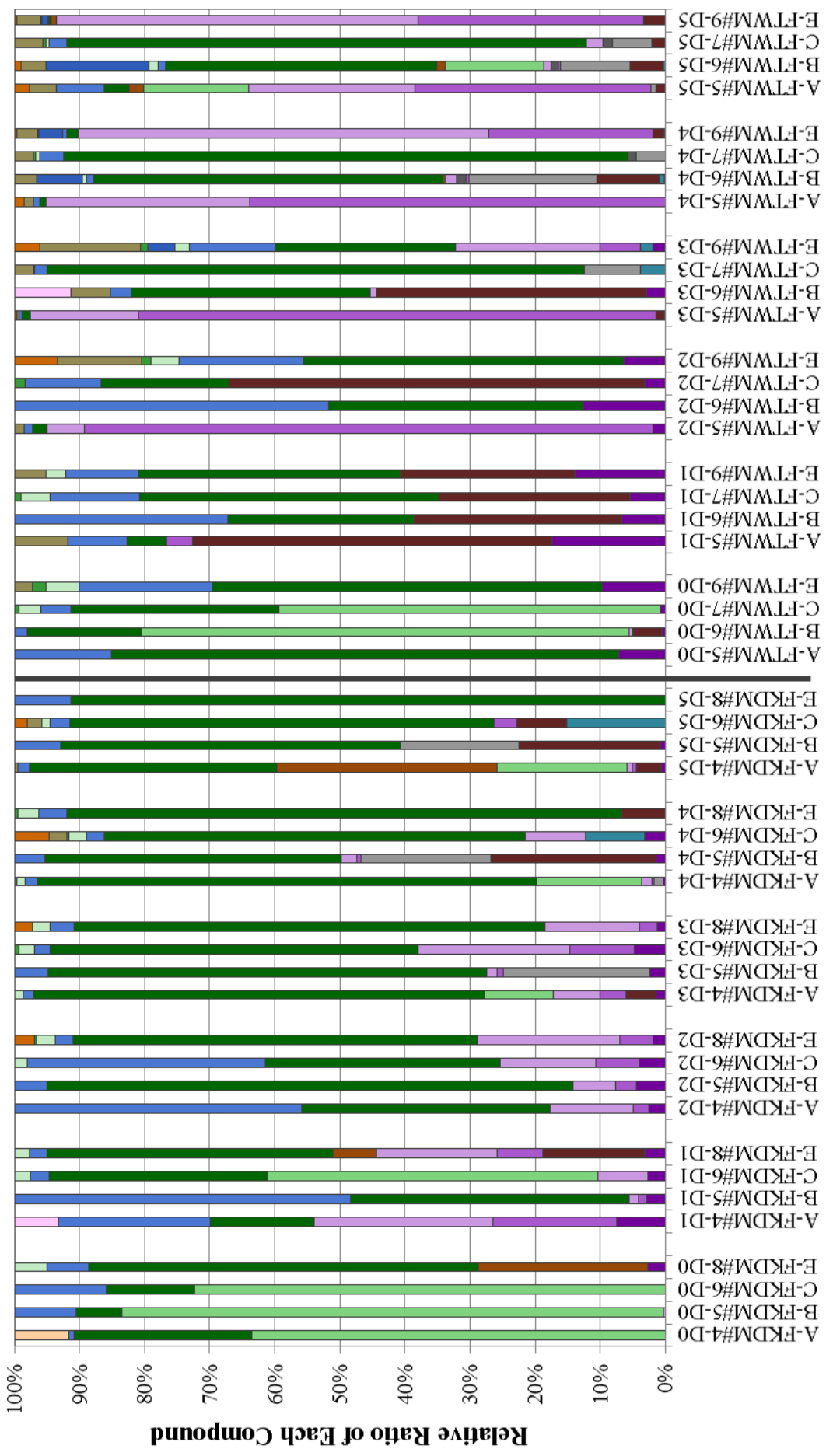

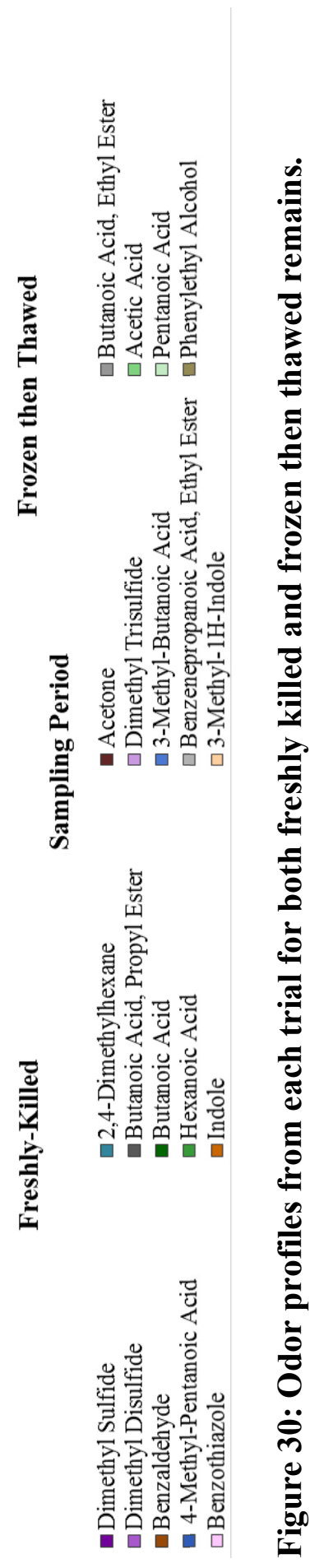


with those findings.

The chemical functional group contributions were assessed using the common VOCs that were discovered. If a compound was present within the four trials, a point value of 1 was assigned, and if it was not present, a point value of 0 was given. The total points for each functional group (alcohols, aldehydes, carboxylic acids, esters, ketones, nitrogen- and sulfur-containing) were calculated and a pie chart was created. For the purpose of simplicity Days 0, 3, and 5 are presented in Figure 31. These results further demonstrated the change in VOCs over time. For the FKD remains, carboxylic acids were more predominant on Days 0 and 5; however, in Day 3 their contribution to the odor profile decreased causing the sulfur-containing compounds to become the main chemical class. Similarly, for the FTW remains, carboxylic acids were predominant, but some sulfur-containing compounds were present, unlike that of the freshly killed mice. On Day 3, alcohols appeared, alongside the carboxylic acids and sulfur-containing compounds, representing $22 \%$ of the total VOCs emitted; nonetheless, carboxylic acids were still the predominant chemical class differing from the FKD remains. On Day 5, a clear distinction between the FKD and FTW remains was observed with respect to the chemical functional groups, as four additional chemical classes emerged; they were aldehydes, esters, ketones, and nitrogen-containing compounds with carboxylic acids and sulfur-containing compounds contributing most with $25 \%$ and $22 \%$, respectively. 
FKD Day 0

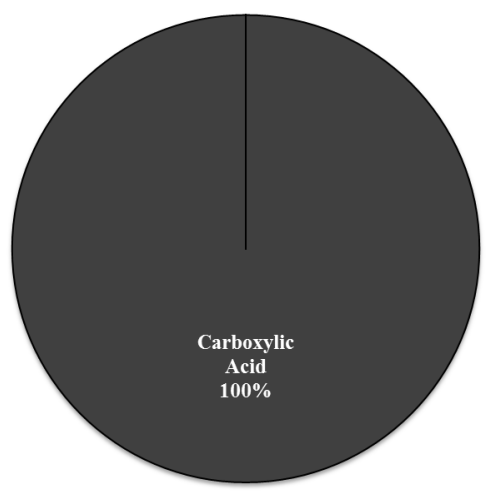

FKD Day 3

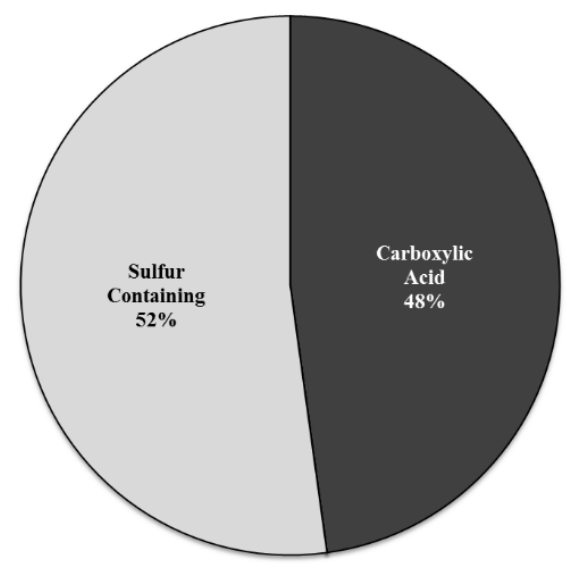

FKD Day 5

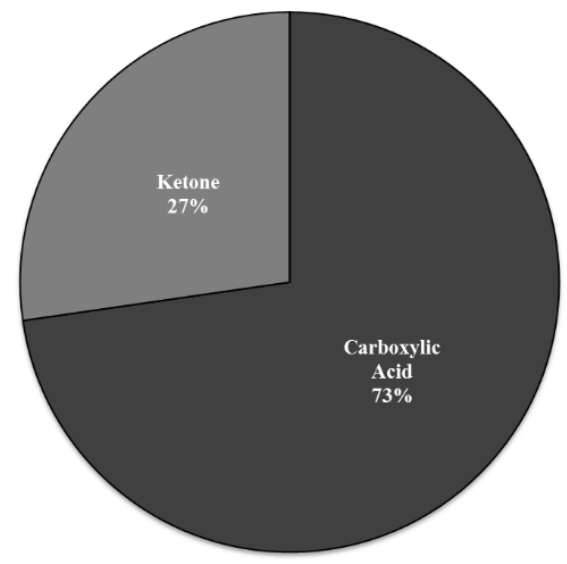

FTW DAY 0

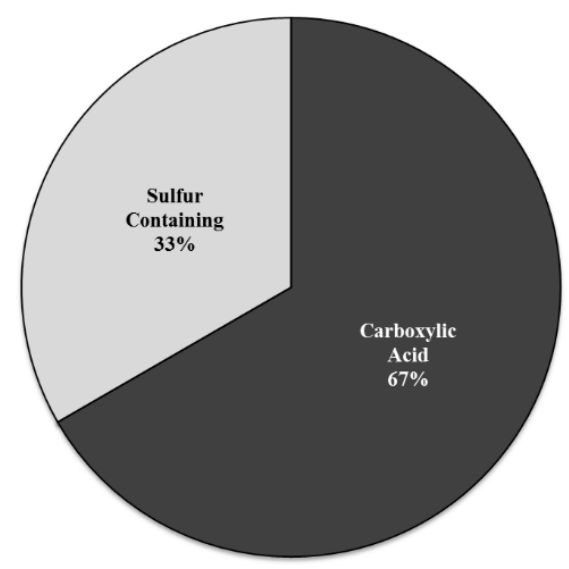

FTW DAY 3

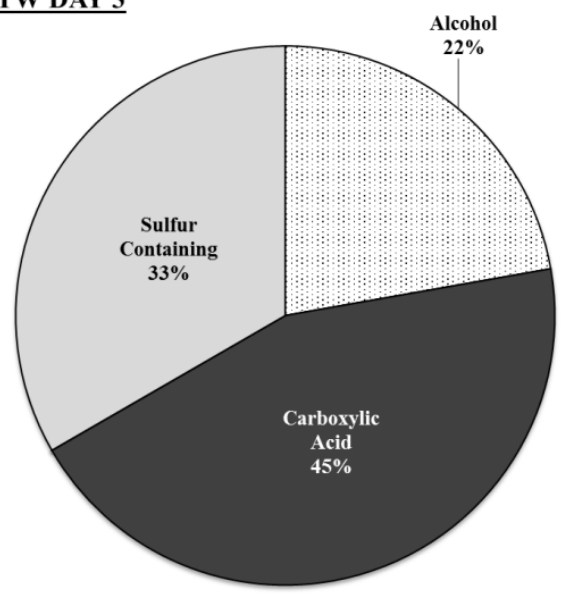

FTW DAY 5

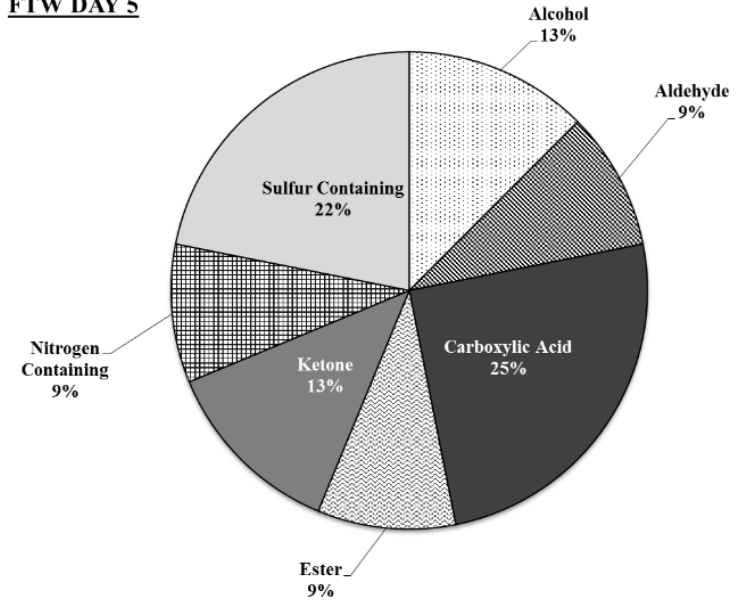

Figure 31: Distribution of chemical functional groups for Days 0, 3, and 5. 
5.4. Assessment of the VOCs Released from Decomposing Remains in their Natural State

The purpose of this study was to evaluate the VOCs released from decomposing remains, during different stages of decomposition, in their natural state. Additionally, the results obtained from this study were to be used for comparisons with future studies involving decomposing remains in non-natural states, such as aquatic and soil environments.

\subsubsection{Human Cadaver Analogues}

Five freshly killed adult, transgenic mice that were housed and fed identically were used; their specifications are listed in Table 15. The mean weight was $29.4 \mathrm{~g}$ with a range of 26-36 $\mathrm{g}$ and the average total length was $17.0 \mathrm{~cm}$ with a range of $16.3-17.5 \mathrm{~cm}$. All mice were euthanized within 1 hour of field placement.

Table 15: Mice specifications.

\begin{tabular}{|c|c|c|c|c|c|}
\hline Mouse & Gender & Weight $(\mathbf{g})$ & $\begin{array}{c}\text { Body } \\
\text { Length } \\
\mathbf{( c m})\end{array}$ & $\begin{array}{c}\text { Tail Length } \\
\mathbf{( c m )}\end{array}$ & $\begin{array}{c}\text { Total } \\
\text { Length } \\
\mathbf{( c m )}\end{array}$ \\
\hline 1 & Female & 36 & 8.7 & 8.4 & 17.1 \\
\hline 2 & Female & 26 & 9.0 & 8.5 & 17.5 \\
\hline 3 & Male & 27 & 7.9 & 8.4 & 16.3 \\
\hline 4 & Male & 30 & 8.8 & 8.6 & 17.4 \\
\hline 5 & Male & 28 & 8.7 & 8.2 & 16.9 \\
\hline
\end{tabular}


5.4.2. Temperature and Relative Humidity of Environment

Using four micro-t loggers the average temperature and relative humidity were determined from hourly measurements that were collected throughout the course of the study (Table 16). The hourly temperature measurements showed a steady increase a little before noon where then the maximum temperature was reached and then a steady decrease as evening approached (Figure 32).

Table 16: The average temperature and relative humidity calculated throughout the course of the trial.

\begin{tabular}{|c|c|c|c|}
\hline \multicolumn{2}{|c|}{ Average Temperature $\left({ }^{\circ} \mathbf{C}\right)$} & \multicolumn{2}{c|}{ Average Relative Humidity (\%) } \\
\hline $\begin{array}{c}\text { Day 0 } \\
(10: 00-23: 00 \text { Hours })\end{array}$ & 26.1 & $\begin{array}{c}\text { Day 0 } \\
(10: 00-23: 00 \text { Hours })\end{array}$ & 91.4 \\
\hline $\begin{array}{c}\text { Day 1 } \\
(00: 00-23: 00 \text { Hours })\end{array}$ & 25.0 & $\begin{array}{c}\text { Day 1 } \\
(00: 00-23: 00 \text { Hours })\end{array}$ & 96.2 \\
\hline $\begin{array}{c}\text { Day 2 } \\
(00: 00-23: 00 \text { Hours })\end{array}$ & 27.9 & $\begin{array}{c}\text { Day 2 } \\
(00: 00-23: 00 \text { Hours })\end{array}$ & 83.9 \\
\hline $\begin{array}{c}\text { Day 3 } \\
(00: 00-23: 00 \text { Hours })\end{array}$ & 28.4 & $\begin{array}{c}\text { Day 3 } \\
(00: 00-23: 00 \text { Hours })\end{array}$ & 81.8 \\
\hline $\begin{array}{c}\text { Day 4 } \\
(00: 00-23: 00 \text { Hours })\end{array}$ & 29.3 & $\begin{array}{c}\text { Day 4 } \\
(00: 00-23: 00 \text { Hours })\end{array}$ & 73.4 \\
\hline $\begin{array}{c}\text { Day 5 } \\
(00: 00-23: 00 \text { Hours })\end{array}$ & 28.1 & $\begin{array}{c}\text { Day 5 } \\
(00: 00-23: 00 \text { Hours })\end{array}$ & 78.0 \\
\hline $\begin{array}{c}\text { Day 6 } \\
(00: 00-23: 00 \text { Hours })\end{array}$ & 25.5 & $\begin{array}{c}\text { Day 6 } \\
(00: 00-23: 00 \text { Hours })\end{array}$ & 92.8 \\
\hline $\begin{array}{c}\text { Day 7 } \\
(00: 00-23: 00 \text { Hours })\end{array}$ & 26.2 & $\begin{array}{c}\text { Day 7 } \\
(00: 00-23: 00 \text { Hours })\end{array}$ & 91.0 \\
\hline $\begin{array}{c}\text { Day 8 } \\
(00: 00-23: 00 \text { Hours })\end{array}$ & 29.1 & $\begin{array}{c}\text { Day 8 } \\
(00: 00-23: 00 \text { Hours })\end{array}$ & 76.3 \\
\hline $\begin{array}{c}\text { Day 9 } \\
(00: 00-23: 00 \text { Hours })\end{array}$ & 27.5 & $\begin{array}{c}\text { Day 9 } \\
(00: 00-23: 00 \text { Hours })\end{array}$ & 83.4 \\
\hline $\begin{array}{c}\text { Day 10 } \\
(00: 00-13: 30 \text { Hours })\end{array}$ & 26.6 & $\begin{array}{c}\text { Day 10 } \\
(00: 00-13: 30 \text { Hours })\end{array}$ & 75.3 \\
\hline
\end{tabular}




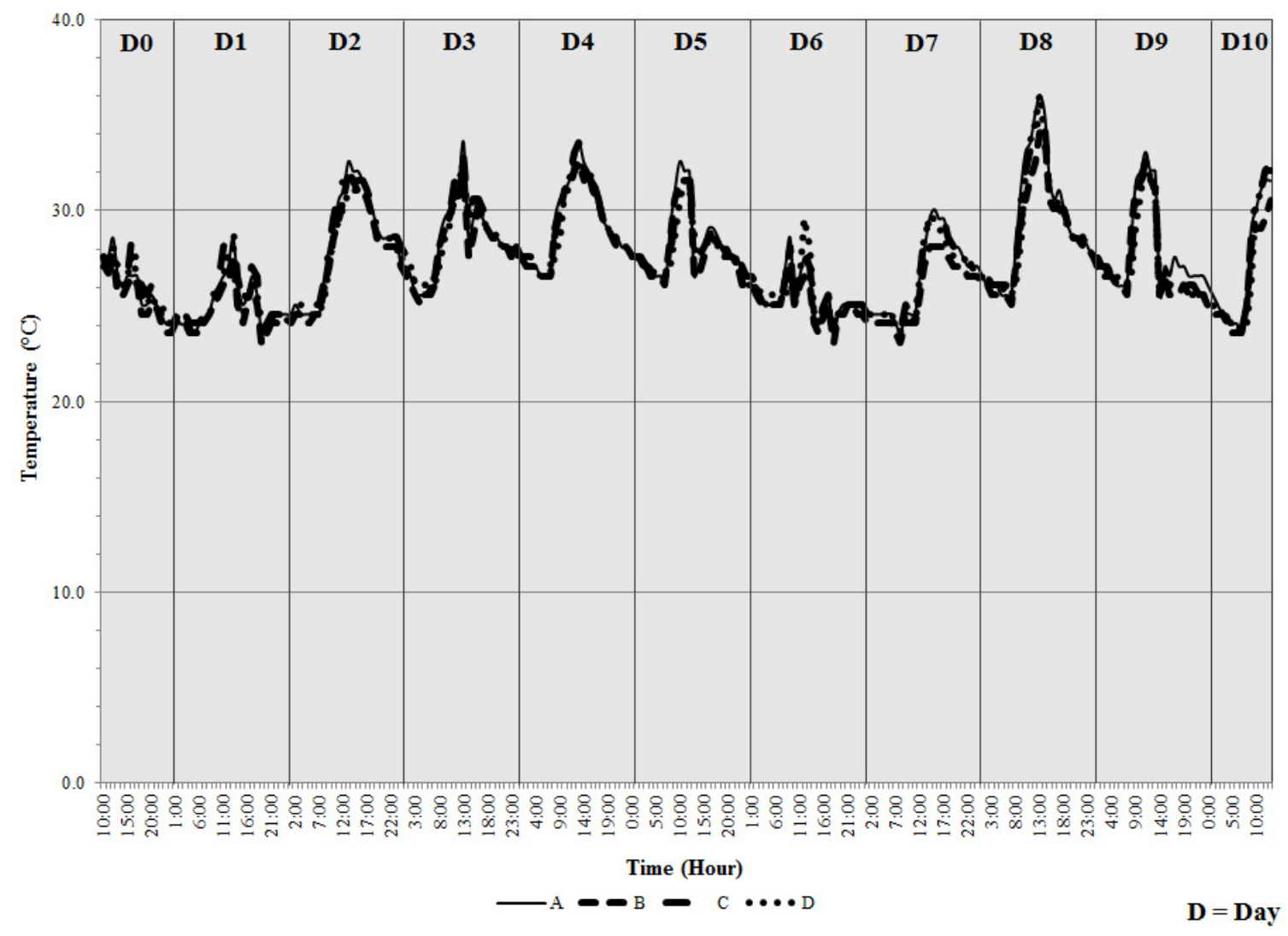

Figure 32: Line graph representing the hourly temperature recordings for each micro-t logger, labelled A-D.

\subsubsection{Visual Observations}

Photographs of all mice were taken on the day they were sampled throughout the course of the trial. For the purpose of simplicity, photos taken of one mouse are presented in Figure 33. Different stages of the decomposition process were observed and based upon the physical characteristics that described each stage, Day 0 would be recognized as fresh, Days 2 and 4 would be considered bloat, Days 6 and 8 as active decay, and Day 10 advanced decay. 


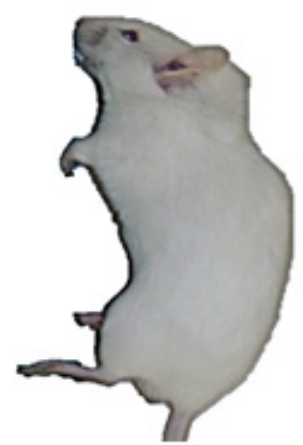

Day 0

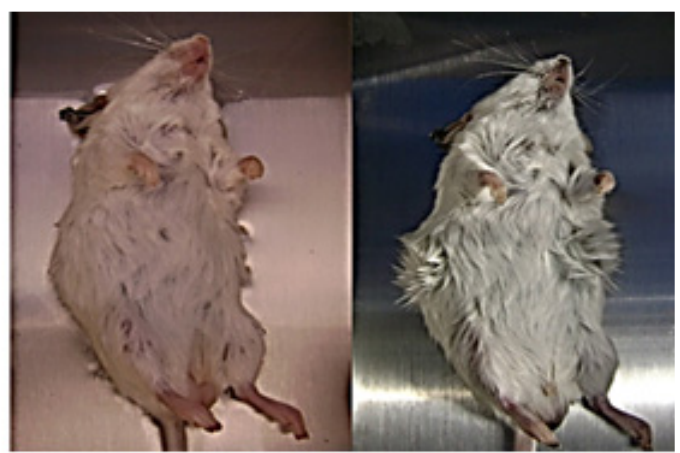

Day 2

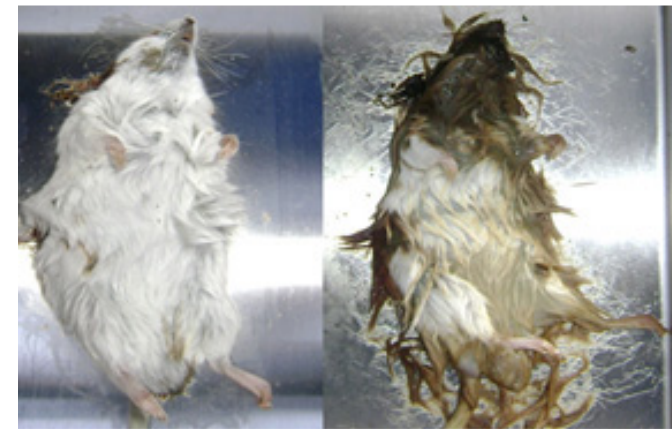

Day 6
Day 8
Day 4

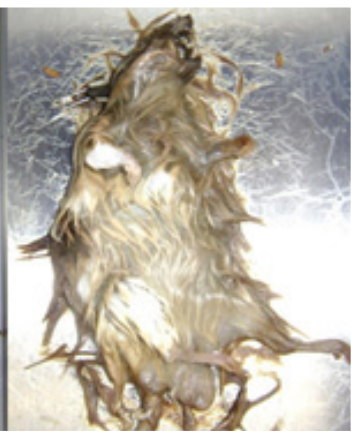

Day 10

Figure 33: Human cadaver analogue progressing through different stages of decomposition.

\subsubsection{Volatile Organic Compounds Detected from Decomposing Remains}

In this study, a total of eighteen VOCs, from various chemical functional groups were extracted and analyzed via HS-SPME/GC-MS. Using the Varian MS Workstation Software, Version 6.6 (Service Pack 1), all compounds detected were verified and quantitated using a seven-point external calibration curve that consisted of diluted standard mixtures (see Section 4.1.1. for listing). Table 17 displays the presence/absence of the compounds that were identified, in a minimum of one mouse, over the course of 
the study. From the data presented, it should be noted that butanoic acid, 3-methylbutanoic acid, pentanoic acid, hexanoic acid, and indole remained consistent as it was detected at all sampling periods unlike 2-methyl-hexanoic acid which appeared on Day 10. Butanoic acid ethyl ester and acetone showed variability as it appeared and disappeared at different periods throughout the study.

Table 17: The volatile organic compounds detected in a minimum of one mouse over the course of the study. An " $X$ " indicates that the compound was present.

\begin{tabular}{|c|c|c|c|c|c|c|c|}
\hline CAS\# & Compound Name & DAY 0 & DAY 2 & DAY 4 & DAY 6 & DAY 8 & DAY 10 \\
\hline $75-18-3$ & Dimethyl Sulfide & $\mathbf{X}$ & $\mathbf{X}$ & $\mathbf{X}$ & $\mathbf{X}$ & $\mathbf{X}$ & \\
\hline $589-43-5$ & 2,4-Dimethylhexane & & & & & $\mathbf{X}$ & \\
\hline $67-64-1$ & Acetone & & $\mathbf{X}$ & & $\mathbf{X}$ & $\mathbf{X}$ & $\mathbf{X}$ \\
\hline $105-54-4$ & Butanoic Acid, Ethyl Ester & & $\mathbf{X}$ & & & $\mathbf{X}$ & \\
\hline $624-92-0$ & Dimethyl Disulfide & & $\mathbf{X}$ & $\mathbf{X}$ & $\mathbf{X}$ & $\mathbf{X}$ & $\mathbf{X}$ \\
\hline $3777-69-3$ & 2-Pentyl Furan & & & & $\mathbf{X}$ & $\mathbf{X}$ & $\mathbf{X}$ \\
\hline $3658-80-8$ & Dimethyl Trisulfide & & $\mathbf{X}$ & $\mathbf{X}$ & $\mathbf{X}$ & $\mathbf{X}$ & $\mathbf{X}$ \\
\hline $64-19-7$ & Acetic Acid & & & $\mathbf{X}$ & $\mathbf{X}$ & $\mathbf{X}$ & $\mathbf{X}$ \\
\hline $100-52-7$ & Benzaldehyde & & & $\mathbf{X}$ & $\mathbf{X}$ & $\mathbf{X}$ & $\mathbf{X}$ \\
\hline $107-92-6$ & Butanoic Acid & $\mathbf{X}$ & $\mathbf{X}$ & $\mathbf{X}$ & $\mathbf{X}$ & $\mathbf{X}$ & $\mathbf{X}$ \\
\hline $503-74-2$ & 3-Methyl-Butanoic Acid & $\mathbf{X}$ & $\mathbf{X}$ & $\mathbf{X}$ & $\mathbf{X}$ & $\mathbf{X}$ & $\mathbf{X}$ \\
\hline $109-52-4$ & Pentanoic Acid & $\mathbf{X}$ & $\mathbf{X}$ & $\mathbf{X}$ & $\mathbf{X}$ & $\mathbf{X}$ & $\mathbf{X}$ \\
\hline $646-07-1$ & 4-Methyl-Pentanoic Acid & & $\mathbf{X}$ & $\mathbf{X}$ & $\mathbf{X}$ & $\mathbf{X}$ & $\mathbf{X}$ \\
\hline $142-62-1$ & Hexanoic Acid & $\mathbf{X}$ & $\mathbf{X}$ & $\mathbf{X}$ & $\mathbf{X}$ & $\mathbf{X}$ & $\mathbf{X}$ \\
\hline $4536-23-6$ & 2-Methyl-Hexanoic Acid & & & & & $\mathbf{X}$ & $\mathbf{X}$ \\
\hline $2021-28-5$ & Benzenepropanoic Acid, Ethyl Ester & & & & $\mathbf{X}$ & $\mathbf{X}$ & $\mathbf{X}$ \\
\hline $60-12-8$ & Phenylethyl Alcohol & & $\mathbf{X}$ & $\mathbf{X}$ & $\mathbf{X}$ & $\mathbf{X}$ & $\mathbf{X}$ \\
\hline $120-72-9$ & Indole & $\mathbf{X}$ & $\mathbf{X}$ & $\mathbf{X}$ & $\mathbf{X}$ & $\mathbf{X}$ & $\mathbf{X}$ \\
\hline
\end{tabular}

The odor profiles of each mouse over time were created using the compounds that were listed in Table 17 (Figure 34). Each color bar represents a different VOC and its length is representative of the relative abundance or percent of that compound to the total composition of the decomposition odors that were generated. From the odor profiles, it can be observed that the detected compounds and abundances change as the remains decompose. Interestingly, the mice decomposed differently, although they were housed 
in the same environment, consumed the same diet, and were euthanized and placed in the field at the exact time. Moreover, the sulfur-containing compounds (shaded in purple) which are attractants of carrion insects, contributed greatly to the odor profiles $[121,150]$.
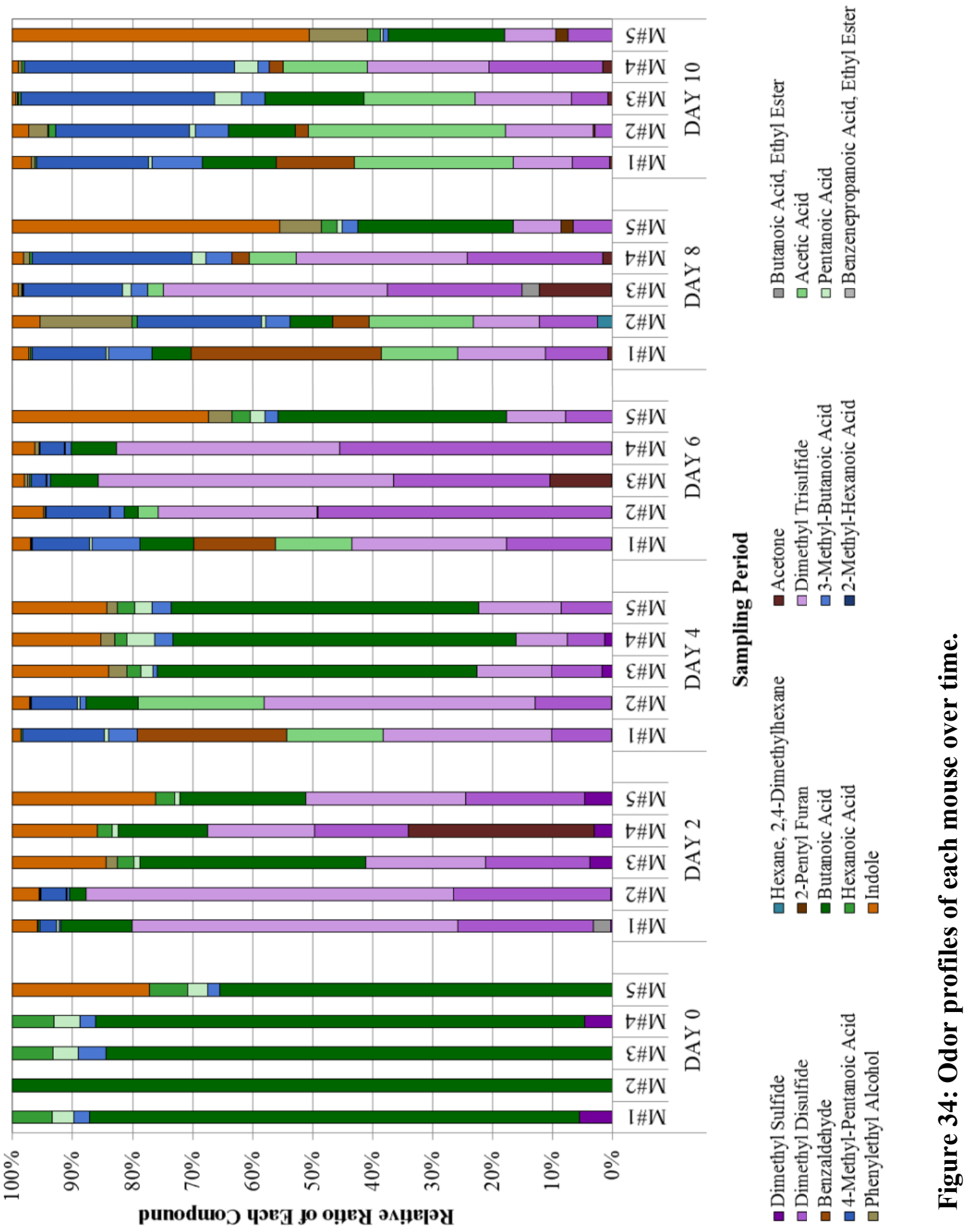


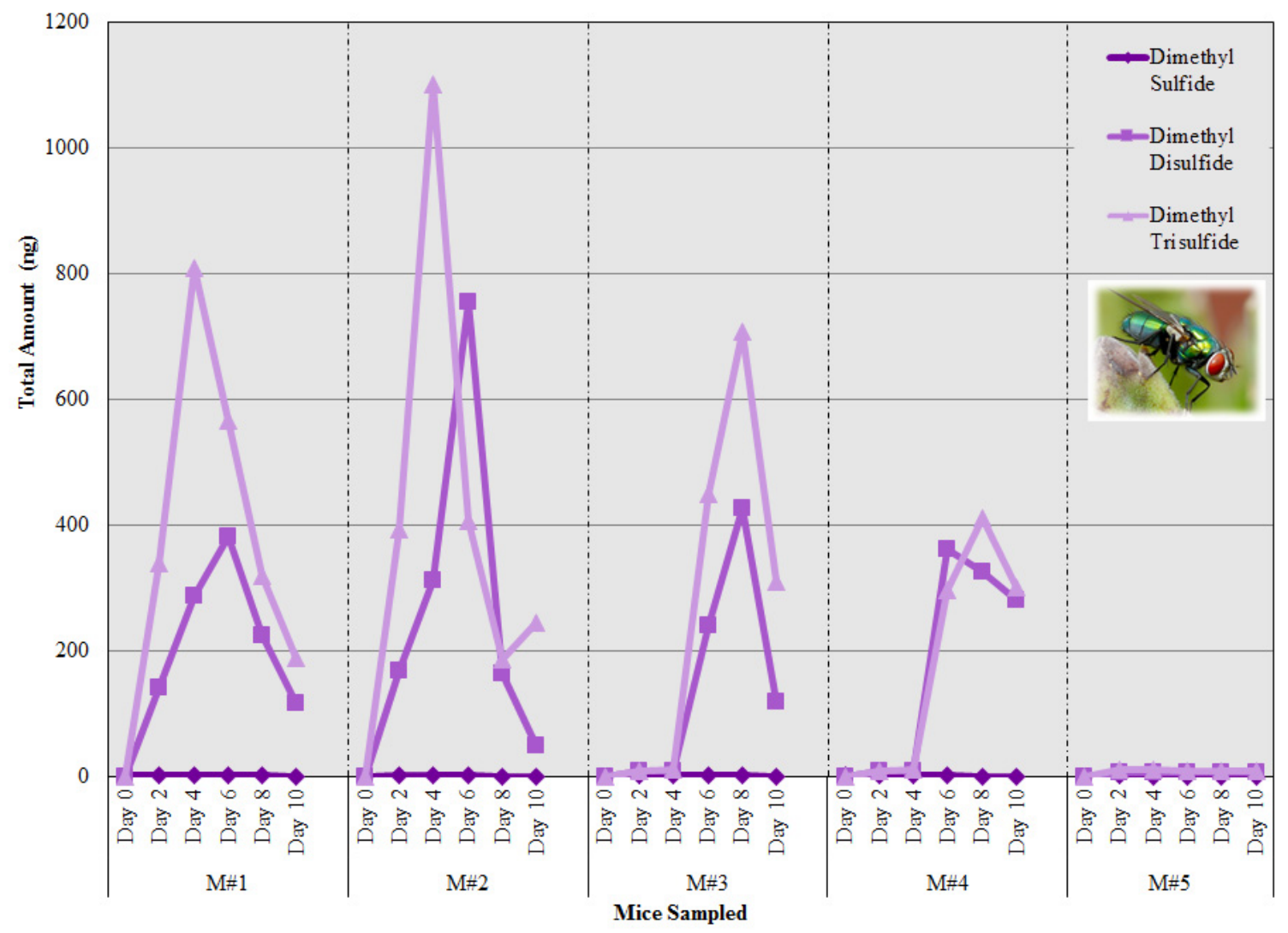

Figure 35: Amount of dimethyl sulfide, disulfide, and trisulfide present in each mouse over time. The image embedded into the graph is that of a blow fly, an insect attracted to carrion.

Figure 35 shows the total amount of dimethyl sulfide, disulfide, and trisulfide for each mouse over the ten day sampling period. When dimethyl disulfide and trisulfide were most abundant, a minimum of one blow fly, an insect attracted to carrion, was observed during sampling. As both compounds decreased, maggots of varying sizes appeared. The image embedded in Figure 35 is an example of a blow fly [151].

Statistical analysis using principal components analysis (PCA) was performed on the normalized data that was collected from each mouse over time. A plot of the first three principal components (Figure 36) revealed two distinct clusters which, from this point forward, will be referred to as Phase I and II. Upon closer examination of the data, 


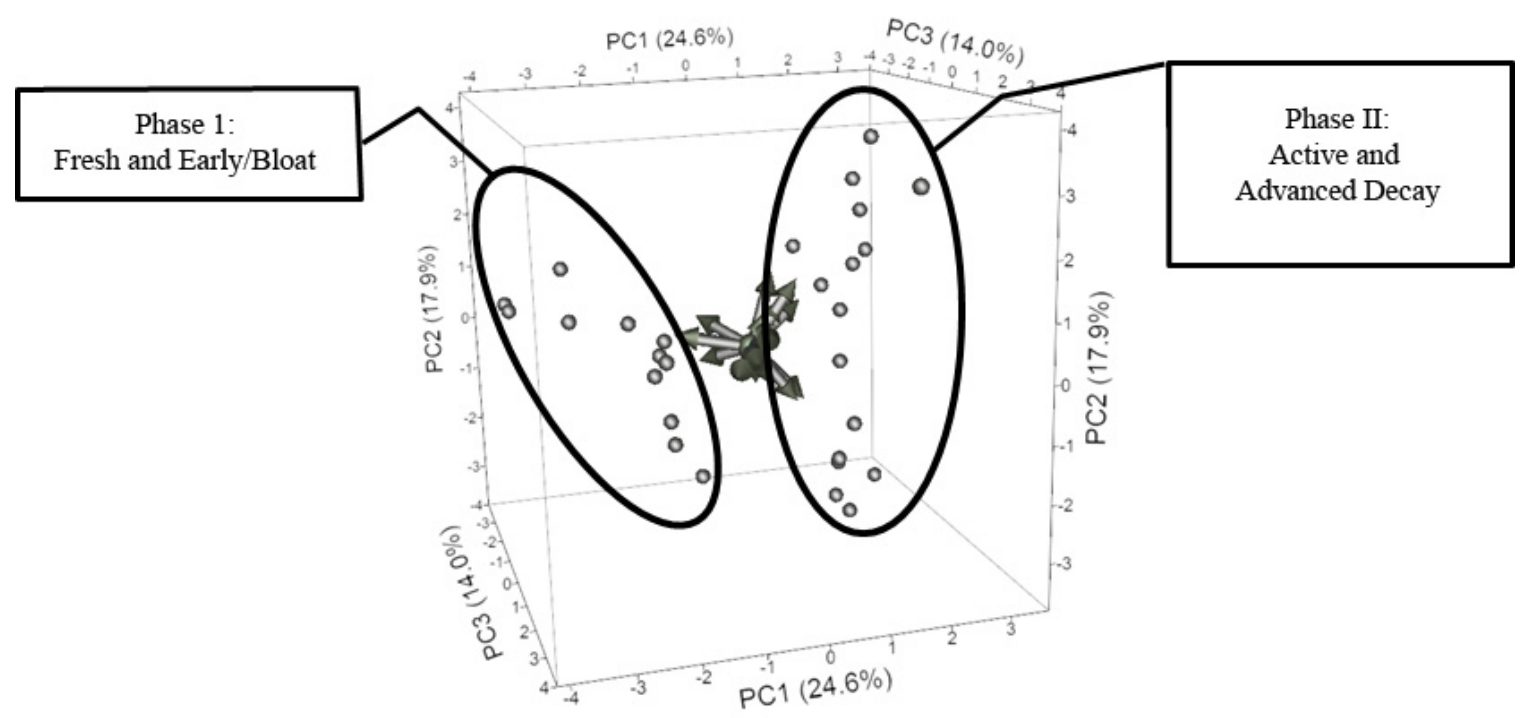

Figure 36: PCA of all mice sampled over time revealing two clusters labelled Phase I and II.

along with observations that were documented during sampling, the formation of the two clusters were dependent upon the stage of decomposition (i.e., fresh, early/bloat, active, and advanced decay) in which the remains were in. Therefore, Phase I consisted of remains that were in the Fresh or Early/Bloat stage and Phase II consisted of remains that were in the Active or Advanced Decay stage. Upon further investigation, it was discovered that through the analysis of the VOCs released from decomposing remains, the progression of decomposition from fresh to advanced decay was discernable using PCA analysis (Figure 37). Aside from the three-dimensional scatterplot, the loading plot was also analyzed revealing the compounds that were causing the formation of the four clusters. For instance, in the Fresh stage, hexanoic acid, butanoic acid, pentanoic acid, and the lack of dimethyl sulfide were the compounds driving that cluster formation. The addition of indole, dimethyl disulfide, dimethyl trisulfide, and 2-pentyl furan aids in the 


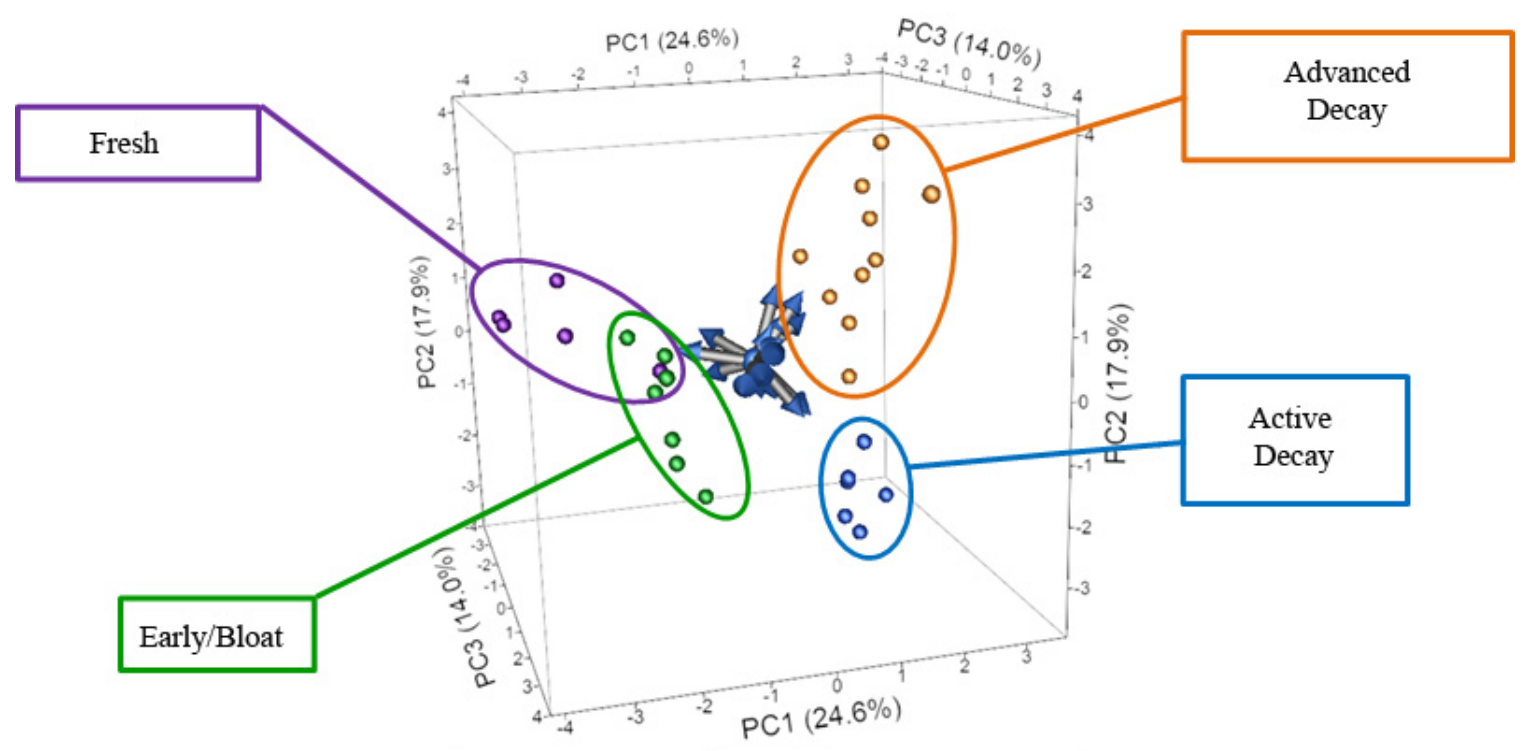

Figure 37: PCA analysis showing four clusters which is representative of four stages of decomposition.

migration from Fresh to the Early/Bloat stage. The minimal appearance of acetone, butanoic acid ethyl ester, and benzenepropanoic acid ethyl ester leads to the clear divide between Phase I and II. The Active Decay stage was driven by dimethyl sulfide, dimethyl disulfide, and dimethyl trisulfide, whereas the formation of the Advanced Decay cluster was aided by the presence of acetic acid, benzaldehyde, 3-methyl-butanoic acid, and 4-methyl-pentanoic acid.

Hierarchical cluster analysis was also performed on the normalized data obtained from each mouse over time (Figure 38). Groupings within the dendogram highlight the similarities between the mice resulting in the formation of clusters that correlate to a specific stage of decomposition. Thus, the findings from HCA were in agreement with PCA - there are specific compounds that are associated with the different phases of decay. Table 18 lists the compounds associated with each of stage of decomposition, as 

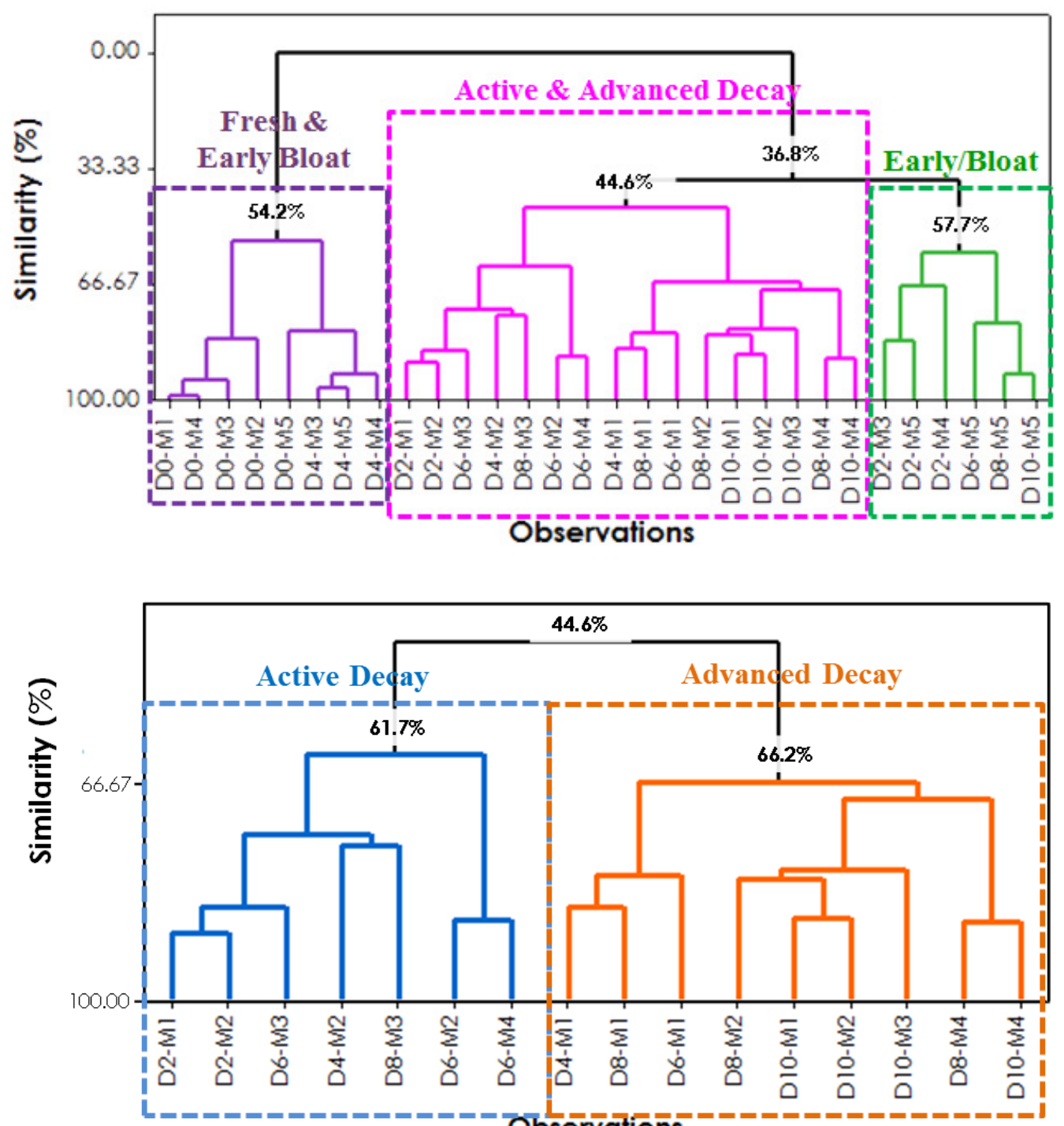

Observations

D: Day

M: Mouse

Figure 38: HCA analysis of mice sampled over time revealing cluster formations for each stage of decomposition.

well as the day each mouse was sampled. As decomposition progresses, changes in the compounds that comprise each stage were observed. For instance, in the Fresh stage, six compounds were detected, as decomposition progressed into the Early/Bloat stage, five additional compounds appeared. The process continued with the addition of four compounds in the active decay stage and two additional VOCs in the advanced decay 


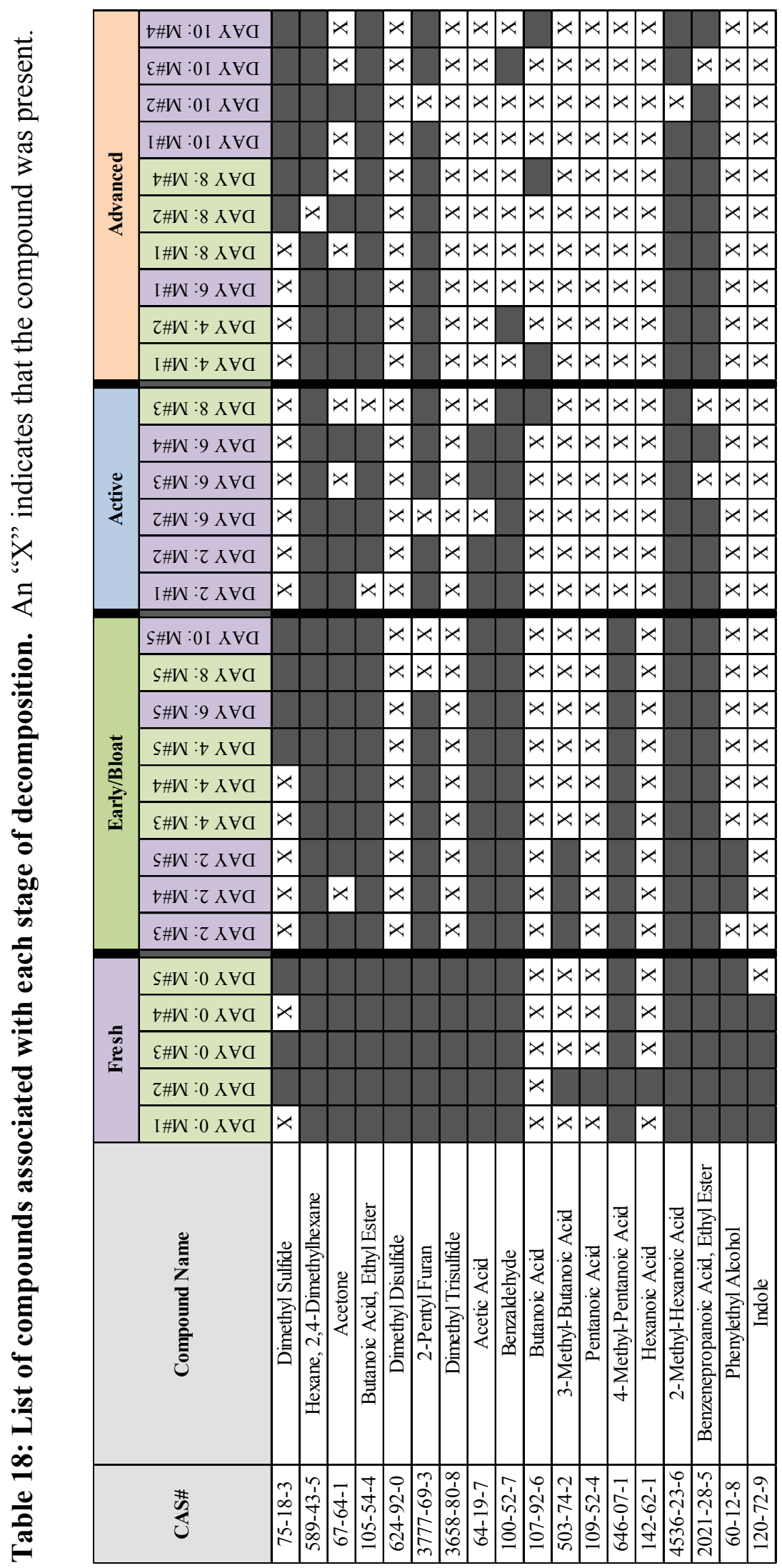


stage. To compliment Table 18 the odor profiles of each mouse separated by stage of decay is presented in Figure 39 where the similarities between each mouse, within each phase of decomposition, is visually clear.

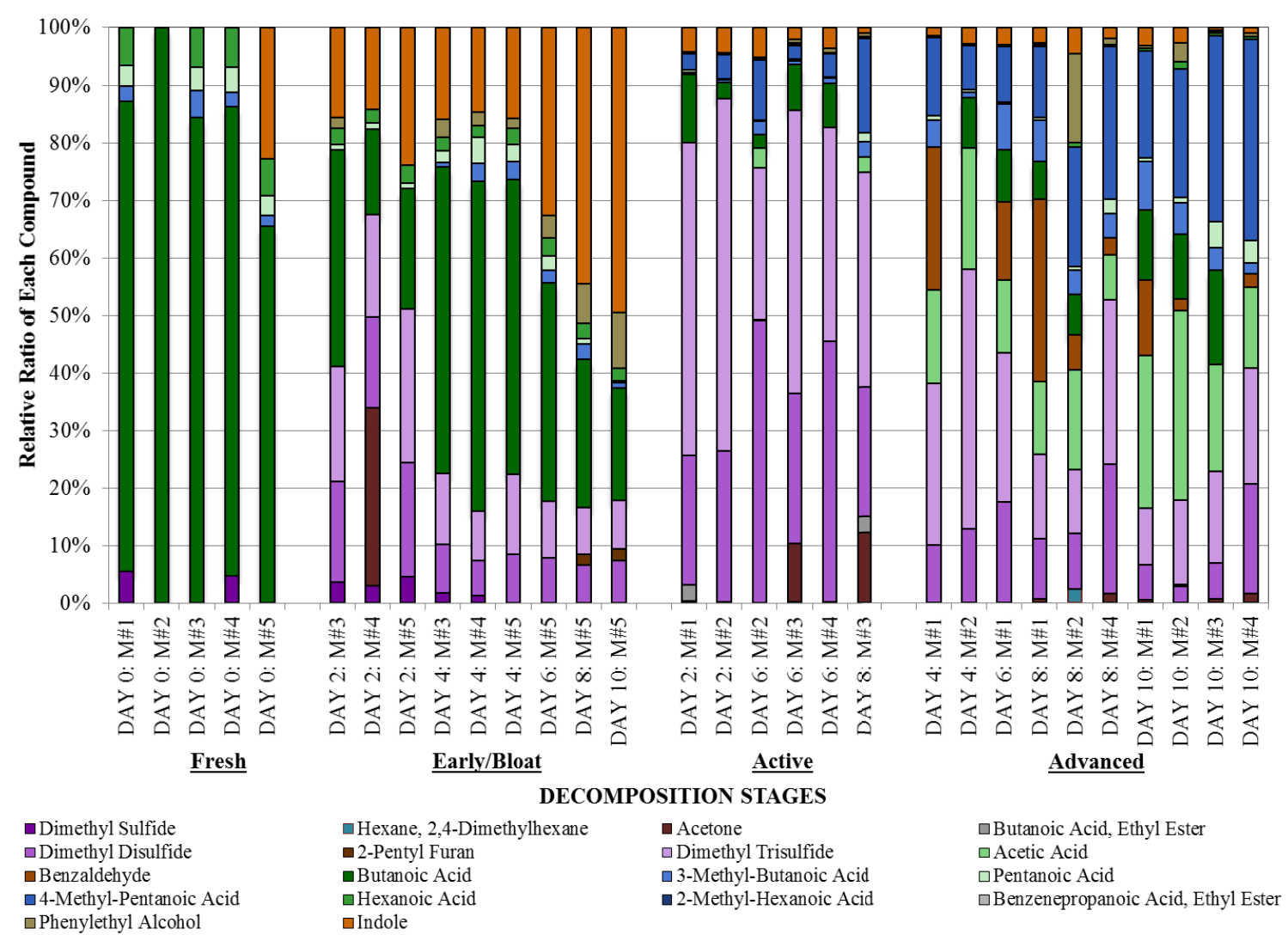

Figure 39: Odor profiles of each mouse by stage of decomposition.

5.5. Evaluation of the VOCs Released from Decomposing Remains Submerged in Different Aquatic Environments

The purpose of this task was to investigate the effects that different aquatic environments have on the compounds released from decomposing remains by 
submerging them in HPLC-grade and synthetic sea water. Headspace and direct immersion SPME were employed in this study to evaluate both the liberated VOCs and the compounds that were not readily released from the water.

\subsubsection{Human Cadaver Analogues}

Twelve freshly killed adult, transgenic mice that were housed and fed identically were used; their specifications are listed in Table 19 and 20. Their average mass of the female mice was $25 \mathrm{~g}$, with a range of $19-32 \mathrm{~g}$, and $32 \mathrm{~g}$ for the male mice, with a range of 20-45 grams. The average total lengths of the female and male mice were $16.6 \mathrm{~cm}$ and $15.7 \mathrm{~cm}$, respectively. Two trials were performed for each aquatic environment.

Table 20: Mice specifications for HPLC-grade water environment.

\begin{tabular}{|c|c|c|c|c|c|}
\hline \multicolumn{6}{|c|}{ HPLC-Grade Water } \\
\hline Trial & Gender & Weight (g) & Body Length (cm) & Tail Length (cm) & Total Length (cm) \\
\hline \multirow{3}{*}{1} & Female & 21 & 9.3 & 8.5 & 17.8 \\
\cline { 2 - 6 } & Female & 19 & 9.3 & 8.4 & 17.7 \\
\cline { 2 - 6 } & Female & 22 & 8.9 & 8.4 & 17.3 \\
\hline \multirow{3}{*}{2} & Female & 32 & 8.3 & 7.4 & 15.7 \\
\cline { 2 - 6 } & Female & 29 & 8.0 & 7.6 & 15.6 \\
\cline { 2 - 6 } & Female & 28 & 8.3 & 7.4 & 15.7 \\
\hline
\end{tabular}

Table 19: Mice specifications for synthetic sea water environment.

\begin{tabular}{|c|c|c|c|c|c|}
\hline \multicolumn{6}{|c|}{ Synthetic Sea Water } \\
\hline Trial & Gender & Weight (g) & Body Length (cm) & Tail Length (cm) & Total Length (cm) \\
\hline \multirow{3}{*}{1} & Male & 20 & 6.9 & 7.2 & 14.1 \\
\cline { 2 - 6 } & Male & 21 & 7.0 & 7.0 & 14.0 \\
\cline { 2 - 6 } & Male & 22 & 7.0 & 7.4 & 14.4 \\
\hline \multirow{3}{*}{2} & Male & 45 & 9.5 & 8.2 & 17.7 \\
\cline { 2 - 6 } & Male & 41 & 8.5 & 8.1 & 16.6 \\
\cline { 2 - 6 } & Male & 43 & 9.0 & 8.2 & 17.2 \\
\hline
\end{tabular}


5.5.2. Temperature and Relative Humidity of Environment

For both aquatic environments the temperature and relative humidity were measured hourly using micro t-loggers (Tables 21 and 22). Upon plotting the measured temperatures, the observed daily trend was a steady increase during the morning until it reached a maximum temperature in the afternoon and concluded with a decrease in the evening (Figures 40 and 41).

Table 21: The average temperature and relative humidity calculated throughout the course of each trial for the HPLC-grade water environment.

\begin{tabular}{|c|c|c|c|c|c|}
\hline \multicolumn{6}{|c|}{ HPLC-Grade Water } \\
\hline \multicolumn{3}{|c|}{ Average Temperature $\left({ }^{\circ} \mathrm{C}\right)$} & \multicolumn{3}{|c|}{ Average Relative Humidity (\%) } \\
\hline & Trial 1 & Trial 2 & & Trial 1 & Trial 2 \\
\hline $\begin{array}{c}\text { Day 0 } \\
(10: 00-23: 00 \text { Hours }) \\
\end{array}$ & 27.0 & 24.0 & $\begin{array}{c}\text { Day 0 } \\
(10: 00-23: 00 \text { Hours }) \\
\end{array}$ & 80.2 & 66.7 \\
\hline $\begin{array}{c}\text { Day 1 } \\
(00: 00-23: 00 \text { Hours }) \\
\end{array}$ & 26.3 & 23.1 & $\begin{array}{c}\text { Day 1 } \\
\text { (00:00-23:00 Hours) } \\
\end{array}$ & 83.1 & 74.7 \\
\hline $\begin{array}{c}\text { Day } 2 \\
(00: 00-23: 00 \text { Hours }) \\
\end{array}$ & 25.6 & 23.8 & $\begin{array}{c}\text { Day } 2 \\
(00: 00-23: 00 \text { Hours }) \\
\end{array}$ & 81.7 & 72.8 \\
\hline $\begin{array}{c}\text { Day } 3 \\
(00: 00-23: 00 \text { Hours }) \\
\end{array}$ & 23.8 & 24.4 & $\begin{array}{c}\text { Day } 3 \\
(00: 00-23: 00 \text { Hours }) \\
\end{array}$ & 83.6 & 77.6 \\
\hline $\begin{array}{c}\text { Day } 4 \\
(00: 00-23: 00 \text { Hours }) \\
\end{array}$ & 22.0 & 22.6 & $\begin{array}{c}\text { Day } 4 \\
\text { (00:00-23:00 Hours) } \\
\end{array}$ & 79.4 & 75.8 \\
\hline $\begin{array}{c}\text { Day } 5 \\
(00: 00-23: 00 \text { Hours }) \\
\end{array}$ & 22.2 & 22.3 & $\begin{array}{c}\text { Day } 5 \\
(00: 00-23: 00 \text { Hours }) \\
\end{array}$ & 83.9 & 73.7 \\
\hline $\begin{array}{c}\text { Day 6 } \\
(00: 00-23: 00 \text { Hours })\end{array}$ & 23.3 & 23.2 & $\begin{array}{c}\text { Day 6 } \\
\text { (00:00-23:00 Hours) } \\
\end{array}$ & 79.5 & 75.2 \\
\hline $\begin{array}{c}\text { Day } 7 \\
(00: 00-23: 00 \text { Hours }) \\
\end{array}$ & 24.0 & 24.2 & $\begin{array}{c}\text { Day } 7 \\
\text { (00:00-23:00 Hours) } \\
\end{array}$ & 77.4 & 78.3 \\
\hline $\begin{array}{c}\text { Day } 8 \\
(00: 00-23: 00 \text { Hours }) \\
\end{array}$ & 25.2 & 24.9 & $\begin{array}{c}\text { Day 8 } \\
(00: 00-23: 00 \text { Hours }) \\
\end{array}$ & 76.3 & 81.1 \\
\hline $\begin{array}{c}\text { Day } 9 \\
(00: 00-23: 00 \text { Hours }) \\
\end{array}$ & 24.4 & 24.3 & $\begin{array}{c}\text { Day } 9 \\
\text { (00:00-23:00 Hours) } \\
\end{array}$ & 71.9 & 81.3 \\
\hline $\begin{array}{c}\text { Day 10 } \\
(00: 00-13: 30 \text { Hours }) \\
\end{array}$ & 23.4 & 19.6 & $\begin{array}{c}\text { Day 10 } \\
(00: 00-13: 30 \text { Hours }) \\
\end{array}$ & 74.9 & 98.7 \\
\hline
\end{tabular}


Table 22: The average temperature and relative humidity calculated throughout the course of each trial for the synthetic sea water environment.

\begin{tabular}{|c|c|c|c|c|c|}
\hline \multicolumn{6}{|c|}{ Synthetic Sea Water } \\
\hline \multicolumn{3}{|c|}{ Average Temperature $\left({ }^{\circ} \mathrm{C}\right)$} & \multicolumn{3}{|c|}{ Average Relative Humidity (\%) } \\
\hline & Trial 1 & Trial 2 & & Trial 1 & Trial 2 \\
\hline $\begin{array}{c}\text { Day 0 } \\
(10: 00-23: 00 \text { Hours }) \\
\end{array}$ & 25.5 & 29.5 & $\begin{array}{c}\text { Day 0 } \\
(10: 00-23: 00 \text { Hours }) \\
\end{array}$ & 88.9 & 70.3 \\
\hline $\begin{array}{c}\text { Day 1 } \\
(00: 00-23: 00 \text { Hours }) \\
\end{array}$ & 23.4 & 27.7 & $\begin{array}{c}\text { Day } 1 \\
(00: 00-23: 00 \text { Hours }) \\
\end{array}$ & 94.7 & 78.7 \\
\hline $\begin{array}{c}\text { Day } 2 \\
(00: 00-23: 00 \text { Hours }) \\
\end{array}$ & 24.4 & 25.7 & $\begin{array}{c}\text { Day } 2 \\
(00: 00-23: 00 \text { Hours }) \\
\end{array}$ & 92.1 & 86.1 \\
\hline $\begin{array}{c}\text { Day } 3 \\
\text { (00:00-23:00 Hours) } \\
\end{array}$ & 27.3 & 26.1 & $\begin{array}{c}\text { Day } 3 \\
\text { (00:00-23:00 Hours) } \\
\end{array}$ & 78.0 & 83.6 \\
\hline $\begin{array}{c}\text { Day 4 } \\
\text { (00:00-23:00 Hours) } \\
\end{array}$ & 26.7 & 28.0 & $\begin{array}{c}\text { Day } 4 \\
\text { (00:00-23:00 Hours) }\end{array}$ & 80.0 & 72.5 \\
\hline $\begin{array}{c}\text { Day } 5 \\
(00: 00-23: 00 \text { Hours })\end{array}$ & 25.7 & 28.7 & $\begin{array}{c}\text { Day 5 } \\
\text { (00:00-23:00 Hours) } \\
\end{array}$ & 78.0 & 73.3 \\
\hline $\begin{array}{c}\text { Day 6 } \\
(00: 00-23: 00 \text { Hours }) \\
\end{array}$ & 25.7 & 28.7 & $\begin{array}{c}\text { Day 6 } \\
\text { (00:00-23:00 Hours) } \\
\end{array}$ & 69.8 & 74.2 \\
\hline $\begin{array}{c}\text { Day } 7 \\
(00: 00-23: 00 \text { Hours }) \\
\end{array}$ & 25.4 & 28.8 & $\begin{array}{c}\text { Day } 7 \\
\text { (00:00-23:00 Hours) } \\
\end{array}$ & 80.0 & 72.9 \\
\hline $\begin{array}{c}\text { Day } 8 \\
(00: 00-23: 00 \text { Hours }) \\
\end{array}$ & 24.2 & 28.8 & $\begin{array}{c}\text { Day } 8 \\
\text { (00:00-23:00 Hours) } \\
\end{array}$ & 90.2 & 74.9 \\
\hline $\begin{array}{c}\text { Day } 9 \\
(00: 00-23: 00 \text { Hours }) \\
\end{array}$ & 23.3 & 28.5 & $\begin{array}{c}\text { Day } 9 \\
\text { (00:00-23:00 Hours) } \\
\end{array}$ & 95.7 & 75.4 \\
\hline $\begin{array}{c}\text { Day 10 } \\
(00: 00-13: 30 \text { Hours }) \\
\end{array}$ & 24.7 & 27.1 & $\begin{array}{c}\text { Day 10 } \\
\text { (00:00-13:30 Hours) }\end{array}$ & 87.2 & 78.5 \\
\hline
\end{tabular}

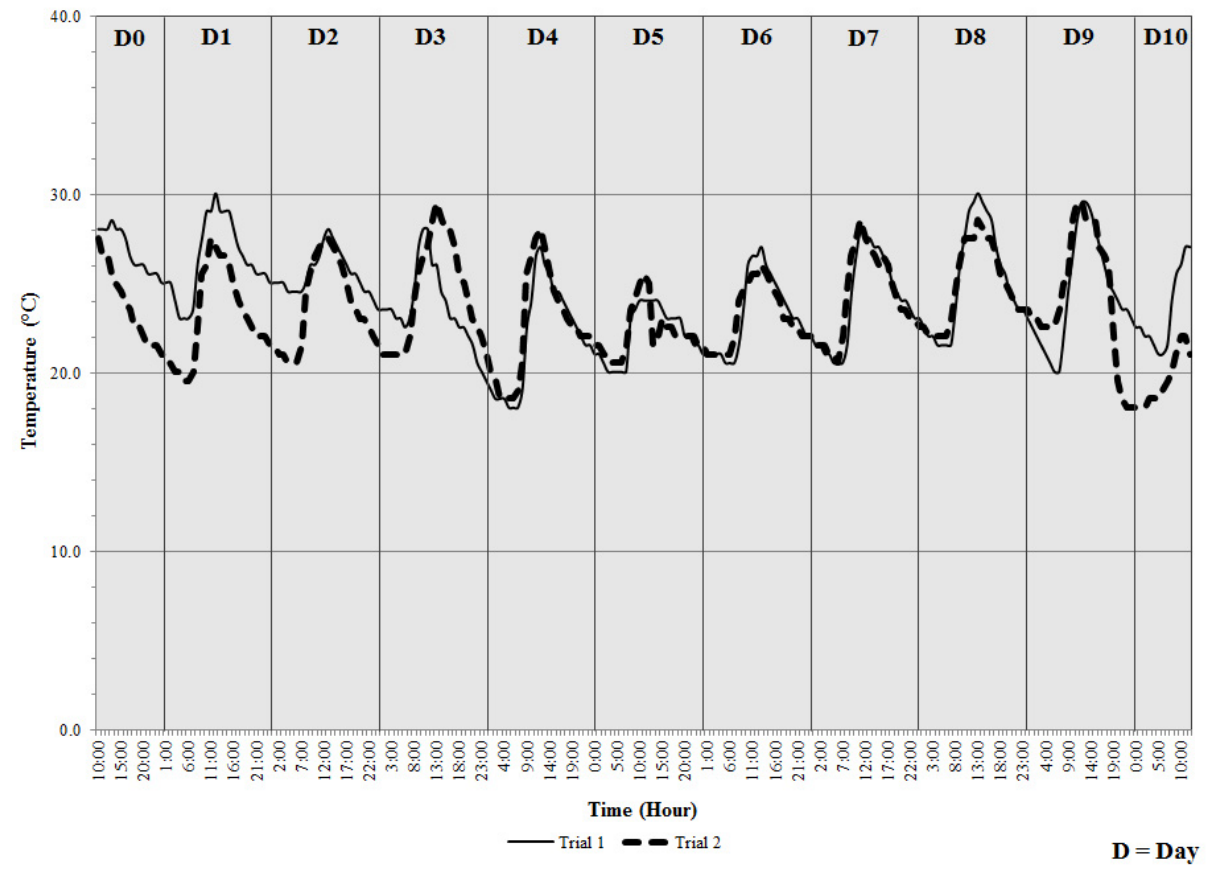

Figure 40: Line graph representing the hourly temperature recordings for each trial performed for HPLC-grade water environment. 


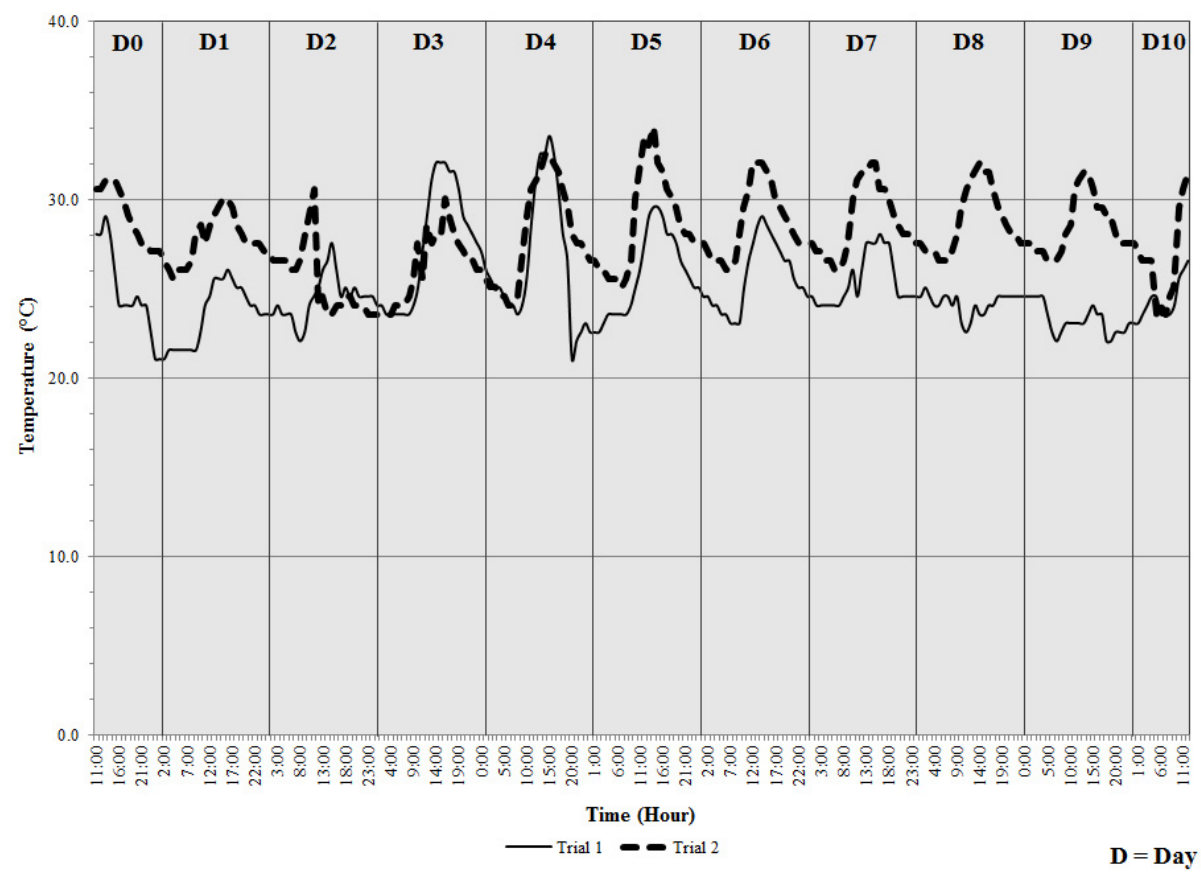

Figure 41: Line graph representing the hourly temperature recordings for each trial performed for synthetic sea water environment.

\subsubsection{Visual Observations}

Photographs were taken of all of the mice throughout the course of each trial for both HPLC-grade and synthetic sea water environments. For the purpose of simplicity, photos taken on Days 2, 6, and 10 are presented in Figures 42-44. In Section 2.1.3.1.3. the stages of decomposition were described for submerged remains. Based upon the physical characteristics listed and depending upon the mouse and type of aquatic environment evaluated, all remains experienced the stages of early floating, early floating decay, and advanced floating decay. However, the physical characteristics described in the first stage, submerged fresh, states that the remains will sink and the phase will end 
upon the remains floating back to the surface. All mice evaluated, floated upon being placed in the water and never sunk.
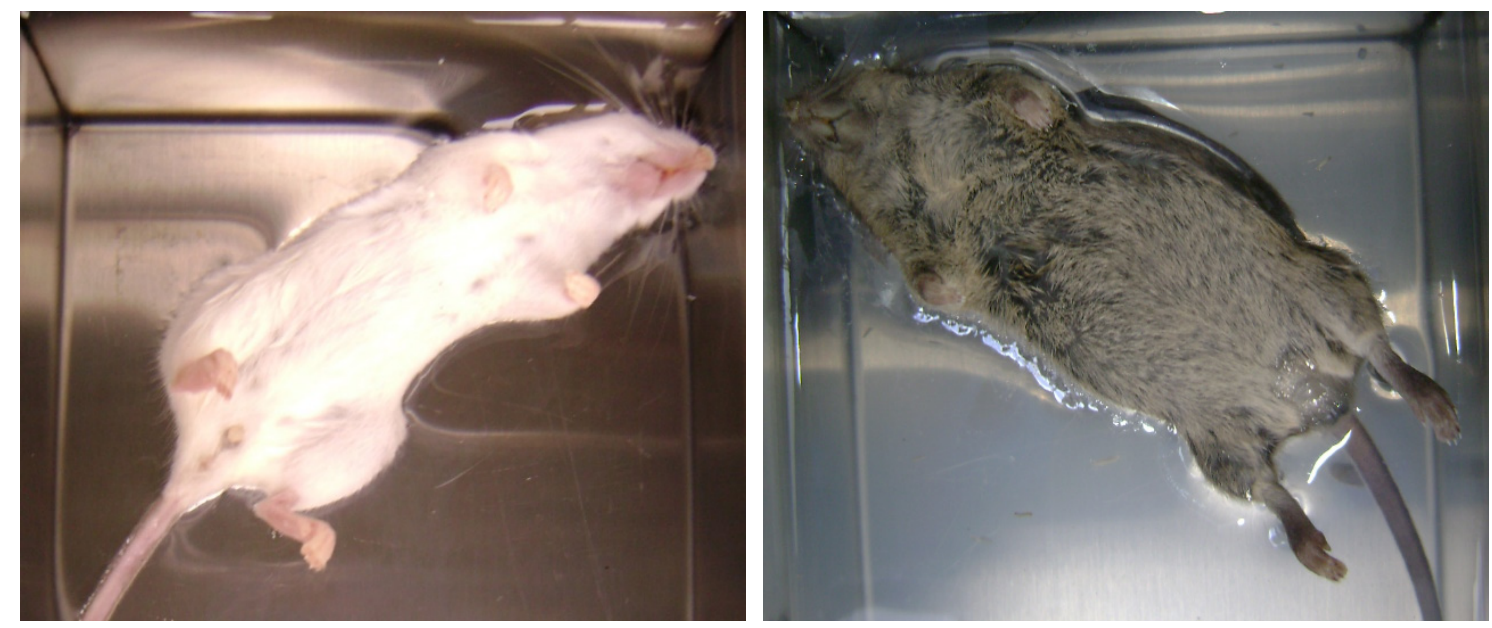

Figure 43: Day 2 of remains submerged in HPLC-grade (left) and synthetic sea (right) water.
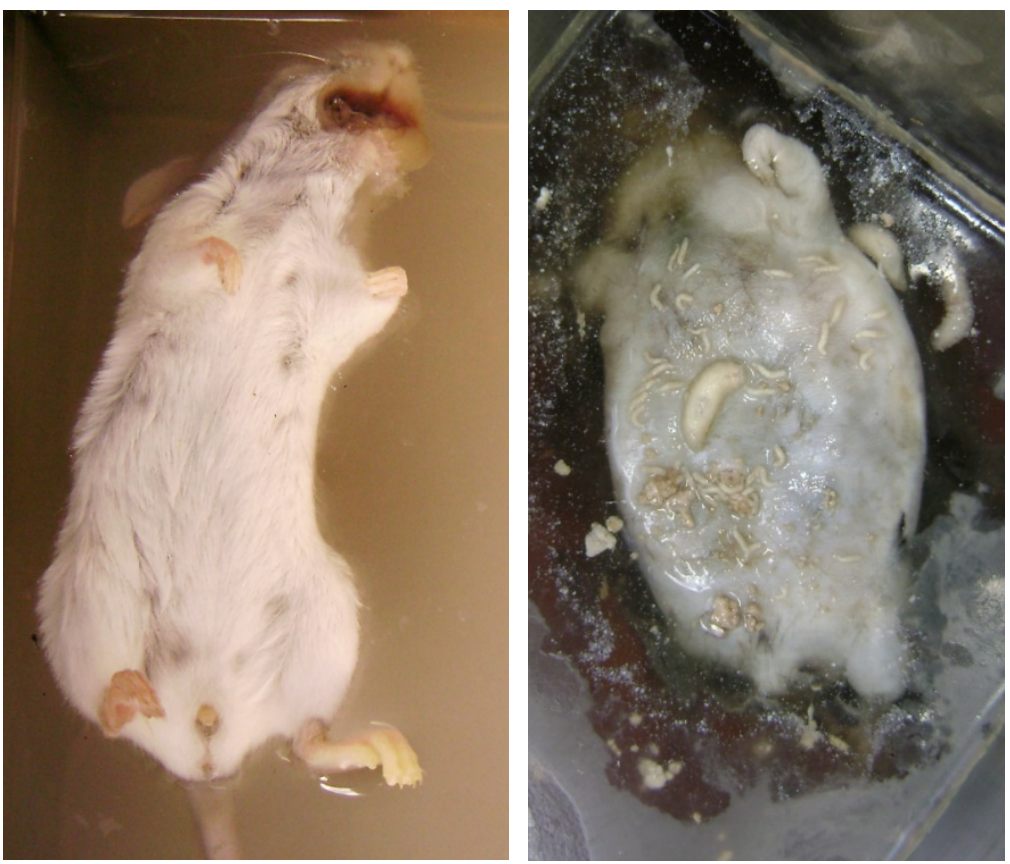

Figure 42: Day 10 of remains submerged in HPLC-grade (left) and synthetic sea (right) water. 

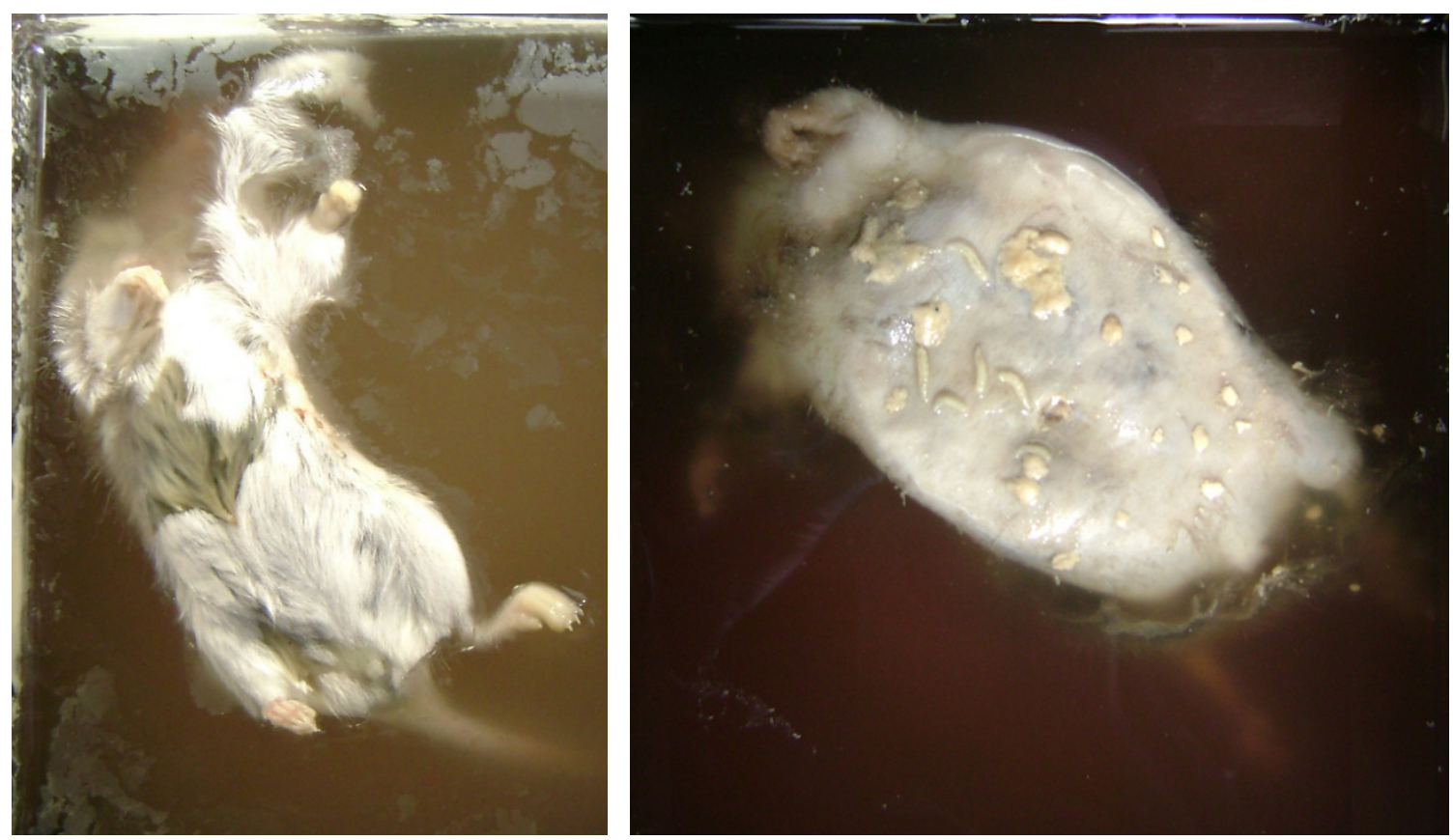

Figure 44: Day 6 of remains submerged in HPLC-grade (left) and synthetic sea (right) water.

\subsubsection{Water Parameters}

Prior to sampling, the $\mathrm{pH}$, conductivity, salinity, total dissolved solids, dissolved oxygen content, and temperature of the water were measured to assess the impact that the decomposing remains had on the aquatic conditions. The results for both trials using HPLC-grade water are presented in Figures 45 and 46.

Throughout the course of each trial, the temperatures varied slightly; however, the same could not be said for the remaining parameters. Minor fluctuations were observed for the $\mathrm{pH}$ as a decrease occurred from Day 0 to Day 2, which was expected as the remains still appeared relatively fresh; however, as the remains progressed through the 
different stages of decomposition the $\mathrm{pH}$ increased. Additionally, the night before Day 4 of Trial 2 there was a severe rain storm that disrupted the position of the tarp closest to the blank H \& S chamber causing particulates to enter into the water; this could have possibly led to the rise in $\mathrm{pH}$ that arose on Day 4. Conversely, for conductivity, salinity, and TDS there was an exponential trend starting from Day 0 which can be attributed to the breakdown of the remains as they decayed. For Trial 1, a decrease in the dissolved oxygen content was observed and expected as the remains were submerged and decomposing in water that was not free flowing. For Day 4 of Trial 1 and every day of Trial 2, no dissolved oxygen content measurements were performed because of a malfunction with the instrument.
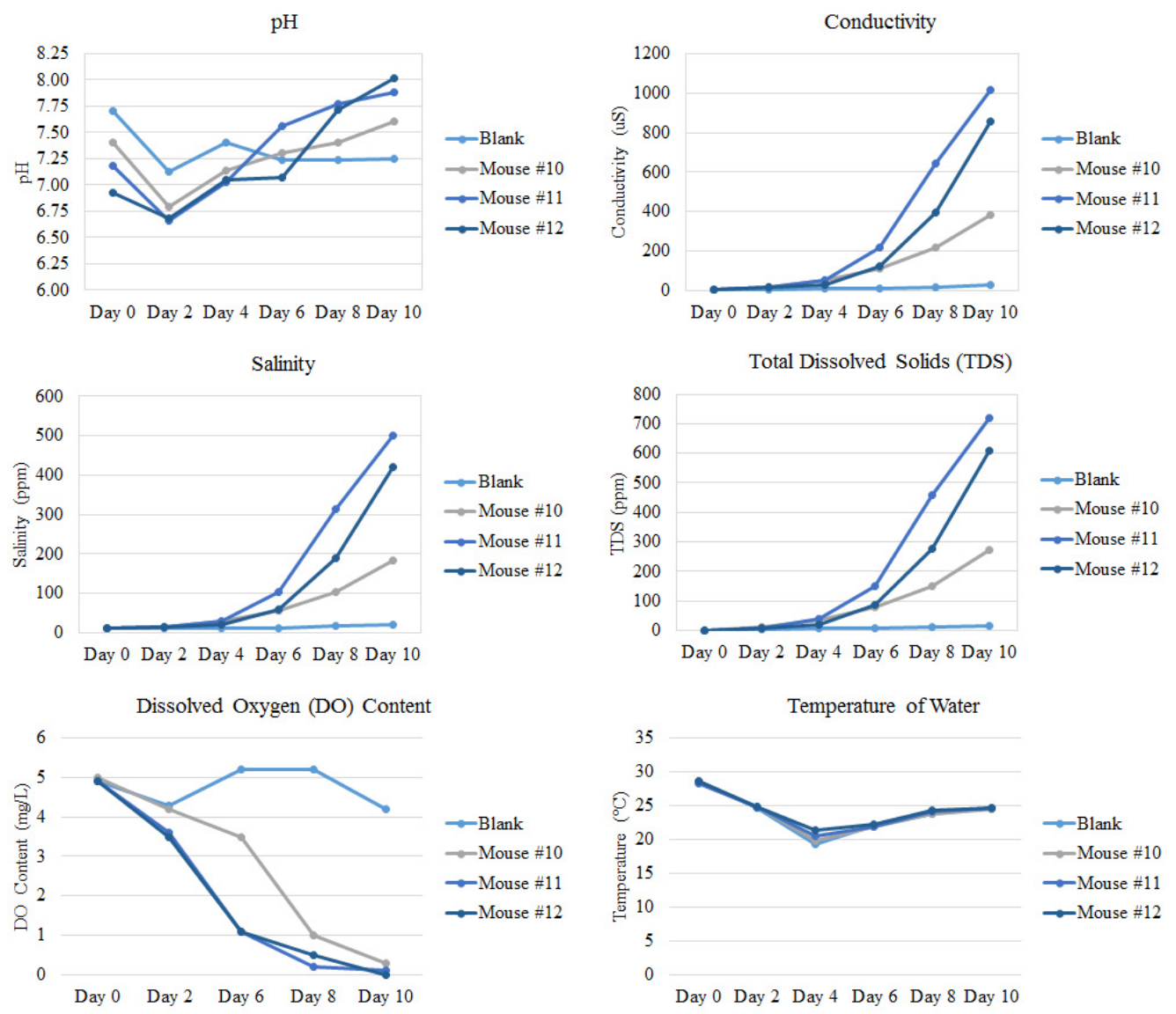

Figure 45: Parameters measured for Trial 1 of the HPLC-grade water environment. 

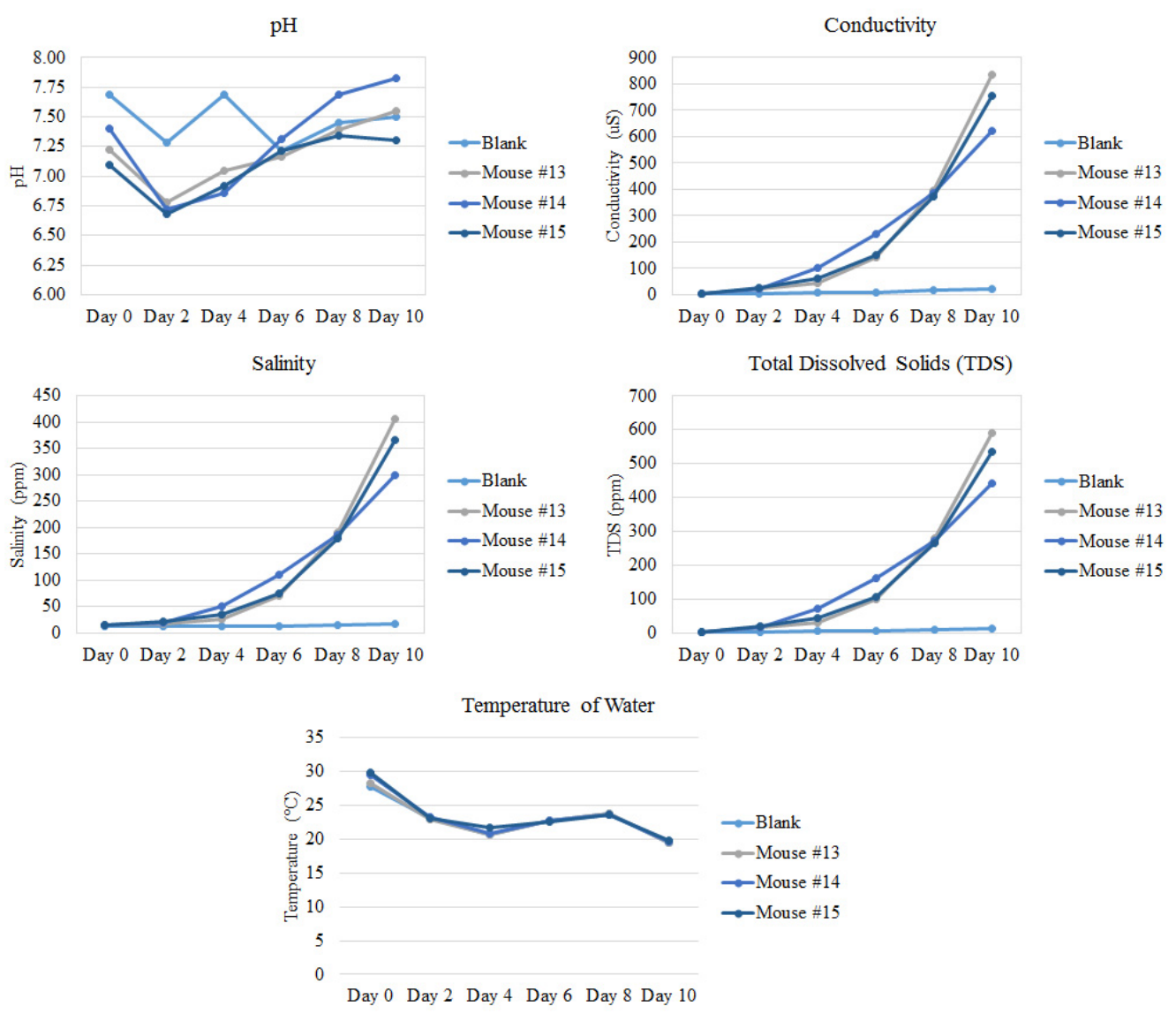

Figure 46: Parameters measured for Trial 2 of the HPLC-grade water environment.

Once again, the $\mathrm{pH}$, temperature, and dissolved oxygen content were measured for both trials of the synthetic sea water environment (Figures 47 and 48). Efforts were made to obtain measurements for conductivity, salinity, and TDS, but to no avail as they were outside the range of the instrument.

Similar to the previously discussed aquatic environment, the water temperature had varied minimally for both trials; however, with regard to $\mathrm{pH}$ and dissolved oxygen content differences were observed. In both trials, the $\mathrm{pH}$ steadily decreased, but for Trial 1, there was a slight increase at Day 8 for Mouse \#16 and \#17, whereas the $\mathrm{pH}$ for Mouse \#18 continued to decrease. Visually, the fur of Mouse \#16 started to slough off exposing 

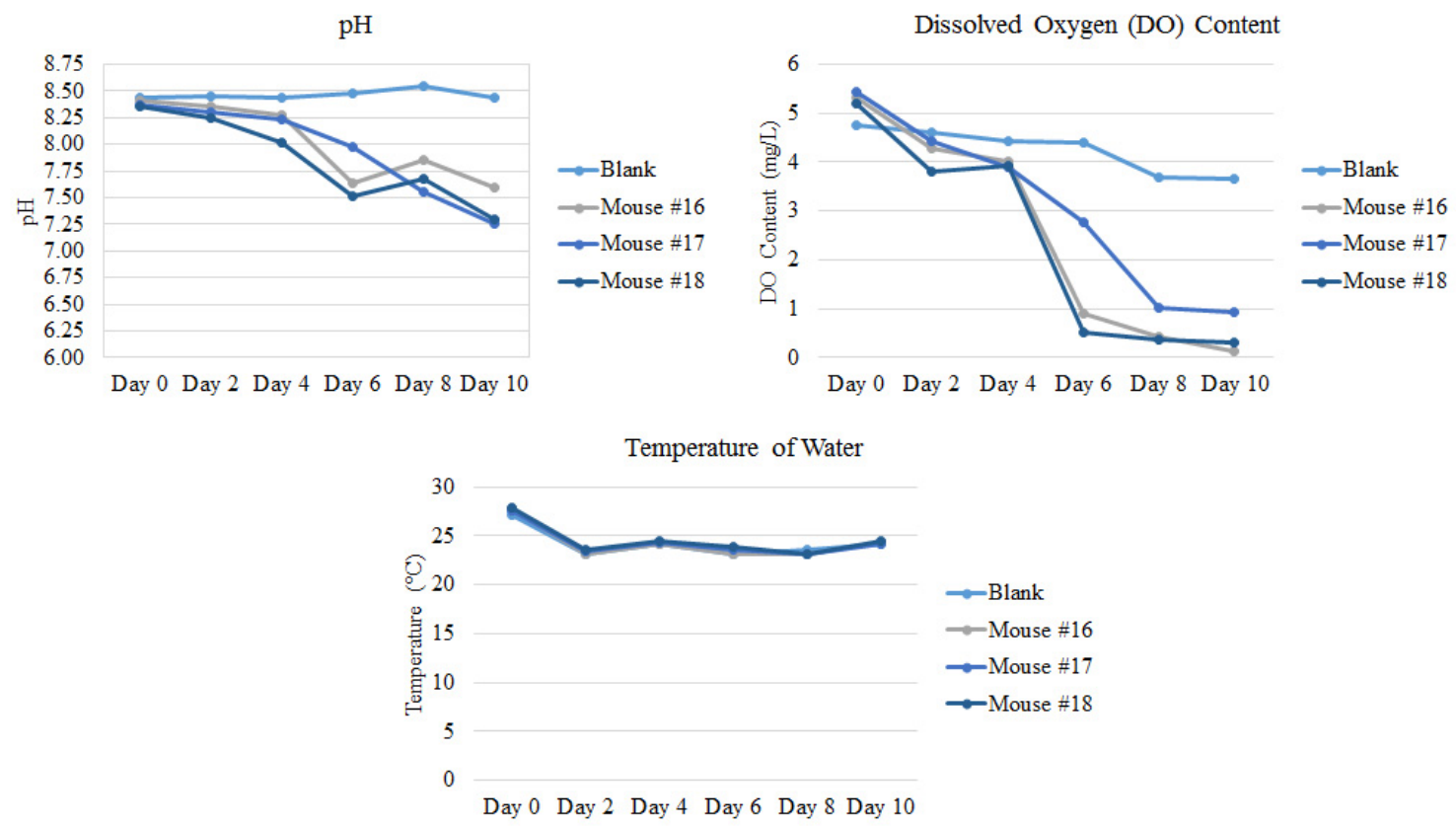

Figure 47: Parameters measured for Trial 1 of the synthetic sea water environment.
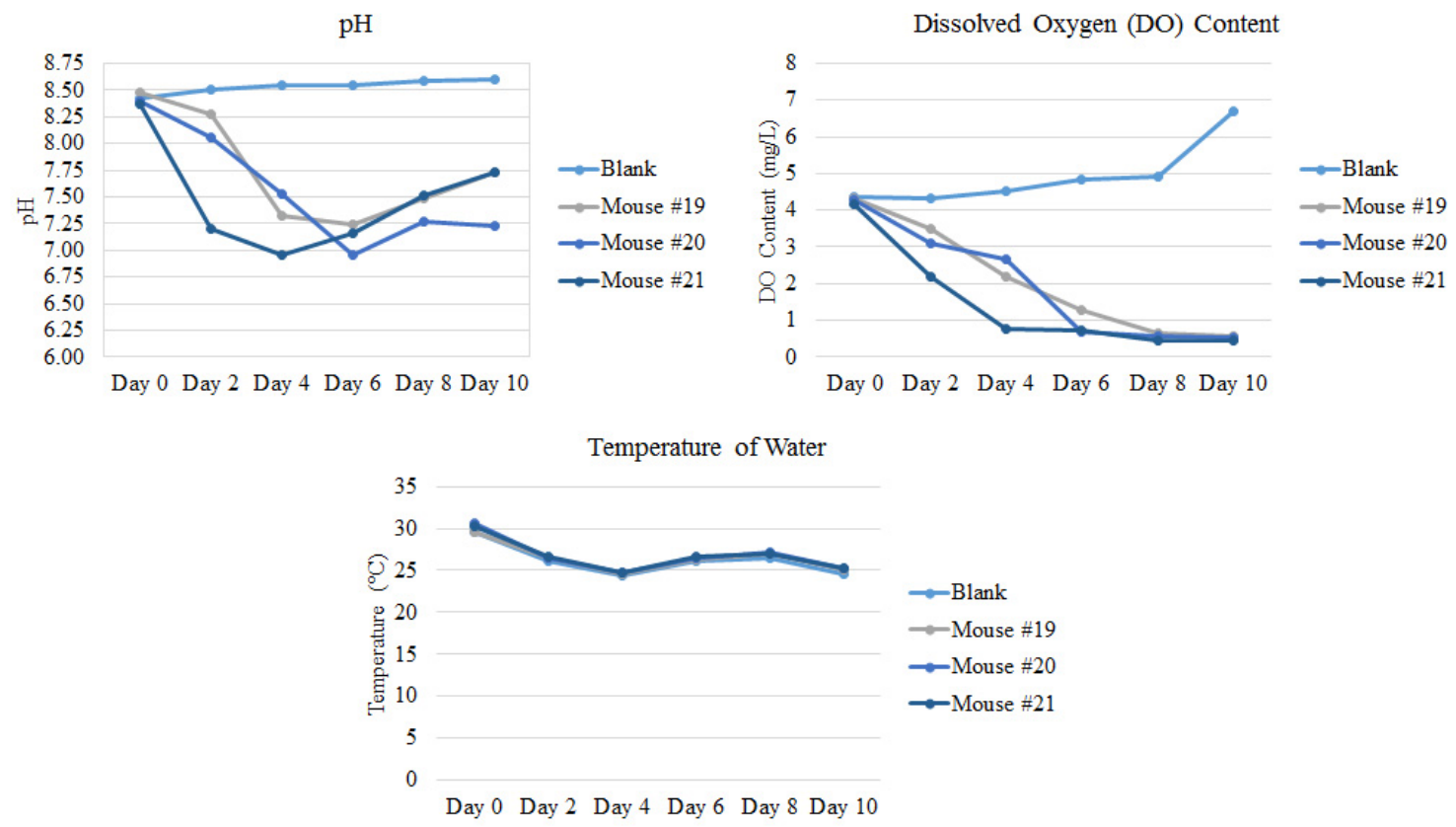

Figure 48: Parameters measured for Trial 2 of the synthetic sea water environment. 
the skin; however, there were no noticeable differences from Day 6 to Day 8 for Mouse \#17. Additionally, the dissolved oxygen content steadily decreased with a minimal increase at Day 4, but thereafter, it continued to reduce to almost zero. Conversely, the trends for the $\mathrm{pH}$ and dissolved oxygen content for Trial 2 appeared similar to that of the HPLC-grade water environment, except that the $\mathrm{pH}$ decreased over a span of six days before increasing, whereas with the HPLC-grade water environment the $\mathrm{pH}$ decreased over a span of two days before increasing.

\subsubsection{Volatile Organic Compounds Detected from Submerged Remains}

For the analysis of remains submerged in HPLC-grade water, fifteen decomposition-associated compounds were detected in a minimum of one mouse and are presented in Table 23. The Varian MS Workstation Software, Version 6.6 (Service Pack 1), was used to verify and quantitate all detected compounds using a seven-point external calibration curve that consisted of diluted standard mixtures (see Section 4.1.1. for listing).

Using both headspace and direct immersion SPME, six common compounds were identified across the two trials: dimethyl disulfide, dimethyl trisulfide, 4-methyl pentanoic acid, phenylethyl alcohol, indole, and 3-methyl-1H-indole. Unlike DI-SPME, HS-SPME extracted five additional compounds which included dimethyl sulfide, 2,4dimethylhexane, butanoic acid propyl ester, 2-pentyl furan, and acetic acid.

The VOCs that were identified were used to assess the odor profile of each mouse over time (Figure 49). Unlike those generated from decomposing remains in their natural 
Table 23: Compounds detected in both trials of HPLC-grade water environments.

\begin{tabular}{|c|c|c|c|c|}
\hline \multirow[b]{2}{*}{ Compound Name } & \multicolumn{2}{|c|}{ TRIAL 1} & \multicolumn{2}{|c|}{ TRIAL 2} \\
\hline & HEADSPACE & $\begin{array}{c}\text { DIRECT } \\
\text { IMMERSION }\end{array}$ & HEADSPACE & $\begin{array}{c}\text { DIRECT } \\
\text { IMMERSION }\end{array}$ \\
\hline Dimethyl Sulfide & $\mathbf{X}$ & & & \\
\hline 2,4-Dimethylhexane & & & $\mathbf{X}$ & \\
\hline Acetone & $\mathbf{X}$ & & & $\mathbf{X}$ \\
\hline Dimethyl Disulfide & $\bar{X}$ & $\mathbf{X}$ & $\mathbf{X}$ & $\bar{X}$ \\
\hline Butanoic Acid, Propyl Ester & $\bar{X}$ & & & \\
\hline 2-Pentyl-Furan & $\mathbf{X}$ & & & \\
\hline Dimethyl Trisulfide & $\bar{X}$ & $\mathbf{X}$ & $\mathbf{X}$ & $\mathbf{X}$ \\
\hline Acetic Acid & & & $\bar{X}$ & \\
\hline Butanoic Acid & $\mathbf{X}$ & & $\mathbf{X}$ & $\mathbf{X}$ \\
\hline 3-Methyl-Butanoic Acid & $\mathbf{X}$ & & $\bar{X}$ & $\bar{X}$ \\
\hline 4-Methyl-Pentanoic Acid & $\mathbf{X}$ & $\mathbf{X}$ & $\bar{X}$ & $\mathbf{X}$ \\
\hline Hexanoic Acid & & & & $\mathbf{X}$ \\
\hline Phenylethyl Alcohol & $\mathbf{X}$ & $\mathbf{X}$ & $\mathbf{X}$ & $\bar{X}$ \\
\hline Indole & $\mathbf{X}$ & $\mathbf{X}$ & $\mathbf{X}$ & $\mathbf{X}$ \\
\hline 3-Methyl-1H-Indole & $\bar{X}$ & $\mathbf{X}$ & $\bar{X}$ & $\bar{X}$ \\
\hline
\end{tabular}

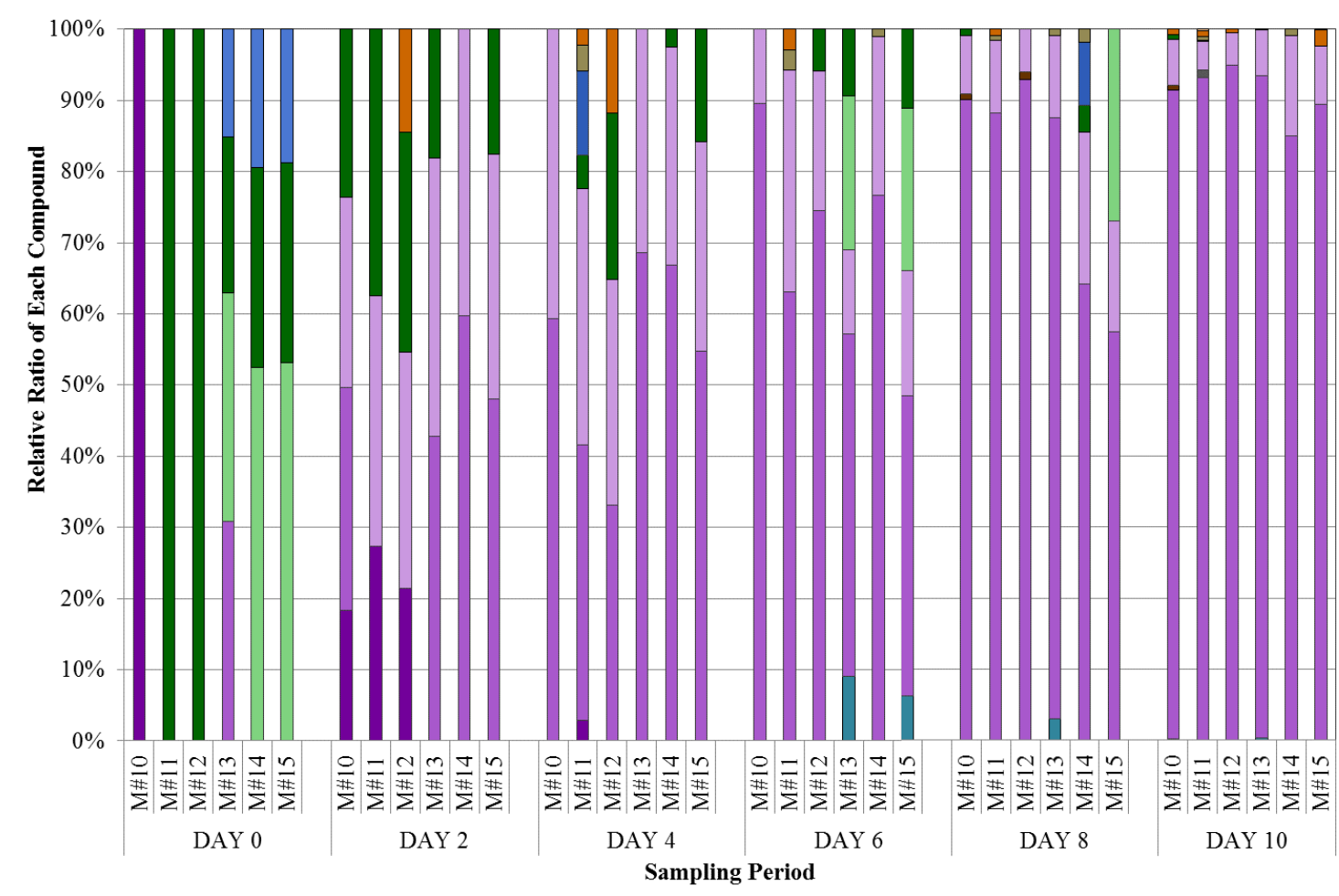

Dimethyl Sulfide - 2-Pentyl Furan

$\square$ 2,4-Dimethylhexane $\square$ Dimethyl Trisulfide -Hexanoic Acid
- Acetone $\square$ Acetic Acid $\square$ Phenylethyl Alcoho
$\square$ Dimethyl Disulfide - Butanoic Acid $\square$ Indole

- Butanoic Acid, Propyl Ester $\square$ 3-Methyl-Butanoic Acid 口3-Methyl-1H-Indole

Figure 49: Odor profiles from all mice (M) that were submerged in HPLC-grade water. 
state (see Figure 34 in Section 5.4.4.) which showed that each mouse decomposed differently; the remains submerged in HPLC-grade water appeared to decompose in a more generalized manner. Upon inspection of Figure 49, dimethyl sulfide, dimethyl disulfide, and dimethyl trisulfide (presented in different shades of purple) were revealed to be the most prevalent compounds released from the submerged remains.

Since direct immersion SPME was also performed using the water samples collected from all mice over time, a similar color chart was created to assess the relative ratio of each compound that was present (Figure 50). Within the first two days of being submerged, one compound, acetone, was identified from one mouse. At Day 4, dimethyl

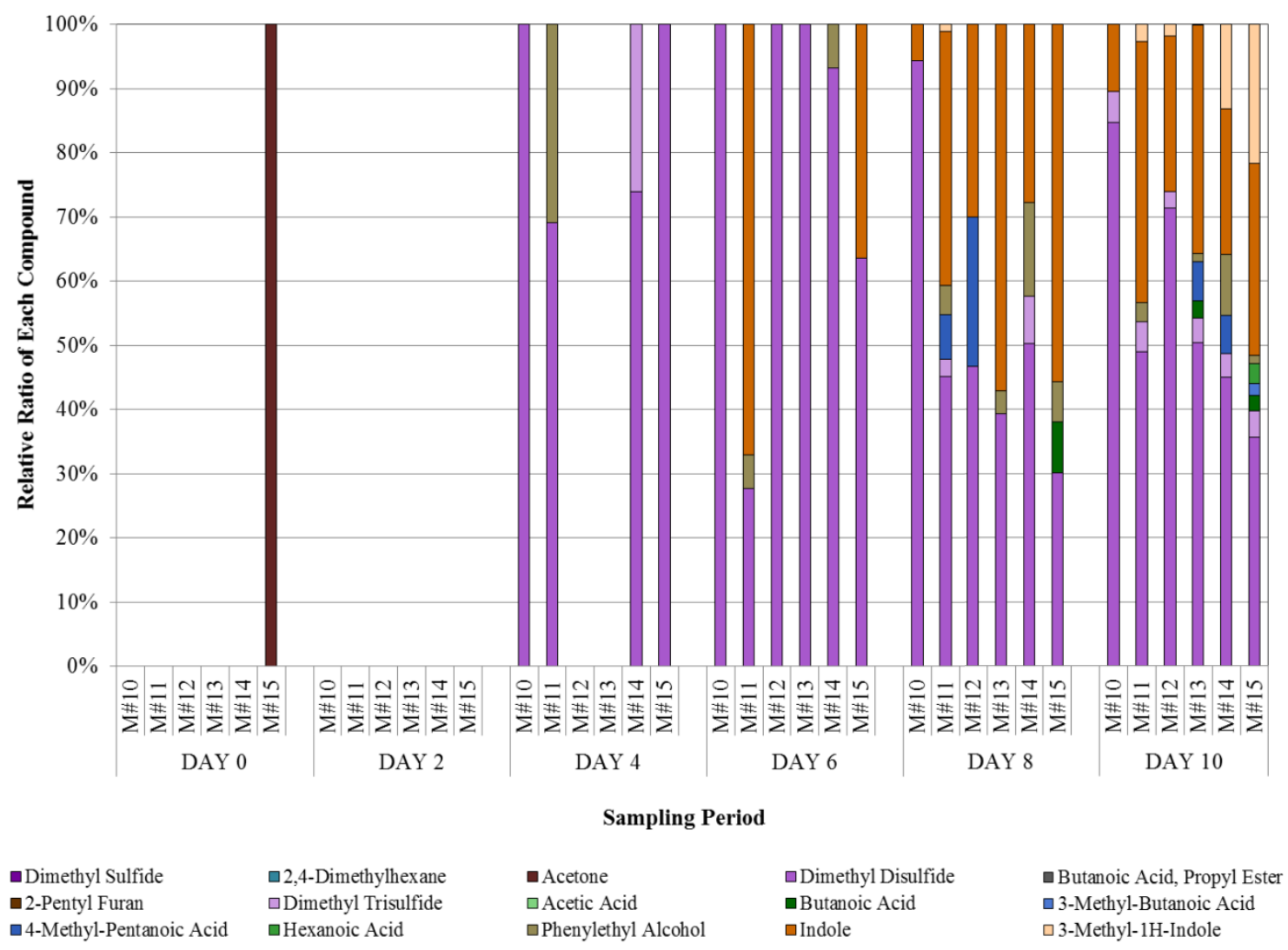

Figure 50: Relative ratio of the compound(s) extracted from the HPLC-grade water samples that were collected from each mouse (M). 
disulfide, dimethyl trisulfide, and phenylethyl alcohol appeared, and like that of the odor profiles, dimethyl disulfide was the most dominant compound. This trend continued until Day 8 when indole emerged in all mice and became the second most prevalent compound in the water samples, although barely seen in the odor profiles which could, however, be attributed to its low volatility.

To expand upon the results gathered thus far, the total mass extracted using both techniques were also evaluated (Figure 51). From the color chart, it is observed that, regardless of the technique (i.e., HS-SPME, DI-SPME), as the remains progressed through the different phases of decomposition a greater abundance of compounds were extracted giving what appeared to be a left-skewed curve.

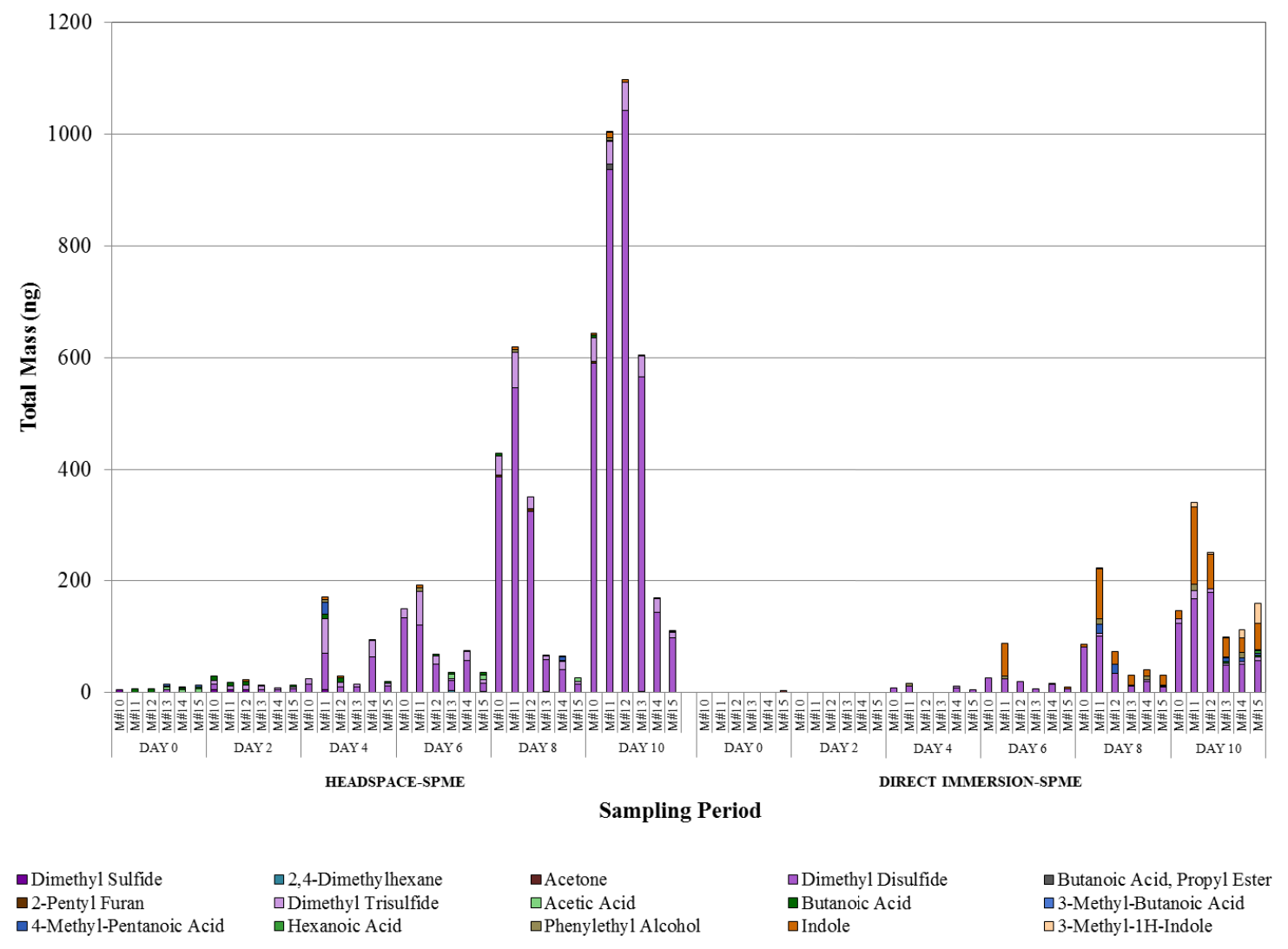

Figure 51: Comparison of the total mass of compounds extracted using headspace and direct immersion SPME from all mice (M). 
Synthetic sea water was the second aquatic environment that was evaluated. A total of twenty-two decomposition-associated compounds were found to be present in the headspace and/or in the collected water samples of at least one mouse (Table 24).

Table 24: Compounds detected in both trials of synthetic sea water environments. An " $\mathrm{X}$ " indicates that the compound was present.

\begin{tabular}{|c|c|c|c|c|}
\hline & \multicolumn{2}{|c|}{ Trial 1 } & \multicolumn{2}{c|}{ Trial 2 } \\
\hline Compound Name & HEADSPACE & $\begin{array}{c}\text { DIRECT } \\
\text { IMMERSION }\end{array}$ & HEADSPACE & $\begin{array}{c}\text { DIRECT } \\
\text { IMMERSION }\end{array}$ \\
\hline 2,2-Dimethylbutane & $\mathbf{X}$ & & $\mathbf{X}$ & \\
\hline Dimethyl Sulfide & $\mathbf{X}$ & & $\mathbf{X}$ & $\mathbf{X}$ \\
\hline 2,4-Dimethylhexane & $\mathbf{X}$ & & $\mathbf{X}$ & \\
\hline Butanoic Acid, Ethyl Ester & $\mathbf{X}$ & & $\mathbf{X}$ & \\
\hline Dimethyl Disulfide & $\mathbf{X}$ & $\mathbf{X}$ & $\mathbf{X}$ & $\mathbf{X}$ \\
\hline Butanoic Acid, Propyl Ester & $\mathbf{X}$ & & $\mathbf{X}$ & \\
\hline 2-Pentyl Furan & $\mathbf{X}$ & & $\mathbf{X}$ & $\mathbf{X}$ \\
\hline Dimethyl Trisulfide & $\mathbf{X}$ & $\mathbf{X}$ & $\mathbf{X}$ & $\mathbf{X}$ \\
\hline Acetic Acid & $\mathbf{X}$ & $\mathbf{X}$ & $\mathbf{X}$ & $\mathbf{X}$ \\
\hline Benzaldehyde & & $\mathbf{X}$ & & $\mathbf{X}$ \\
\hline Butanoic Acid & $\mathbf{X}$ & $\mathbf{X}$ & $\mathbf{X}$ & $\mathbf{X}$ \\
\hline 3-Methyl-Butanoic Acid & $\mathbf{X}$ & $\mathbf{X}$ & $\mathbf{X}$ & $\mathbf{X}$ \\
\hline Pentanoic Acid & $\mathbf{X}$ & & $\mathbf{X}$ & $\mathbf{X}$ \\
\hline 4-Methyl-Pentanoic Acid & $\mathbf{X}$ & $\mathbf{X}$ & $\mathbf{X}$ & $\mathbf{X}$ \\
\hline Benzenepropanoic Acid, Ethyl Ester & $\mathbf{X}$ & $\mathbf{X}$ & $\mathbf{X}$ & $\mathbf{X}$ \\
\hline Phenylethyl Alcohol & $\mathbf{X}$ & & $\mathbf{X}$ & $\mathbf{X}$ \\
\hline Indole & $\mathbf{X}$ & $\mathbf{X}$ & $\mathbf{X}$ & $\mathbf{X}$ \\
\hline 3-Methyl-1H-Indole & & & & $\mathbf{X}$ \\
\hline
\end{tabular}

Dimethyl disulfide, dimethyl trisulfide, acetic acid, butanoic acid, 3-methyl-butanoic acid, pentanoic acid 4-methyl, benzenepropanoic acid ethyl ester, and indole were found using both headspace and direct immersion solid-phase microextraction. Benzaldehyde and 3-methyl-1H-indole were the only compounds detected in the collected water samples, whereas 2,2-dimethylbutane, dimethyl sulfide, 2,4-dimethylhexane, butanoic acid ethyl ester, and butanoic acid propyl ester were only found in the headspace above at least one mouse. 
The identified VOCs were used to create an odor profile of each mouse for both trials over time (Figure 52). Similarly, to what was observed with those remains submerged in HPLC-grade water, the sulfur-containing compounds (different shades of purple) were most prevalent. Interestingly, dimethyl sulfide and dimethyl disulfide appeared in five out of the six mice at Day 0, whereas those remains submerged in HPLC-grade water had one mouse that produced dimethyl sulfide and another that generated dimethyl disulfide. At Day 6, the odor profiles changed dramatically for M\#19-21 with the disappearance of dimethyl disulfide. This extreme change could have been caused by the disarticulation of the head of M\#19, the extreme bloat that M\#20 had

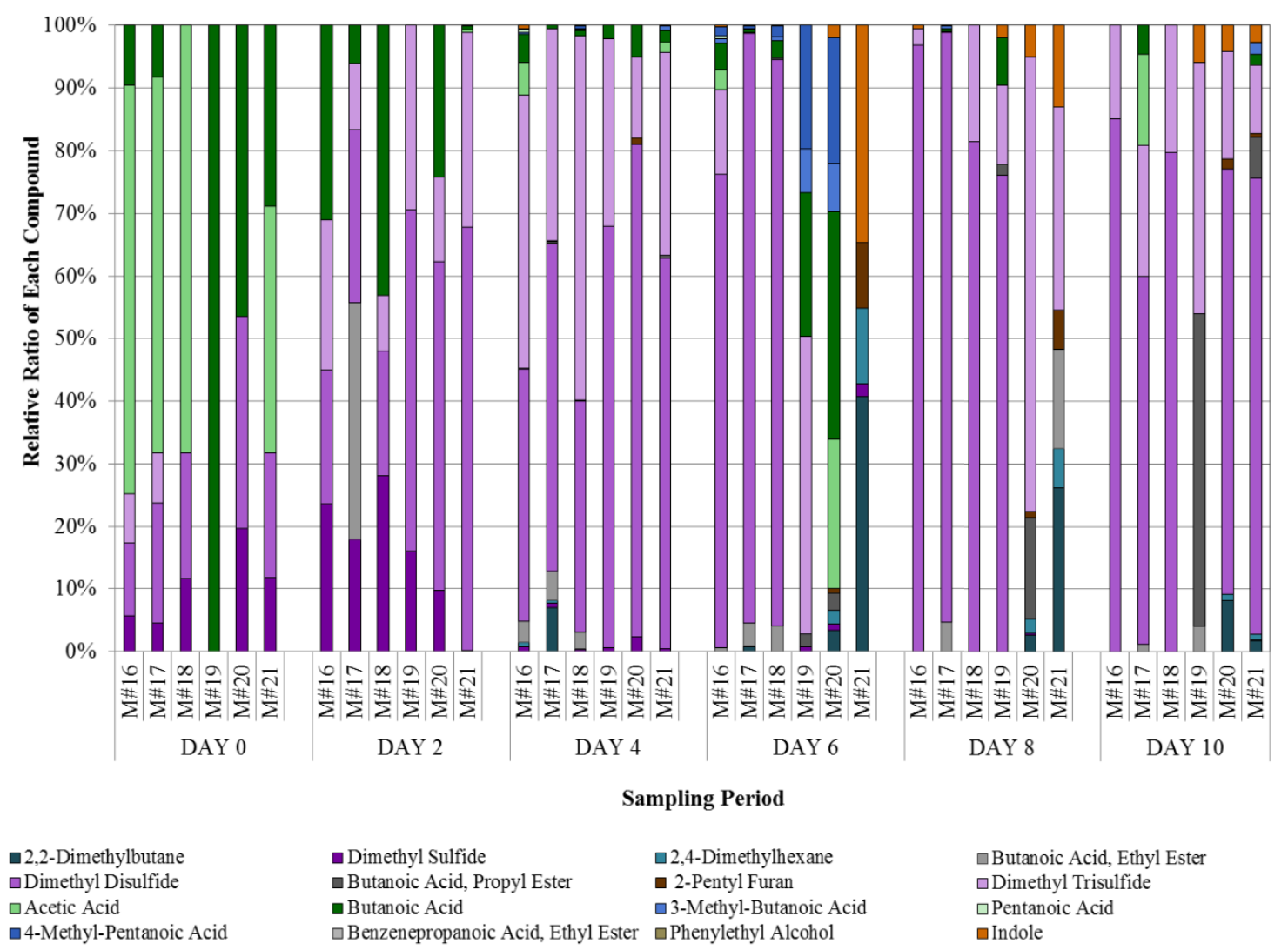

undergone, and the sloughing off of the fur for $\mathrm{M} \# 21$ causing it to be unrecognizable.

Figure 52: Odor profiles of all mice (M) that were submerged in synthetic sea water. 
Nevertheless, as the remains continued to decompose, the odor profiles changed resulting in the reappearance of dimethyl trisulfide at Day 8 and dimethyl disulfide at Day 10 .

Water samples were also collected from remains submerged in synthetic sea water and a color chart was created to assess the relative ratio of the compounds that were present (Figure 53). On Day 6 for M\#20, the sample was lost during GC-MS analysis due to a power outage.

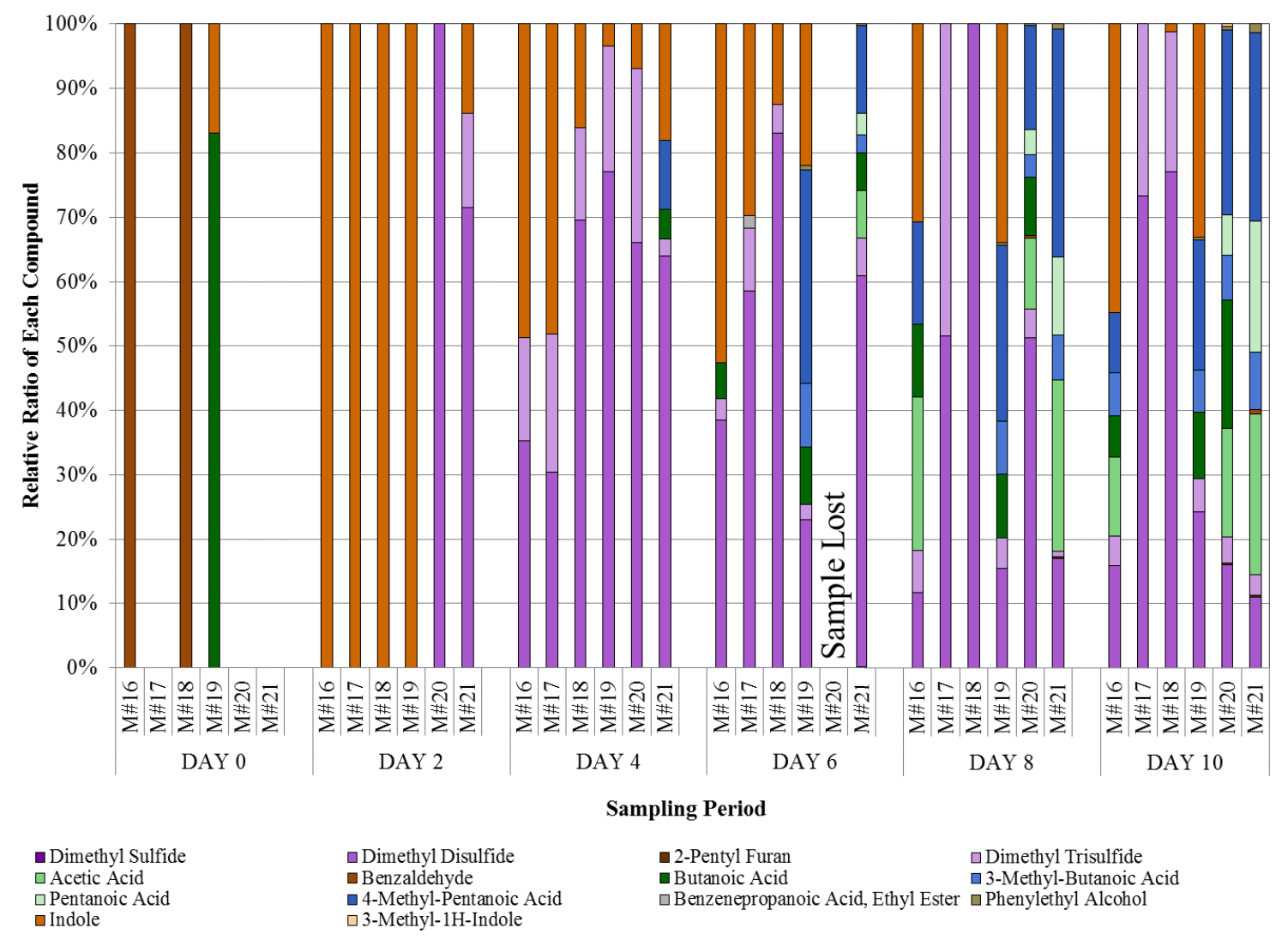

Figure 53: Relative ratio of each compound present in the water samples collected from all mice (M).

In contrast to the samples collected from the HPLC-grade water environment, remains submerged in synthetic sea water showed extreme differences in the relative ratio of compounds. For instance, in samples collected from remains submerged in HPLC- 
grade water, no compounds were found on Day 2 and indole made its appearance on Day 6. Conversely, three compounds (indole, dimethyl disulfide, and dimethyl trisulfide) were present on Day 2 from samples collected from remains submerged in the synthetic sea water environment. Moreover, indole was the most frequent compound appearing in four out of the six collected water samples.

A comparison of the total mass extracted using HS-SPME and DI-SPME was also performed to determine if any trends existed (Figure 54). Similar to what was observed with the HPLC-grade environment, HS-SPME extracted a greater mass of compounds in comparison to DI-SPME, with the sulfur-containing compounds contributing the most to the overall abundance. When comparing both aquatic environments, the remains submerged in HPLC-grade water released the greatest mass of compounds on Day 10, resulting in what looks similar to a left-skewed curve; however, with synthetic sea water that was not the case. The greatest mass of compounds released by mice submerged in synthetic sea water varied between samples, having occurred on Days 4 or 6 for HSSPME and for DI-SPME: Day 6 for M\#16-18 and \#21, Day 8 for M\#20, and Day 10 for M\#19. Thus, revealing that the type and total mass of VOCs released from remains submerged in synthetic sea water varied greatly as no trends were observed. However, with those remains submerged in HPLC-grade water, a trend was observed, in such that as the remains progressed through the different phases of decomposition, the total mass of VOCs increased with minimal variation in the compounds present. 


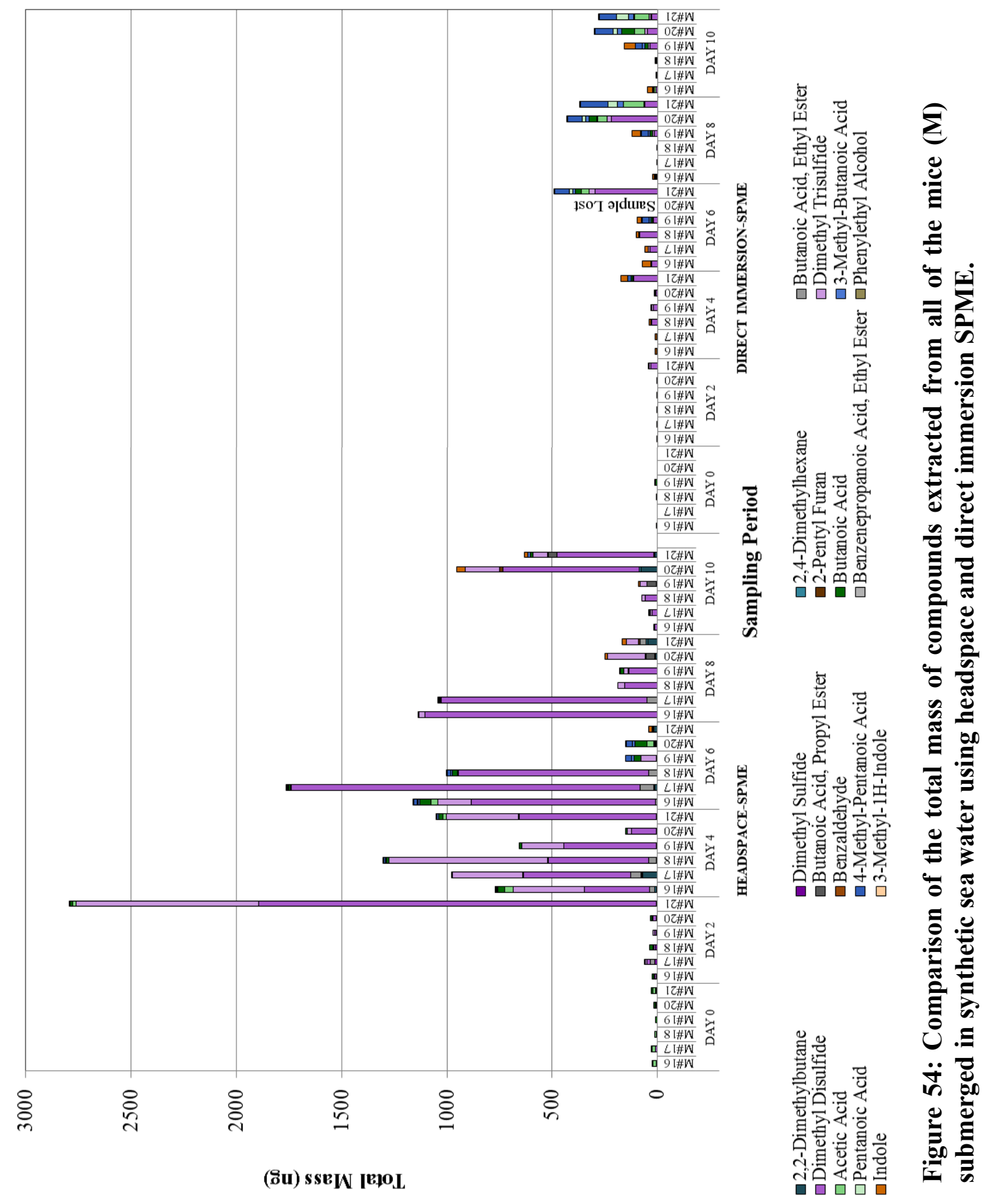


5.6. Assessment of the VOCs Released from Decomposing Remains Buried in Different Soil Environments

The purpose of this task was to investigate the effects that characteristically different soil environments, sand and Canadian Sphagnum peat moss, have on the compounds released from decomposing remains. In addition, throughout the course of each soil evaluation the top layer of the soil was disturbed by probing some of the samples to assess its effects on the liberated VOCs. In real-life scenarios, soil probes are often employed when searching for human remains when using HRD canines as it enhances the exchange of air and allows for the release of decomposition odor [94].

\subsubsection{Human Cadaver Analogues}

Eight freshly killed adult, transgenic mice that were housed and fed identically were used; their specifications are listed in Table 25. Their average mass was $36 \mathrm{~g}$, for the female mice, with a range of $31-43 \mathrm{~g}$, and $47.5 \mathrm{~g}$ for the male mice, with a range of 36-53 grams. The average total lengths of the female and male mice were $17.0 \mathrm{~cm}$ and $17.2 \mathrm{~cm}$, respectively. 
Table 25: Mice specifications for both soil environments.

\begin{tabular}{|c|c|c|c|c|c|}
\hline \multicolumn{6}{|c|}{ Sand } \\
\hline Trial & Gender & Weight (g) & Body Length $(\mathrm{cm})$ & Tail Length (cm) & Total Length $(\mathrm{cm})$ \\
\hline \multirow{2}{*}{ 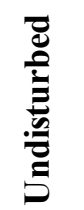 } & Female & 35 & 8.2 & 8.4 & 16.6 \\
\hline & Female & 43 & 9.1 & 8.5 & 17.6 \\
\hline \multirow{2}{*}{ 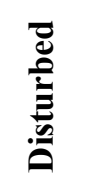 } & Female & 31 & 8.0 & 9.0 & 17.0 \\
\hline & Female & 33 & 8.2 & 8.6 & 16.8 \\
\hline \multicolumn{6}{|c|}{ Canadian Sphagnum Peat Moss } \\
\hline Trial & Gender & Weight (g) & Body Length (cm) & Tail Length (cm) & Total Length (cm) \\
\hline \multirow{2}{*}{ 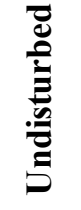 } & Male & 36 & 8.1 & 8.5 & 16.6 \\
\hline & Male & 49 & 8.9 & 8.1 & 17.0 \\
\hline \multirow{2}{*}{ 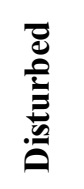 } & Male & 52 & 9.0 & 8.4 & 17.4 \\
\hline & Male & 53 & 9.5 & 8.2 & 17.7 \\
\hline
\end{tabular}

5.6.2. Temperature and Relative Humidity of Environment

Micro-t loggers were used to measure the temperature and relative humidity on an hourly basis throughout the course of study for both soil environments (Table 26). The hourly temperature measurements showed a steady increase a little before noon where maximum temperature was reached and then a steady decrease as evening approached (Figure 55). 
Table 26: The average temperature and relative humidity for both soil types.

\begin{tabular}{|c|c|c|c|c|c|}
\hline \multicolumn{3}{|c|}{ Average Temperature $\left({ }^{\circ} \mathrm{C}\right)$} & \multicolumn{3}{|c|}{ Average Relative Humidity (\%) } \\
\hline & Sand & $\begin{array}{c}\text { Canadian } \\
\text { Sphagnum Peat } \\
\text { Moss }\end{array}$ & & Sand & $\begin{array}{c}\text { Canadian } \\
\text { Sphagnum Peat } \\
\text { Moss } \\
\end{array}$ \\
\hline $\begin{array}{c}\text { Day 0 } \\
(10: 00-23: 00 \text { Hours }) \\
\end{array}$ & 30.8 & 25.5 & $\begin{array}{c}\text { Day 0 } \\
(10: 00-23: 00 \text { Hours })\end{array}$ & 64.4 & 87.6 \\
\hline $\begin{array}{c}\text { Day } 1 \\
(00: 00-23: 00 \text { Hours }) \\
\end{array}$ & 27.7 & 25.2 & $\begin{array}{c}\text { Day } 1 \\
(00: 00-23: 00 \text { Hours }) \\
\end{array}$ & 82.2 & 86.3 \\
\hline $\begin{array}{c}\text { Day } 2 \\
(00: 00-23: 00 \text { Hours }) \\
\end{array}$ & 28.7 & 25.1 & $\begin{array}{c}\text { Day } 2 \\
(00: 00-23: 00 \text { Hours }) \\
\end{array}$ & 74.6 & 85.9 \\
\hline $\begin{array}{c}\text { Day } 3 \\
(00: 00-23: 00 \text { Hours }) \\
\end{array}$ & 28.6 & 28.0 & $\begin{array}{c}\text { Day } 3 \\
(00: 00-23: 00 \text { Hours }) \\
\end{array}$ & 71.4 & 76.4 \\
\hline $\begin{array}{c}\text { Day } 4 \\
(00: 00-23: 00 \text { Hours })\end{array}$ & 28.2 & 28.4 & $\begin{array}{c}\text { Day } 4 \\
(00: 00-23: 00 \text { Hours })\end{array}$ & 73.6 & 74.1 \\
\hline $\begin{array}{c}\text { Day } 5 \\
(00: 00-23: 00 \text { Hours }) \\
\end{array}$ & 26.5 & 26.7 & $\begin{array}{c}\text { Day } 5 \\
(00: 00-23: 00 \text { Hours }) \\
\end{array}$ & 85.5 & 82.0 \\
\hline $\begin{array}{c}\text { Day 6 } \\
\text { (00:00-23:00 Hours) } \\
\end{array}$ & 27.9 & 27.4 & $\begin{array}{c}\text { Day 6 } \\
(00: 00-23: 00 \text { Hours }) \\
\end{array}$ & 77.5 & 80.9 \\
\hline $\begin{array}{c}\text { Day } 7 \\
(00: 00-23: 00 \text { Hours }) \\
\end{array}$ & 28.8 & 26.3 & $\begin{array}{c}\text { Day } 7 \\
(00: 00-23: 00 \text { Hours }) \\
\end{array}$ & 76.9 & 86.5 \\
\hline $\begin{array}{c}\text { Day } 8 \\
(00: 00-23: 00 \text { Hours }) \\
\end{array}$ & 27.8 & 27.1 & $\begin{array}{c}\text { Day } 8 \\
(00: 00-23: 00 \text { Hours }) \\
\end{array}$ & 82.1 & 83.6 \\
\hline $\begin{array}{c}\text { Day } 9 \\
(00: 00-23: 00 \text { Hours }) \\
\end{array}$ & 28.2 & 28.2 & $\begin{array}{c}\text { Day } 9 \\
(00: 00-23: 00 \text { Hours }) \\
\end{array}$ & 77.2 & 80.1 \\
\hline $\begin{array}{c}\text { Day 10 } \\
(00: 00-13: 30 \text { Hours }) \\
\end{array}$ & 28.9 & 28.4 & $\begin{array}{c}\text { Day 10 } \\
(00: 00-13: 30 \text { Hours }) \\
\end{array}$ & 70.9 & 79.2 \\
\hline $\begin{array}{c}\text { Day } 11 \\
(00: 00-13: 30 \text { Hours })\end{array}$ & 27.0 & 28.8 & $\begin{array}{c}\text { Day } 11 \\
(00: 00-13: 30 \text { Hours })\end{array}$ & 78.0 & 76.1 \\
\hline $\begin{array}{c}\text { Day 12 } \\
(00: 00-13: 30 \text { Hours }) \\
\end{array}$ & 28.6 & 27.3 & $\begin{array}{c}\text { Day } 12 \\
(00: 00-13: 30 \text { Hours }) \\
\end{array}$ & 74.3 & 80.2 \\
\hline $\begin{array}{c}\text { Day 13 } \\
\text { (00:00-13:30 Hours) } \\
\end{array}$ & 29.1 & 27.3 & $\begin{array}{c}\text { Day 13 } \\
(00: 00-13: 30 \text { Hours }) \\
\end{array}$ & 72.8 & 77.3 \\
\hline $\begin{array}{c}\text { Day } 14 \\
(00: 00-13: 30 \text { Hours }) \\
\end{array}$ & 29.0 & 27.6 & $\begin{array}{c}\text { Day } 14 \\
(00: 00-13: 30 \text { Hours }) \\
\end{array}$ & 70.3 & 78.7 \\
\hline $\begin{array}{c}\text { Day } 15 \\
(00: 00-13: 30 \text { Hours })\end{array}$ & 29.0 & 26.9 & $\begin{array}{c}\text { Day } 15 \\
(00: 00-13: 30 \text { Hours })\end{array}$ & 72.1 & 82.7 \\
\hline $\begin{array}{c}\text { Day 16 } \\
(00: 00-13: 30 \text { Hours }) \\
\end{array}$ & 29.1 & 26.0 & $\begin{array}{c}\text { Day 16 } \\
(00: 00-13: 30 \text { Hours }) \\
\end{array}$ & 72.3 & 87.5 \\
\hline $\begin{array}{c}\text { Day } 17 \\
(00: 00-13: 30 \text { Hours }) \\
\end{array}$ & 26.8 & 26.2 & $\begin{array}{c}\text { Day } 17 \\
(00: 00-13: 30 \text { Hours }) \\
\end{array}$ & 86.3 & 86.5 \\
\hline $\begin{array}{c}\text { Day 18 } \\
(00: 00-13: 30 \text { Hours }) \\
\end{array}$ & 27.8 & 27.3 & $\begin{array}{c}\text { Day 18 } \\
(00: 00-13: 30 \text { Hours }) \\
\end{array}$ & 84.0 & 81.7 \\
\hline
\end{tabular}




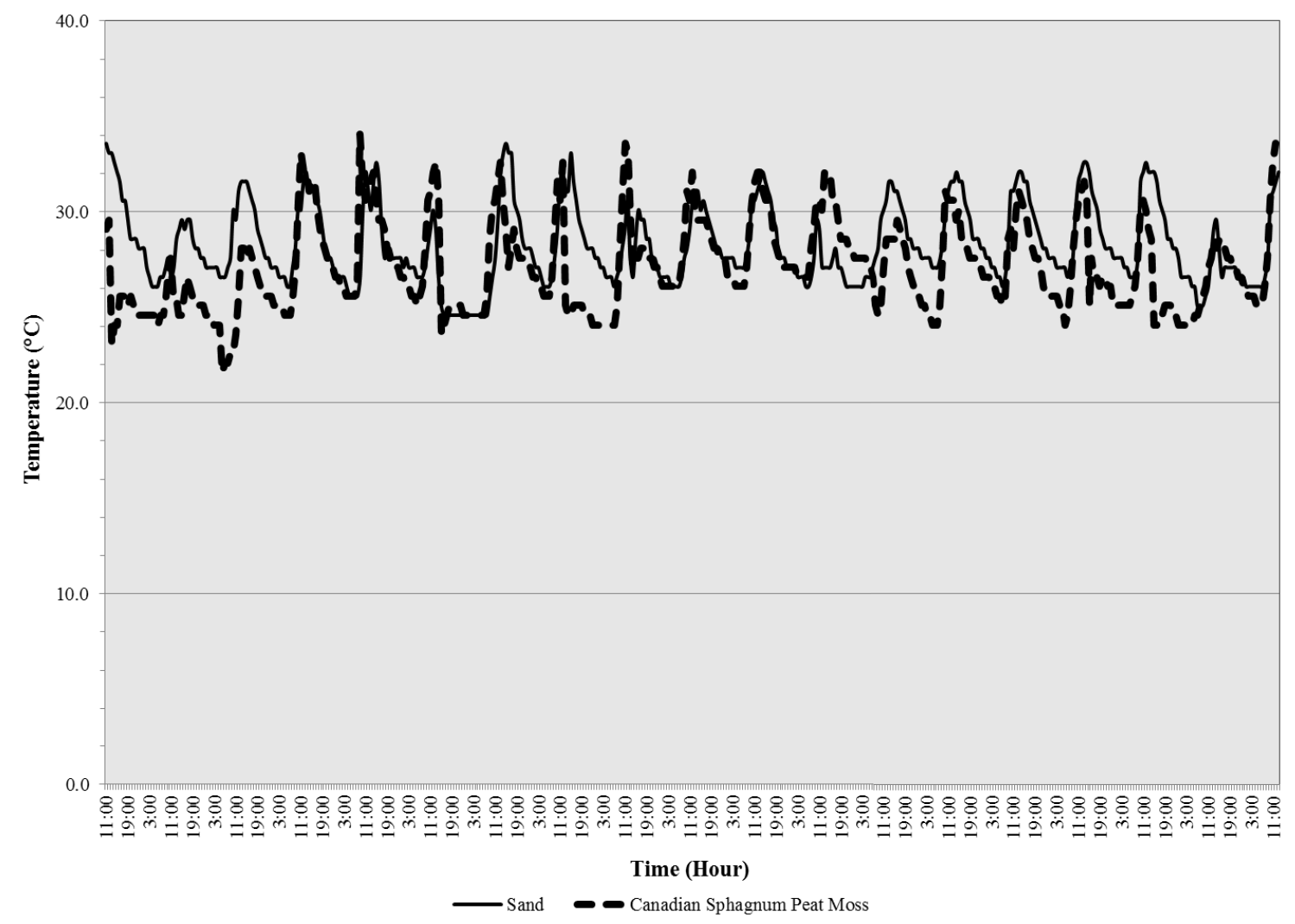

Figure 55: Line graph representing the hourly temperature recordings for both soil types.

\subsubsection{Visual Observations}

Photographs were taken of all mice throughout the course of each soil evaluation. As they were buried, physical assessments could not be made; however, changes in how the soil environment appeared were observed for those remains buried in sand. For instance, for those mice that had their top layer of soil disturbed, the sand was elevated above the remains on Day 2 and then receded on Day 4, whereas for those mice with an undisturbed soil environment, the sand elevated above the remains of only Mouse \#22 on Day 4 and then receded on Day 6. The sand for Mouse \#23 did not change in appearance 
throughout the course of the trial. For all mice buried in the Canadian Sphagnum peat moss, no physical changes to the soil environment were observed throughout the course of the trial. Photos taken prior to burial (Day 0) and upon disinterment (Day 18) are presented for each soil environment (Figures 56-57).
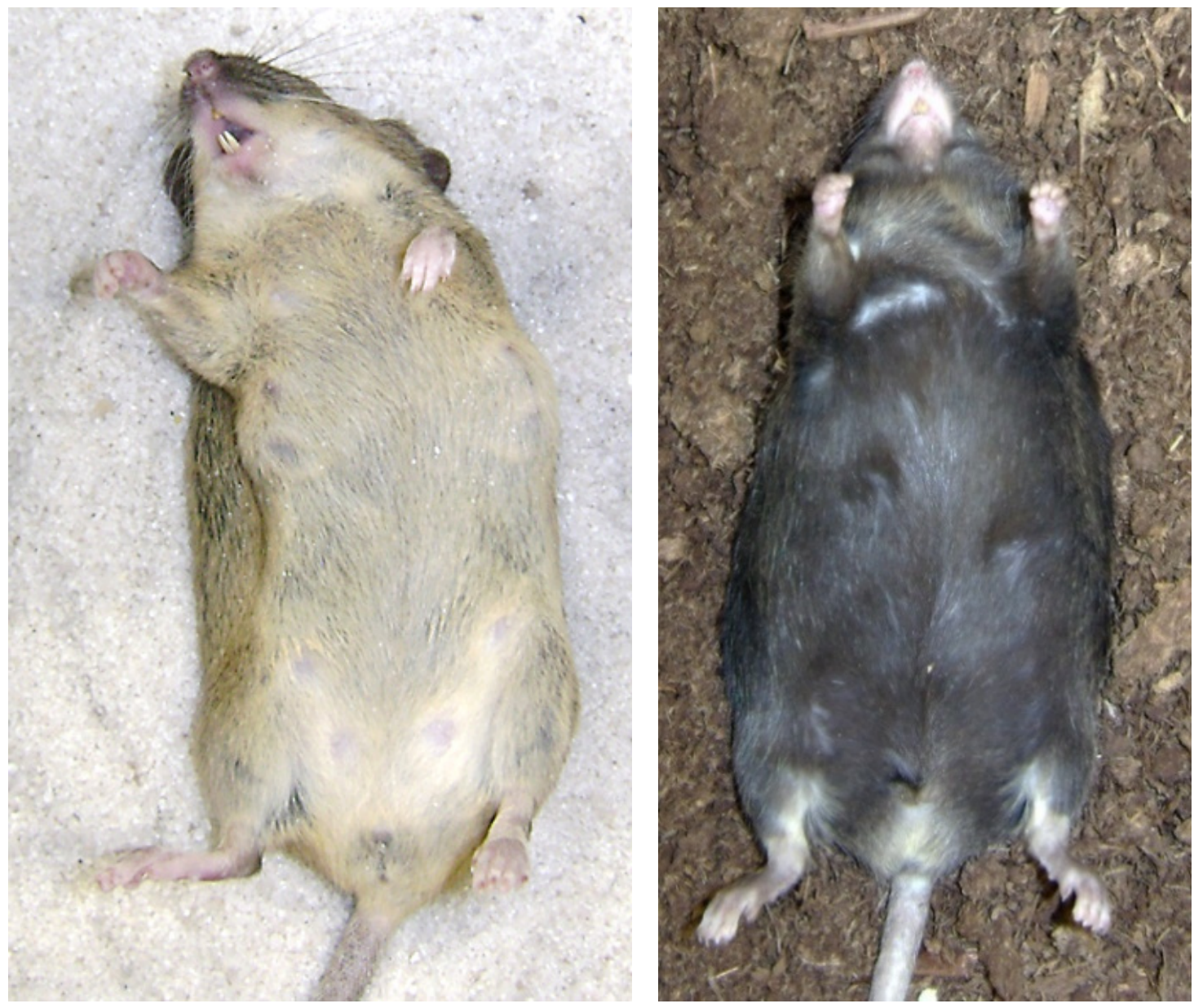

Figure 56: Remains prior to burial in Sand (left) and Canadian Sphagnum peat moss (right). 

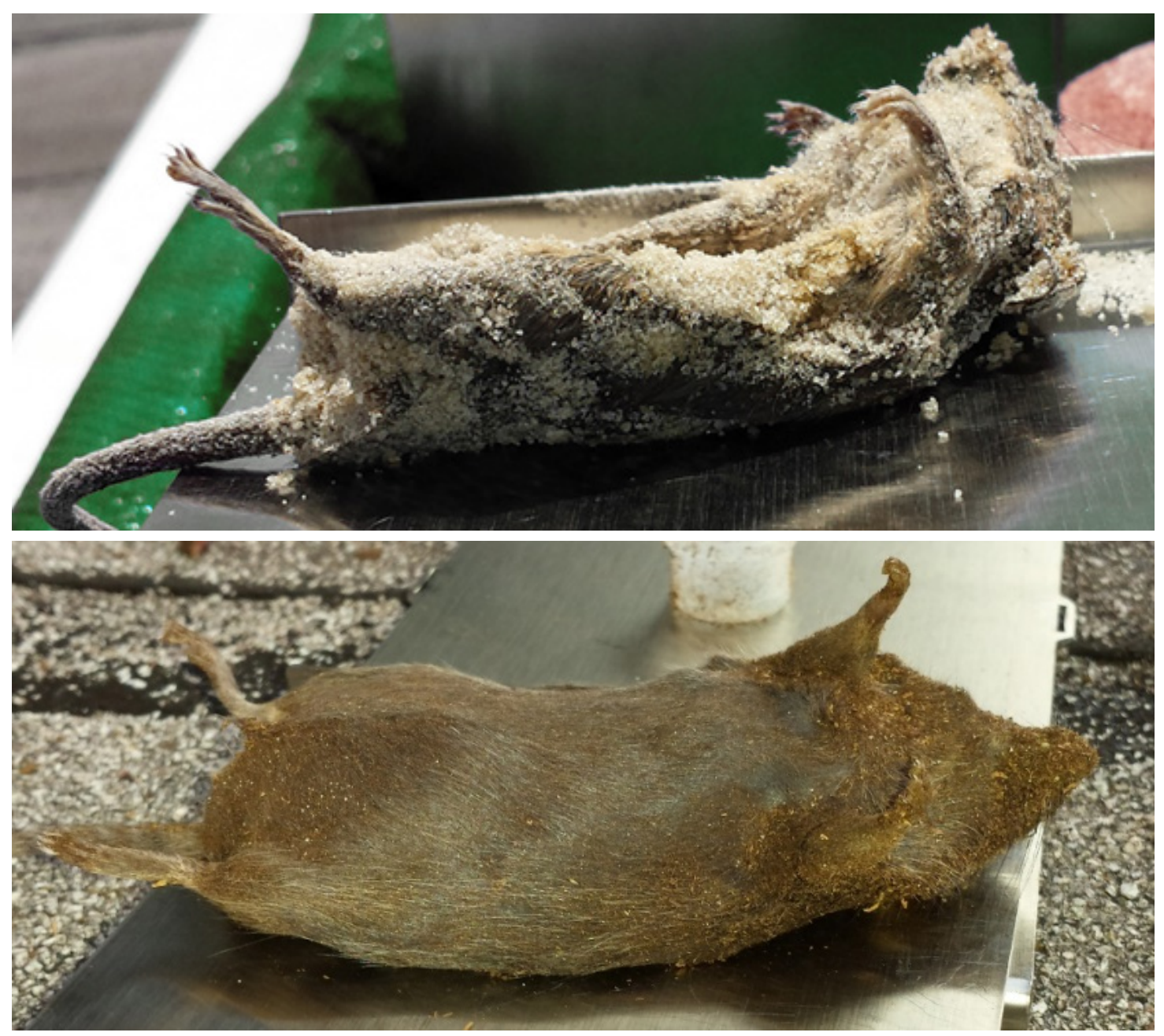

Figure 57: Remains upon disinterment from Sand (top) and Canadian Sphagnum peat moss (bottom).

Upon disinterment, all mice that were buried in the Canadian Sphagnum peat moss appeared as though they were in the early/bloat phase of decomposition. With regard to the remains buried in sand, both of the mice that experienced a disturbed environment, as well as Mouse \#22, which was in an undisturbed setting, seemed desiccated, mummified like, while Mouse \#23, which was also in an undisturbed soil environment, looked as if it was in the early/bloat stage of decay. 


\subsubsection{Temperature of Soil at Each Sampling Period}

Prior to sampling, the temperature of the soil was randomly measured in triplicate.

The results for both soil environments are presented in Table 27.

Table 27: Temperature measurements performed prior to sampling for both Sand and Canadian Sphagnum peat moss. (UN): Undisturbed soil environment; (DB): Disturbed soil environment.

\begin{tabular}{|c|c|c|c|c|c|c|c|c|c|c|c|c|c|c|c|}
\hline & \multicolumn{15}{|c|}{ Temperature $\left({ }^{\circ} \mathrm{C}\right)$ Measured at Each Sampling Period for Sand } \\
\hline & \multicolumn{3}{|c|}{ Day 0} & \multicolumn{3}{|c|}{ Day 2} & \multicolumn{3}{|c|}{ Day 4} & \multicolumn{3}{|c|}{ Day 6} & \multicolumn{3}{|c|}{ Day 8} \\
\hline & T1 & $\mathrm{T} 2$ & $\mathrm{~T} 3$ & T1 & $\mathrm{T} 2$ & $\mathrm{~T} 3$ & T1 & $\mathrm{T} 2$ & $\mathrm{~T} 3$ & T1 & $\mathrm{T} 2$ & T3 & T1 & $\mathrm{T} 2$ & $\mathrm{~T} 3$ \\
\hline UN-Blank & 28.3 & 26.8 & 27.2 & 27.8 & 27.5 & 27.8 & 26.3 & 26.3 & 26.7 & 25.9 & 25.6 & 25.7 & 27.2 & 27.3 & 27.6 \\
\hline UN-Mouse \#22 & 30.4 & 30.8 & 30.5 & 28.0 & 27.7 & 28.1 & 27.1 & 26.5 & 27.1 & 25.9 & 25.5 & 25.6 & 27.6 & 27.4 & 27.7 \\
\hline UN-Mouse \#23 & 28.5 & 29.8 & 28.5 & 28.0 & 27.8 & 28.0 & 26.6 & 26.4 & 26.9 & 25.9 & 25.5 & 25.7 & 27.8 & 27.5 & 27.9 \\
\hline DB-Mouse $\# 25$ & 30.6 & 31.5 & 29.9 & 28.5 & 28.0 & 28.8 & 27.1 & 27.3 & 27.8 & 25.7 & 25.8 & 25.8 & 27.6 & 27.7 & 27.9 \\
\hline DB-Mouse \#26 & 30.0 & 32.6 & 31.2 & 28.5 & 28.2 & 28.5 & 27.5 & 27.4 & 27.9 & 25.9 & 25.7 & 25.9 & 28.1 & 27.7 & 28.1 \\
\hline \multirow[t]{3}{*}{ DB-Blank } & 28.1 & 27.0 & 26.9 & 27.7 & 27.6 & 27.8 & 26.2 & 26.4 & 26.4 & 25.6 & 25.3 & 25.4 & 27.1 & 27.2 & 27.4 \\
\hline & \multicolumn{3}{|c|}{ Day 10} & \multicolumn{3}{|c|}{ Day 12} & \multicolumn{3}{|c|}{ Day 14} & \multicolumn{3}{|c|}{ Day 16} & \multicolumn{3}{|c|}{ Day 18} \\
\hline & T1 & $\mathrm{T} 2$ & T3 & T1 & $\mathrm{T} 2$ & T3 & $\mathrm{T} 1$ & $\mathrm{~T} 2$ & T3 & T1 & $\mathrm{T} 2$ & $\mathrm{~T} 3$ & T1 & $\mathrm{T} 2$ & T3 \\
\hline UN-Blank & 28.7 & 28.9 & 29.6 & 28.5 & 28.2 & 28.6 & 28.7 & 28.1 & 28.9 & 28.5 & 28.3 & 28.9 & 29.1 & 28.4 & 29.1 \\
\hline UN-Mouse \#22 & 29.7 & 29.3 & 30.7 & 28.9 & 28.4 & 29.1 & 29.2 & 28.3 & 29.6 & 29.6 & 29.6 & 30.5 & 30.4 & 29.3 & 30.3 \\
\hline UN-Mouse \#23 & 29.6 & 28.7 & 30.0 & 28.8 & 28.5 & 28.9 & 28.9 & 28.3 & 29.1 & 29.1 & 28.6 & 29.7 & 29.4 & 28.8 & 29.5 \\
\hline DB-Mouse \#25 & 29.6 & 29.5 & 30.3 & 28.8 & 28.6 & 28.9 & 29.2 & 28.5 & 29.5 & 30.2 & 29.6 & 30.6 & 30.3 & 29.5 & 30.6 \\
\hline DB-Mouse \#26 & 29.9 & 29.5 & 30.8 & 29.1 & 28.9 & 29.3 & 29.7 & 29.0 & 30.2 & 31.4 & 29.9 & 31.1 & 30.5 & 29.9 & 31.3 \\
\hline \multirow[t]{4}{*}{ DB-Blank } & 28.9 & 28.7 & 29.1 & 28.2 & 28.6 & 29.0 & 28.7 & 28.4 & 28.7 & 28.7 & 28.4 & 28.8 & 29.0 & 28.8 & 29.6 \\
\hline & \multicolumn{15}{|c|}{ Temperature $\left({ }^{\circ} \mathrm{C}\right)$ Measured at Each Sampling Period for Canadian Sphagnum Peat Moss } \\
\hline & \multicolumn{3}{|c|}{ Day 0} & \multicolumn{3}{|c|}{ Day 2} & \multicolumn{3}{|c|}{ Day 4} & \multicolumn{3}{|c|}{ Day 6} & \multicolumn{3}{|c|}{ Day 8} \\
\hline & T1 & $\mathrm{T} 2$ & $\mathrm{~T} 3$ & T1 & $\mathrm{T} 2$ & $\mathrm{~T} 3$ & T1 & $\mathrm{T} 2$ & $\mathrm{~T} 3$ & T1 & $\mathrm{T} 2$ & $\mathrm{~T} 3$ & T1 & $\mathrm{T} 2$ & $\mathrm{~T} 3$ \\
\hline UN-Blank & 27.3 & 26.1 & 26.2 & 23.0 & 22.8 & 22.7 & 28.6 & 28.5 & 28.6 & 27.4 & 27.4 & 27.9 & 29.8 & 29.4 & 29.6 \\
\hline DB-Mouse \#27 & 28.2 & 27.2 & 27.1 & 23.0 & 22.9 & 22.8 & 28.8 & 28.6 & 28.4 & 28.9 & 27.9 & 27.7 & 29.7 & 29.2 & 29.2 \\
\hline UN-Mouse \#28 & 28.5 & 28.0 & 27.8 & 22.7 & 22.6 & 22.7 & 28.9 & 28.3 & 28.2 & 28.2 & 27.6 & 27.6 & 28.6 & 28.3 & 28.2 \\
\hline DB-Mouse \#29 & 28.7 & 29.1 & 29.0 & 22.9 & 22.6 & 22.5 & 29.8 & 28.8 & 28.8 & 228.2 & 27.9 & 27.7 & 28.7 & 28.7 & 29.0 \\
\hline UN-Mouse \#30 & 29.2 & 29.5 & 29.3 & 22.8 & 22.7 & 22.7 & 29.2 & 29.0 & 29.1 & 28.5 & 28.0 & 27.9 & 29.1 & 28.6 & 29.0 \\
\hline \multirow[t]{3}{*}{ DB-Blank } & 31.3 & 29.7 & 30.1 & 22.6 & 22.8 & 22.7 & 29.6 & 29.7 & 30.4 & 28.9 & 28.1 & 28.1 & 29.4 & 29.6 & 30.8 \\
\hline & \multicolumn{3}{|c|}{ Day 10} & \multicolumn{3}{|c|}{ Day 12} & \multicolumn{3}{|c|}{ Day 14} & \multicolumn{3}{|c|}{ Day 16} & & Day 18 & \\
\hline & T1 & $\mathrm{T} 2$ & T3 & T1 & $\mathrm{T} 2$ & T3 & T1 & $\mathrm{T} 2$ & T3 & T1 & $\mathrm{T} 2$ & T3 & T1 & $\mathrm{T} 2$ & T3 \\
\hline UN-Blank & 30.2 & 29.7 & 29.4 & 24.6 & 24.7 & 24.7 & 30.3 & 29.4 & 29.0 & 29.1 & 28.6 & 28.4 & 28.9 & 28.9 & 28.9 \\
\hline DB-Mouse \#27 & 30.1 & 29.5 & 29.3 & 24.4 & 24.7 & 24.7 & 30.2 & 29.0 & 28.7 & 28.0 & 28.0 & 28.3 & 28.2 & 28.1 & 28.3 \\
\hline UN-Mouse \#28 & 29.0 & 28.7 & 28.3 & 24.8 & 25.0 & 25.0 & 29.1 & 28.7 & 28.7 & 28.1 & 28.2 & 28.5 & 27.8 & 27.8 & 27.8 \\
\hline DB-Mouse \#29 & 29.8 & 29.0 & 28.8 & 24.1 & 24.5 & 24.7 & 28.3 & 27.7 & 27.5 & 27.9 & 27.5 & 27.7 & 27.1 & 27.2 & 27.3 \\
\hline UN-Mouse \#30 & 29.0 & 28.9 & 29.0 & 24.3 & 24.7 & 24.6 & 28.2 & 28.6 & 28.5 & 27.6 & 27.8 & 27.9 & 27.0 & 26.9 & 27.0 \\
\hline DB-Blank & 29.0 & 28.7 & 28.8 & 21.3 & 24.7 & 25.0 & 28.2 & 27.9 & 28.2 & 28.0 & 27.9 & 28.2 & 27.5 & 27.4 & 27.5 \\
\hline
\end{tabular}

5.6.5. Volatile Organic Compounds Detected from Buried Remains

In this study, two different types of soil environments were evaluated: sand and Canadian Sphagnum peat moss, as well as the effects of disturbing the soil environment, via probing, had on the liberated volatile organic compounds.

A total of sixteen compounds were extracted from remains buried in sand and 
analyzed via HS-SPME/GC-MS. Using the Varian MS Workstation Software, Version 6.6 (Service Pack 1), all of the compounds that were detected were verified and quantitated using a seven-point external calibration curve that consisted of diluted standard mixtures (see Section 4.1.1. for listing). Table 28 displays the presence/absence of the VOCs that were identified over time. Upon initial inspection, it can be observed that when comparing the undisturbed versus disturbed soil environments a greater number of compounds were detected for those remains that experienced a disturbed environment. For instance, on Day 0 three compounds were identified for those remains that experienced a disturbed soil environment, whereas only one compound was detected for those mice that were in an undisturbed setting. By Day 2, those environments that were disturbed had more than three times the amount of compounds present than what was seen from those environments that were undisturbed. Thereafter, the number of VOCs identified for each sampling period ranged from 10-11 for those remains that were in an undisturbed environment while those that were in a disturbed setting detected between 9-14 compounds.

Dimethyl sulfide, a compound that was found to be highly prevalent in decomposing remains in their natural state, was minimally present. The type of compounds identified, as well as their frequency of occurrence differed between undisturbed and disturbed environments. For example, 2-methyl hexanoic acid appeared from only one mouse that was in an undisturbed setting while benzonitrile and 4-methylpentanoic acid only appeared in those mice that had their soil environments disturbed. Additionally, 2,2-dimethylbutane, 2,4-dimethylhexane, and 2-pentyl furan were detected more frequently in undisturbed environments while indole and butanoic acid, ethyl ester 


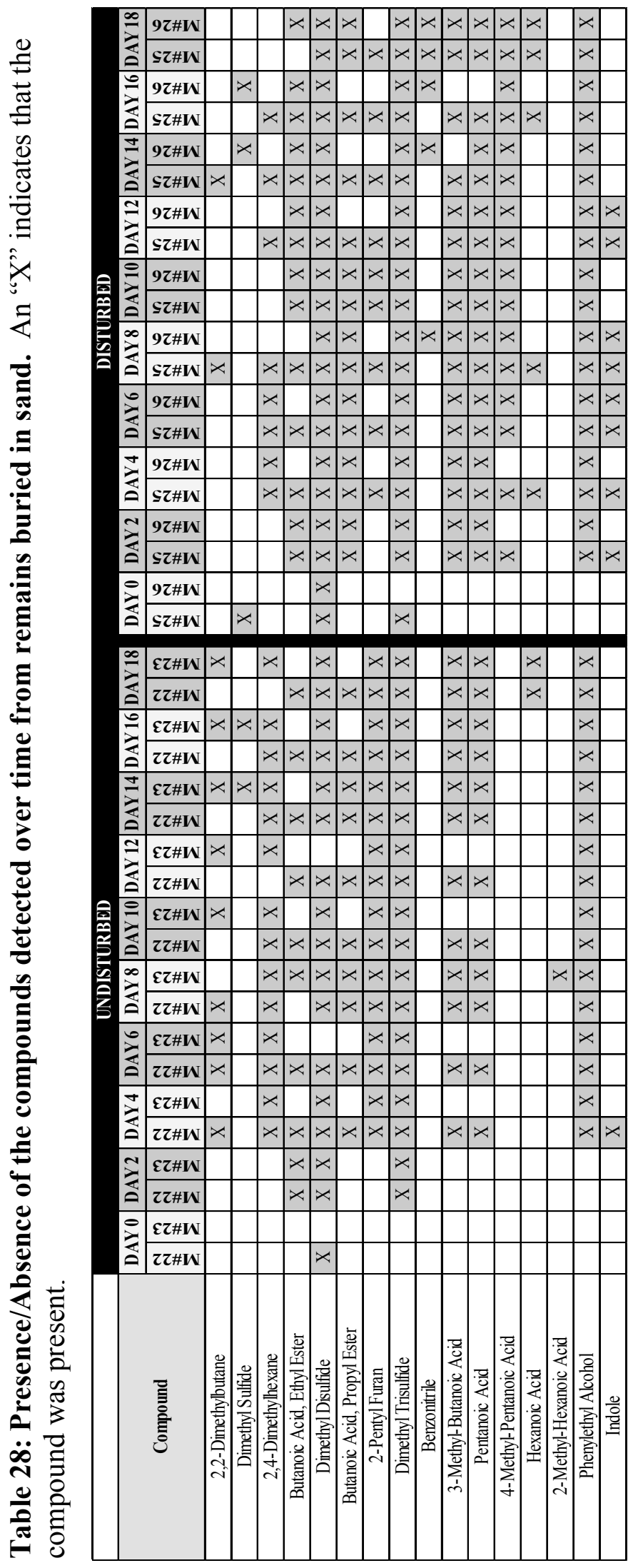


were most prevalent in those that were in a disturbed setting. It should be noted that both disturbed and undisturbed soil environments had common, frequently occurring compounds and they were dimethyl disulfide, dimethyl trisulfide, 3-methyl-butanoic acid, pentanoic acid, and phenylethyl alcohol.

Using the VOCs identified in Table 28, color charts representing the odor profiles for both undisturbed and disturbed soil environments were created (Figure 58). Upon visual inspection, it can be observed that the odor profiles for both settings (undisturbed and disturbed) varied as different compounds were most prevalent to each. Additionally, when making assessments of the compounds present within a setting type (disturbed and undisturbed) the mice that were placed in an undisturbed environment varied greatly in the type and amount of compounds present whereas for those that were in a disturbed setting had similar compounds and contributions. Moreover, the VOCs that contributed the most to the overall odor profile for each setting type were identified. The sulfurcontaining compounds (different shades of purple), 3-methyl-butanoic acid (lighter shade of blue), and 4-methyl-pentanoic acid (darker shade of blue) were identified as contributing most to the odor profiles from those remains that experienced a disturbed soil environment. However, for those remains in an undisturbed setting, butanoic acid ethyl ester (gray), pentanoic acid (light green), and 2,2-dimethylbutane (dark teal) were the VOCs that contributed most to the odor profile.

To expand upon the results, the total mass of compounds extracted were also assessed (Figure 59) to further investigate how disturbing the soil environment effected the liberation of volatile organic compounds. On Day 2 the detected abundance of VOCs were substantially greater for those remains that experienced a disturbed environment 


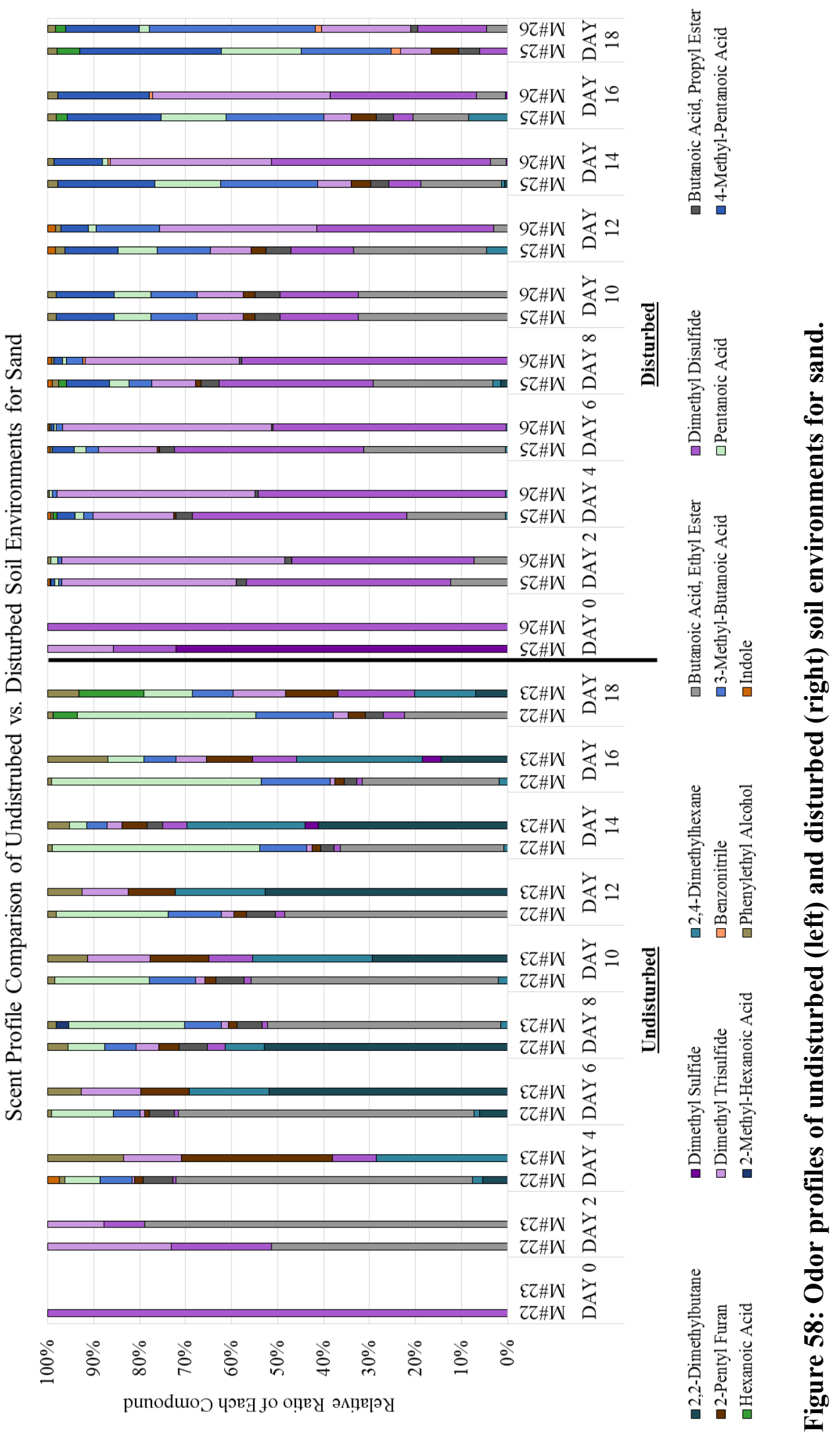




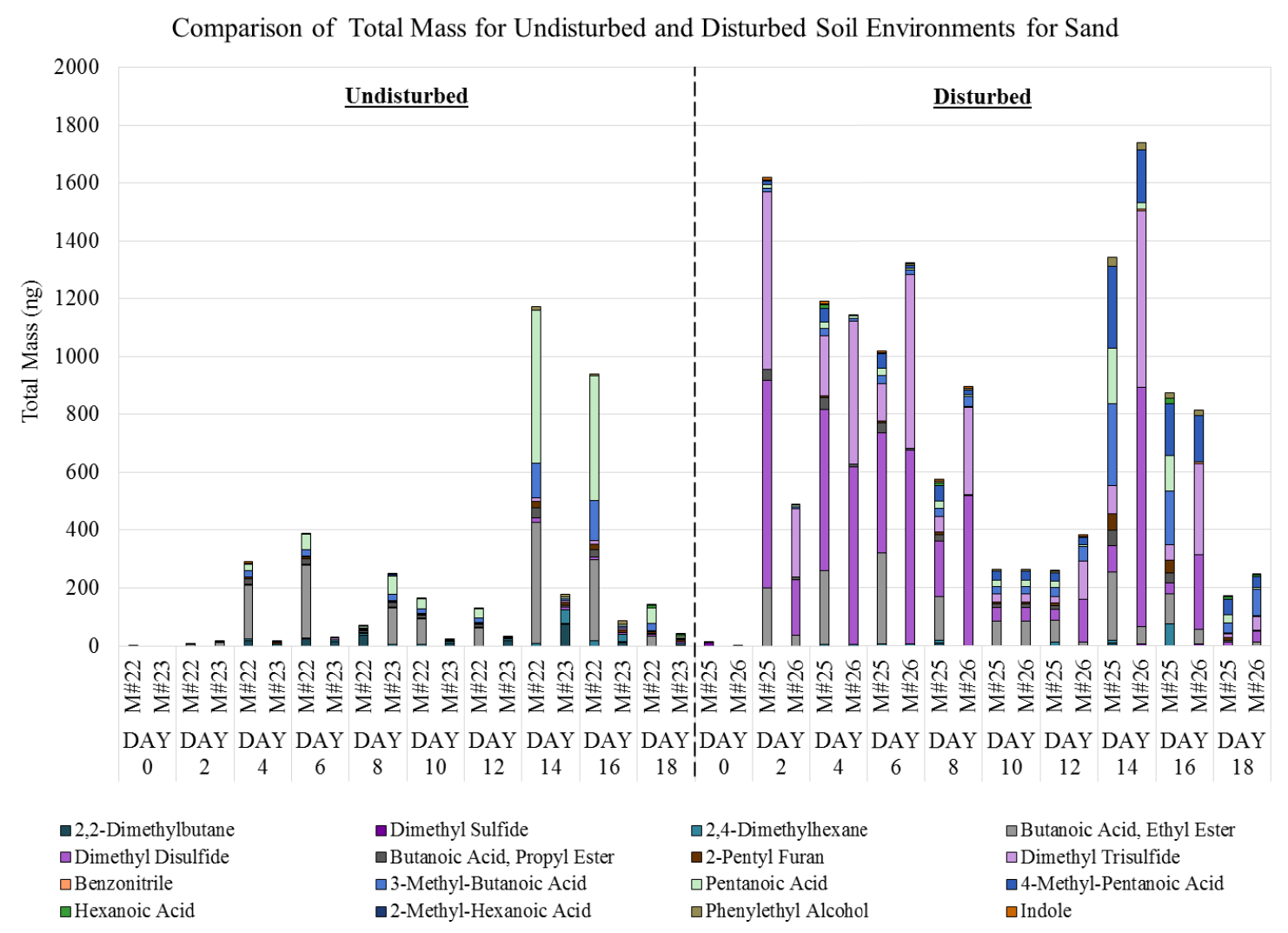

Figure 59: Comparison of the total mass extracted from undisturbed (left) and disturbed (right) soil environments for buried in sand.

than with those that were in an undisturbed setting. Although the remains progressed through the decomposition process, which was evident from the visual observations (see Section 5.6.3.), the total mass did not steadily increase in abundance, but instead it fluctuated throughout the entire 18 day study.

Remains placed in disturbed and undisturbed soil environments were also assessed using Canadian Sphagnum peat moss. Overall, a total of eleven decompositionassociated compounds were extracted and analyzed via HS-SPME/GC-MS. Using the Varian MS Workstation Software, Version 6.6 (Service Pack 1), all compounds detected were verified and quantitated using a seven-point external calibration curve that consisted 
of diluted standard mixtures (see Section 4.1.1. for listing). Table 29 displays the presence/absence of the VOCs that were identified over time.

Upon initial inspection, it can be observed that a greater number of compounds were detected from those remains that experienced a disturbed environment. At the beginning of the study (Day 0-6), 1-2 VOCs were identified from those remains in an undisturbed setting, whereas 2-6 compounds were detected from those in a disturbed environment. Thereafter, the number of VOCs identified for each sampling period ranged from 3-7 for those remains in an undisturbed setting while 6-11 compounds were liberated from those that were in a disturbed environment.

Differences in the type of compounds that were identified and their frequency of occurrence also differed between undisturbed and disturbed soil environments. Acetone, for example, appeared from only one mouse that did not experience a disturbed environment while butanoic acid propyl ester, 4-methyl-pentanoic acid, and hexanoic acid only appeared in those mice that experienced a disturbed environment. Additionally, 2,2-dimethylbutane appeared from one mouse in an undisturbed setting throughout the sampling period, whereas it appeared from both mice that had their environments disturbed. Interestingly, dimethyl trisulfide appeared in only one mouse that was in an undisturbed setting at Day 7, but with regard to those that experienced a disturbed environment, it appeared in Mouse \#28 on Day 2, in both mice from Days 4-8, thereafter, it only appeared in Mouse \#30 from Days 10-18. This was not the case with those remains buried in sand, where it appeared on Day 0 from one mouse placed in a disturbed environment, but then appeared on Day 2-18 from those remains that were buried in both 


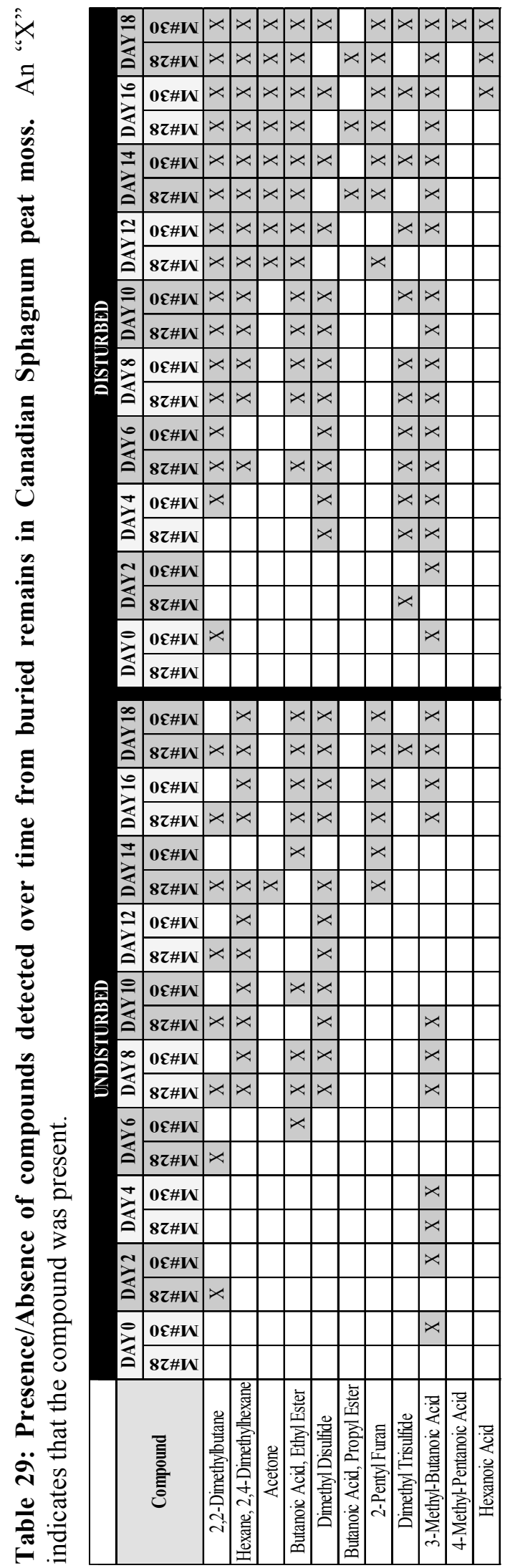


disturbed and undisturbed environments. It should be noted that only two compounds (dimethyl disulfide and 2,4-dimethylhexane) were identified as common, frequently occurring compounds from those remains that were buried in Canadian Sphagnum peat moss which was fewer than what was observed with those mice buried in sand which had five compounds.

Using the VOCs identified in Table 29, color charts representing the odor profiles for both undisturbed and disturbed environments were created (Figure 60). Upon visual inspection, it can be observed that the odor profiles of undisturbed and disturbed environments differed with respect to the most prevalent compounds. However, within the setting type (undisturbed and disturbed) there were similarities in the compounds that were present and their contributions. For instance, 3-methyl-butanoic acid (blue) was most prevalent from Days 0-4 for the undisturbed environments; thereafter, dimethyl disulfide (purple) and butanoic acid ethyl ester (gray) became the most contributing compounds in the odor profiles. For disturbed environments, 2,2-dimethylbutane (dark teal), 3-methyl-butanoic acid (blue), dimethyl disulfide (light purple), dimethyl trisulfide (dark purple) were the most contributing compounds from Days 0-10, but from Days 1218, acetone (dark reddish brown) appeared alongside dimethyl trisulfide to become the most contributing volatile organic compounds.

To expand upon these results, the total mass of compounds extracted from both types of environments were also assessed to further investigate the effect that disturbing the soil environment had on the liberated VOCs (Figure 61). Unlike that of the sand environment, a trend was observed in relation to the total mass of compounds extracted throughout the entire sampling period. For those remains that were placed in undisturbed 


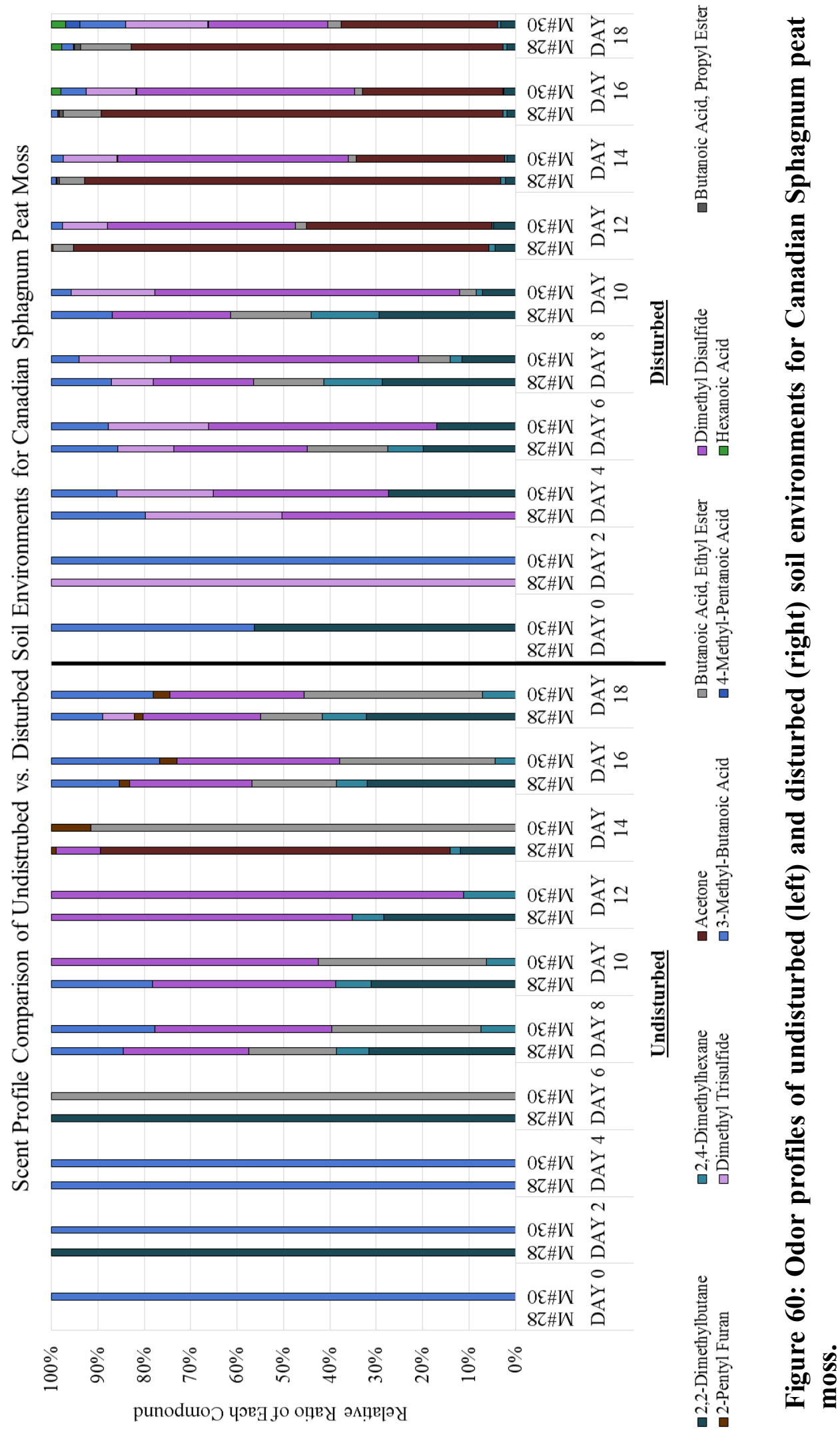




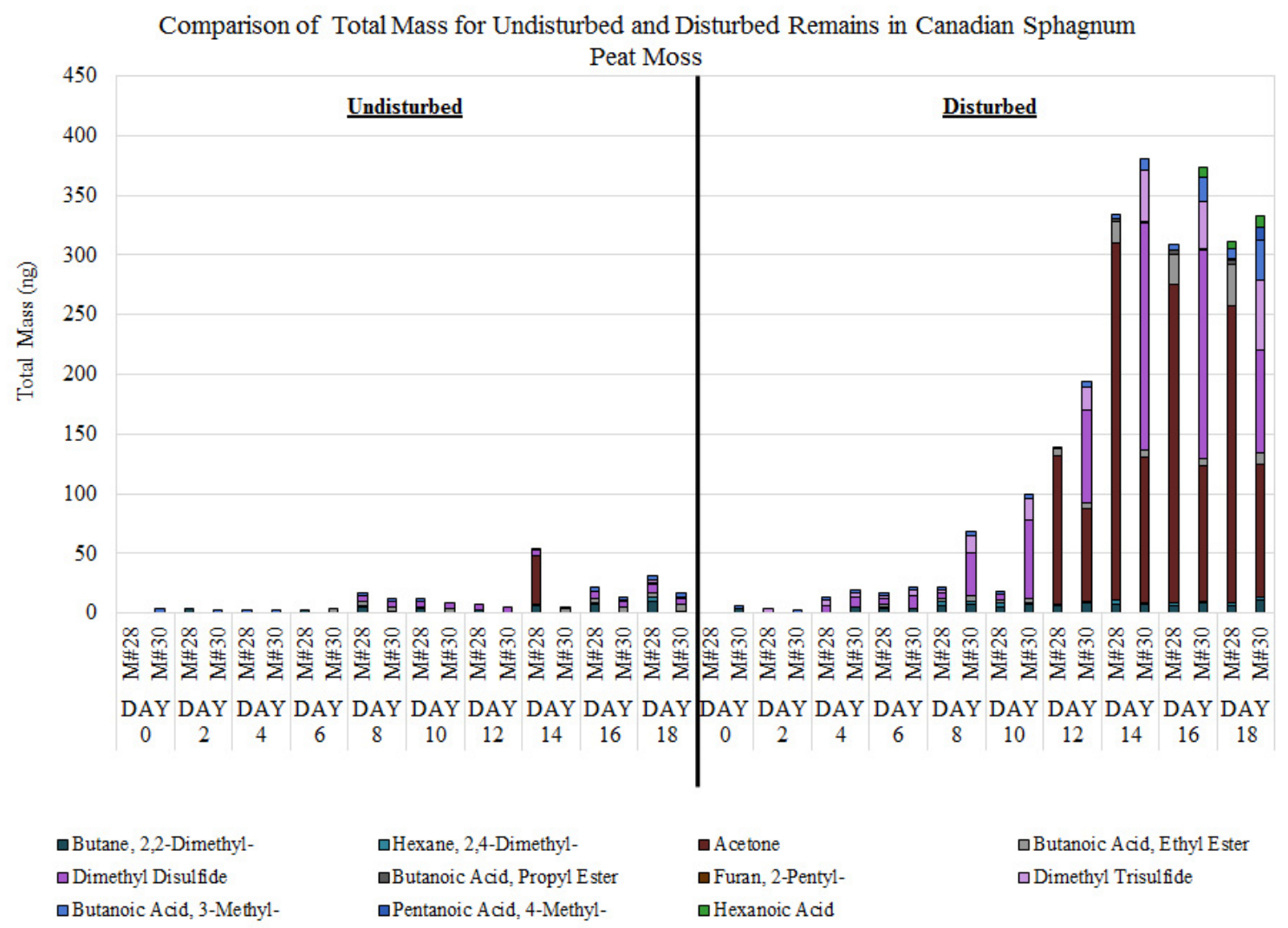

Figure 61: Comparison of the total mass extracted from undisturbed (left) and disturbed (right) soil environments for Canadian Sphagnum peat moss.

environments, the overall abundance of compounds stayed well below $100 \mathrm{ng}$ with minimal increases as the remains decomposed; however, the same could not be said for those mice that experienced a disturbed environment. Over time, as the remains decomposed a steady increase in the total mass of compounds extracted was observed resulting in a trend that would appear visually similar to a left-skewed curve.

As both soil environments were characteristically different, a comparison of the liberated VOCs from remains placed in undisturbed and disturbed environments of both 
sand and Canadian Sphagnum peat moss were assessed. Table 30 lists the compounds that were identified for both disturbed and undisturbed environments for each soil type.

Table 30: Comparison of the VOCs extracted from both soil environments. An "X" indicates that the compound was present.

\begin{tabular}{|c|c|c|c|c|}
\hline & \multicolumn{2}{|c|}{ Sand } & $\begin{array}{c}\text { Canadian Sphagnum Peat } \\
\text { Moss }\end{array}$ \\
\hline Compound & Undisturbed & Disturbed & Undisturbed & Disturbed \\
\hline 2,2-Dimethylbutane & $\mathrm{X}$ & $\mathrm{X}$ & $\mathrm{X}$ & $\mathrm{X}$ \\
\hline Dimethyl Sulfide & $\mathrm{X}$ & $\mathrm{X}$ & & \\
\hline 2,4-Dimethylhexane & $\mathrm{X}$ & $\mathrm{X}$ & $\mathrm{X}$ & $\mathrm{X}$ \\
\hline Acetone & & & $\mathrm{X}$ & $\mathrm{X}$ \\
\hline Butanoic Acid, Ethyl Ester & $\mathrm{X}$ & $\mathrm{X}$ & $\mathrm{X}$ & $\mathrm{X}$ \\
\hline Dimethyl Disulfide & $\mathrm{X}$ & $\mathrm{X}$ & $\mathrm{X}$ & $\mathrm{X}$ \\
\hline Butanoic Acid, Propyl Ester & $\mathrm{X}$ & $\mathrm{X}$ & & $\mathrm{X}$ \\
\hline 2-Pentyl Furan & $\mathrm{X}$ & $\mathrm{X}$ & $\mathrm{X}$ & $\mathrm{X}$ \\
\hline Dimethyl Trisulfide & $\mathrm{X}$ & $\mathrm{X}$ & $\mathrm{X}$ & $\mathrm{X}$ \\
\hline Benzonitrile & & $\mathrm{X}$ & & \\
\hline 3-Methyl-Butanoic Acid & $\mathrm{X}$ & $\mathrm{X}$ & $\mathrm{X}$ & $\mathrm{X}$ \\
\hline Pentanoic Acid & $\mathrm{X}$ & $\mathrm{X}$ & & \\
\hline 4-Methyl-Pentanoic Acid & & $\mathrm{X}$ & & $\mathrm{X}$ \\
\hline Hexanoic Acid & $\mathrm{X}$ & $\mathrm{X}$ & & $\mathrm{X}$ \\
\hline 2-Methyl-Hexanoic Acid & $\mathrm{X}$ & & & \\
\hline Phenylethyl Alcohol & $\mathrm{X}$ & $\mathrm{X}$ & & \\
\hline Indole & $\mathrm{X}$ & $\mathrm{X}$ & & \\
\hline
\end{tabular}

Overall, a total of seventeen compounds were identified from both soil environments. Six compounds were common in both soil environments regardless if they were disturbed or undisturbed, which included: 2,2-dimethylbutane, 2,4-dimethyl hexane, butanoic acid ethyl ester, dimethyl disulfide, 2-pentyl furan, and dimethyl trisulfide. Interestingly, 4-methyl-pentanoic acid was identified from both soil types, but only when they were disturbed. Additionally, it was discovered that some compounds were only 
detected from those mice buried in a specific soil environment. For instance, benzonitrile, 2-methyl-hexanoic acid, phenylethyl alcohol, indole, and dimethyl sulfide

were detected from remains buried in sand, whereas acetone was only found from those remains buried in Canadian Sphagnum peat moss.

To further investigate the differences between both soil types, the total mass of compounds extracted from all of the mice in both types of settings (disturbed and undisturbed) were assessed (Figure 62). The remains buried in sand generated a greater number and mass of compounds in comparison to those remains buried in Canadian Sphagnum peat moss. Thus, the type of soil in which the remains are buried, not only affects the manner in which it decays, but it also impacts the type and abundance of VOCs released. 


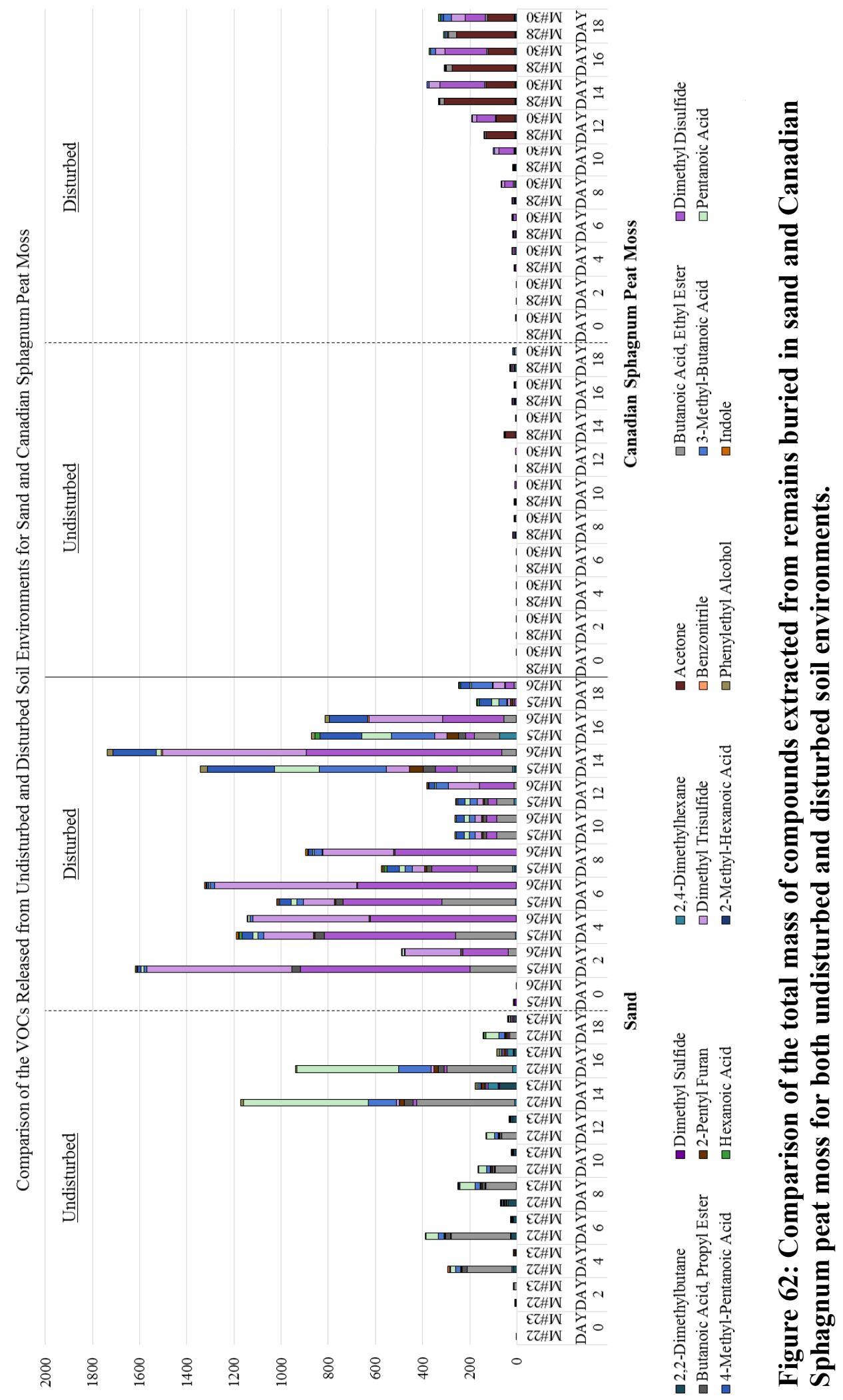

(ฮิน) SseW [вาОL 


\subsection{Evaluation of the VOCs Released from Human Remains}

The purpose of this study was to evaluate the scent of death at various stages of decomposition to determine if each phase was comprised of specific compounds or if there are common compounds present throughout the course of decomposition.

\subsubsection{Subject Information}

Overall, a total of twenty-eight subjects were sampled over a period of four weeks. Several of the subjects were sampled multiple times as they transitioned through the different stages of decay. Two subjects, D55-2013 and D57-2013, were sampled twice in the same stage of decay. Pretreated collection materials were sent to the Forensic Anthropology Center at Texas State in a total of ten batches, labelled A-J, and was used to sample the subjects; thereafter, the materials were shipped back to FIU for instrumental analysis.

Tables 31 and 32 list the subjects' identification number, sex, age, approximate weight at death, cause of death, autopsied (if known), the stage of decomposition at the time of sampling using the torso score described in Megyesi et al. [26], the approximate temperature at the time in which they were sampled, as well as the particular batch that was used to sample the subject. Those subjects that were sampled on more than one occasion are highlighted in green. 


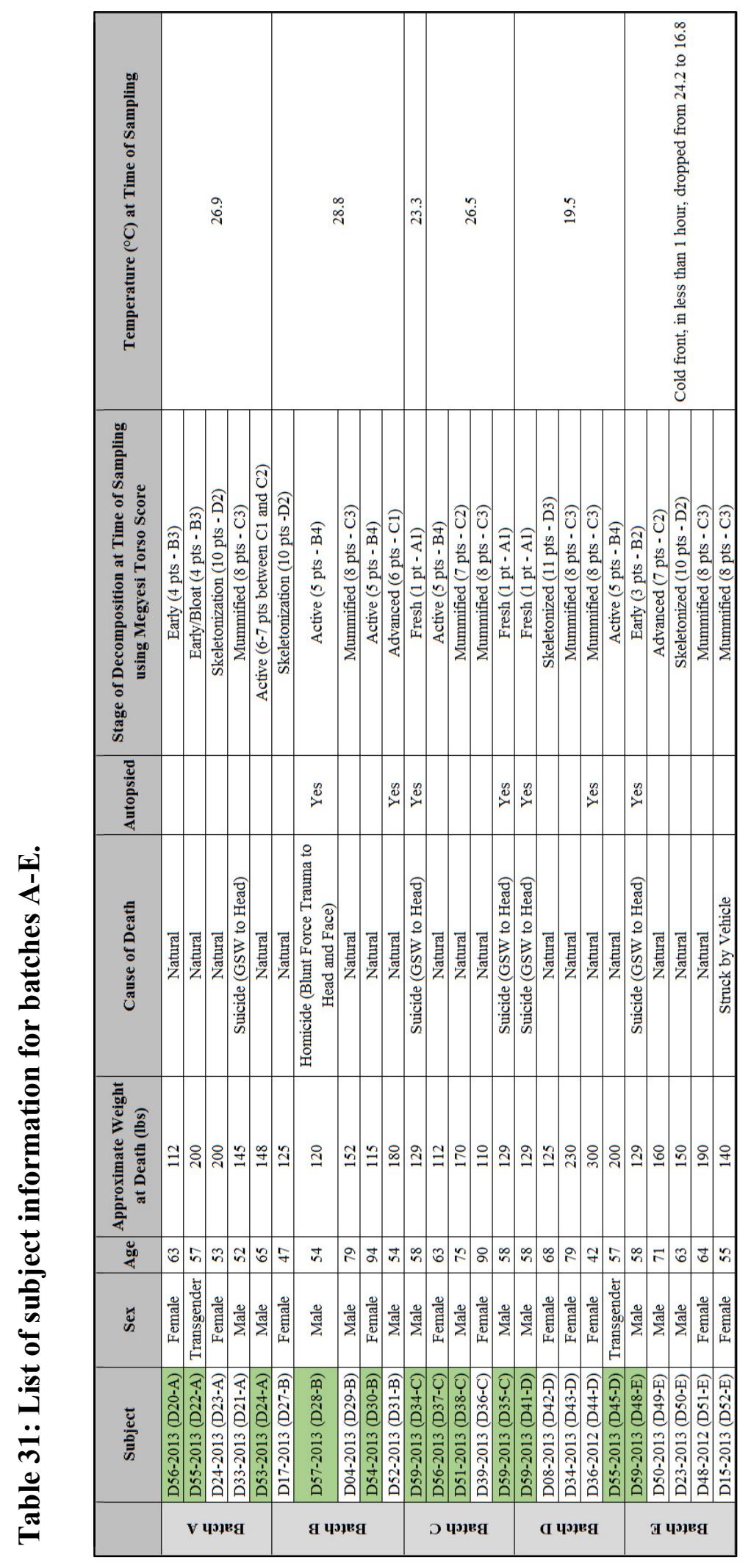




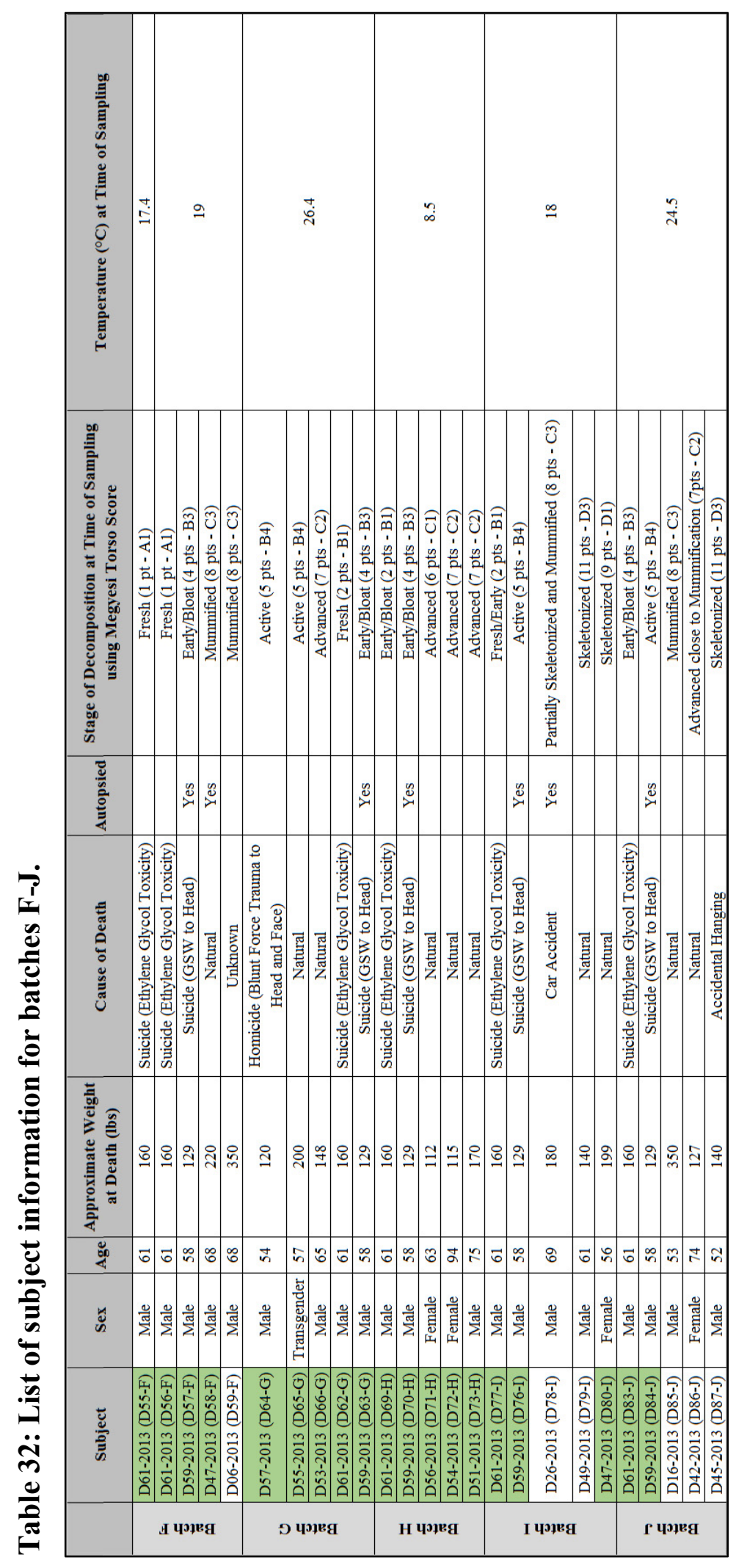




\subsubsection{Visual Observations}

Photographs of all subjects were taken on the day they were sampled. For the purpose of simplicity, photos depicting each stage of decomposition for one subject are presented in Figures 64-68.

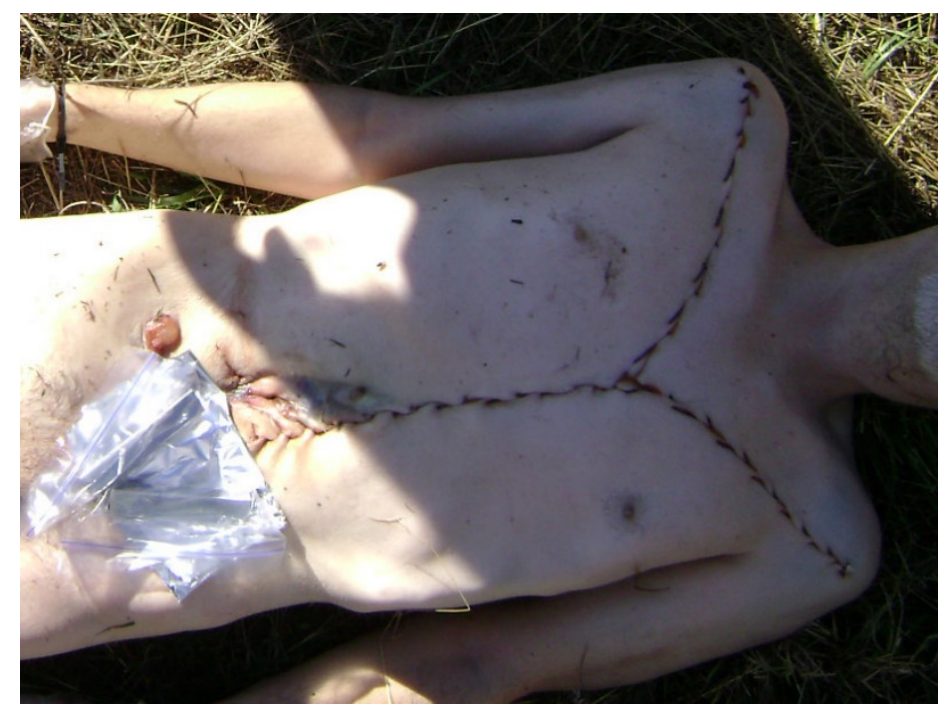

Figure 63: Subject D59-2013 - Stage of Decay Fresh

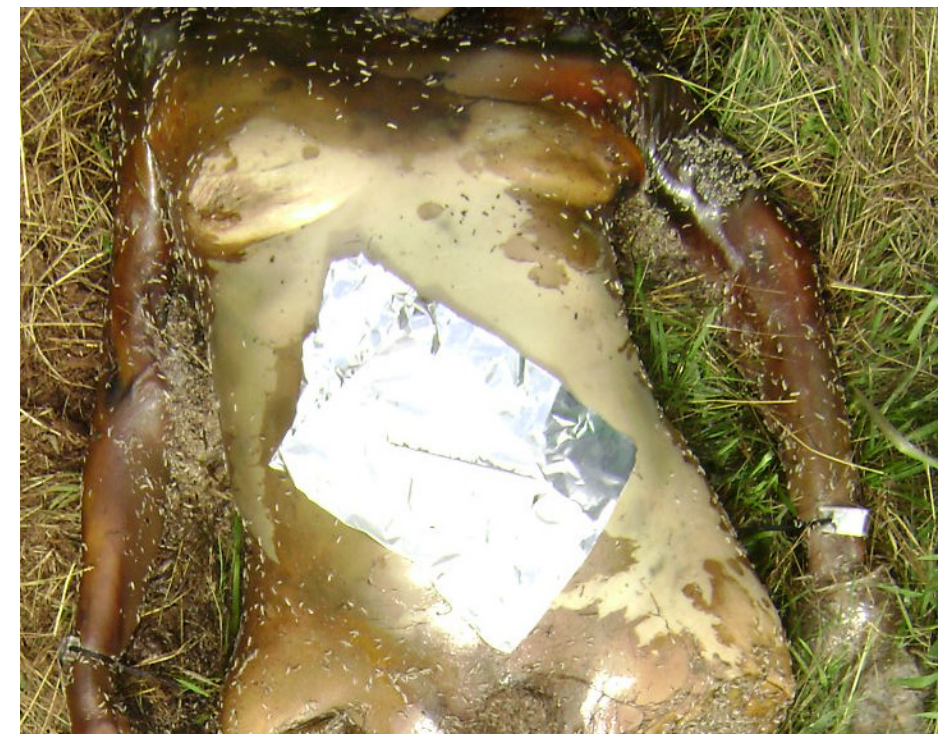

Figure 64: Subject D56-2013 - Stage of Decay Early/Bloat 


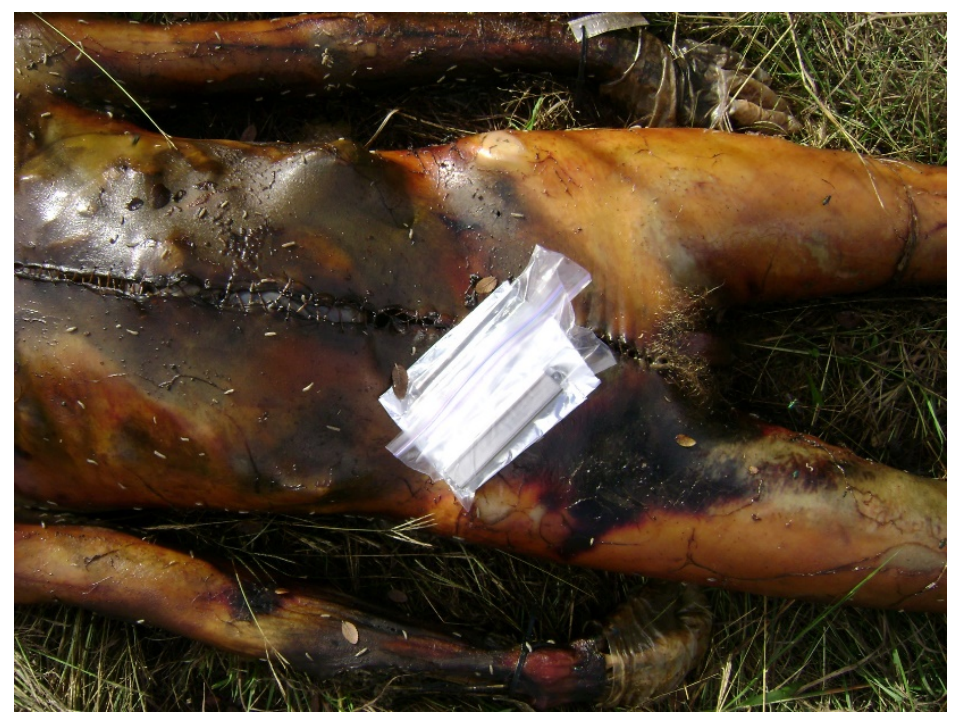

Figure 65: Subject D57-2013 - Stage of Decay Active 


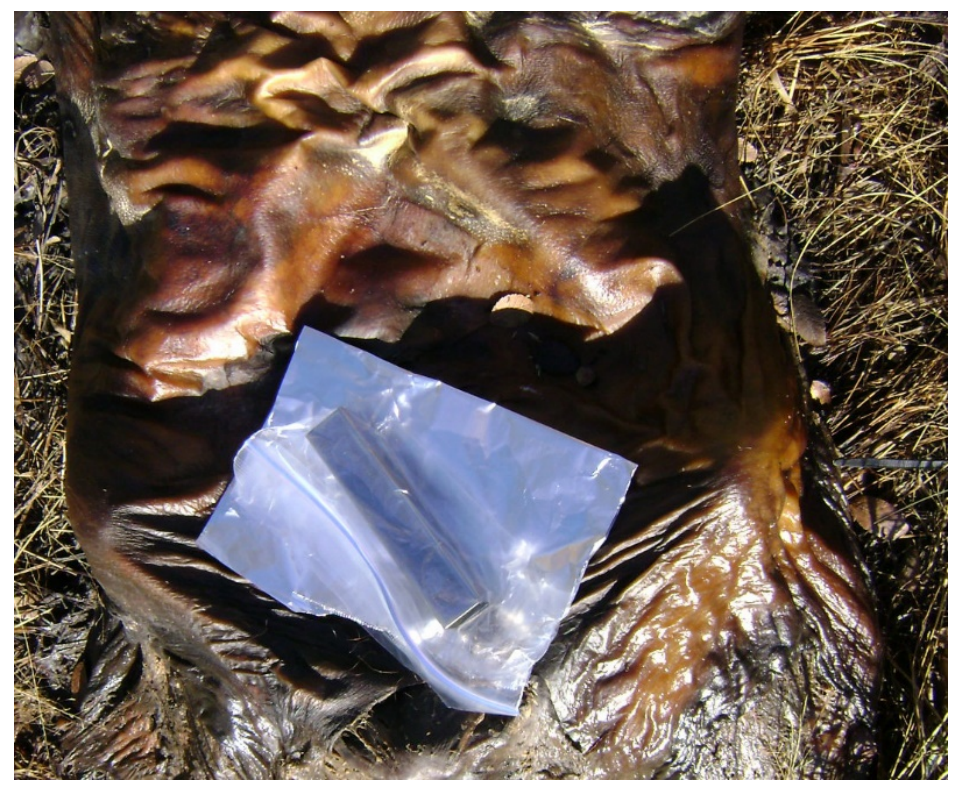

Figure 66: Subject D56-2013 - Stage of Decay Advanced 


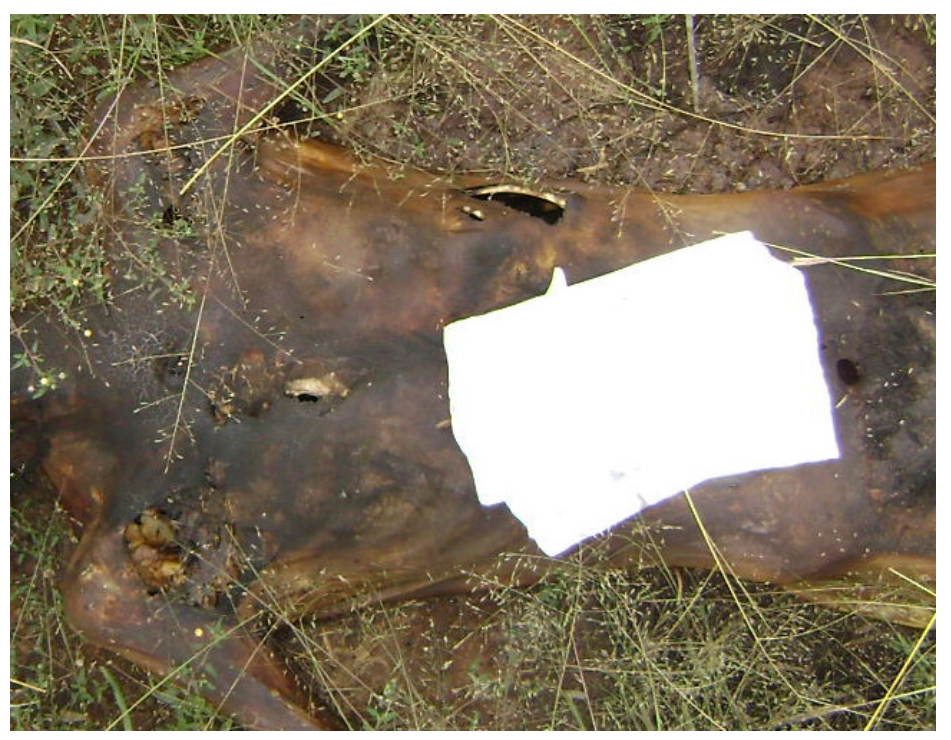

Figure 67: Subject D33-2013 - Stage of Decay Mummification 


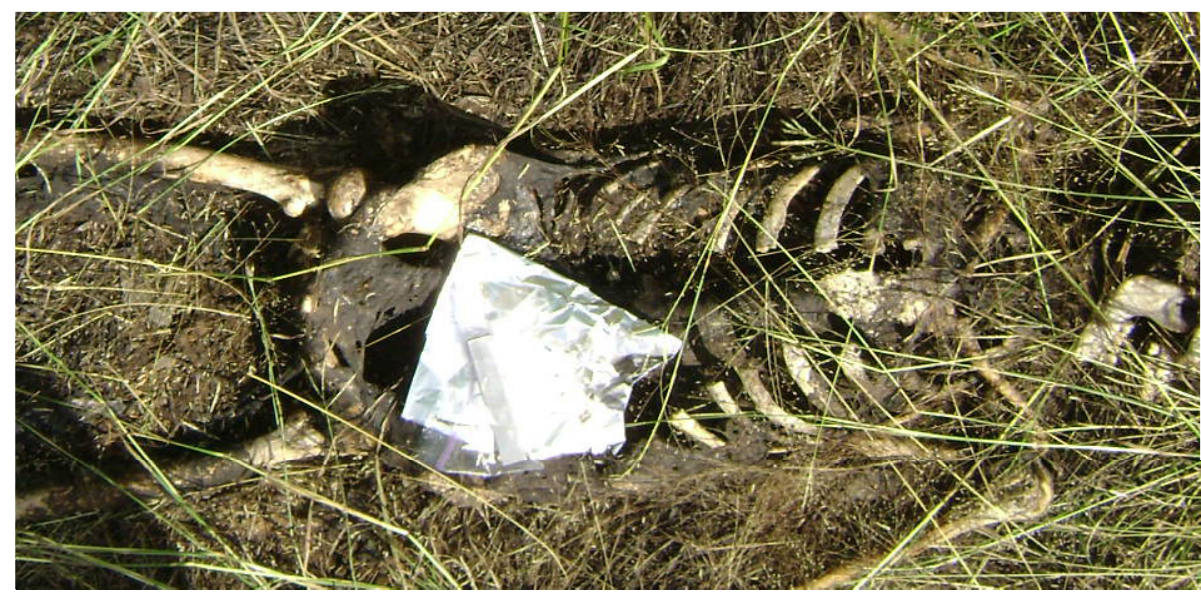

Figure 68: Subject D24-2013 - Stage of Decay - Skeletonization

5.7.3. Volatile Organic Compounds Released from Decomposing Human Remains

Six different stages of decomposition were evaluated and they included: fresh, early/bloat, active decay, advanced decay, mummification, and skeletonization. Eight subjects were sampled for each of these groups, except for mummification in which there were ten.

A total of twenty-six decomposition-associated compounds were identified via HS-SPME/GC-MS. Using the Varian MS Workstation Software, Version 6.6 (Service Pack 1), all compounds detected were verified and quantitated using a seven-point external calibration curve that consisted of diluted standard mixtures (see Section 4.1.1. for listing). Table 33 displays the presence/absence of the VOCs that were identified from a minimum of one subject for each stage of decomposition that was evaluated. 
According to current literature, twelve of the twenty-six VOCs identified were never previously found to be released from human remains. Thus, this study was the first to report 2,4-dimethylhexane, 3-methyl-butanoic acid, 4-methyl-pentanoic acid, 2methyl-hexanoic acid, benzenepropanoic acid ethyl ester, phenylethyl alcohol, pyridine, (E)-2-octenal, (E)-2-nonenal, dodecanal, nonadecane, and 1-hexadecanol as VOCs from decomposing human remains. Although the compounds listed in Table 33 were found in a minimum of one subject for each phase of decay, common compounds were still identifiable across all stages of decomposition; they included: 2,4-dimethylhexane, acetophenone, 3-methyl-butanoic acid, phenylethyl alcohol, 2-heptanone, heptanal, octanal, (E)-2-octenal, 1-octen-3-ol, (E)-2-nonenal, and 4-methyl phenol, were observed.

Further inspection of Table 33 revealed that dimethyl sulfide was solely discovered in the mummification stage, unlike that of decomposing human cadaver analogues (in their natural state) in which dimethyl sulfide was discovered in the first three stages of decomposition: fresh, early/bloat, and active decay. Additionally, benzonitrile only appeared in the early/bloat phase of human remains, but was not found to be released from decomposing human cadaver analogues in their natural state. Moreover, hexanoic acid, 2-methyl-hexanoic acid, benzenepropanoic acid ethyl ester, 2,2-dimethylbutane, and 3-methyl-1H-indole were discovered in the early/bloat and active decay stage of human decomposition, whereas 2,2-dimethylbutane and 3-methyl$1 \mathrm{H}$-indole were not found in the odors released from decomposing human cadaver analogues in their natural state. 


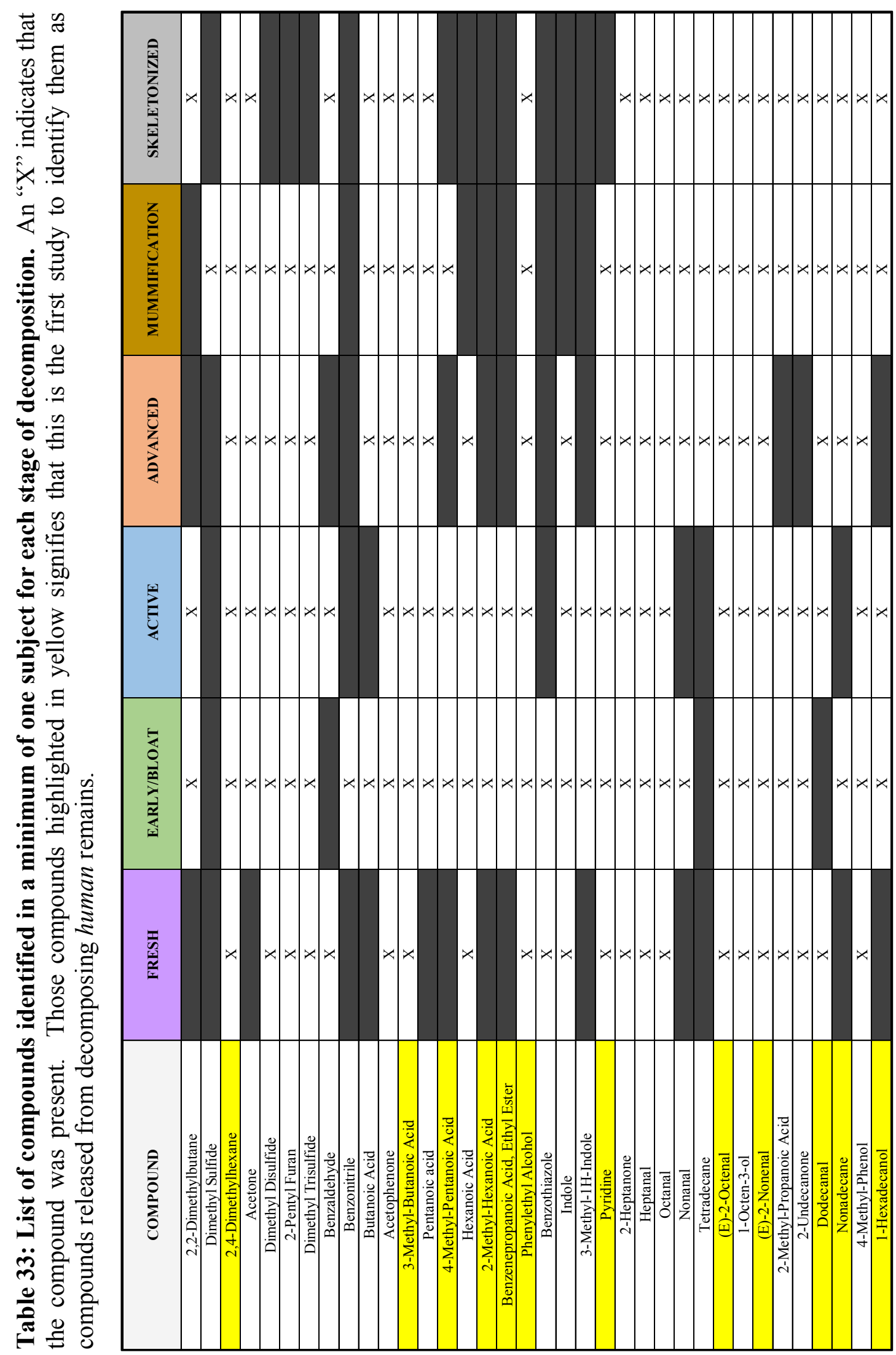


To further investigate the odors released from decomposing human remains, common compounds in each stage of decomposition needed to be determined. Therefore, those VOCs that were present in more than $70 \%$ of the subjects sampled, for each stage of decomposition, were classified as common compounds and are listed in Table 34. A total of twelve compounds were identified: two for the fresh stage, twelve for early/bloat, eleven for active decay, nine for advanced decay, five for mummification, and none for skeletonization. It must be noted that only one compound, (E)-2-octenal, was what separated the early/bloat and active decay stage as they shared the remaining eleven compounds. Common VOCs were identified within the fresh, early/bloat, active decay, advanced decay, and the mummification stages; however, no compounds were shared across all stages of decay. 


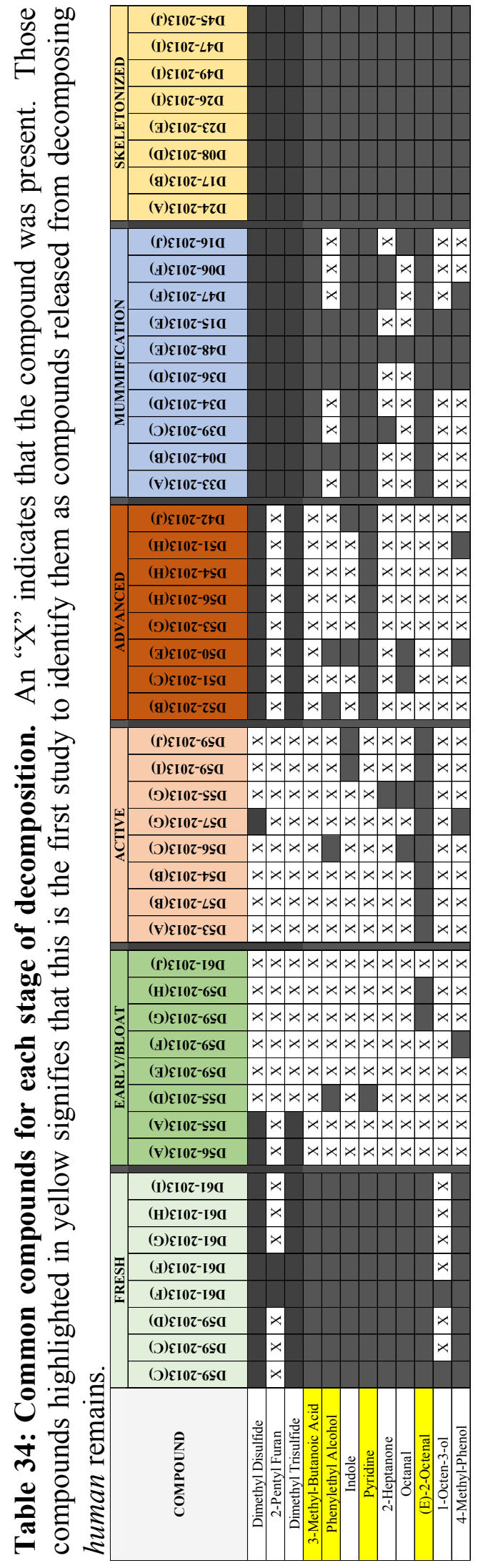


Using the common compounds that were identified for each stage of

decomposition, odor profiles for each subject were generated (Figure 69).

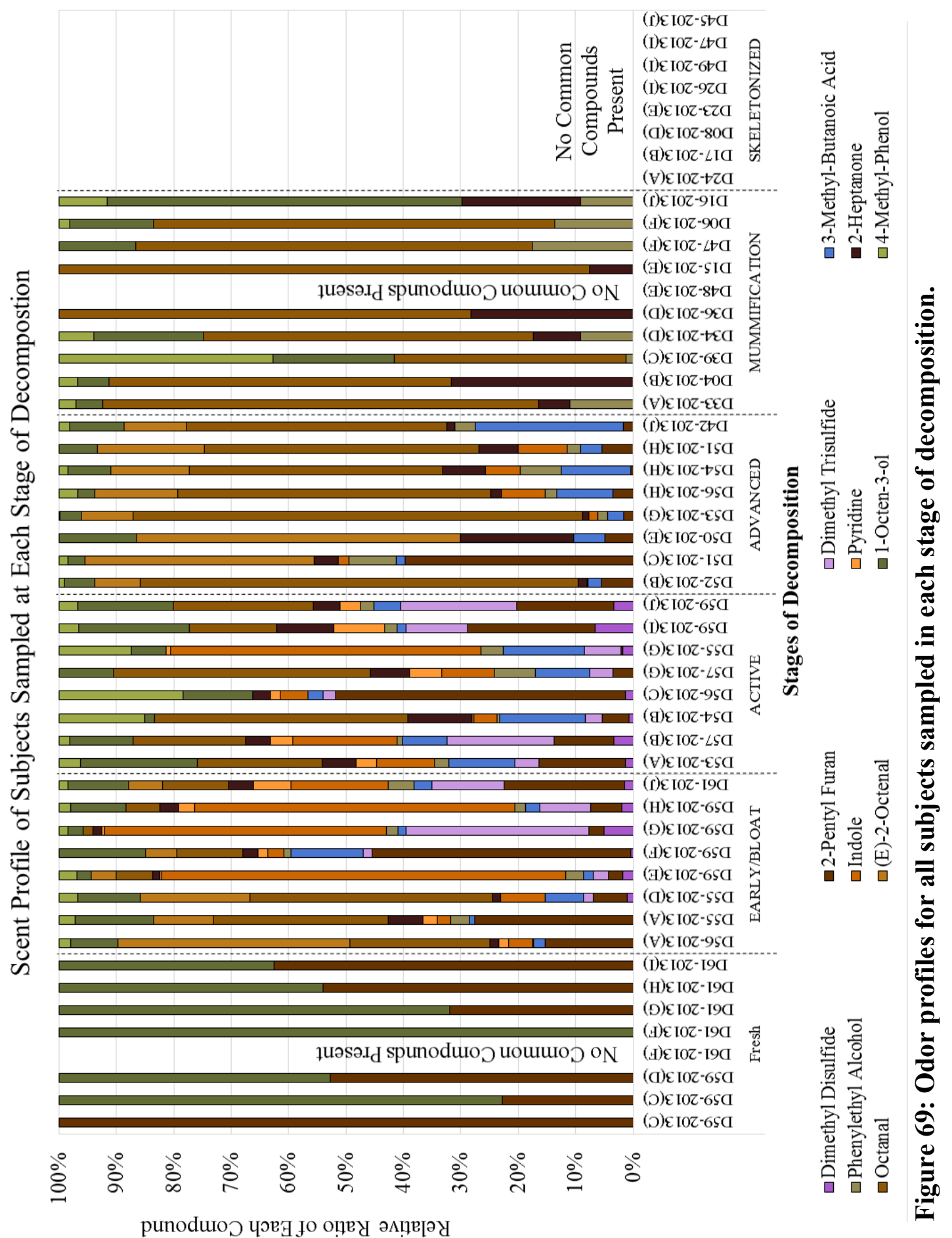


Since, each color bar represents a different VOC and its length is representative of the relative abundance or percent of that compound to the total composition of the odor profile. It can be observed that the individual subjects within the fresh decomposition stage appear to have relatively similar odor profiles. The same is true for those subjects within both the advanced decay and mummification stages. However, those subjects within the early/bloat and active decay stage do not vary greatly between each other. These results do not mimic those that were obtained for the human cadaver analogues that decomposed in their natural state (see Section 5.4.4.). In that study, the type and relative abundance of each compound for both the early/bloat and active decay stages were similar, with minimal variation, as was shown from the results obtained using PCA and HCA. Thus, for this study PCA was performed using the normalized data to determine if cluster formation occurs for each stage of decomposition, as was seen with the human cadaver analogues. A plot of the first three principal components presented in Figure 70 revealed four clusters of which three represented the fresh, advanced decay, and mummification stage, and the fourth consisted of the early/bloat (green) and active decay (blue) phases. Subsequently, HCA was performed on the normalized data to assess the similarities between each stage of decay (Figures 71 and 72). Groupings within the dendogram highlight the similarities between each subject resulting in the formation of clusters which correlates to either the fresh, advanced decay, or mummification stage. However, HCA also revealed similarities between the early/bloat and active decay stages. Thus, the findings from HCA are in agreement with PCA - there are specific compounds associated with the different phases of decomposition; however, for the early/bloat and active decay stages, the VOCs identified were too similar to distinguish each stage. 


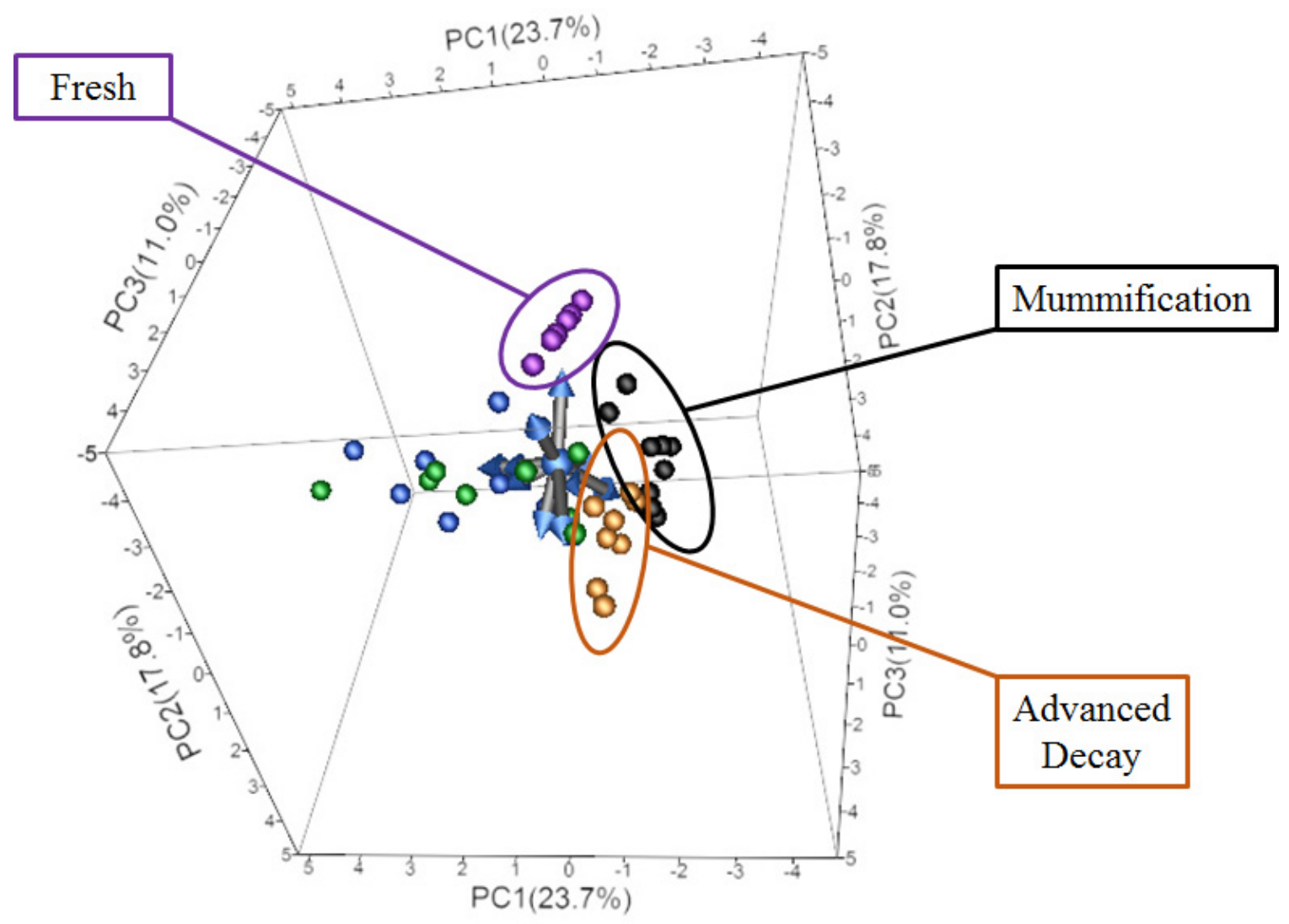

Figure 70: PCA analysis revealing three clusters which is representative of three different stages of decomposition.

It should be noted that each subject was classified into a specific stage of decay based upon the visual observations of their torso region according to the Megyesi Torso Score [26]. Assessment was conducted in this fashion because for some subjects their extremities (e.g., upper thigh region, head, arms, etc.) were more decayed than their torso as tissue was removed for HRD canine training or injuries that occurred at death, such as a self-inflicted gunshot wound or car accident. These factors could have attributed to the inability to distinguish between the early/bloat and active decay stages. 


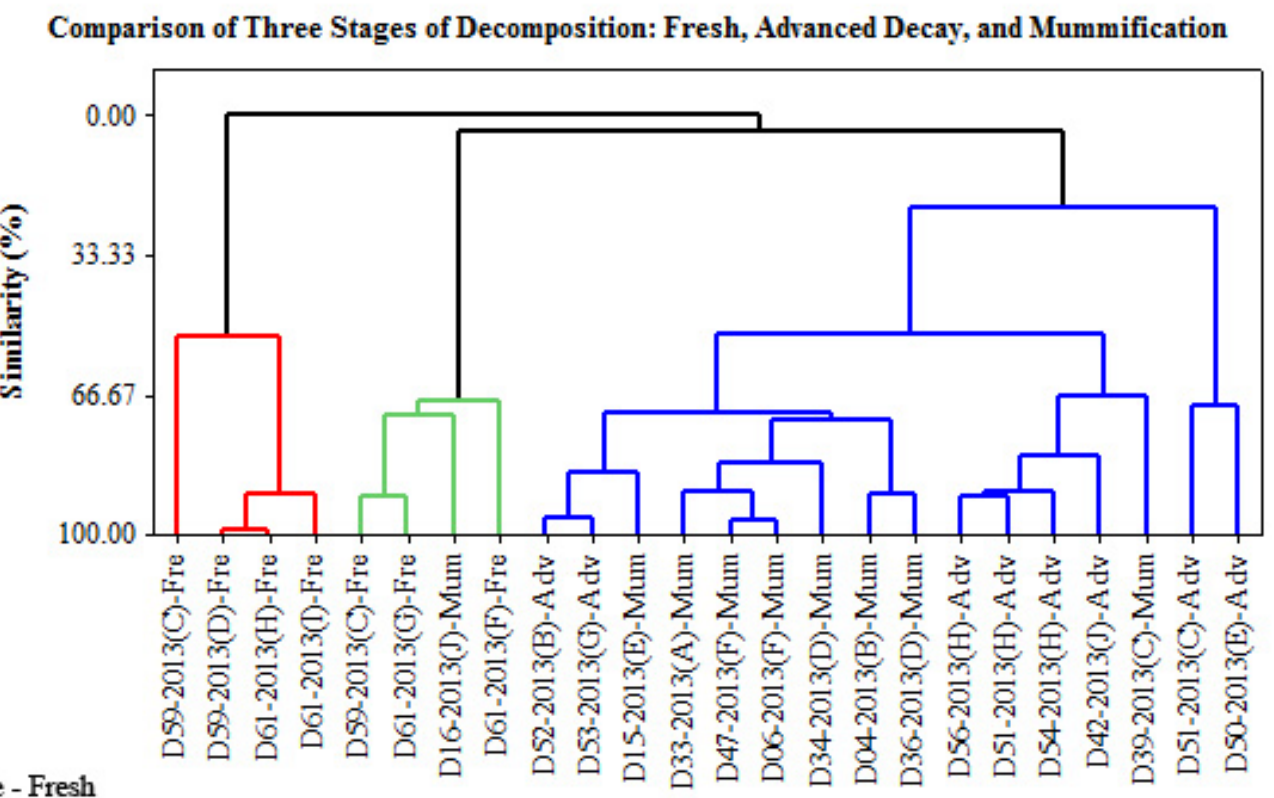

Adv - Advanced Decay

Mum - Mummification

Subjects Sampled

Figure 71: HCA of subjects sampled at three different stages of decay.

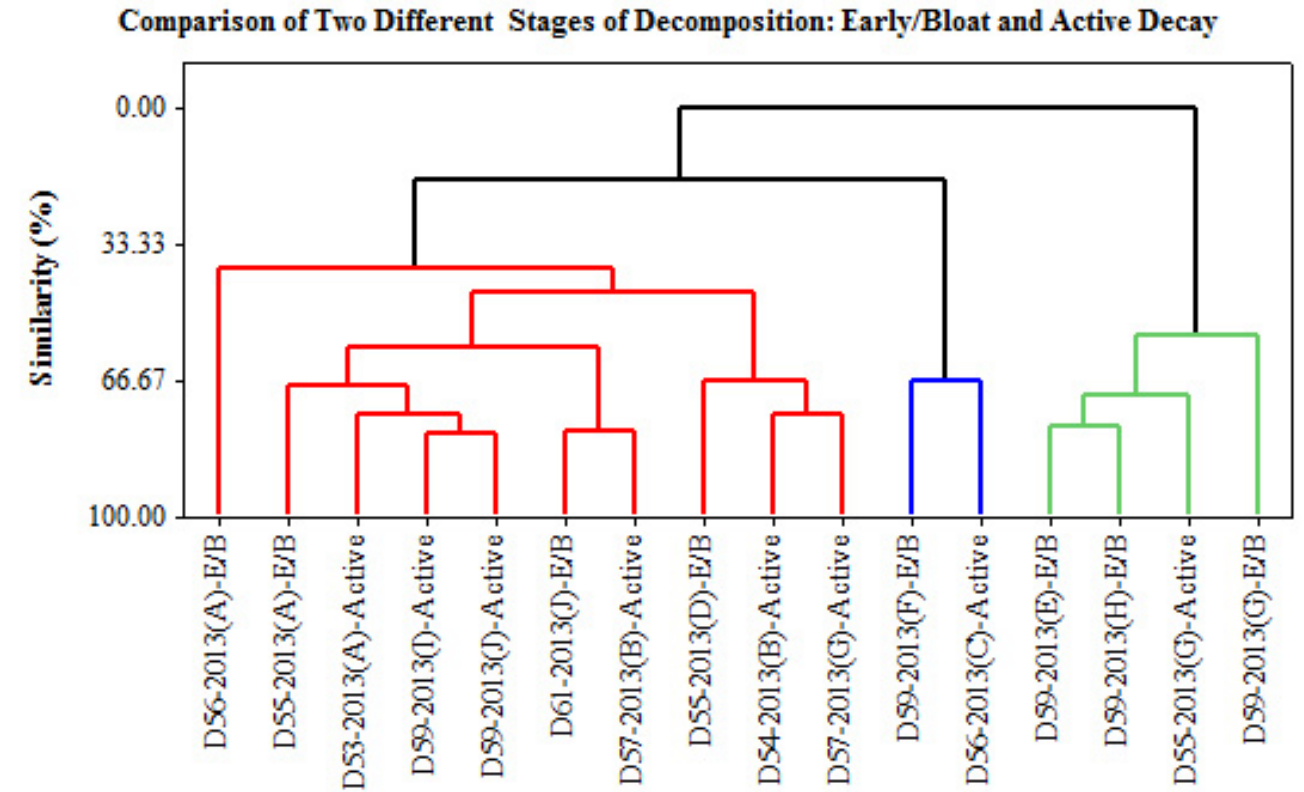

E/B - Early/Bloat

Subjects Sampled

Figure 72: HCA of subjects sampled at two different stages of decay. 


\section{CONCLUSION}

To date, there has been limited research performed on the scent of death and the few studies that have been conducted were done so under conditions that were not well controlled (i.e., remains were refrigerated or frozen upon death, experienced trauma, used pieces rather than whole bodies), which could have effected the rate of decay and subsequently, the VOCs that were released. The objective of this dissertation research was to evaluate the scent of death during the different stages of decomposition, under controlled settings, using human remains and analogues. In addition, frozen, aquatic, and soil environments were assessed to determine the impact these conditions had on the VOCs liberated.

A method optimization study was performed to evaluate two different extraction techniques: Activated Charcoal Strip (ACS) and Solid-Phase Microextraction (SPME). In addition, different gas chromatographic column chemistries were explored to determine the best stationary phase suitable for the analysis of decomposition-associated compounds. The results revealed that the Carboxen/Polydimethylsiloxane SPME fiber in combination with GC-MS fitted with a Sol-Gel Wax column provided the best response and selectivity.

The volatile organic compounds released from freshly killed and frozen then thawed remains were monitored over a period of six days. A total of nineteen VOCs from different chemical functional groups were discovered. Seventeen of those compounds were previously reported in literature as decomposition-associated compounds; however, this study was the first to report the presence of 2,4- 
dimethylhexane, butanoic acid propyl ester, and benzenepropanoic acid ethyl ester from decomposing remains. As the scent of death is produced from the degradation of carbohydrates, proteins, and lipids, these newly discovered compounds could be attributed to the breakdown of carbohydrates and lipids $[23,24,77,87]$. However, it is important to remember that the exact pathways to the formation of these descompositionassociated compounds are not specifically known in detail or are still, in its entirety, not known $[79,145]$.

Final analyses revealed differences between those remains that were freshly killed and those that were frozen then thawed. For instance, eight common compounds were identified for the freshly killed remains, whereas eleven were discovered for those that were frozen then thawed. Additionally, it was observed that the number of compounds, as well as their abundances changed over time. Furthermore, the chemical functional group contributions for both sets of remains were analyzed and at Day 5, it was evident that the frozen then thawed remains produced relatively different odor profiles than that of the freshly killed. The findings from this study revealed the effects that frozen environments have on the scent of death and its potential impact on remains that undergo cold or freezing climatic conditions. As the temperature rises and thawing occurs, the manner in which the remains decompose will differ, modifying the odor profile which may prove pertinent when using human remains detection canines. In addition, when conducting studies on the scent of death, freshly killed remains should be used to obtain a more accurate picture of the volatile organic compounds released during the decomposition process. 
Over a ten day period, the scent of death released from freshly killed human cadaver analgoues was evaluated resulting in the detection of eighteen compounds. This study showed that as the remains migrate through each phase of decomposition, not only are physical changes observed, but changes in the liberated VOCs also occurred. Furthermore, changes in the types and total mass of compounds that were identified upon inspection of the odor profiles corroborated the physical changes that were being observed as the remains decomposed. Principal components analysis was performed resulting in the formation of two distinct clusters: Phase I and II. Further investigation revealed that Phase I consisted of the fresh and early/bloat stages of decay, whereas Phase II was comprised of active and advanced decay. Moreover, it was discovered that each stage of decomposition was distinguishable based upon the type and total mass of compounds present. This study was the first of its kind to correlate the liberated volatile organic compounds with the stage of decomposition and bringing into light a factor that should be considered when training human remains detection (HRD) canines - the stage of decay of the training aid.

The VOCs released from remains submerged in two different aquatic environments (HPLC-grade and synthetic sea water) were evaluated over a ten day period. Headspace and direct immersion SPME were both employed to assess the liberated VOCs, as well as the compounds contained in the water matrix. The results from this study revealed that remains submerged in HPLC-grade water decomposed in a more generalized manner when compared to those remains submerged in synthetic sea water. Headspace-SPME analysis showed that dimethyl sulfide, dimethyl disulfide, and dimethyl trisulfide were the volatile organic compounds that contributed the most to the 
odor profiles in both aquatic environments; however, differences were observed with regard to the collected water samples, as the relative ratios of dimethyl disulfide and indole varied. Additionally, as remains decomposed in HPLC-grade water, the total mass of compounds extracted increased over time generating what would visually appear as a left-skewed curve. Conversely, the total mass extracted from remains submerged in synthetic sea water varied daily with no observable trends. Thus, depending upon the aquatic environment, the rate and manner in which the remains decompose may vary; however, the liberated volatile organic compounds appear to be similar, in such that the sulfur-containing compounds were the most dominant which differed from those remains that decomposed in their natural state.

The volatile organic compounds released from buried remains have been previously explored; however, little was known about the type and characteristics of the soil in which the remains were interred. Thus, this study used two previously characterized soils (sand and Canadian Sphagnum peat moss) to assess the effects that two characteristically different soil environments had on the liberated VOCs. To mimic real-life scenarios in which soil probes are utilized when searching for human remains using HRD canines, this study also explored the effects that disturbing the soil environment had on the scent of death that was released. The results of this study revealed that the characteristics of the soil in which the remains were interred either enhanced or hindered the liberated VOCs, as well as the rate of decay. Additionally, when comparing the effects of disturbed versus undisturbed soil environments, those that were probed resulted in a greater number and total mass of VOCs, specifically dimethyl disulfide and dimethyl trisulfide, than soil that was not disturbed and thus, corroborates 
the use of soil probes when searching for human remains using HRD canines as it allows for the release of decomposition odor.

After having a better understanding of the types of compounds released from decomposing human cadaver analogues, the VOCs released from twenty-eight deceased humans that were exposed to outdoor environmental conditions were evaluated at different stages of decay. A total of twenty-six decomposition-associated compounds were identified with twelve of those VOCs having never been previously reported as being released from decomposing human remains. Thus, this study was the first of its kind to identify 2,4-dimethylhexane, 3-methyl butanoic acid, 4-methyl pentanoic acid, 2methyl hexanoic acid, benzenepropanoic acid ethyl ester, pyridine, (E)-2-nonenal, nonadecane, (E)-2-octenal, dodecanal, phenylethyl alcohol, and 1-hexadecanol as decomposition-associated compounds. Additionally, using the VOCs identified, those that were found to be common in each stage of decay were assessed using PCA and HCA. It was determined that the early/bloat and active decay stages could not be discriminated, but, the fresh, advanced decay, and mummification stages could be distinguished based upon the type and abundance of the volatile organic compounds extracted. These findings are in agreement with those that were obtained using human cadaver analogues, in such that a correlation between the stage of decay and the liberated VOCs was determined. Thus, it is recommended that the training aids employed for human remains detection canines vary by stage of decay and include bone, as no common compounds were identified from skeletal remains.

The results obtained from this research have provided new insight into the scent of death and the factors that can dramatically effect it, specifically, frozen, aquatic, and 
soil environments, by either manipulating the release of the compounds that comprise the odor or enhancing/hindering its liberation. In addition, these results demonstrated that the different stages of decomposition can be distinguished, based upon the type and total mass of each compound present. Thus, based upon these findings, it is suggested that the training aids that are employed for human remains detection (HRD) canines should 1) be characteristic of remains that have undergone decomposition in different environmental settings, and 2) represent each stage of decay, to ensure that the HRD canines have been trained to the various odors that they are likely to encounter in an operational situation. 


\section{REFERENCES}

1. State of Florida v. Casey Marie Anthony, Case No. 2008-CF-015606-A-O, Circuit Court of the Ninth Judicial Circuit in and for Orange County, Florida, 2008.

2. Guide to Casey Anthony Case Legal Doc. (2008) OrlandoSentinel.com. Accessed 1211-2013. http://media.trb.com/media/acrobat/2008-08/41844520.pdf.

3. Katie Escherich. TIMELINE: Caylee Anthony Case Captivates Country. (2011) ABC News. Accessed 12-11-2013. http://abcnews.go.com/TheLaw/caylee-anthony-casetimeline-autopsy-released/story?id $=6448060 \&$ singlePage $=$ true .

4. CNN Library. Casey Anthony Trial Fast Facts. (2013) CNN U.S. Accessed 12-112013. http://www.cnn.com/2013/11/04/us/casey-anthony-trial-fast-facts/.

5. NBCNEWS.com. Timeline: Casey Anthony case. (2011) Crime \& courts on NBCNEWS.com. Accessed 12-13-2013. http://www.nbcnews.com/id/43643707/\#.UqtC4PRDuSp.

6. Hayes, A. Scientist: Body in Casey Anthony's trunk 'only plausible explanation'. (2011) CNN Justice. Accessed 12-13-2013. http://www.cnn.com/2011/CRIME/06/06/florida.casey.anthony.trial/.

7. CrimeTimeVids. Casey Anthony Trial Day 11 Part 1 of 4. (2013) Accessed 12-132013. http://www.youtube.com/watch?v=gk48FDGtZ0Y.

8. CrimeTimeVids. Casey Anthony Trial Day 11 Part 2 of 4. (2013) Accessed 12-13$2013 \mathrm{http}: / /$ www.youtube.com/watch?v=JWHh3tQls7w.

9. CrimeTimeVids. Casey Anthony Trial Day 11 Part 3 of 4. (2013) Accessed 12-132013. http://www.youtube.com/watch?v=pjuYVgqmr-g.

10. Jessica Hopper. Casey Anthony Trial: Air Samples of Anthony's Trunk could be O.J. Simpson Moment. (2011) ABC News. Accessed 12-13-2013. http://abcnews.go.com/US/casey_anthony_trial/casey-anthony-trial-air-samplestrunk-oj-simpson/story?id $=13773007 \&$ singlePage $=$ true.

11. Marisol Bello. Forensic push the limits in Casey Anthony trial. (2011) USA Today. Accessed 12-13-2013. http://usatoday30.usatoday.com/news/nation/2011-06-30casey-anthony-murder-trial_n.htm.

12. Camille Mann. Casey Anthony Trial Update: Expert in Human Decomposition Called. (2011) CBS News. Accessed 12-13-2013. http://www.cbsnews.com/news/casey-anthony-trial-update-expert-in-humandecomposition-called/. 
13. Fox News. Novel forensics tool used in Anthony trial. (2011) FoxNews.com. Accessed 12-14-2013. http://www.foxnews.com/us/2011/06/08/novel-forensics-toolused-in-anthony-trial/.

14. Oxford Dictionaries. Taphonomy. (2013) Oxford Dictionaries. Accessed 12-14-2013. http://www.oxforddictionaries.com/definition/english/taphonomy.

15. Haglund WD and Sorg MH (1997) Method and Theory of Forensic Taphonomy Research. In: Forensic Taphonomy: The Postmortem Fate of Human Remains. Haglund WD and Sorg MH, Eds. CRC Press, Boca Raton.

16. Stejskal SM (2013) Death, Decomposition, and Detector Dogs: From Science to Scene. CRC Press, Boca Raton.

17. Haglund WD and Sorg MH (1997) Introduction to Forensic Taphonomy. In: Forensic Taphonomy: The Postmortem Fate of Human Remains. Haglund WD and Sorg MH, Eds. CRC Press, Boca Raton.

18. Vass AA, Bass WM, Wolt JD, Foss JE, and Ammons JT (1992) Time since death determinations of human cadavers using soil solution. J Forensic Sci 37:1236.

19. Byers SN (2008) Introduction to Forensic Anthropology. Pearson Education, Inc., Boston.

20. Goff ML (2009) Early post-mortem changes and stages of decomposition in exposed cadavers. Exp Appl Acarol 49:21-36.

21. Galloway A, Birkby WH, Jones AM, Henry TE, and Parks BO (1989) Decay rates of human remains in an arid environment. J Forensic Sci 34:607.

22. Mann RW, Bass WM, and Meadows L (1990) Time since death and decomposition of the human body: variables and observations in case and experimental field studies. J Forensic Sci 35:103-111.

23. Evans WED (1963) The Chemistry of Death. Charles C Thomas Publisher, Springfield.

24. Vass AA. 2001. Beyond the grave-understanding human decomposition. Microbiology Today 28, 190.

25. Reed HB (1958) A study of dog carcass communities in Tennessee, with special reference to the insects. American Midland Naturalist 59: 213-245.

26. Megyesi MS, Nawrocki SP, and Haskell NH (2005) Using accumulated degree-days to estimate the postmortem interval from decomposed human remains. J Forensic Sci 50:618-626. 
27. Anderson GS and VanLaerhoven SL (1996) Initial studies on insect succession on carrion in southwestern British Columbia. J Forensic Sci 41:617-625.

28. Clark MA, Worrell MB, and Pless JE (1997) Postmortem Changes in Soft Tissues. In: Forensic Taphonomy: The Postmortem Fate of Human Remains. Haglund WD and Sorg MH, Eds. CRC Press, Boca Raton.

29. Johnson MD (1975) Seasonal and microseral variations in the insect populations on carrion. American Midland Naturalist 93:79-90.

30. Payne JA (1965) A summer carrion study of the baby pig Sus scrofa Linnaeus. Ecology 46:592-602.

31. Parks CL (2011) A Study of the Human Decomposition Sequence in Central Texas*. J Forensic Sci 56:19-22.

32. Davies L (1999) Seasonal and spatial changes in blowfly production from small and large carcasses at Durham in lowland northeast England. Medical and Veterinary Entomology 13:245-251.

33. de Moretti T, Ribeiro OB, Thyssen PJ, and Solis DR (2008) Insects on decomposing carcasses of small rodents in a secondary forest in Southeastern Brazil. European Journal of Entomology 105:691-696.

34. Smith RJ and Heese B (1995) Carcass selection in a high altitude population of the burying beetle, Nicrophorus investigator (Silphidae). The Southwestern Naturalist 40:50-55.

35. Smith KE and Wall R (1997) The use of carrion as breeding sites by the blowfly Lucilia sericata and other Calliphoridae. Medical and Veterinary Entomology 11:3844.

36. Tomita K (1975) On putrefactions and floatations of dead bodies under water. Hiroshima Journal of Medical Sciences 24:117.

37. Weitzel MA (2005) A report of decomposition rates of a special burial type in Edmonton, Alberta from an experimental field study. J Forensic Sci 50:641.

38. Bygarski K and LeBlanc HN (2013) Decomposition and Arthropod Succession in Whitehorse, Yukon Territory, Canada. J Forensic Sci 58:413-418.

39. Matuszewski S, Bajerlein D, Konwerski S, and Szpila K (2010) Insect succession and carrion decomposition in selected forests of Central Europe. Part 2: Composition and residency patterns of carrion fauna. Forensic Sci Int 195:42-51. 
40. Stokes KL, Forbes SL, Benninger LA, Carter DO, and Tibbett M (2009) Decomposition studies using animal models in contrasting environments: evidence from temporal changes in soil chemistry and microbial activity. In: Criminal and Environmental Soil Forensics. Ritz K, Dawson L, and Miller D, Eds. Springer, Netherlands.

41. Turner B and Wiltshire P (1999) Experimental validation of forensic evidence: a study of the decomposition of buried pigs in a heavy clay soil. Forensic Sci Int 101:113-122.

42. Voss SC, Cook DF, and Dadour IR (2011) Decomposition and insect succession of clothed and unclothed carcasses in Western Australia. Forensic Sci Int 211:67-75.

43. Wilson AS, Janaway RC, Holland AD, Dodson HI, Baran E, Pollard AM, and Tobin DJ (2007) Modelling the buried human body environment in upland climes using three contrasting field sites. Forensic Sci Int 169:6-18.

44. Bugajski KN, Seddon CC, and Williams RE (2011) A comparison of blow fly (Diptera: Calliphoridae) and beetle (Coleoptera) activity on refrigerated only versus frozen-thawed pig carcasses in Indiana. Journal of Medical Entomology 48:12311235.

45. Grassberger M and Frank C (2004) Initial study of arthropod succession on pig carrion in a central European urban habitat. Journal of Medical Entomology 41:511523.

46. Michaud JP, Majka CG, Prive JP, and Moreau G (2010) Natural and anthropogenic changes in the insect fauna associated with carcasses in the North American Maritime lowlands. Forensic Sci Int 202:64-70.

47. Segura NA, Usaquen W, Sanchez MC, Chuaire L, and Bello F (2009) Succession pattern of cadaverous entomofauna in a semi-rural area of Bogota, Colombia. Forensic Sci Int 187:66-72.

48. Simpson G and Strongman DB (2002) Carrion insects on pig carcasses at a rural and an urban site in Nova Scotia. Canadian Society of Forensic Science 35:123-144.

49. Tabor KL, Brewster CC, and Fell RD (2004) Analysis of the successional patterns of insects on carrion in southwest Virginia. Journal of Medical Entomology 41:785-795.

50. Voss SC, Forbes SL, and Dadour IR (2008) Decomposition and insect succession on cadavers inside a vehicle environment. Forensic Science, Medicine, and Pathology $4: 22-32$.

51. Adlam RE and Simmons T (2007) The Effect of Repeated Physical Disturbance on Soft Tissue Decomposition-Are Taphonomic Studies an Accurate Reflection of Decomposition?*. J Forensic Sci 52:1007-1014. 
52. Abd El-bar MM and Sawaby RF (2011) A preliminary investigation of insect colonization and succession on remains of rabbits treated with an organophosphate insecticide in El-Qalyubiya Governorate of Egypt. Forensic Sci Int 208:26-30.

53. Widya M, Moffatt C, and Simmons T (2012) The Formation of Early Stage Adipocere in Submerged Remains: A Preliminary Experimental Study*. J Forensic Sci 57:328-333.

54. Querido D (1993) Postmortem changes in resistivity of the anterior abdominal wall during the early postmortem period in rats. Forensic Sci Int 60:163-177.

55. Micozzi MS (1986) Experimental study of postmortem change under field conditions: effects of freezing, thawing, and mechanical injury. J Forensic Sci 31:953-961.

56. Litten-Brown JC, Corson AM, and Clarke L (2010) Porcine models for the metabolic syndrome, digestive and bone disorders: a general overview. Animal 4:899-920.

57. Schoenly KG, Haskell NH, Hall RD, and Gbur JR (2007) Comparative performance and complementarity of four sampling methods and arthropod preference tests from human and porcine remains at the Forensic Anthropology Center in Knoxville, Tennessee. Journal of Medical Entomology 44:881-894.

58. Catts EP and Goff ML (1992) Forensic entomology in criminal investigations. Annual Review of Entomology 37:253-272.

59. Simmons D (2008) The use of animal models in studying genetic disease: transgenesis and induced mutation. Nature Education 1:70.

60. Tomberlin JK and Adler PH (1998) Seasonal colonization and decomposition of rat carrion in water and on land in an open field in South Carolina. Journal of Medical Entomology 35:704-709.

61. Rodriguez WC (1997) Decomposition of Buried and Submerged Bodies. In: Forensic Taphonomy: The Postmortem Fate of Human Remains. Haglund WD and Sorg MH, Eds. CRC Press, Boca Raton.

62. Fiedler S and Graw M (2003) Decomposition of buried corpses, with special reference to the formation of adipocere. Naturwissenschaften 90:291-300.

63. Carter DO, Yellowlees D, and Tibbett M (2010) Moisture can be the dominant environmental parameter governing cadaver decomposition in soil. Forensic Sci Int 200:60-66.

64. Bass WM (1997) Outdoor Decomposition Rates in Tennessee. In: Forensic Taphonomy: The Postmortem Fate of Human Remains. Haglund WD and Sorg MH, Eds. CRC Press, Boca Raton. 
65. Micozzi MS (1997) Frozen Environments and Soft Tissue Preservation. In: Forensic Taphonomy: The Postmortem Fate of Human Remains. Haglund WD and Sorg MH, Eds. CRC Press, Boca Raton.

66. Micozzi MS (1991) Postmortem Change in Human and Animal Remains. Charles C Thomas Publisher, Springfield.

67. McCauley, Ann M., Jones, Clain, and Jacobsen, Jeff. Basic Soil Propertieis. (2005) Montana State University: Soil and Water Management. Accessed 8-5-2010. http://landresources.montana.edu/SWM/.

68. Bot A and Benites J (2005) The Importance of Soil Organic Matter: Key to Drought Resistant Soil and Sustained Food and Production. Food and Agriculture Organization of the United Nations, Rome.

69. McCauley, Ann M., Jones, Clain, and Jacobsen, Jeff. Soil pH and Organic Matter. (2009) Montana State University: Nutrient Management. Accessed 1-2-2014. http://landresources.montana.edu/nm/.

70. Carter DO and Tibbett M (2008) Cadaver Decomposition and Soil: Processes. In: Soil Analysis in Forensic Taphonomy: Chemical and Biological Effects of Buried Human Remains. Tibbett M and Carter DO, Eds. CRC Press, Boca Raton.

71. Dent BB, Forbes SL, and Stuart BH (2004) Review of human decomposition processes in soil. Environmental Geology 45:576-585.

72. Haglund WD and Sorg MH (2002) Human remains in water environments. In: Advances in Forensic Taphonomy: Method, Theory, and Archaeological Perspectives. Haglund WD and Sorg MH, Eds. CRC Press, Boca Raton.

73. Payne JA and King EW (1972) Insect succession and decomposition of pig carcasses in water. Journal of the Georgia Entomological Society 7:153-162.

74. Haefner JN, Wallace JR, and Merritt RW (2004) Pig decomposition in lotic aquatic systems: the potential use of algal growth in establishing a postmortem submersion interval (PMSI). J Forensic Sci 49:330.

75. Anderson GS and Hobischak NR (2004) Decomposition of carrion in the marine environment in British Columbia, Canada. Int J Legal Med 118:206-209.

76. Dodson P (1973) The significance of small bones in paleontological interpretation. Contributions to Geology (Laramie) 12:15-19.

77. Gill-King H (1997) Chemical and Ultrastructural Aspects of Decomposition. In: Forensic Taphonomy: The Postmortem Fate of Human Remains. Haglund WD and Sorg MH, Eds. CRC Press, Boca Raton. 
78. Janaway RC, Percival SL, and Wilson AS (2009) Decomposition of human remains. In: Microbiology and Aging. Percival SL, Ed. Springer, New York.

79. Paczkowski S and Schutz S (2011) Post-mortem volatiles of vertebrate tissue. Appl Microbiol Biotechnol 91:917-935.

80. Boumba VA, Ziavrou KS, and Vougiouklakis T (2008) Biochemical pathways generating post-mortem volatile compounds co-detected during forensic ethanol analyses. Forensic Sci Int 174:133-151.

81. Gottschalk G (1986) Bacterial Metabolism. Springer, New York.

82. Waksman SA and Starkey RL (1931) The soil and the microbe. Wiley, New York.

83. A. E. Reynold and G. F. Cahill. 1965. Handbook of physiology: Adipose tissue. American Physiological Society, Washington, D.C.

84. Frankel EN (1983) Volatile lipid oxidation-products. Progress in Lipid Research 22:1-33.

85. Vass AA, Smith RR, Thompson CV, Burnett MN, Wolf DA, Synstelien JA, Dulgerian N, and Eckenrode BA (2004) Decompositional Odor Analysis Database. J Forensic Sci 49:760-769.

86. Vass AA, Smith RR, Thompson CV, Burnett MN, Dulgerian N, and Eckenrode BA (2008) Odor Analysis of Decomposing Buried Human Remains*. J Forensic Sci $53: 384-391$.

87. Statheropoulos M, Spiliopoulou C, and Agapiou A (2005) A study of volatile organic compounds evolved from the decaying human body. Forensic Sci Int 153:147-155.

88. Statheropoulos M, Agapiou A, Spiliopoulou C, Pallis GC, and Sianos E (2007) Environmental aspects of VOCs evolved in the early stages of human decomposition. Sci Total Environ 385:221-227.

89. DeGreeff L and Furton K (2011) Collection and identification of human remains volatiles by non-contact, dynamic airflow sampling and SPME-GC/MS using various sorbent materials. Anal Bioanal Chem 401:1295-1307.

90. Hoffman EM, Curran AM, Dulgerian N, Stockham RA, and Eckenrode BA (2009) Characterization of the volatile organic compounds present in the headspace of decomposing human remains. Forensic Sci Int 186:6-13.

91. Cablk ME, Szelagowski EE, and Sagebiel JC (2012) Characterization of the volatile organic compounds present in the headspace of decomposing animal remains, and compared with human remains. Forensic Sci Int 220:118-125. 
92. Dekeirsschieter J, Verheggen FJ, Gohy M, Hubrecht F, Bourguignon L, Lognay G, and Haubruge E (2009) Cadaveric volatile organic compounds released by decaying pig carcasses (Sus domesticus L.) in different biotopes. Forensic Sci Int 189:46-53.

93. Brasseur C, Dekeirsschieter J, Schotsmans EMJ, de Koning S, Wilson AS, Haubruge E, and Focant JF (2012) Comprehensive two-dimensional gas chromatography-timeof-flight mass spectrometry for the forensic study of cadaveric volatile organic compounds released in soil by buried decaying pig carcasses. J Chromatogr A 1255:163-170.

94. Rebmann A, David E., and Sorg MH (2000) Cadaver Dog Handbook: Forensic Training and Tactics for the Recovery of Human Remains. CRC Press, Boca Raton.

95. Oesterhelweg L, Krober S, Rottmann K, Willhoft J, Braun C, Thies N, Puschel K, Silkenath J, and Gehl A (2008) Cadaver dogs-A study on detection of contaminated carpet squares. Forensic Sci Int 174:35-39.

96. Walker JC, Hall SB, Walker DB, Kendal-Reed MS, Hood A, and Niu XF (2003) Human Odor Detectability: New Methodology Used to Determine Threshold and Variation. Chem Senses 28:817-826.

97. Walker DB, Walker JC, Cavnar PJ, Taylor JL, Pickel DH, Hall SB, and Suarez JC (2006) Naturalistic quantification of canine olfactory sensitivity. Appl Anim Behav Sci 97:241-254.

98. Craven BA, Paterson EG, and Settles GS (2010) The fluid dynamics of canine olfaction: unique nasal airflow patterns as an explanation of macrosmia. J R Soc Interface 7:933-943.

99. Scientific Working Group on Dog and Orthogonal Detector Guidelines. SWGDOG SC8- Substance Detector Dogs: Human Remains Detection (HRD) Land and Water. (2009) SWGDOG. Accessed 1-2-2014. http://swgdog.fiu.edu/approvedguidelines/sc8_human_remains.pdf.

100. Lasseter AE, Jacobi KP, Farley R, and Hensel L (2003) Cadaver dog and handler team capabilities in the recovery of buried human remains in the Southeastern United States. J Forensic Sci 48:617-621.

101. DeGreeff LE. Development of a Dynamic Headspace Concentration Technique for the Non-Contact Sampling of Human Odor Samples and the Creation of Canine Training Aids. Ph.D. Dissertation, Florida International University, Miami, FL, 2010 .

102. Scheppers Wercinski SA and Pawliszyn J (1999) Solid Phase Microextraction Theory. In: Solid Phase Microextraction: A Practical Guide. Scheppers Wercinski SA, Ed. Marcel Dekker, Inc., New York. 
103. Pawliszyn J (1997) Solid phase microextraction: theory and practice. Wiley-Vch, New York.

104. Zhang Z, Yang MJ, and Pawliszyn J (1994) Solid-Phase Microextraction. A Solvent-Free Alternative for Sample Preparation. Anal Chem 66:844-853.

105. Zhang Z and Pawliszyn J (1993) Headspace solid-phase microextraction. Anal Chem 65:1843-1852.

106. Shirey RE (1999) SPME Fibers and Selection for Specific Applications. In: Solid Phase Microextraction: A Practical Guide. Scheppers Wercinski SA, Ed. Marcel Dekker, Inc., New York.

107. Shirey RE (2000) Optimization of extraction conditions and fiber selection for semivolatile analytes using solid-phase microextraction. J Chromatogr Sci 38:279288.

108. Sigma-Aldrich Co. Carbowax-Polyethylene Glycol. (2013) 12-27-2013. http://www.sigmaaldrich.com/analytical-chromatography/analyticalproducts.html?TablePage $=18156581$.

109. Pawliszyn J (2000) Theory of solid-phase microextraction. J Chromatogr Sci 38:270-278.

110. Kumar A, Malik AK, and Matysik FM (2009) Analysis of biological samples using solid-phase microextraction. Bioanal Rev 1:35-55.

111. Polo M, Llompart M, Garcia-Jares C, and Cela R (2005) Multivariate optimization of a solid-phase microextraction method for the analysis of phthalate esters in environmental waters. J Chromatogr A 1072:63-72.

112. Furton KG, Bruna J, and Almirall JR (1995) A simple, inexpensive, rapid, sensitive and solventless technique for the analysis of accelerants in fire debris based on SPME. J High Res Chromatog 18:625-629.

113. Furton KG, Wu L, and Almirall JR (2000) Optimization of solid-phase microextraction (SPME) for the recovery of explosives from aqueous and postexplosion debris followed by gas and liquid chromatographic analysis. J Forensic Sci 45:857.

114. Balasubramanian S and Panigrahi S (2011) Solid-phase microextraction (SPME) techniques for quality characterization of food products: a review. Food Bioprocess Tech 4:1-26.

115. Curran AM, Rabin SI, Prada PA, and Furton KG (2005) Comparison of the volatile organic compounds present in human odor using SPME-GC/MS. J Chem Ecol 31:1607-1619. 
116. DeGreeff LE, Curran AM, and Furton KG (2011) Evaluation of selected sorbent materials for the collection of volatile organic compounds related to human scent using non-contact sampling mode. Forensic Sci Int 209:133-142.

117. Kusano M, Mendez E, and Furton KG (2011) Development of headspace SPME method for analysis of volatile organic compounds present in human biological specimens. Anal Bioanal Chem 400:1817-1826.

118. Brown JS, Prada PA, Curran AM, and Furton KG (2013) Applicability of emanating volatile organic compounds from various forensic specimens for individual differentiation. Forensic Sci Int 226:173-182.

119. Curran AM, Prada PA, and Furton KG (2010) The differentiation of the volatile organic signatures of individuals through SPME-GC/MS of characteristic human scent compounds. J Forensic Sci 55:50-57.

120. Tolliver SS. Identification of Canis Familiaris singuarture odor chemicals in human remains using derivatization solid-phase microextraction/gas chromatography/mass spectrometry. MSFS Thesis, Florida International University, Miami, FL, 2005.

121. Kalinova B, Podskalska H, Ruzicka J, and Hoskovec M (2009) Irresistible bouquet of death-how are burying beetles (Coleoptera: Silphidae: Nicrophorus) attracted by carcasses. Naturwissenschaften 96:889-899.

122. Lorenzo N, Wan T, Harper R, Hsu YL, Chow M, Rose S, and Furton K (2003) Laboratory and field experiments used to identify Canis lupus var. familiaris active odor signature chemicals from drugs, explosives, and humans. Anal Bioanal Chem 376:1212-1224.

123. Akdeniz N, Koziel JA, Ahn HK, Glanville TD, Crawford BP, and Raman DR (2010) Laboratory scale evaluation of volatile organic compound emissions as indication of swine carcass degradation inside biosecure composting units. Bioresource Technol 101:71-78.

124. Penton Z (1999) Method Development with Solid Phase Microextraction. In: Solid Phase Microextraction: A Practical Guide. Scheppers Wercinski SA, Ed. Marcel Dekker, Inc., New York.

125. Dietz WR (1991) Improved Charcoal Packaging for Accelerant Recovery by Passive Diffusion. J Forensic Sci 36:111-121.

126. Newman RT, Dietz WR, and Lothridge K (1996) The use of activated charcoal strips for fire debris extractions by passive diffusion. Part 1: the effects of time, temperature, strip size and sample concentration. J Forensic Sci 41:361-370.

127. Arrowhead Forensics, Inc. Activated Charcoal Strips. (2013). Accessed 12-27-2013. http://www.crime-scene.com/store/media/A-1503.jpg. 
128. Pert AD, Baron MG, and Birkett JW (2006) Review of analytical techniques for arson residues. J Forensic Sci 51:1033-1049.

129. American Society of Testing and Materials (2001) ASTM Method E1618-01 Standard Test Method for Ignitable Liquid Residues in Extracts from Fire Debris Samples by Gas Chromatography-Mass Spectrometry. In: Annual Book of ASTM Standards. ASTM International, West Conshohocken.

130. Dawling S, Jickells S, and Negrusz A (2008) Gas Chromatography. In: Clarke's Analytical Forensic Toxicology; $1^{\text {st }}$ Ed. Jickells $\mathrm{S}$ and Negrusz A, Eds. Pharmaceutical Press, Grayslake.

131. Skoog DA, Holler FJ, and Crouch SR (2007) Principles of Instrumental Analysis. Thomson Brooks/Cole, Belmont.

132. Tipler A. 2009. Reducing the Use of Helium in Gas Chromatography. Gases \& Instrumentation.

133. Agilent Technologies. 2010. Agilent J\& W GC Column Selection Guide. Agilent Technologies, Inc, Santa Clara.

134. SGE Analytical Science. SolGel-Wax. (2013) SGE Analytical Science. Accessed 414-2011. http://www.sge.com/products/columns/gc-columns/solgel-wax.

135. de Hoffmann E and Stroobant V (2007) Mass Spectrometry: Principles and Applications. John Wiley \& Sons Ltd., Chichester.

136. Watson D, Jickells S, and Negrusz A (2008) Mass Spectrometry. In: Clarke's Analytical Forensic Toxicology; $1^{\text {st }}$ Ed. Jickells $\mathrm{S}$ and Negrusz A, Eds. Pharmaceutical Press, Chicago.

137. EMD Millipore. Water in the Laboratory - A Tutorial. (2013) EMD Millipore Corporation. Accessed 1-2-2014.

http://www.millipore.com/lab_water/clw4/tutorial\&tabno=1.

138. American Society of Testing and Materials (2013) ASTM Method D1141-98 Standard Practice for the Preparation of Substitute Ocean Water. In: Annual Book of ASTM Standards. ASTM International, West Conshohocken.

139. Chen Z. Natural Organic Matter and Colloid-Facilitated Arsenic Transport and Transformation in Porous Soil Media. Ph.D. Dissertation, Florida International University, Miami, FL, 2006.

140. Prada PA, Curran AM, and Furton KG (2010) Comparison of extraction methods for the removal of volatile organic compounds (VOCs) present in sorbents used for human scent evidence collection. Anal Methods 2:470-478. 
141. Prada PA. Evaluation of Contact and Non-Contact Trapping Efficiencies of Human Scent Chemical Profiles and Their Stabilities Under Different Environmental Conditions. Ph.D. Dissertation, Florida International University, Miami, FL, 2010.

142. Beebe KR, Pell RJ, and Seasholtz MB (1998) Chemometrics: A Practical Guide. John Wiley \& Sons, Inc., New York.

143. Miller JN and Miller JC (2005) Statistics and Chemometrics for Analytical Chemistry. Ashford Colour Press, Gosport, Hants.

144. Eriksson L, Johansson E, Kettaneh-Wold N, Trygg J, Wikstrom C, and Wold S (2006) Multi- and Megavariate Data Analysis Part 1: Basic Principles and Applications. Umetrics AB, Sweden.

145. Statheropoulos M, Agapiou A, Zorba E, Mikedi K, Karma S, Pallis GC, Eliopoulos C, and Spiliopoulou C (2011) Combined chemical and optical methods for monitoring the early decay stages of surrogate human models. Forensic Sci Int 210:154-163.

146. Dekeirsschieter J, Stefanuto PH, Brasseur C, Haubruge E, and Focant J-F (2012) Enhanced characterization of the smell of death by comprehensive two-dimensional gas chromatography-time-of-flight mass spectrometry (GCxGC-TOFMS). PLoS ONE 7:e39005. doi: 10.1371/journal.pone.0039005.

147. Hadrich C, Ortmann C, Reisch R, Liebing G, Ahlers H, and Mall G (2010) An electronic body-tracking dog? Int J Legal Med 124:43-47.

148. Gottzein AK, Musshoff F, and Madea B (2010) Qualitative screening for volatile organic compounds in human blood using solid-phase microextraction and gas chromatography-mass spectrometry. J Mass Spectrom. 45:391-397.

149. Kasper J, Mumm R, and Ruther J (2012) The composition of carcass volatile profiles in relation to storage time and climate conditions. Forensic Sci Int 223:6471.

150. Paczkowski S, Maibaum F, Paczkowska M, and Schutz S (2012) Decaying mouse volatiles perceived by Calliphora vicina rob.-desv. J Forensic Sci 57:1497-1506.

151. Heigan M. Blow Fly Image. (2013). Accessed 3-28-2013. http://anti-matter3d.com/Stapeliads/hi/Blow_Fly_on_S_Gigantea.jpg. 


\section{APPENDIX}

The Decomposition-Associated Compound Database containing over four hundred compounds, separated by their chemical functional group and listed from lowest to highest boiling points are presented in Tables 35-40. In addition, the type of remains (e.g., human remains, pig remains, etc.) from which the compound was discovered was also documented, along with its corresponding literature reference. Those compounds highlighted in gray signify that the CAS number could not be obtained or the name of the compound is not clarified in the article. 
Table 35: Decomposition-associated compound database. Listed are compounds pertaining to the functional groups aldehydes, alicyclics, and alcohols. Those compounds highlighted in gray signify that the CAS number could not be obtained or the name of the compound is not clarified in the article.

\begin{tabular}{|c|c|c|c|c|c|c|c|c|c|c|c|c|c|c|c|c|}
\hline 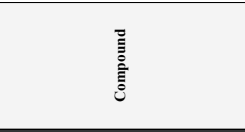 & 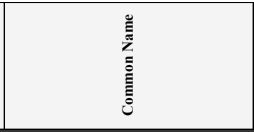 & 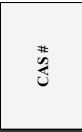 & 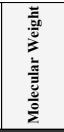 & 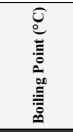 & 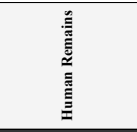 & 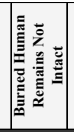 & 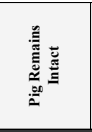 & 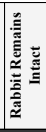 & 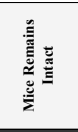 & 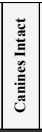 & 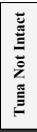 & 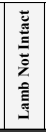 & 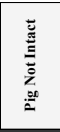 & 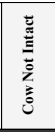 & 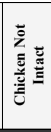 & 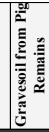 \\
\hline \multicolumn{17}{|c|}{ ALDEHYDES } \\
\hline Propanal & Propionaldehyde & $123-38-6$ & 58.079 & $\frac{40.1}{48}$ & {$[07]$} & & $\frac{11406]}{[146]}$ & {$[147]$} & & & & & & & & \\
\hline 2-Propenal & Acrolein & $107-02-8$ & 56.063 & 52.6 & & & [92] & & & & & & & & & \\
\hline 2-Methylpropanal & Isobutanal or 2-Methyl-1-Propanal & $78-84-2$ & 72.106 & 64.5 & & & {$[92]$} & 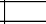 & & & & 列 & & & & \\
\hline Butanal & Butyraldehyde & $123-72-8$ & 72.106 & 74.8 & & & {$[92,145]$} & & & & & & & & & \\
\hline Butanal, 3-methyl & 3-Methylbutanal or Isovaleraldehyde & $590-86-3$ & 86.130 & $93.5 \pm 8.0$ & [88] & & {$[145]$} & & & & & & & & & \\
\hline 2-Methylbutanal & 2-Methyl butyraldehyde & $96-17-3$ & 86.130 & 95 & & & {$[92]$} & & & & & & & & & \\
\hline Pentanal & Valeraldehyde & $110-62-3$ & 86.132 & 103 & [87] & & {$[92]$} & & & & & & & & & \\
\hline 2-Butenal & & $4170-30-3$ & 70.090 & 104 & & & [92] & & & & & & & & & \\
\hline Hexanal & Caproaldehyde & $66-25-1$ & 100.158 & 131 & {$[87,90,122]$} & & {$[146]$} & & [149] & & & & [91] & {$[91]$} & [91] & \\
\hline 2-Hexenal & & $505-57-7$ & 98.140 & 146.5 & {$[90]$} & & & & & & & & & & & \\
\hline Heptanal & Heptaldehyde & $111-71-7$ & \begin{tabular}{|l|l|l|l|l|l|l|}
1145 \\
\end{tabular} & 152.8 & {$[90,122]$} & & {$[92,146]$} & & {$[149,150]$} & & & & & {$[91]$} & [91] & \\
\hline 2-Furaldehyde & Furfural & $98-01-1$ & 96.085 & 161.7 & [89] & & & & & & & & & & & \\
\hline 2-Heptenal & Butylacrolein & $2463-63-0$ & 112.169 & 166 & {$[90]$} & & & & & & & & & & [91] & \\
\hline Octanal & Caprylic Aldehyde & $124-13-0$ & 128.212 & 171 & {$[90]$} & & {$[146]$} & & [149] & & & & & [91] & [91] & \\
\hline 2,4-Heptadienal & & $5910-85-0$ & 110.150 & $177.4 \pm 9.0$ & {$[90]$} & & & & & & & & & & [91] & \\
\hline Benzaldehyde & Benzenecarboxaldehyde & $100-52-7$ & 106.122 & 178.8 & {$[85,120,90,122,89]$} & & {$[92,146,145]$} & & [149] & [89] & & & [91] & [89] & {$[91,89$} & [93] \\
\hline 2-Nonenal & & $2463-53-8$ & 140.220 & 188 & {$[90]$} & & & & & & & & {$[91]$} & {$[91]$} & [91] & \\
\hline 2-Octenal & & $2363-89-5$ & 126.200 & 190.1 & {$[90]$} & & {$[146]$} & & & & & & \begin{tabular}{|l|l|}
{$[91]$} \\
\end{tabular} & [11] & {$[91]$} & \\
\hline Nonanal & Nonaldehyde & $124-19-6$ & 142.238 & 191 & {$[85,86,90,89]$} & & [146] & {$[147]$} & {$[150]$} & & & & {$[91,89]$} & {$[91,89]$} & [91] & \\
\hline Decanal & Capraldehyde & $112-31-2$ & 156.265 & 208.5 & {$[85,86,89]$} & & & [147] & & & & & [91] & {$[91,89]$} & [91] & \\
\hline 2,4-Nonadienal & & $6750-03-4$ & 138.210 & 222.4 & [90] & & & & & & & & [91] & & [91] & \\
\hline (E)-2-Decanal & & & & & & & & & & & [89] & & & & & \\
\hline Nonenal & & & & & & & [146] & & & & 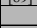 & & & & & \\
\hline Propanal, 2,2-dimethyl & & & & & & & {$[146]$} & & & & & & & & & \\
\hline 2-Butenal, 3-methyl- & & & & & & & {$[146]$} & & & & & & & & & \\
\hline Pentanal, 2-methyl & & & & & & & [146] & & & & & & & & & \\
\hline Methylglyoxal & & & & & & & {$[146]$} & & & & & & & & & \\
\hline \multirow{2}{*}{\multicolumn{17}{|c|}{ Propanal, 2-hydroxy }} \\
\hline & & & & & & & & & & & & & & & & \\
\hline Cyclohexane & Hexahydrobenzene & $110-82-7$ & 84.159 & $73.5 \pm 3.0$ & {$[87]$} & & {$[145]$} & & & & & & & & & \\
\hline Cylcopentane, methyl & Methylcyclopentane & $96-37-7$ & 84.160 & 80.73 & [87] & & {$[145]$} & & & & & & & & & \\
\hline Cyclohexane, 1,3,5-trimethyl & & $1839-63-0$ & 126.240 & 139.5 & [87] & & & & & & & & & & & \\
\hline 3-Carene & $\begin{array}{l}\text { Bicyclo[4.1.0]hept-3-ene,3,7,7-trimethyl } \\
\text { or } \delta \text {-3-Carene }\end{array}$ & $13466-78-9$ & 136.234 & 168 & & & & & [149] & & & & & & & \\
\hline d-Limonene & $\begin{array}{l}\text { (+)-Limonene or p-Mentha-1,8-diene, } \\
\text { (R)- }\end{array}$ & $5989-27-5$ & 136.234 & 178 & {$[87,88]$} & & & & & & & & & & & \\
\hline Cyclohexylcyclohexane & & $92-51-3$ & 166.303 & 238 & & & {$[92]$} & & & & & & & & & \\
\hline $\begin{array}{l}\text { Cyclohexane, } 1,4 \text {-dimethyl } \\
\end{array}$ & & $589-90-2$ & 112.210 & $125.9 \pm 7.0$ & {$[87]$} & & & & & & & & & & & \\
\hline Cyclohexane, 1,2,4-trimethyl(1-alpha) & Cyclohexane, 1,2,4-trimethyl & $2234-75-5$ & 126.240 & $143.5 \pm 7.0$ & {$[87]$} & & & & & & & & & & & \\
\hline $\begin{array}{l}\text { Cyclohexane, 1-ethyl, 4-methyl } \\
\text { (a) }\end{array}$ & 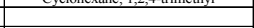 & $3728-56-1$ & 126.240 & $150.8 \pm 7.0$ & $\frac{[10]}{[87]}$ & & & & & & & & & & & \\
\hline Cyclohexane, 1,1,2,3-tetramethyl & & $6783-92-2$ & 140.270 & $155.8 \pm 7.0$ & {$[87]$} & & & & & & & & & & & \\
\hline Camphene & & $79-92-5$ & 136.230 & $158.6 \pm 7.0$ & {$[120]$} & & & & & & & & & & & \\
\hline Limonene & & $138-86-3$ & 136.230 & $175.4 \pm 20.0$ & {$[120]$} & & & & [149] & & & & & & & \\
\hline Cyclopentane, butyl- & & & & & & & {$[146]$} & & & & & & & & & \\
\hline & & & & & HOLS & & & & & & & & & & & \\
\hline Ethanol & Ethyl Alcohol & $64-17-5$ & \begin{tabular}{|l|l|}
46.068 \\
\end{tabular} & 78.29 & {$[87,88]$} & & {$[146]$} & & & & & & {$[123]$} & & & \\
\hline 2-Propanol & Isopropyl Alcohol & 67-63-0 & 60.095 & 82.3 & [88] & & [145] & {$[147]$} & & & & & [123] & & & \\
\hline 1-Propanol & Propyl Alcohol & $71-23-8$ & 60.095 & 97.2 & & & & {$[147]$} & & & & & & & & \\
\hline 2-Butanol & sec-Butyl alcohol & $78-92-2$ & 74.121 & 99.51 & & & {$[145]$} & & & & & & {$[123]$} & & & \\
\hline (2S)-Butan-2-ol & & $4221-99-2$ & 74.122 & 100 & & & [92] & & & & & & & & & \\
\hline 1-Propanol, 2-methyl & Isobutyl Alcohol & $78-83-1$ & 74.121 & 107.89 & {$[87]$} & & {$[146,145]$} & & & & & & & & & \\
\hline 3-Methylbutan-2-ol & $\begin{array}{c}\text { 2-Butanol, 3-methyl- or Isopropyl } \\
\text { methyl carbinol }\end{array}$ & $598-75-4$ & 88.150 & 112 & & & {$[92]$} & & & & & & & & & \\
\hline 1-Butanol & Butyl Alcohol & $71-36-3$ & 74.121 & 117.73 & [87] & & {$[92,146,145]$} & {$[147]$} & [149] & & & & & & & \\
\hline 3-Methylbutan-1-ol & $\begin{array}{l}\text { 1-Butanol, 3-methyl- or Isopentyl } \\
\text { alcohol }\end{array}$ & $123-51-3$ & 88.148 & 131.1 & & & [92] & & {$[149,150]$} & & & & & & & \\
\hline 1-Pentanol & & $71-41-0$ & 88.148 & 137.98 & {$[87,90,122]$} & & {$[92,146]$} & {$[147]$} & & & & & [91] & [91] & [91] & \\
\hline 1-Pentanol, 2-methyl & & $105-30-6$ & 102.174 & 149 & {$[87]$} & & {$[145]$} & & & & & & & & & \\
\hline 1-Hexanol & $\begin{array}{l}\text { Caproyl Alcohol } \\
\end{array}$ & $111-27-3$ & 102.174 & 157.6 & {$[87,90]$} & & {$[1146,145]$} & & {$[149,150]$} & & & & [91] & [91] & [91] & \\
\hline 2-Heptanol & & $543-49-7$ & 116.201 & $160-162$ & & & & & & & & & \begin{tabular}{|l|l|}
{$[123]$} \\
\end{tabular} & & & \\
\hline Furfuryl alcohol & 2-Furanmethanol & $98-00-0$ & 98.101 & 171 & {$[89]$} & & & & & & & & & & & \\
\hline 1-Octen-3-ol & & $3391-86-4$ & 128.212 & 174 & {$[120,90]$} & & {$[145]$} & & {$[149,150]$} & & & & [91] & {$[91]$} & [91] & \\
\hline 1-Heptanol & Heptyl Alcohol & \begin{tabular}{|l|}
$111-70-6$ \\
\end{tabular} & 116.201 & 176.45 & & & {$[146]$} & & & & & & \begin{tabular}{|l|l|}
{$[123]$} \\
\end{tabular} & & & \\
\hline Phenol & Hydroxybenzene & $108-95-2$ & 94.111 & 181.87 & {$[88,89]$} & & {$[92,145]$} & & {$[149,150]$} & & & & \begin{tabular}{|l|l|}
{$[123]$} \\
\end{tabular} & {$[89]$} & & [93] \\
\hline 1-Hexanol, 2-ethyl & & $104-76-7$ & 130.228 & 184.6 & {$[85,88,90,89]$} & & {$[92,145]$} & & & & & [89] & {$[91,89]$} & {$[91,89]$} & [91] & \\
\hline 1-Octanol & Capryl Alcohol & $111-87-5$ & 130.228 & 195.16 & {$[90,89]$} & & {$[146]$} & & {$[149]$} & & & & {$[123]$} & & & \\
\hline P-Cresol * & 4-Methylphenol & \begin{tabular}{|l|l|}
$106-44-5$ \\
\end{tabular} & \begin{tabular}{|l|l|}
100.220 \\
108.138 \\
\end{tabular} & $\frac{193.10}{201.98}$ & $\frac{[9,89,120]}{[88,120}$ & & $\frac{192,146]}{2}$ & & & & & & & & & \\
\hline Phenol, 4-methyl ${ }^{*}$ & p-Cresol & $106-44-5$ & 108.138 & 201.98 & {$[88,120]$} & & {$[92,146]$} & & & & & & & & & \\
\hline 2-Phenyl-2-Propanol & $\alpha, \alpha$-Dimethyl benzenemethanol & $617-94-7$ & 136.190 & 202 & {$[85,86]$} & & & & & & & & & & & \\
\hline 2-Methoxy Phenol & Guaiacol & $90-05-1$ & 124.138 & 205 & & & & & & & & & & & & \\
\hline Benzyl alcohol & Benzenemethanol & $100-51-6$ & 108.138 & 205.31 & {$[89]$} & & {$[146]$} & & [149] & & & & & & & \\
\hline 1,3-Propanediol & 1,3-Propylene glycol & $504-63-2$ & 76.095 & 214.4 & & & & | & & & & & & & & \\
\hline 4-Ethyl phenol & & $123-07-9$ & 122.164 & 217.9 & & & {$[146]$} & & & & & & & & & \\
\hline Phenethyl alcohol & Benzeneethanol or 2-Phenylethanol & $60-12-8$ & \begin{tabular}{|l|l|l|l|l|l|l|}
122.164 \\
\end{tabular} & 218.8 & & & {$[92,146]$} & & [149] & & & & & & & \\
\hline Benzene-1,4-diol & Quinol or p-Hydroquinone & \begin{tabular}{|l|}
$123-31-9$ \\
\end{tabular} & 110.111 & 285 & & & {$[92]$} & & & & & & & & & \\
\hline Bomeol & & & & & & & & & & [89] & & & & & & \\
\hline 2,2-Methyoxyethoxy ethanol & & & & & [89] & & & & & [89] & & & & & & \\
\hline 1,2,3-Propanetriol & & & & & & & {$[146]$} & & & & & & & & & \\
\hline Benzenemethanol, $\alpha$-methyl & & & & & & & {$[146]$} & & & & & & & & & \\
\hline 1-Hexen-2-ol & & & & & & & {$[146]$} & & & & & & & & & \\
\hline
\end{tabular}


Table 36: Decomposition-associated compound database. Listed are compounds pertaining to the functional group alcohols, amines, aromatics, and carboxylic acids. Those compounds highlighted in gray signify that the CAS number could not be obtained or the name of the compound is not clarified in the article.

\begin{tabular}{|c|c|c|c|c|c|c|c|c|c|c|c|c|c|c|c|c|}
\hline 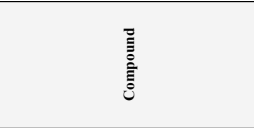 & 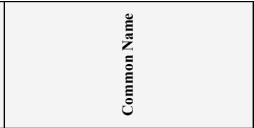 & 葵 & 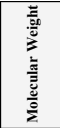 & 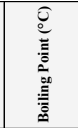 & 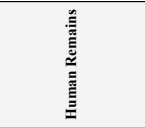 & 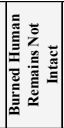 & 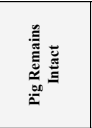 & 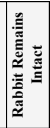 & 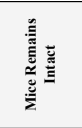 & 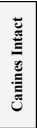 & 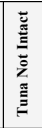 & 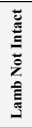 & 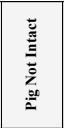 & 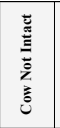 & 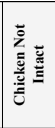 & 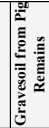 \\
\hline & & & & ALCOHOL & CONTINUED & & & & & & & & & & & \\
\hline$\frac{\text { 1-Hexen-3-ol }}{\text { 1-Pentanol, 4-methyl }}$ & & & & & & & {$[146]$} & & & & & & & & & \\
\hline $\begin{array}{l}\text { 1-Pentanol, 4-methyl } \\
\text { 2-Hexanol }\end{array}$ & & & & & & & [146] & & [149] & & & & & & & \\
\hline $\begin{array}{l}\text { 2-Hexanol } \\
\text { 3-Hexanol }\end{array}$ & & & & & & & [146] & & & & & & & & & \\
\hline 3-Hexanol & & & & & & & {$[146]$} & & & & & & & & & \\
\hline 2-Hexen-1-ol & & & & & & & [146] & & & & & & & & & \\
\hline 1-Tridecanol & & & & & & & {$[146]$} & & & & & & & & & \\
\hline 3-Hexene-2,5-diol & & & & & & & [146] & & & & & & & & & \\
\hline 7-Octen-4-ol & & & & & & & {$[146]$} & & & & & & & & & \\
\hline Cyclohexanol & & & & & & & {$[146]$} & & & & & & & & & \\
\hline $\begin{array}{l}\text { Cyclopentanedecaol } \\
\end{array}$ & & & & & & & {$[146]$} & & & & & & & & & \\
\hline \multicolumn{17}{|l|}{ Phenol, 2-ethyl- } \\
\hline Trimethylamine & $\mathrm{N}, \mathrm{N}$-Dimethylmethanamine & $75-50-3$ & 59.110 & 2.87 & {$[122]$} & & {$[92,146,145]$} & & & & & & [91] & [91] & [91] & \\
\hline Pyrrole & 1H-Pyrrole or Imidole & $109-97-7$ & 67.090 & 129.79 & & & [92] & & & & & & & & & \\
\hline Putrescine & 1,4-Butanediamine & $110-60-1$ & 88.151 & 158.5 & {$[24]$} & & & & & & & & & & & \\
\hline Cadaverine & 1,5-Diaminopentane & $462-94-2$ & 102.178 & 179 & {$[24]$} & & & & & & & & & & & \\
\hline Indole & 1H-Indole or 2,3-Benzopyrrole & $120-72-9$ & 117.149 & 253.6 & {$[24,90]$} & & {$[92,146]$} & & {$[149,150]$} & & & & {$[123,91]$} & [91] & [91] & [93] \\
\hline 3-Methylindole * & 1H-Indole, 3-Methyl-or Skatole & $83-34-1$ & 131.174 & 266 & {$[24,120]$} & & {$[146]$} & & & & & & & & & \\
\hline Skatole * & 3-Methyl-1H-Indole & $83-34-1$ & 131.174 & 266 & {$[24,120]$} & & & & & & & & & & & \\
\hline Methenamine & Hexamethylenetetramine & $100-97-0$ & 140.186 & 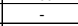 & {$[85,86]$} & & {$[145]$} & & & & & & & & & \\
\hline 2-Anthracenamine & & $613-13-8$ & 193.244 & - & & & {$[122]$} & & & & & & & & & \\
\hline 1-Butanamine, 3-methyl- & & & & & & & [146] & & & & & & & & & \\
\hline 1H-Pyrrole, 2,5-dimethyl- & & & & & & & {$[146]$} & & & & & & & & & \\
\hline Methanediamine, $\mathrm{N}, \mathrm{N}, \mathrm{N}^{\prime}, \mathrm{N}^{\prime}$-tetramethyl- & & & & & & & [146] & & & & & & & & & \\
\hline $\begin{array}{l}\text { Propylamine } \\
\end{array}$ & & & & & & & [146] & & & & & & & & & \\
\hline \multicolumn{17}{|l|}{$\begin{array}{c}\text { Propylamine, } \mathrm{N}, \mathrm{N}, 2,2 \text {-tetramethyl-, } \mathrm{N}- \\
\text { oxide }\end{array}$} \\
\hline \multirow{2}{*}{\multicolumn{17}{|c|}{\begin{tabular}{l|l}
\multicolumn{2}{c}{ AROMATICS } \\
80.09 & {$[87,86]$} \\
\end{tabular}}} \\
\hline & & & & & & & & & & & & & & & & \\
\hline Toluene * & Methylbenzene & $108-88-3$ & 92.139 & 110.63 & {$[87,85,86,88,6,7,89]$} & {$[148]$} & {$[146,145]$} & & & & & & [91] & {$[91,89]$} & [91] & \\
\hline Benzene, methyl * & Toluene or Methylbenzene & $108-88-3$ & 92.140 & 110.63 & {$[87,85,86,88,6,7,89]$} & [148] & {$[146,145]$} & & & & & & [91] & {$[91,89]$} & [91] & \\
\hline Benzene, ethyl & Ethylbenzene or Phenylethane & $100-41-4$ & 106.170 & 136.16 & {$[87,85,86]$} & & {$[146,145]$} & & & & & & & & & \\
\hline Benzene, 1,4-dimethyl * & $\mathrm{p}$-Xylene or 1,4-Dimethylbenzene & $106-42-3$ & 106.165 & 138.23 & {$[87,85,86,88,90]$} & & [146] & & & & & & [91] & {$[91,89]$} & [91] & \\
\hline p-Xylene * & 1,4-Dimethylbenzene & $106-42-3$ & 106.165 & 138.23 & {$[87,85,86,88,90]$} & & [146] & & & & & & [91] & {$[91,89]$} & [91] & \\
\hline m-Xylene * & 1,3-dimethylbenzene & $108-38-3$ & 106.165 & 139.07 & {$[87,88]$} & & [145] & & & & & & & & & \\
\hline Benzene, 1,3-dimethyl- * & $\mathrm{m}$-Xylene or 1,3-Dimethylbenzene & $108-38-3$ & 106.170 & 139.07 & {$[87,88]$} & & {$[145]$} & & & & & & & & & \\
\hline o-Xylene* & 1,2-Dimethylbenzene & $95-47-6$ & 106.165 & 144.5 & {$[85,86,88]$} & & {$[146,145]$} & & & & & & & & [89] & \\
\hline Benzene, 1,2-dimethyl ${ }^{*}$ & o-Xylene or 1,2-Dimethylbenzene & $95-47-6$ & 106.170 & 144.5 & {$[85,86,88]$} & & {$[146,145]$} & & & & & & & & [89] & \\
\hline Styrene & Vinylbenzene & $100-42-5$ & 104.150 & 145 & {$[85,86,88,89]$} & & {$[145]$} & & & & & & & & & \\
\hline Benzene, propyl & Propylbenzene or Isocumene & $103-65-1$ & 120.190 & 159.24 & {$[87]$} & & {$[145]$} & & & & & & & & & \\
\hline Benzene, 1-ethyl, 3-methyl & 3-Ethyltoluene & $620-14-4$ & 120.190 & 161.3 & {$[87]$} & & {$[145]$} & & & & & & & & & \\
\hline Benzene, 1-ethyl, 4-methyl & 4-Ethyltoluene & $622-96-8$ & 120.190 & 162 & {$[87]$} & & & & & & & & & & & \\
\hline Benzene, 1,3,5-trimethyl & 1,3,5-Trimethylbenzene or Mesitylene & $108-67-8$ & 120.190 & 164.74 & [87] & & [145] & & & & & & & & & \\
\hline Benzene, 1-ethyl, 2-methyl * & 2-Ethyltoluene & $611-14-3$ & 120.190 & 165.2 & {$[87,85,86]$} & & & & & & & & & & & \\
\hline Benzene, 2-ethyl, 1-methy| * & 2-Ethyltoluene & $611-14-3$ & 120.190 & 165.2 & {$[87,85,86]$} & & & & & & & & & & & \\
\hline Styrene, $\alpha$-methyl- * & $\begin{array}{l}\text { Isopropenylbenzzene or } \alpha \text {-Methyl } \\
\text { Styrene }\end{array}$ & 98-83-9 & 118.175 & 165.4 & [88] & & & & & & & & & & & \\
\hline Benzene, (1-methylethenyl)- * & $\begin{array}{l}\text { Isopropenylbenzene or } \alpha \text {-Methyl } \\
\text { Styrene }\end{array}$ & $98-83-9$ & 118.180 & 165.4 & {$[88]$} & & & & & & & & & & & \\
\hline Benzene, 1,2,4-trimethyl & $\begin{array}{l}\text { 1,2,4-Trimethylbenzene or } \\
\text { Pseudocumene }\end{array}$ & $95-63-6$ & 120.190 & 169.38 & [87] & & & & & & & & & & & \\
\hline Benzene, 1,2,3-trimethyl & $\begin{array}{l}\text { 1,2,3-Trimethylbenzene or } \\
\text { Hemimellitene }\end{array}$ & $526-73-8$ & 120.190 & 176.12 & {$[87,88,89]$} & & & & & & & & & & & \\
\hline 1-H-Indene, 2,3-dihydro & Indane & $496-11-7$ & 118.180 & 176.5 & {$[87]$} & & & & & & & & & & & \\
\hline 1-Methyl-4-(1-methylethyl) benzene & $\begin{array}{l}\text { 1-Isopropyl-4-methylbenzene or p- } \\
\text { Cymene }\end{array}$ & $99-87-6$ & 134.218 & 177.1 & & & {$[92,146,145]$} & & & & & & & & & \\
\hline Benzene (1-methoxypropyl) & & 59588-12-4 & 150.220 & 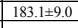 & {$[85,86]$} & & & & & & & & & & & \\
\hline Benzene, 1,2-diethyl & o-Diethylbenzene or 1,2-Diethylbenzene & $135-01-3$ & 134.220 & 184 & [87] & & & & & & & & & & & \\
\hline p-Xylene, 2 -ethyl- * & & $1758-88-9$ & 134.218 & 186.9 & {$[88]$} & & & & & & & & & & & \\
\hline Benzene, 2-ethyl-1,4-dimethyl- * & 2-Ethyl-1,4-dimethylbenzene & $1758-88-9$ & 134.220 & 186.9 & {$[88]$} & & & & & & & & & & & \\
\hline Naphthalene & & $91-20-3$ & 128.171 & 217.9 & {$[85,86,88]$} & & {$[146,145]$} & & & & & & & & & \\
\hline Naphthalene, 1-methyl - * & & $90-12-0$ & 142.197 & 244.7 & {$[85]$} & & & & & & & & & & & \\
\hline a-methylnaphthalene * & 1-Methylnaphthalene & $90-12-0$ & \begin{tabular}{|l|l|}
142.197 \\
\end{tabular} & 244.7 & {$[85]$} & & & & & & & & & & & \\
\hline Isoquinoline & & $119-65-3$ & 129.159 & - & & & {$[146]$} & & & & & & & & & \\
\hline 1(3H)-Isobenzofuranone & & $87-41-2$ & 134.132 & - & & & {$[146]$} & & & & & & & & & \\
\hline C4-Benzene & & & & & {$[85]$} & & & & & & & & & & & \\
\hline Naphthalene, 2,6-diisopropyl & & & & & & & {$[146]$} & & & & & & & & & \\
\hline Benzene, 1-methylethyl- & & & & & & & {$[146]$} & & & & & & & & & \\
\hline & & & & CARBOX & LIC ACIDS & & & & & & & & & & & \\
\hline Formic Acid & Methanoic acid & $64-18-6$ & 46.026 & 101 & & & [92] & & & & & & & & & \\
\hline Acetic acid & & $64-19-7$ & \begin{tabular}{|l|l|}
60.052 \\
\end{tabular} & 117.9 & [89] & & {$[145]$} & & {$[149]$} & & [89] & & & & & \\
\hline Propanoic acid * & Propionic Acid & $79-09-4$ & 74.079 & 141.15 & {$[120,90]$} & & {$[122,92]$} & {$[147]$} & [149] & & & & & & & \\
\hline Propionic acid * & Propanoic Acid & $79-09-4$ & 74.079 & 141.15 & {$[120,90]$} & & {$[122,92]$} & [147] & [149] & & & & & & & \\
\hline 2-Methylpropanoic acid & Isobutyric Acid & $79-31-2$ & \begin{tabular}{|l|l|}
88.106 \\
\end{tabular} & 154.45 & [89] & & {$[92,146]$} & & {$[149]$} & & & & & & & \\
\hline Butanoic acid * & Butyric Acid & $107-92-6$ & 88.106 & 163.75 & {$[120,90,122]$} & & {$[122,92,146]$} & {$[147]$} & [149] & & & & & & & \\
\hline Butyric acid * & Butanoic Acid & $107-92-6$ & 88.106 & 163.75 & {$[120,90,122]$} & & {$[122,92,146]$} & {$[147]$} & [149] & & & & & & & \\
\hline Butanoic acid, 2-methyl & 2-Methylbutanoic Acid & $116-53-0$ & 102.130 & 176.5 & [87] & & {$[92,146]$} & {$[147]$} & & & [89] & & & & [91] & \\
\hline
\end{tabular}


Table 37: Decomposition-associated compound database. Listed are compounds pertaining to the functional groups carboxylic acids, ethers, and esters. Those compounds highlighted in gray signify that the CAS number could not be obtained or the name of the compound is not clarified in the article.

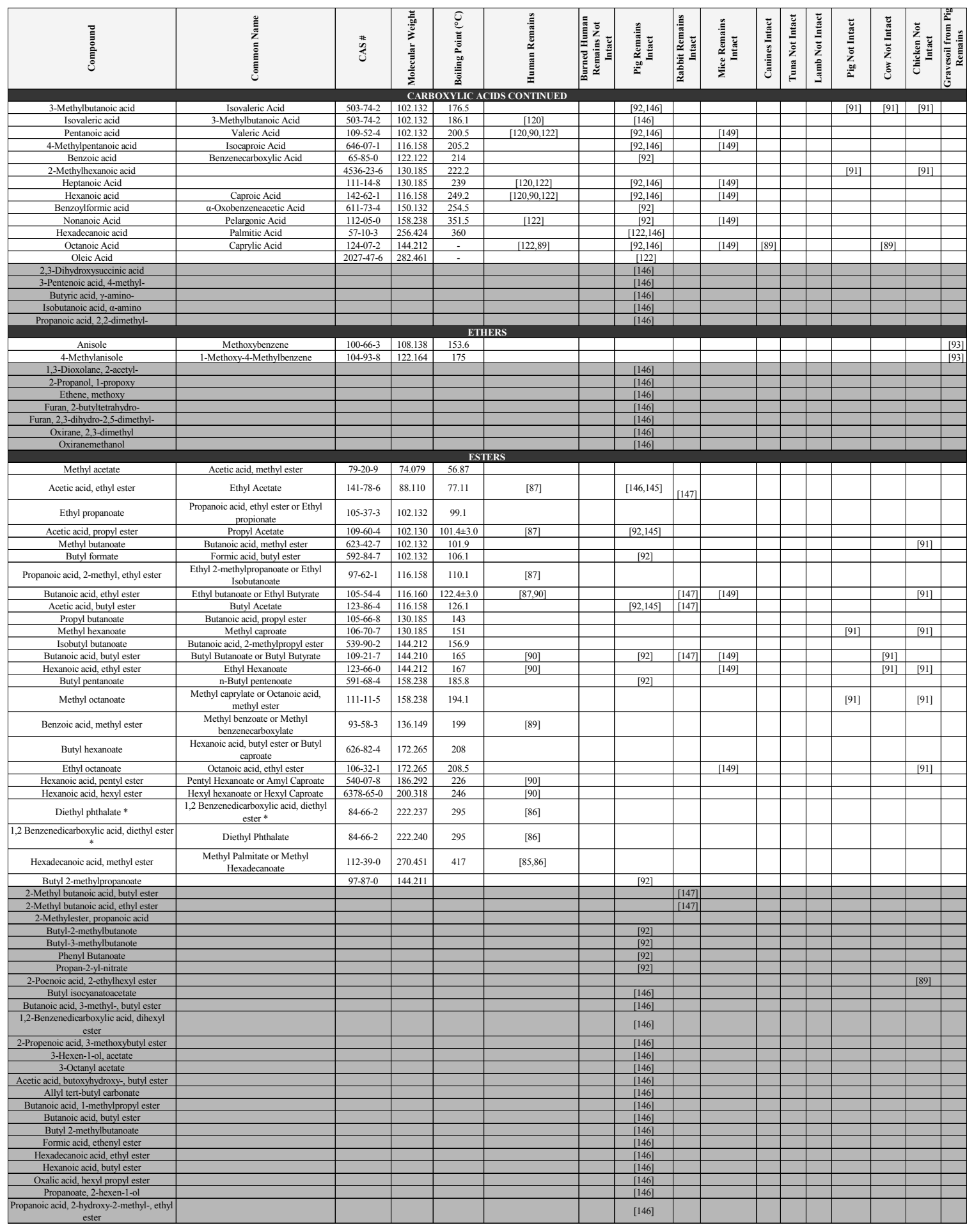


Table 38: Decomposition-associated compound database. Listed are compounds pertaining to the functional group esters, halogen-containing compounds, heterocyclics, and hydrocarbons. Those compounds highlighted in gray signify that the CAS number could not be obtained or the name of the compound is not clarified in the article.

\begin{tabular}{|c|c|c|c|c|c|c|c|c|c|}
\hline 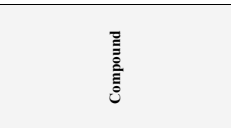 & 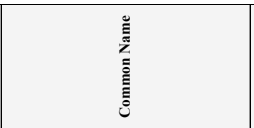 & 英 & 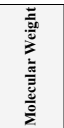 & 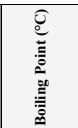 & 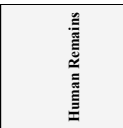 & 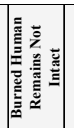 & 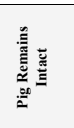 & 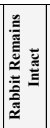 & 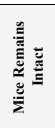 \\
\hline Propanoic acid 2-methyl- butyl ester & & & & ESTERS C & ONTINUED & & & & \\
\hline $\begin{array}{l}\text { Propanoic acid, 2-methyl-, butyl ester } \\
\text { Propanoic acid, butyl ester }\end{array}$ & & & & & & & [146] & & \\
\hline Vinyl butyrate & & & & & & & {$[146]$} & & \\
\hline Cyanic acid, propyl ester & & & & & & & {$[146]$} & & \\
\hline Cyanic acid, 2-methylpropyl ester & & & & & & & [146] & & \\
\hline Butyl isocyanatoacetate & & & & & & & {$[146]$} & & \\
\hline & & & & HALOGEN- & CONTAINING & & & & \\
\hline Methane,chlorodifluoro & Chlorodifluoromethane or HCFC-22 & $75-45-6$ & 86.469 & -40.7 & {$[87]$} & & & & \\
\hline Dichlorodifluoromethane & CFC-12 & $75-71-8$ & 120.914 & -29.8 & {$[85,86]$} & & & & \\
\hline Methane, chloro & Methyl Chloride & $74-87-3$ & \begin{tabular}{|c|c|}
50.488 \\
\end{tabular} & -24.09 & {$[87]$} & & & & \\
\hline Dichlorotetrafluoroethane & $\begin{array}{c}\text { 1,2-Dichloro-1,1,2,2-2-tetrafluoroethane or } \\
\text { CFC-114 }\end{array}$ & $76-14-2$ & 170.920 & 3.5 & {$[85,86]$} & & & & \\
\hline Trichloromonofluoromethane & \begin{tabular}{|l|} 
Trichlorofluoromethane or CFC-11 \\
\end{tabular} & $75-69-4$ & 137.368 & 23.7 & {$[85,86]$} & & & & \\
\hline 1,1-dichloro-1-fluoroethane & $\begin{array}{l}\text { 1,1-Dichloro-1-fluoroethane, HCFC- } \\
\text { 14lb, Freon } 141\end{array}$ & $1717-00-6$ & 116.950 & 32 & {$[86]$} & & & & \\
\hline Ethane, 1,1,2-trichloro-1,2,2-trifluoro & $\begin{array}{l}\text { 1,1,2-Trichloro-1,2,2-trifluoroethane or } \\
\text { CFC-113 }\end{array}$ & $76-13-1$ & 187.375 & 47.7 & [86] & & & & \\
\hline Chloroform & Trichloromethane & $67-66-3$ & 119.378 & 61.17 & {$[85,86]$} & & [145] & & \\
\hline Carbon Tetrachloride * (CTC) & Tetrachloromethane & $56-23-5$ & 153.823 & 76.8 & {$[87,85,86]$} & & & & \\
\hline Tetrachloromethane * & Carbon Tetrachloride & $56-23-5$ & 153.823 & 76.8 & {$[87,85,86]$} & & {$[145]$} & & \\
\hline 1-Chloro-butane & Butyl chloride & $109-69-3$ & 92.567 & 78.4 & & & {$[92]$} & & \\
\hline Trichloroethene & Trichlorethylene & $79-01-6$ & 131.388 & 87.21 & {$[85,86]$} & & & & \\
\hline Trichloroethane & & $25323-89-1$ & & 113.8 & {$[85]$} & & & & \\
\hline Tetrachloroethene * & Perchloroethylene & $127-18-4$ & 165.833 & 121.3 & {$[85,86,90]$} & & & & \\
\hline Tetrachloroethylene * & Perchloroethylene & $127-18-4$ & 165.833 & 121.3 & {$[85,86,90]$} & & & & \\
\hline Ethane, tetrachloro & TCA or Tetrachloroethane & $25322-20-7$ & - & 146.5 & {$[88]$} & & & & \\
\hline Propane, 1-bromo-2-methyl & & & & & & & {$[146]$} & & \\
\hline 1-Chloroheptylacetate & & & & & & & [146] & & \\
\hline 1-lodo-2-methylundecane & & & & & & & {$[146]$} & & \\
\hline Acetamidine, hydrochloride- & & & & & & & {$[146]$} & & \\
\hline Butane, 1-bromo-2-methyl- & & & & & & & {$[146]$} & & \\
\hline & & & HET & EROCYCLI & CS / AROMATICS & & & & \\
\hline 2-Ethyl Furan & & $3208-16-0$ & 96.127 & 92.5 & {$[87]$} & & & & \\
\hline 2-Butylfuran & Furan, 2-butyl- & $4466-24-4$ & 124.180 & $146.2 \pm 9.0$ & {$[87]$} & & & & \\
\hline 2-Pentyl Furan & & $3777-69-3$ & 138.210 & \begin{tabular}{|l|l|}
$169.7 \pm 9.0$ \\
\end{tabular} & {$[90,120,122]$} & & {$[146]$} & & \\
\hline 2,5-Dimethyltetrahydrofuran & & $1003-38-9$ & 100.158 & & & & & & \\
\hline & & & & HYDRO & CARBONS & & & & \\
\hline 1-Propene & Propene and Propylene & $115-07-1$ & 42.080 & -47.69 & {$[87]$} & & & & \\
\hline Propane & LPG & $74-98-6$ & 44.096 & -42.1 & & & & {$[147]$} & \\
\hline 1-Propene, 2-methyl & Isobutene & $115-11-7$ & \begin{tabular}{|l|l|}
56.107 \\
\end{tabular} & -6.9 & {$[87]$} & & {$[146]$} & & \\
\hline But-1-ene & & $106-98-9$ & 56.107 & -6.26 & & & {$[92]$} & & \\
\hline Butane & & $106-97-8$ & 58.122 & -0.5 & & & {$[146]$} & {$[147]$} & \\
\hline (E)-But-2-ene & trans-2-Butene & $624-64-6$ & 56.107 & 0.88 & & & {$[92]$} & & \\
\hline 1-Pentene & $a$-Amylene & $109-67-1$ & 70.133 & 29.96 & [87] & & {$[92]$} & & \\
\hline Isoprene & 2-Methyl-1,3-Butadiene & $78-79-5$ & 68.118 & 34 & [87] & & {$[145]$} & & \\
\hline Pentane & & $109-66-0$ & 72.149 & 36.06 & [87] & & [145] & {$[147]$} & \\
\hline 1,3-Pentadiene & & $504-60-9$ & 68.120 & 44.1 & [87] & & & & \\
\hline Butane, 2,2-dimethyl & 2,2-Dimethylbutane or Neohexane & $75-83-2$ & 86.180 & $48.4 \pm 7.0$ & [87] & & & & \\
\hline Butane, 2,3-dimethyl & 2,3-Dimethylbutane or Disisopropyl & $79-29-8$ & 86.180 & \begin{tabular}{|l|l|}
$58.7 \pm 7.0$ \\
\end{tabular} & {$[87]$} & & & & \\
\hline 2-Pentene, 4-methyl & & $\begin{array}{l}4461-48-7 \\
\end{array}$ & 84.160 & \begin{tabular}{|l|}
$59.3 \pm 7.0$ \\
\end{tabular} & {$[87]$} & & & & \\
\hline Pentane, 2-methyl & Isohexane & $107-83-5$ & 86.175 & 60.26 & {$[87,85]$} & & {$[145]$} & & \\
\hline Pentane, 3-methyl & & $96-14-0$ & 86.175 & 63.27 & 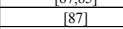 & & $\frac{[15]}{[145]}$ & & \\
\hline 1-Hexene & & $592-41-6$ & 84.159 & 63.48 & {$[87]$} & & [145] & & \\
\hline Hexane & & $110-54-3$ & 86.175 & 68.73 & {$[87,86,88]$} & & {$[145]$} & {$[147]$} & \\
\hline (Z)-Hex-2-ene & cis-2-Hexene & $7688-21-3$ & 84.159 & 68.8 & & & {$[92]$} & & \\
\hline Pentane, 2,4-dimethyl & & $108-08-7$ & 100.202 & 80.49 & {$[87]$} & & & & \\
\hline Butane, 2,2,3-trimethyl & 2,2,3-Trimethylbutane or Triptane & $464-06-2$ & 100.200 & $81.7 \pm 7.0$ & [87] & & & & \\
\hline Pentane, 2,3-dimethyl & & $565-59-3$ & 100.202 & 89.78 & {$[87]$} & & & & \\
\hline Hexane, 2-methyl & 2-Methylhexane & $591-76-4$ & 100.202 & 90.04 & {$[87]$} & & & & \\
\hline Hexane, 3-methyl & & $589-34-4$ & 100.200 & \begin{tabular}{|l|l|}
$90.7 \pm 7.0$ \\
\end{tabular} & [87] & & [145] & & \\
\hline 1-Heptene & & $592-76-7$ & 98.186 & 93.64 & [87] & & [145] & & \\
\hline 1-Heptene & & $592-76-7$ & \begin{tabular}{|c|}
98.186 \\
\end{tabular} & 93.64 & & & {$[92]$} & & \\
\hline Heptane & & $142-82-5$ & 100.202 & 98.4 & {$[87,85,88]$} & & [145] & {$[147]$} & \\
\hline Pentane, 2,3,4-trimethyl & & $565-75-3$ & 114.229 & 113.5 & [87] & & & & \\
\hline $\begin{array}{l}\text { Pentane, } 2,3,3, \text {-trimethyl } \\
\end{array}$ & & $\frac{505-15-3}{560-21-4}$ & 114.229 & 114.8 & {$[87]$} & & & & \\
\hline Hexane, 2,3-dimethyl & 2,3-Dimethylhexane & $584-94-1$ & 114.229 & 115.62 & [87] & & & & \\
\hline Heptane, 2 -methyl & 2-Methylheptane & $592-27-8$ & 114.229 & 117.66 & {$[87]$} & & & & \\
\hline 4-Methylheptane & & $589-53-7$ & 114.229 & 117.72 & & & [92] & & \\
\hline Heptane, 3-methyl & 3-Methylheptane & $589-81-1$ & 114.229 & 118.9 & [87] & & & & \\
\hline 3-Octene & & $592-98-3$ & 112.210 & $120.9 \pm 7.0$ & [87] & & & & \\
\hline 2-Octene & & $111-67-1$ & 112.210 & $125.4 \pm 3.0$ & {$[87]$} & & & & \\
\hline Octane & & $111-65-9$ & 114.229 & 125.67 & [88] & & {$[146]$} & [147] & \\
\hline Heptane, 2,4-dimethyl & 2,4-Dimethylheptane & $2213-23-2$ & 128.255 & 132.9 & [87] & & {$[146]$} & & \\
\hline Octane, 2-methyl & & $3221-61-2$ & 128.255 & 143.2 & [87] & & & & \\
\hline$\alpha$-Pinene & 2-Pinene & $80-56-8$ & 136.234 & 156.2 & [87] & & {$[146,145]$} & & \\
\hline Octane, 3,6-dimethyl & & $15869-94-0$ & 142.282 & 160.8 & {$[87]$} & & & & \\
\hline$\beta$-myrcene & 7-Methyl-3-methylene-1,6-octadiene & $123-35-3$ & 136.234 & 167 & & & & & \\
\hline Decane & & $124-18-5$ & 142.282 & 174.15 & [88] & & [145] & & \\
\hline 2-Methyldecane & & $6975-98-0$ & 156.309 & 189.3 & & & {$[92]$} & & \\
\hline 1-Undecene & & $821-95-4$ & 154.293 & 192.7 & [88] & & & & \\
\hline Undecane & Hendecane & $1120-21-4$ & 156.309 & 195.9 & {$[85,86,89]$} & & {$[146,145]$} & & {$[20]$} \\
\hline 1-Dodecene & & $112-41-4$ & 168.319 & 213.4 & & & & & \\
\hline Dodecane & & $112-40-3$ & 170.334 & 216.3 & & & {$[146,145]$} & & \\
\hline Tridecane & & $629-50-5$ & 184.361 & 235.47 & {$[120,89]$} & & {$[145]$} & & \\
\hline Tetradecane & & $629-59-4$ & 198.388 & 253.58 & {$[89]$} & & {$[146,145]$} & & \\
\hline Pentadecane & & $629-62-9$ & 212.415 & 270.6 & [89] & & [145] & & \\
\hline Hexadecane & Cetane & $544-76-3$ & 226.441 & 286.86 & [89] & & [146] & & \\
\hline Heptadecane & & $629-78-7$ & 240.468 & 302 & {$[89]$} & & & & \\
\hline Eicosane & Icosane & $112-95-8$ & 282.547 & 343 & & & {$[9,16]$} & & \\
\hline 2,6-Dimethylundecane & & $17301-23-4$ & 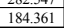 & $\frac{-19}{-1}$ & & & $\frac{a, 1,1]}{[92]}$ & & \\
\hline Decane, trimethyl & & $98060-54-9$ & 184.365 & 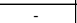 & [88] & & & & \\
\hline
\end{tabular}


Table 39: Decomposition-associated compound database. Listed are compounds pertaining to the functional groups hydrocarbons, ketones, and nitrogen-containing compounds. Those compounds highlighted in gray signify that the CAS number could not be obtained or the name of the compound is not clarified in the article.

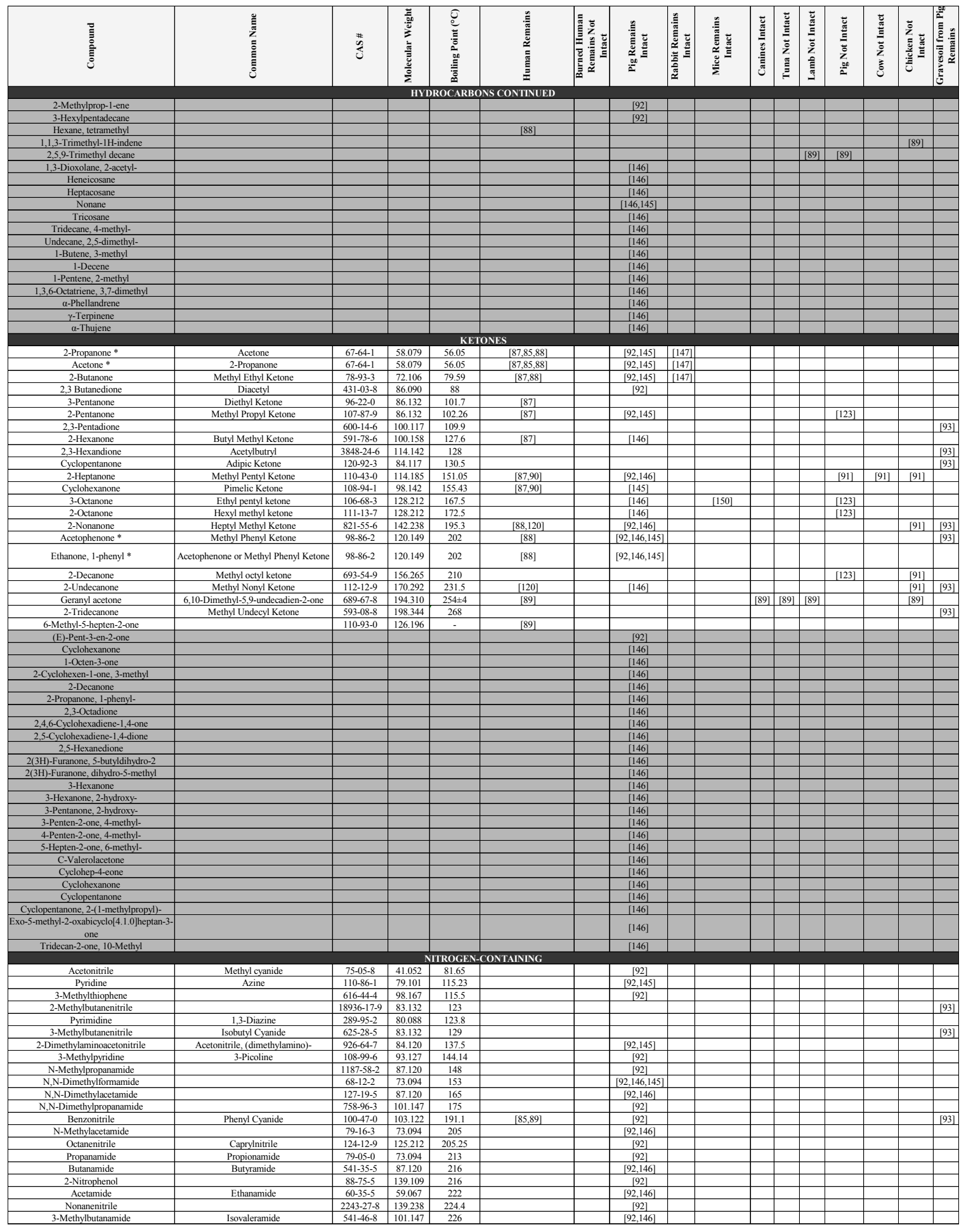


Table 40: Decomposition-associated compound database. Listed are compounds pertaining to the functional group nitrogen-, oxygen-, and sulfur-containing compounds. Those compounds highlighted in gray signify that the CAS number could not be obtained or the name of the compound is not clarified in the article.

\begin{tabular}{|c|c|c|c|c|c|c|c|c|c|c|c|c|c|c|c|c|}
\hline 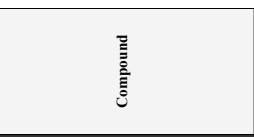 & 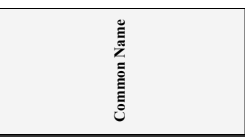 & 菜 & 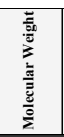 & 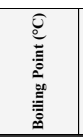 & 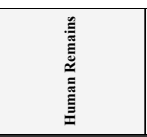 & 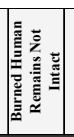 & 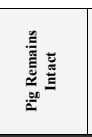 & 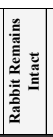 & 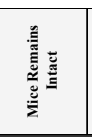 & 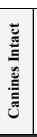 & 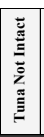 & 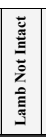 & 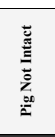 & 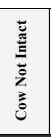 & 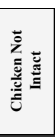 & 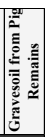 \\
\hline Quinoxaline & 1,4-Benzodiazine & $91-19-0$ & $\begin{array}{l}\text { NITROC } \\
130.147\end{array}$ & \begin{tabular}{|l|} 
EN-CONTA \\
229.5
\end{tabular} & INING CONTINUED & & {$[92]$} & & & & & & & & & \\
\hline 2-Phenylacetonitrile & Benzeneacetonitrile or Benzyl cyanide & $140-29-4$ & 117.149 & 233.5 & & & [92] & & & & & & & & & \\
\hline Quinazoline & 1,3-Benzodiazine & $253-82-7$ & 130.147 & 241 & & & {$[92,146]$} & & & & & & & & & \\
\hline 2-Piperidinone & Piperidin-2-one & $675-20-7$ & 99.131 & 256 & & & {$[92,146]$} & & & & & & & & & \\
\hline N,N-Dimethylbenzamide & & $611-74-5$ & 149.189 & 272 & & & [92] & & & & & & & & & \\
\hline N-Methylbenzamide & & $613-93-4$ & 135.163 & 291 & & & [92] & & & & & & & & & \\
\hline 2,3,5-Trimethylpyrazine & Pyrazine, trimethyl- & $14667-55-1$ & 122.167 & & & & {$[92,146]$} & & & & & & & {$[91]$} & [91] & \\
\hline Benzooxazole & & & & & & & {$[92]$} & & & & & & & & & \\
\hline $\mathrm{N}, \mathrm{N}$-Dimethylnitrousamide & & & & & & & {$[92]$} & & & & & & & & & \\
\hline 2-Propanol, 1-amino- & & & & & & & {$[146]$} & & & & & & & & & \\
\hline 1-Butanol, 1-amino- & & & & & & & [146] & & & & & & & & & \\
\hline Pentanamide & & & & & & & [146] & & & 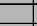 & & & & & & \\
\hline Propanamide & & & & & & & [146] & & & & & & & & & \\
\hline Propanamide, 2-methyl & & & & & & & [146] & & & & & & & & & \\
\hline Propanamide, N-methyl & & & & & & & [146] & & & & & & & & & \\
\hline Propanamide, N,2-dimethyl & & & & & & & [146] & & & & & & & & & \\
\hline Propanenitrile, 3-dimethylamino- & & & & & & & [146] & & & & & & & & & \\
\hline Formaide, (2-acetylphenyl)- & & & & & & & [146] & & & & & & & & & \\
\hline N-Methylvaleramide & & & & & & & [146] & & & & & & & & & \\
\hline Formamide, N-(2-methylpropyl)- & & & & & & & [146] & & & & & & & & & \\
\hline Formamide, N-butyl- & & & & & & & [146] & & & & & & & & & \\
\hline Formamide, N-methyl- & & & & & & & [146] & & & & & & & & & \\
\hline Formamide, N-phenyl- & & & & & & & [146] & & & & & & & & & \\
\hline Hexanamide, N-methyl- & & & & & & & [146] & & & & & & & & & \\
\hline Heptanonitrile & & & & & & & [146] & & & & & & & & & \\
\hline Hexanamide & & & & & & & [146] & & & & & & & & & \\
\hline Quinazoline, 2,4-dimethyl- & & & & & & & [146] & & & & & & & & & \\
\hline Quinazoline, 4-methyl- & & & & & & & [146] & & & & & & & & & \\
\hline Pyrazine, tetramethyl- & & & & & & & [146] & & [149] & & & & & & & \\
\hline Pyrazine, 2-butyl-3,5-dimethyl- & & & & & & & {$[146]$} & & & & & & & & & \\
\hline Pyrazine, 2,3-dimethyl- & & & & & & & [146] & & & & & & & & & \\
\hline Pyrazine, 2,5-dimethyl- & & & & & & & [146] & & & & & & & & & \\
\hline Pyrazine, 2,6-dimethyl- & & & & & & & [146] & & & & & & & & & \\
\hline Pyrazine, 3-ethyl-2,5-dimethyl- & & & & & & & [146] & & [149] & & & & & & & \\
\hline Pyrazine, 3,5-diethyl-2-methyl- & & & & & & & [146] & & & & & & & & & \\
\hline Pyrazine, methyl & & & & & & & [146] & & & & & & & & & \\
\hline Quinoline & & & & & & & {$[146]$} & & & & & & & & & \\
\hline Pyridine, 2-methyl- & & & & & & & [146] & & & & & & & & & \\
\hline Pyridine, 2,6-dimethyl- & & & & & & & [146] & & & & & & & & & \\
\hline 1-Butanamine, 3-methyl & & & & & & & [146] & & & & & & & & & \\
\hline 1-Butanol, 4-amino & & & & & & & [146] & & & & & & & & & \\
\hline 1-Decamine & & & & & & & {$[146]$} & & & & & & & & & \\
\hline 1-Heptadecanamine & & & & & & & [146] & & & & & & & & & \\
\hline 2-Piperidinone & & & & & & & [146] & & & & & & & & & \\
\hline 2,3-Butanediol, dinitrate & & & & & & & [146] & & & & & & & & & \\
\hline Acetamide, N-methyl- & & & & & & & {$[146]$} & & & & & & & & & \\
\hline Benzaldehyde, 2-amino & & & & & & & [146] & & & & & & & & & \\
\hline Acetic acid, [(aminocarbonyl)amino]oxo- & & & & & & & [146] & & & & & & & & & \\
\hline $\begin{array}{l}\text { 2,3-Dihydrooxazole, 2-t-butyl-4-(1- } \\
\text { hydroxy-1-methylethyl)-3- } \\
\text { methyoxycarbonyl-5-methyl- }\end{array}$ & & & & & & & [146] & & & & & & & & & \\
\hline 5,5-Dimethylimidazolidin-2,4-diimine & & & & & & & [146] & & & & & & & & & \\
\hline & & & & OXYGEN-C & ONTAINING & & & & & & & & & & & \\
\hline Hydroperoxide, 1-ethylbutyl & & & & & & & [146] & & & & & & & & & \\
\hline Hydroperoxide, 1-methylpentyl & & & & & & & [146] & & & & & & & & & \\
\hline Hydroperoxide, 1-methylbutyl & & & & & & & [146] & & & & & & & & & \\
\hline & & & & SULFUR-CI & ONTAINING & & & & & & & & & & & \\
\hline Carbon oxide sulfide & & $463-58-1$ & 60.075 & -50 & [87] & & & - & & & & & & & & \\
\hline Dimethyl sulfide & 2-Thiapropane & $75-18-3$ & 62.134 & 37.33 & [88] & & [145] & & [121] & & & & & & & \\
\hline Sulfur Dioxide & & $7446-09-5$ & 64.064 & -10.05 & {$[85,86]$} & & {$[92]$} & & {$[121]$} & & & & & & & \\
\hline Carbon disulfide & Carbon Bisulfide & $75-15-0$ & 76.141 & 46 & {$[87,85,86]$} & & & & & & & & & [91] & [91] & \\
\hline Methyl thoacetate & & $1534-08-3$ & 90.140 & $97-99$ & & & & & {$[121]$} & & & & & & & \\
\hline Dimethyl disulfide & $\begin{array}{l}\text { Methyl Disulfide or } \\
\text { Methyldisulfanylmethane }\end{array}$ & $624-92-0$ & 94.199 & 109.74 & {$[87,85,86,88,90,122]$} & & {$[92,146,145]$} & [147] & $\begin{array}{c}{[121,149,150} \\
]\end{array}$ & & & & [123] & & & [93] \\
\hline Disulfide, methyl ethyl & & $20333-39-5$ & 108.230 & \begin{tabular}{|l|l|}
$121.0 \pm 9.0$ \\
\end{tabular} & {$[87,88]$} & & {$[145]$} & & & & & & & & & \\
\hline Disulfide, methyl propyl & & $2179-60-4$ & 122.252 & 154.1 & {$[87]$} & & & & & & & & & & & \\
\hline Dimethyl trisulfide & & $3658-80-8$ & 126.264 & $183.1 \pm 23.0$ & {$[87,85,86,88,89]$} & & {$[16,145]$} & & {$[121,149,150$} & & & & [123] & & & [93] \\
\hline Methanethiol & & $74-93-1$ & 130.147 & 229.5 & & & {$[92,145]$} & & {$[121]$} & & & & & & & \\
\hline Benzothiazole & Benzosulfonazole & $95-16-9$ & 135.187 & 231 & [85] & & {$[145]$} & & & & & & & & & \\
\hline Dimethyl tetrasulfide & & $5756-24-1$ & 158.330 & 243.100 & & & {$[145]$} & & {$[121,149]$} & & & & & & & \\
\hline 2,4-dimethylthiane, S,S-dioxide & $\begin{array}{l}\text { cis-2,4-dimethylthiane, S,S-dioxide or } \\
\text { 2,4-dimethylthiane, 1,1-dioxide }\end{array}$ & & 162.250 & & [85] & & & & & & & & & & & \\
\hline 1-Methylsulfanylethanone & & & & & & & {$[92]$} & & & & & & & & & \\
\hline 1-Methylsulfonyloxybutane & & & & & & & [92] & & & & & & & & & \\
\hline Methadithione & & & & & & & [92] & & & & & & & & & \\
\hline Methylsulfanyldisulfanylmethane & & & & & & & {$[92]$} & & & & & & & & & \\
\hline Benzenesulfonic acid, 4-hydroxy & & & & & & & {$[146]$} & & & & & & & & & \\
\hline Dicyclohexyldisulphide & & & & & & & {$[146]$} & & & & & & & & & \\
\hline Dothiepin & & & & & & & [146] & & & & & & & & & \\
\hline Methane, sulfonylbis- & & & & & & & [146] & & & & & & & & & \\
\hline Sulfone, butyl ispropyl & & & & & & & {$[146]$} & & & & & & & & & \\
\hline Sulfurous acid, dicyclyhexyl ester & & & & & & & {$[146]$} & & & & & & & & & \\
\hline
\end{tabular}


VITA

NORMA IRIS CARABALLO

Born, Miami, Florida

2005-2008

B.Sc., Chemistry

Dual Minor, Psychology and Criminal Justice

Certification, Forensic Science

Florida International University

Miami, Florida

2007-2008

Undergraduate Research Assistant

Florida International University

Miami, Florida

2008

Forensic Science Internship

Florida International University

Miami, Florida

2009-2013

Research Assistant

Florida International University

Miami, Florida

$1^{\text {st }}$ Place in Forensics and Crime Poster Session at the Graduate and Professional Student Committee Scholarly Forum

Florida International University

Miami, Florida

2012

Forensic Sciences Foundation Student Scholarship Award

2013

$1^{\text {st }}$ Place in Forensics and Crime Oral Presentation Session at the Graduate and Professional Student Committee Scholarly Forum

Florida International University

Miami, Florida

Forensic Sciences Foundation Student Travel Grant Award

2013-2014

Teaching Assistant

Florida International University

Miami, Florida 


\section{PUBLICATIONS}

N.I. Caraballo, M. Cerreta, K. Hentschel, D. Wescott, K.G. Furton. An Evaluation of the Volatile Organic Compounds Released from Decomposing Human Remains. In Preparation.

N.I. Caraballo, V. Shellman, K.G. Furton. Frozen-Thawed vs. Freshly Killed Remains: An Assessment of the Volatile Organic Compounds released during the Decomposition Process. In Preparation.

\section{PRESENTATIONS}

N.I. Caraballo and K.G. Furton, Scent of the Living and the Dead: Its Application in Criminal Investigations, Contemporary Methods of Forensic Anthropology and Crime Scene Investigation, Broward Sheriff's Office, Fort Lauderdale, Florida, May 1, 2013.

N.I. Caraballo and K.G. Furton, Submerged Remains: A Study on the Scent of Death, $2^{\text {nd }}$ Annual International Forensic Research Institute (IFRI) Symposium, Florida International University, Miami, Florida, March 13-14, 2013.

N.I. Caraballo and K.G. Furton, An Investigation Into the Volatile Organic Compounds Released From Submerged Remains, $65^{\text {th }}$ Annual Scientific Meeting of the Academy of Forensic Sciences (AAFS), Washington, D.C., February 18-23, 2013.

N.I. Caraballo and K.G. Furton, Method Optimization for the Detection of Volatile Organic Compounds from Decomposing Remains, The Pittsburgh Conference on Analytical Chemistry and Applied Spectroscopy (PITTCON), Orlando, Florida, March 12-15, 2012.

N.I. Caraballo and K.G. Furton, Frozen-Thawed vs. Freshly Killed: A Comparison of the Volatile Organic Compounds Detected from Decomposing Remains, $64^{\text {th }}$ Annual Scientific Meeting of the Academy of Forensic Sciences (AAFS), Atlanta, Georgia, February 20-25, 2012.

N.I. Caraballo, H.K. Holness, D.K. Mills and K.G. Furton, Evaluation of the Scent Transfer Unit ${ }^{\mathrm{TM}}$ (STU-100) for the Collection of Human Odor from Porous Objects, $63^{\mathrm{RD}}$ Annual Scientific Meeting of the Academy of Forensic Sciences (AAFS), Chicago, Illinois, February 21-26, 2011.

N.I. Caraballo, H.K. Holness, D.K. Mills and K.G. Furton, A Preliminary Evaluation For the Utilization of the Scent Transfer Unit (STU-100) for the Collection of Human Odor from Porous and Non-Porous Objects, $86^{\text {th }}$ ACS Florida Annual Meeting and Exposition (FAME), Innisbrook, Florida, May 13 - 15, 2010. 